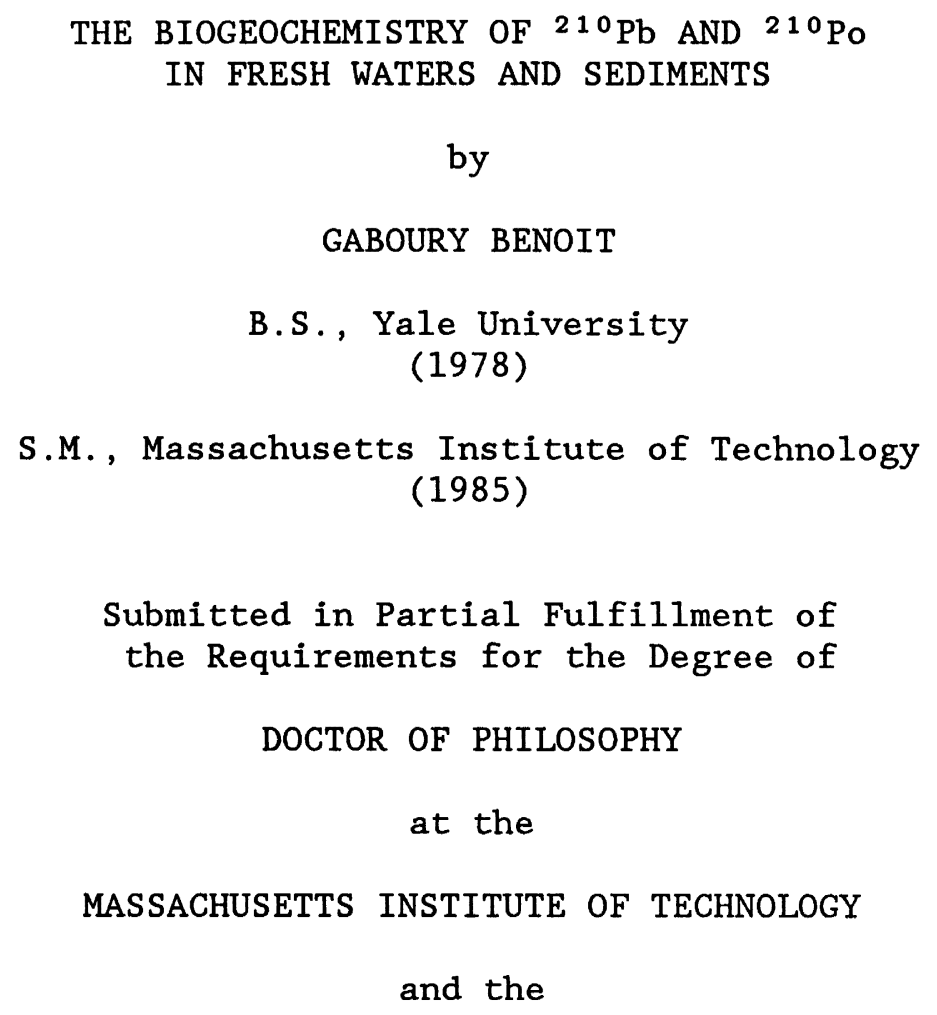

The author hereby grants to MIT and WHOI permission to reproduce and distribute copies of this thesis in whole or in part.

Signature of Author

Joint Program in Oceanography
Massachusetts Institute of Technology/
Woods Hole Oceanographic Institution

Certified by

Harold F. Hemond Thesis Supervisor

Accepted by

John M. Edmond

Chairman, Joint Committee for Chemical Oceanography Massachusetts Institute of Technology/ Woods Hole Oceanographic Institution 
THE BIOGEOCHEMISTRY OF $210 \mathrm{~Pb}$ AND $21^{\circ} \mathrm{PO}$ IN FRESH WATERS AND SEDIMENTS

by

\section{GABOURY BENOIT}

Submitted to the Joint Program in Chemical Oceanography in January 1988 in partial fulfillment of the requirements for the degree of Doctor of Philosphy in Oceanography

\section{ABSTRACT}

The focus of this work was geochemical cycling of $210 \mathrm{~Pb}$ in lakes, including the water column, sediments, and their interactions with each other. A special goal was to elucidate processes that might influence the distribution and fluxes of the radionuclide in ways that could effect $210 \mathrm{~Pb}$ sediment dating.

A mass balance for the epilimnion showed that $210 \mathrm{~Pb}$ inputs by precipitation were matched by outputs on settling particles, indicating that direct uptake by bottom sediments was inconsequential. Below the epilimnion, vertical eddy diffusion was calculated by the heat flux gradient method including corrections for both radiant heating and heat loss to sediments. Vertical mixing was very low because of stability imparted by a steep temperaturejdensity gradient extending right to the sediment water interface. Anoxic conditions caused remobilization of reduced iron, which reprecipitated at the oxycline and returned to the bottom via settling. ${ }^{210} \mathrm{~Pb}$ followed the same pattern except that, at the interface, it was scavenged rather than precipitated. Below the zone of precipitation, both $210 \mathrm{~Pb}$ and iron distributions could be described by a mode1 consisting of constant release from anoxic sediments, horizontal transport, and simple dilution in the water column. Cycling of 210 Po was complicated by unidentified additional factors.

A finite difference model (SEDIMIX) was used to find the combination of sedimentation and Fickian redistribution that provided the best fit to the $210 \mathrm{~Pb}$ sediment data. Sedimentation rates were found to increase linearly with overlying water depth. The magnitude of the Fickian component of $210 \mathrm{~Pb}$ transport was equal to calculated rates of pore water diffusive flux, which is probably more important than sediment mixing in this lake.

$210 \mathrm{~Pb}, 210 \mathrm{Po}$, and ancillary geochemical parameters were measured on the solid fraction and pore waters of two cores taken from the deepest basin in August and September. The radionuclides were two orders of magnitude higher than in overlying water and had steep concentration gradients that could support substantial diffusive fluxes. Fe, Mn, S(II), and alkalinity did not have similar gradients. ${ }^{210} \mathrm{~Pb}$ partition coefficients ranged from 1500 to 15000 , decreasing with depth, and seemed to be controlled by sorption on iron oxides. Remobilization to the water column apparently comes from a thin layer of iron-rich floc near the sediment water interface. Deeper in the cores, diffusive transport can cause redistribution of $210 \mathrm{~Pb}$ to an extent that can affect $2{ }^{\circ} \mathrm{Pb}$ dating.

Thesis Supervisor: Dr. Harold Hemond 



\section{TABLE OF CONTENTS}

LIST OF TABLES

LIST OF FIGURES

DEDICATION

ACKNOWLEDGEMENTS

CHAPTER 1 BACKGROUND AND PREVIOUS RESEARCH

1.1 INTRODUCTION

1.1.1 IMPORTANCE OF $210 \mathrm{~Pb}$ DATING

1.1.2 SIGNIFICANCE OF STABLE LEAD CONTAMINATION

1.1.3 ASSUMPTIONS OF 210Pb DATING METHODS

1.2 PREVIOUS INVESTIGATIONS

1.2.1 210Pb GEOCHEMISTRX IN THE MARINE ENVIRONMENT

1.2.2 $210 \mathrm{~Pb}$ GEOCHEMISTRY IN FRESH WATERS

1.2.2.1 Groundwater Studies

1.2.2.3 Lake Studies

1.3 REMOBILIZATION FROM SEDIMENTS

1.4 LAKE MASS BALANCES

1.5 THIS RESEARCH

CHAPTER 2 STUDY SITE

CHAPTER 3 METHODS

3.1 SAMPLE COLLECTION

48

3.2 SAMPLE PREPARATION

50

3.3 METHODS OF ANALYSIS

55

3.4 METHODS OF 210Po AND 210Pb ANALYSIS

57

CHAPTER 4 THE WATER COLUMN

71 
4.1 INTRODUCTION

4.2 METHODS 71

4.3 RESULTS AND DISCUSSION 72

4.3.1 TEMPERATURE 72

$\begin{array}{ll}4.3 .2 \text { DISSOLVED OXYGEN } & 76\end{array}$

$\begin{array}{ll}4.3 .3 \text { LIGHT } & 78\end{array}$

4.3.4 IRON AND MANGANESE $\quad 82$

4.3.5 pH AND ALKALINITY 95

$\begin{array}{ll}4.3 .6 & \text { SULFIDE }\end{array}$

$\begin{array}{lll}4.3 .7210 \mathrm{~Pb} & 105\end{array}$

$\begin{array}{lll}4.3 .8 & 210 \mathrm{Po} & 109\end{array}$

$\begin{array}{ll}4.4 \text { THE EPILIMNETIC MODEL } & 112\end{array}$

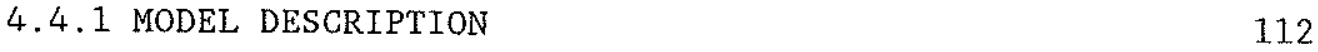

$\begin{array}{ll}\text { 4.4.2 ERROR ANALYSIS } & 116\end{array}$

$\begin{array}{ll}\text { 4.4.3 MODEL RESULTS } & 117\end{array}$

$\begin{array}{ll}4.5 \text { THE HYPOLIMNION } & 129\end{array}$

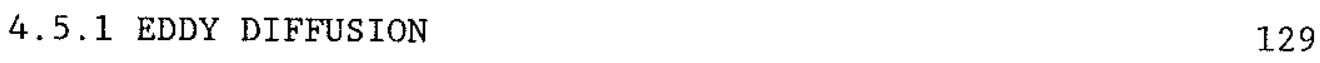

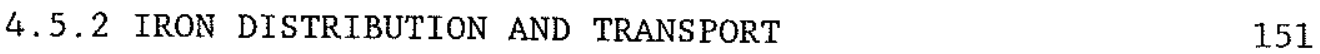

4.5.3 CONTROLS ON 210Pb DISTRIBUTIONS AND FLUXES 164

4.5.4 CONTROLS ON 210PO DISTRIBUTIONS AND FLUXES 171

CHAPTER 5 SEDIMENTS I 210Pb DISTRIBUTIONS AND INVENTORIES 183

5.1 INTRODUCTION 183

$\begin{array}{ll}5.2 \text { METHODS } & 184\end{array}$

$\begin{array}{ll}5.3 \text { RESULTS AND DISCUSSION } & 185\end{array}$

$\begin{array}{ll}5.4 \text { SEDIMENT MIXING MODEL } & 186\end{array}$

$\begin{array}{ll}5.4 .1 \text { MODEL DESCRIPTION } & 186\end{array}$

$\begin{array}{ll}5.4 .2 \text { MODEL IMPLEMENTATION } & 189\end{array}$ 
5.4.3 MODEL RESULTS

5.5 SEDIMENT ACCUMULATION RATES 200

5.6 SEDIMENT 210Pb INVENTORIES 205

5.7 SEDIMENT MIXING RATES 208

5.8 SEDIMENTATION PROCESSES IN THE NORTHERN BASIN 210

5.8.1 EVIDENCE FROM 137Cs 215

CHAPTER 6 SEDIMENTS II 210Pb SPECIATION AND REMOBILIZATION 225

$\begin{array}{lll}6.1 & \text { INTRODUCTION } & 225\end{array}$

6.2 METHODS 226

6.2.1 SAMPLE COLLECTION AND TREATMENT 226

$\begin{array}{lll}6.3 & \text { RESULTS AND DISCUSSION } & 228\end{array}$

6.3.1 SOLID PHASE $210 \mathrm{~Pb} \quad 228$

6.3.2 PORE WATER 210Pb AND 210Po 230

6.3.3 IRON AND MANGANESE 244

6.3.4 ALKALINITY 251

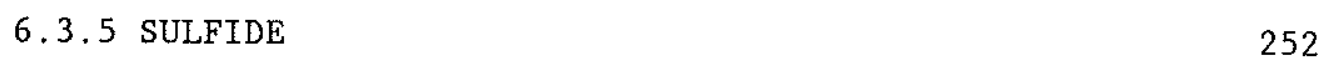

6.4 SEQUENTIAL LEACHING RESULTS 253

6.5 CONTROLS ON $210 \mathrm{~Pb}$ PARTITIONING AND TRANSPORT 258

6.5.1 ESTIMATES OF $210 \mathrm{~Pb}$ MOBILITY 258

6.5.1.1 Detailed Calculation of Pore Water Fluxes 259

6.5.1.2 Sources of Uncertainty 262

6.5.1.3 Significance of Diffusive Transport 267

6.5.2 SEDIMENT-PORE WATER PARTITIONING 269

6.6 THE SEDIMENT WATER INTERFACE - SURFICIAL FLOCS 274

$\begin{array}{lll}\text { CHAPTER } 7 & \text { SUMMARY } & 282\end{array}$

$\begin{array}{ll}\text { BIBLIOGRAPHY } & 290\end{array}$ 
LIST OF TABLES

TABLE 3.2a SEQUENTIAL LEACHING PROTOCOL

TABLE 4.3.5a ALKALINITY AND pH IN THE WATER COLUMN 96

TABLE 4.3.5b STOICHIOMETRY OF ORGANIC MATTER OXIDATION REACTIONS 98

TABLE $4.3 .5 \mathrm{c}$ ALKALINITY MASS BALANCE CALCULATION 99

TABLE 4.3.6a SULFIDE IN THE WATER COLUMN 100

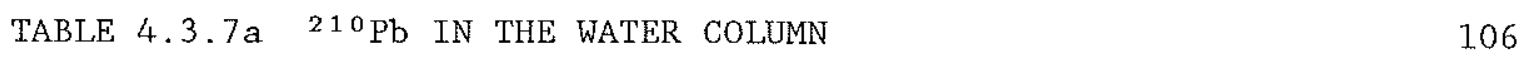

$\begin{array}{lll}\text { TABLE } 4.3 .8 \mathrm{a} & 210 \mathrm{PO} \text { IN THE WATER COLUMN } & 110\end{array}$

TABLE 4.4.3a MASS BALANCE OF DISSOLVED $210 \mathrm{~Pb}$ IN THE EPILIMNION 118

TABLE 4.4.3b MASS BALANCE OF PARTICULATE $210 \mathrm{~Pb}$ IN THE EPILIMNION 119

TABLE $4.4 .3 \mathrm{C}$ MASS BALANCE OF DISSOLVED $21{ }^{\circ} \mathrm{PO}$ IN THE EPILIMNION 126

TABLE 4.4.3d MASS BALANCE OF PARTICULATE $2{ }^{20}$ Po IN THE EPILIMNION 128

TABLE 4.5.1a EDDY DIFFUSION COEFFICIENTS AND UNCERTAINTIES

TABLE 4.5.2a AVERAGE BOTTOM SLOPE AS A FUNCTION OF DEPTH 159

TABLE 4.5.2b DIFFUSIVE BOUNDARY LAYER MEASUREMENTS 162

TABLE $4.5 .3 \mathrm{a}$ HYPOLIMNETIC $210 \mathrm{~Pb}$ SEDIMENT TRAP FLUXES 170

TABLE 5.4.3a SEDIMENT ACCUMULATION AND MIXING RATES 193

TABLE 6.3.1a SOLID PHASE ${ }^{210} \mathrm{~Pb}$ DATA FOR CORES 85-1 AND 85-2 229

TABLE 6.3.2a PORE WATER CHEMISTRY 231

TABLE $6.3 .2 \mathrm{~b} \quad 21{ }^{\circ} \mathrm{Pb}$ PARTITION COEFFICIENTS 239

TABLE 6.3.2c STABLE LEAD IN CORE 85-2 240

TABLE 6.3.3a IRON AND MANGANESE IN CORE 85-2 245

TABLE 6.4a SEQUENTIAL LEACHING OF CORE 85-2 AND WATER COLUMN SOLIDS 254

TABLE 6.5.1a COMPARISON OF PORE WATER DIFFUSION AND SEDIMIX
"MIXING" FLUXES

TABLE 6.5.1.1a DIFFUSIVE $210 \mathrm{~Pb}$ FLUXES IN PORE WATERS 261 
TABLE 6.5.1b INORGANIC LEAD SPECIATION 265

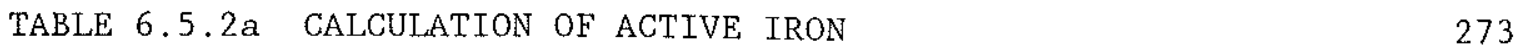

TABLE $6.6 \mathrm{a}$ CHARACTERISTICS OF INTERFACIAL FLOC 277 


\section{LIST OF FIGURES}

FIGURE $1.2 \mathrm{a}$ PARTICULATE $210 \mathrm{~Pb}$ IN THE COLUMBIA RIVER, WASHINGTON, AS A FUNCTION OF DISCHARGE 25

FIGURE 2a BICKFORD RESERVOIR BATHYMETRY AND SAMPLING SITES 43

FIGURE $2 b \quad$ BICKFORD RESERVOIR HISTORY 44

$\begin{array}{lll}\text { FIGURE 2c MAP OF THE WATERSHED } & 46\end{array}$

FIGURE 3a INFLUENCE OF PLATING TIME ON ROOM TEMPERATURE PLATING EFFICIENCY OF POLONIUM

FIGURE 3b EFFECT OF HOT HCl TREATMENT ON AN IRON COATED PLANCHET 63

FIGURE 3c LOSS OF RADIUM FROM STEEL PLATING DISK ON DARKENING 69

FIGURE 4.3.1a ISOPLETHS OF TEMPERATURE IN THE WATER COLUMN 73

FIGURE 4.3.1b DEPTH OF THE BASE OF THE EPILIMNION AND OF THE OXIC-ANOXIC INTERFACE OVER TIME

FIGURE 4.3.2a ISOPLETHS OF DISSOLVED OXYGEN IN THE WATER COLUMN 77

FIGURE 4.3.3a LIGHT ATTENUATION IN THE WATER COLUMN - 4 SEPT 85

FIGURE 4.3.3b LIGHT ATTENUATION IN THE WATER COLUMN - 19 SEPT $85 \quad 80$

FIGURE 4.3.4a ISOPLETHS OF TOTAL MANGANESE IN THE WATER COLUMN 83

FIGURE 4.3.4b ISOPLETHS OF TOTAL IRON IN THE WATER COLUMN

FIGURE $4.3 .4 \mathrm{c}$ ISOPLETHS OF PARTICULATE IRON IN THE WATER COLUMN 87

FIGURE 4.3.4d ISOPLETHS OF SPM IN THE WATER COLUMN

FIGURE 4.3.4e PROFILES OF PARTICULATE IRON IN THE WATER COLUMN SUMMER 91

FIGURE 4.3.4f PROFILES OF PARTICULATE IRON IN THE WATER COLUMN FALI. 92

FIGURE 4.3.4g PROFILES OF TOTAL IRON IN THE WATER COLUMN - FALL 93

FIGURE 4.3.4h PROFILES OF TOTAL IRON IN THE WATER COLUMN - SUMMER 94

FIGURE 4.3.6a IRON AND SULFIDE IN THE WATER COLUMN - FeS
SATURATION STATUS

$\begin{array}{lll}\text { FIGURE } 4.3 .6 \mathrm{~b} & 210 \mathrm{~Pb} \text { PARTITIONING IN THE HYPOLIMNION } & 104\end{array}$ 
FIGURE 4.3.7a ISOPLETHS OF TOTAL 210Pb IN THE WATER COLUMN

FIGURE $4.3 .7 \mathrm{~b}$ TOTAL $210 \mathrm{~Pb}$ LEVELS IN SURFACE AND BOTTOM WATERS

108

FIGURE 4.3.8a ISOPLETHS OF TOTAL 210PO IN THE WATER COLUMN

111

FIGURE 4.5.1a TEMPERATURES AT FIXED DEPTHS IN THE WATER COLUMN AS A FUNCTION OF TIME

FIGURE 4.5.1b LONG-TERM VARIATION IN WATER COLUMN TEMPERATURE AT $12 \mathrm{~m}$

FIGURE $4.5 .1 \mathrm{c}$ LAKE MENDOTA SEDIMENT HEATING SIMULATION

141

FIGURE 4.5.1d ISOPLETHS OF EDDY DIFFUSIVITY IN THE WATER COLUMN 148

FIGURE 4.5.1e Kz AS A FUNCTION OF DENSITY STABILITY 150

FIGURE 4.5.2a and $\mathrm{b}$ THE CONSTANT FLUX, RAPID HORIZONTAL MIXING MODEL FOR IRON AND $210 \mathrm{~Pb}$

155

FIGURE 4.5.2c HYPSOGRAPHIC CURVE FOR BICKFORD RESERVOIR 158

FIGURE $4.5 .3 \mathrm{a}$ TOTAL $210 \mathrm{~Pb}$ VS. IRON IN THE WATER COLUMN 167

FIGURE 4.5.4a TOTAL 210Po VS. TOTAL 210Pb IN THE WATER COLUMN 172

FIGURE 4.5.4b TOTAL 210Po VS. CUMULATIVE ORGANIC MATTER OXIDATION 174

FIGURE $4.5 .4 \mathrm{c}$ and $\mathrm{d}$ TOTAL 210Po VS. TOTAL MANGANESE AND TOTAL IRON IN THE WATER COLUMN

FIGURE $4.5 .4 \mathrm{e}$ TOTAL IRON VS. TOTAL MANGANESE IN THE WATER COLUMN 176

FIGURE 4.5.4f TOTAL MANGANESE VS. WATER COLUMN OXYGEN CONSUMPTION 178

FIGURE $4.5 .4 \mathrm{~g}$ TOTAL IRON VS. WATER COLUMN OXYGEN CONSUMPTION 179

FIGURE $4.5 .4 \mathrm{~h}$ HORIZONTAL TRANSPORT MODEL FOR 210PO 181

FIGURE 5.4.1a R.M.S. ERROR OF A SEDIMIX GENERATED PROFILE AS A FUNCTION OF SEDIMENTATION AND MIXING RATES

FIGURE 5.4.3a and $\mathrm{b}$ SOLID PHASE 210Pb DATA FOR CORES 81-1 AND 81-2 194

FIGURE 5.4.3c and d SOLID PHASE 210Pb DATA FOR CORES 81-4 AND 81-5 195

FIGURE $5.4 .3 \mathrm{e}$ and $f$ SOLID PHASE 210Pb DATA FOR CORES 81-6 AND 84-1 196

FIGURE 5.4.3g and $h$ SOLID PHASE 210Pb DATA FOR CORES 84-2 AND 84-6 197

FIGURE 5.4.3i and $j$ SOLID PHASE 210Pb DATA FOR CORES 85-1 AND 85-2 198 
FIGURE 5.4.3k and 1 SOLID PHASE $210 \mathrm{~Pb}$ DATA FOR CORES 84-7 AND 86-2 199

FIGURE 5.5a BULK SEDIMENT ACCUMULATION RATE AS A FUNCTION OF THE DEPTH OF THE OVERLYING WATER COLUMN

FIGURE $5.5 \mathrm{~b} \quad 210 \mathrm{~Pb}$ ACCUMULATION RATE AS A FUNCTION OF THE DEPTH OF THE OVERLYING WATER COLUMN

FIGURE $5.6 a^{210} \mathrm{~Pb}$ BUILD-UP IN SEDIMENTS VS. THE BULK SEDIMENT ACCUMULATION RATE

FIGURE $5.8 \mathrm{a}$ and $\mathrm{b}$ SOLID PHASE ${ }^{210} \mathrm{~Pb}$ DATA FOR CORES $84-3$ AND $84-4$

FIGURE $5.8 \mathrm{c}$ and $\mathrm{d}$ SOLID PHASE $210 \mathrm{~Pb}$ DATA FOR CORES 84-5 AND 86-1 212

FIGURE 5.8.1a and $\mathrm{b}$ COMPARISON OF SOLID PHASE ${ }^{137} \mathrm{Cs}$ AND ${ }^{210} \mathrm{~Pb}$ DATA FOR CORES 86-1 AND 86-2.

FIGURE $5.8 .1 \mathrm{c}{ }^{137} \mathrm{Cs}$ INVENTORY AS A FUNCTION OF SEDIMENT ACCUMULATION RATE

FIGURE 6.3.2a PORE WATER CONCENTRATIONS OF $210 \mathrm{~Pb}$, ALKALINITY, MANGANESE, AND IRON - 27 AUGUST 1985 (CORE 85-1)

FIGURE 6.3.2b PORE WATER CONCEN CRATIONS OF $210 \mathrm{~Pb}$, ALKALINITY, MANGANESE, IRON, AND SULFIDE - 25 SEPT 1985 (CORE 85-1)

FIGURE 6.4a SEQUENTIAL LEACHING ANALYSIS OF CORE 85-2 AND OF CERTAIN WATER COLUMN SOLIDS

FIGURE 6.5.2a PARTITIONING OF $210 \mathrm{~Pb}$ IN BICKFORD SEDIMENTS - $\mathrm{K}_{\mathrm{D}}{ }^{\prime} \mathrm{s}$ AS A FUNCTION OF SOLIDS CONCENTRATION 
DEDICATION

For my mother and father. 


\section{AGKNOWLEDGEMENTS}

My first and deepest thanks are due my advisor, Harry Hemond, whose scientific, moral, and financial support were key to the genesis of this thesis.

Expert, thorough, and invaluable scientific advice was provided by my thesis committee: Michael Bacon, Edward Sholkovitz, and Karl

Turekian.

A very special thanks is extended to the many people who helped with SCUBA diving during the research. Every dive meant a long drive to a remote location and a trip into icy, dark, bottom waters. At best, in the summer, the work was tolerable, while in the fall it could be miserable. Through it all Yehuda Agnon, Ken Buesseler, Maggie Goud, Harry Hemond, Karen Hronek, Harry Jenter, Keith Stolzenbach, and John Wilkin worked without a word of complaint and even came back for more. This thesis could not have been done without their expert assistance. Maggie especially was willing to dive again and again, showing in still another way what a good friend she is. Terry Rioux's efficiency in providing equipment from the WHOI dive locker and in corralling divers was a great help.

Dr. Edward Sholkovitz provided laboratory facilities for porewater extractions and ${ }^{137} \mathrm{Cs}$ analyses. Ken Buesseler assisted with ${ }^{1{ }^{37} \mathrm{Cs}}$ counting. Paulo Rossman and John Wilkins gave advice on the implementation of SEDIMIX. Bob Hudson helped with recovery of the sampling platform at the end of the ' 85 season.

I am grateful to Karen Hronek for everything from assistance in sampling, diving, and analyses to being my representative in Cambridge when I worked remotely from Washington, Indiana, or Michigan. Her friendship and help were a ray of sunlight on many a dark day.

The 1986 Boston Red Sox provided a lifetime's worth of thrills and entertainment, bringing the World Series to an inevitably tragic seventh game.

Jani Benoit was an able assistant, both in the field and laboratory. Her efficiency, thoroughness, and skill made it possible to complete three times the number of analyses I could have managed alone. I am especially thankful for her tireless good humor and sisterly affection.

Special appreciation goes to my wife, D'Ann de Simone, for her love, patience, and understanding.

Financial support for parts of this work has come from a National Science Foundation graduate research fellowship, a U.S. Geological Survey water resources research grant, three National Wildlife Federation environmental conservation fellowships, the Massachusetts D.W.P.C., and a Geological Society of America graduate award. 


\section{CHAPTER 1 BACKGROUND AND PREVIOUS RESEARCH}

\subsection{INTRODUCTION}

\subsubsection{IMPORTANGE OF $210 \mathrm{~Pb}$ DATING}

Over the past two decades, $210 \mathrm{~Pb}$ dating has gained acceptance as the most precise and reliable method for age determination of lake sediments deposited during the last $100 \mathrm{y}$. This time period is of special interest since it has been marked by man's greatest impact on the lacustrine environment. Sediments usually contain the only available record of that impact, so that their chemical stratigraphy evaluated in the light of an accurate dating technique yields valuable information about the history of environmental contamination.

Other widely used geochronometric methods include ${ }^{14} \mathrm{C}$ dating and the use of identifiable stratigraphic horizons of known age. Examples include layers recognized on the basis of pollen, forest fire ash layers, and peaks in the fall-out radionuclides ${ }^{137} \mathrm{Cs},{ }^{90} \mathrm{Sr}$, and $239,240 \mathrm{Pu}$. Another sediment dating method is based on measurement of the remnant magnetization in sediments which is then compared to the historically measured value of magnetic variation at a given site. The main disadvantage of the ${ }^{14} \mathrm{C}$ method is that it becomes reliable only for sediments older than five hundred years. The stratigraphic methods provide the age of only a single layer from which one can calculate an average sedimentation rate since the layer was deposited. Furthermore, they are subject to a number of complications and uncertainties. First, the date that the layer was deposited may not be known accurately. Second, mixing can cause postdepositional redistribution of the accumulated layer. Also, especially in the case of ${ }^{137} \mathrm{Cs}$, chemical remobilization and migration of the peak can cause inaccuracies (NORTON 
et a1. [1985]). Methods that are based on the magnetic properties of sediments also are problematical. It remains controversial whether the direction of magnetization is locked into sediments at the time of sediment deposition or whether it can change as the result of such processes as bioturbation and early diagenesis (BROOKS [1984]). Although not immune to problems from mixing and the like, $2{ }^{\circ} \mathrm{Pb}$ dating gives a continuous record of sedimentation, and it is valid for the period from 100 years ago to the present, unlike these other methods. For those reasons, ${ }^{210} \mathrm{~Pb}$ is the method of choice in most instances.

\subsubsection{SIGNIFICANCE OF STABLE LEAD CONTAMINATION}

The behavior of lead in the aquatic environment is especially worthy of study. In at least some environments, lead is the trace metal whose release into the environment has most greatly exceeded its natural flux (HEIT et a1., 1981). Lead is the single most frequent and second most abundant contaminant of hazardous waste dumps nationwide (JOSEPHSON [1986]). Nearly all of the lead in the world's surface oceans is believed to be derived from leaded gasoline (SCHAULE and PATTERSON [1983]). Even the most distant locations on the globe, the arctic and antarctic, exhibit the effects of lead pollution; the latest measurements of polar ice cores show that man's activities have caused a three hundred-fold rise in lead since the beginning of the industrial revolution (NG and PATTERSON, 1981). Lead is highly toxic and causes adverse health effects both through acute and chronic exposure (NRIAGU, 1978). Significant adverse health effects at very low exposure levels continue to be found (eg. BELLINGER et al. [1987]), and it has even been proposed that there is a nearly universal form of lead poisoning that goes unrecognized because there are no controls that have not been 
exposed chronically to low lead levels (SETTLE and PATTERSON [1980]). Ingestion of lead in drinking water is one of the three principal causes of lead poisoning. While most of this lead is leached from pipes and soldered joints, a better understanding of the aqueous geochemistry of this element can only help to reduce the hazard it poses to aquatic ecosystems and man.

\subsubsection{ASSUMPTIONS OF $21^{\circ} \mathrm{Pb}$ DATING METHODS}

Since the method was first proposed (GOLDBERG [1963]), at least three methods have been used to convert ${ }^{210} \mathrm{~Pb}$ profiles into information on the age of sediments. All of these differ in detail, but they share two major assumptions. The first is that the delivery of $210 \mathrm{~Pb}$ to the sediments is constant, at least during extended intervals. The second is that $210 \mathrm{~Pb}$ is immobile, at least at depth, where physical mixing of sediments is inoperative. Two frequently made additional assumptions are that the removal of $210 \mathrm{~Pb}$ from the water column to sediments is very rapid, and that direct precipitation to the lakes surface is the only source of $210 \mathrm{~Pb}$. When taken together, these two provide a mechanism whereby the delivery of $210 \mathrm{~Pb}$ to sediments would remain constant.

The most general method, that of MCCAFFREY (1977) and of APPLEBY and OLDFIELD (1978), requires only the two conditions of immobility and constant supply. This method is commonly referred to as the Constant Rate of Supply method (C.R.S.). The older Constant Initial Concentration (C.I.C.) method of KRISHNASWAMI et al. (1971) is simpler to apply but requires the additional assumption that the rate of deposition of bulk sediment as well as that of $21{ }^{\circ} \mathrm{Pb}$ is constant. The third method, that of BINFORD and BRENNER (1986), is a modification of the C.R.S. method with a number of additional assumptions that make it 
applicable only for estimating instantaneous, average, basin-wide sedimentation in a limited number of lake systems.

The C.I.C. and C.R.S. methods rest on disparate assumptions, and each may be valid in different lakes or at different times in the same lake. APPLEBY et a1. (1979) compared model-derived ages for three lakes to true ages inferred from varves. They found that C.R.S. calculated ages agreed with the varves to within ten years, while the C.I.C. calculated ages often were 20 to 40 years too young. The age differences were most pronounced when profiles of the $\log$ of ${ }^{210} \mathrm{~Pb} v s$. depth departed from straight lines because of kinks or bends. Similar results were found by OLDFIELD et al (1978). Here C.R.S. derived ages matched dates of a known ash layer and gave sediment accumulation rates that matched ${ }^{14} \mathrm{C}$ derived rates. O.I.C. calculated ages were in error by from 40 to 50 years for some depth intervals.

On the other hand, WAN et al. (1987) found that C.I.C. ages were more accurate than C.R.S, ages for varved sediments of Greifensee, Switzerland. Also, the C.I.C. model may be more reliable for calculating ages in those cases where watershed development accelerates erosion thus causing a rapid increase in sediment (and $210 \mathrm{~Pb}$ ) accumulation in a lake. The ${ }^{210} \mathrm{~Pb}$ depth profile in such a case would be noticeably kinked, as has been observed in several instances (e.g. BERTINE and MENDECK [1978], BARNES et al. [1978]). Using the C.I.C. assumptions, one would interpret this profile as resulting from two separate periods during each of which the assumptions of the C.I.C. technique were separately valid. The outcome of such an analysis would be two different constant values for the sediment accumulation rate, one operative on each side of the inflection point in the profile. In 
contrast, analysis of the profile by the C.R.S. method would give a constant sediment accumulation rate below the kink. Above this point, the sedimentation rate would not be constant and would have to increase in a continuously varying manner in order to yield the observed straight line on a $\log -1$ inear profile. It seems unreasonably fortuitous that sedimentation would vary in exactly the right way to yield a straight line ${ }^{210} \mathrm{~Pb}$-depth profile, so the occurrence of this type of profile argues for analysis by the C.I.C. method. A possible physical mechanism that could cause this type of profile is increased erosion from the watershed. Such an increase likely would augment delivery of both bulk sediment and $210 \mathrm{~Pb}$ to the lake. This was in fact the case for reservoirs studied by McCALL et al. (1984). Concomitant variation of $210 \mathrm{~Pb}$ and bulk sediment accumulation rates violates the C.R.S. assumptions, rendering that method unusable in such systems.

Recent studies by a number of investigators have cast doubt on the assumption that there is always constant delivery of $210 \mathrm{~Pb}$ due to quantitative removal of radionuclide which is supplied exclusively by direct atmospheric deposition. CORNETT et al. (1984) found that ${ }^{210} \mathrm{~Pb}$ was not captured quantitatively in 5 Canadian shield lakes, whose sediments contained from 17 to $80 \%$ of total inputs. BENOIT and HEMOND (1987a) performed a detailed mass balance of $21{ }^{\circ} \mathrm{Pb}$ over the course of 1 year in a New England lake. They found that about half of all the $210 \mathrm{~Pb}$ input to the lake was supplied by the watershed. Only about half of all $210 \mathrm{~Pb}$ inputs were captured within the lake, the rest being lost from the lake as outflow. STILLER and IMBODEN (1986) carried out an approximate mass balance for Lake Kinneret, Israel, and found that the major sources of $210 \mathrm{~Pb}$ input were Jordan River inflow and in situ production from 
${ }^{22} \mathrm{Rn}$ in the water column. NORTON et al. (1985) found that ${ }^{210} \mathrm{~Pb}$ supported by $222 \mathrm{Rn}$ influx in groundwater was the most important source of $210 \mathrm{~Pb}$ to sediments in 3 Colorado lakes. In each case, long term variability in such factors as radon supply and degassing, delivery of $210 \mathrm{~Pb}$ from the watersheds, total annual river flow (as could be caused by water diversion or impoundment), or the efficiency of $210 \mathrm{~Pb}$ capture by the lakes could lead to long term changes in total ${ }^{210} \mathrm{~Pb}$ delivery to sediments thereby violating the constant delivery assumption.

As will be described below, a number of other recent studies suggest that the assumption of immobility of $210 \mathrm{~Pb}$ in sediments may also be violated for some lakes. Since violation of either assumptions constant supply or immobility in sediments - can lead to significant errors in $210 \mathrm{~Pb}$ dating, clearly it is important to understand those factors that control $210 \mathrm{~Pb}$ cycling in the lake water column and in sediments .

A number of investigators have documented lake cores with anomalous $210 \mathrm{~Pb}$ distributions (e.g. MURCHIE [1975], BARNES et al. [1978], BERTINE and MENDECK [1978], BRUGAN [1978], MEGUMI [1978], ROBBINS et a1. [1978], HIRSCHBERG and SCHUBEL (1979), VON DAMM et al. [1979], STILLER [1979], BAXTER et al. [1981], EVANS and RIGLER [1983], MCCALL et al. [1984]). Within the context of conventional $2{ }^{10} \mathrm{~Pb}$ dating schemes, these anomalous distributions have been interpreted as resulting from such processes as mixing of surface sediments by the activities of benthic organisms (ROBBINS et al. [1977], GOLDBERG et al. [1979], KRISHNASWAMI et al. [1980]), compaction (ROBBINS AND EDGINGTON [1975], FARMER [1978]), sediment slumping (VON DAMM et al. [1979]), changes in sedimentation rates (BERTINE and MENDECK [1978]), storm events that cause irregular 
episodic mixing or erosion of a zone of surface sediment (ROBBINS et al. [1978]), disturbance or incomplete recovery of the upper layers of sediment by the coring device (BARNES et al. [1978]), varying dilution by allochthonous inputs (BLOESCH and EVANS [1982]), and even enhanced absorption of $210 \mathrm{~Pb}$ by high concentrations of $\mathrm{Mn}$ in certain intervals (MEGUMI [1978]). Such profiles might alternatively be explained in terms of violation of $210 \mathrm{~Pb}$ dating assumptions. It is important to realize, however, that $210 \mathrm{~Pb}$ dating assumptions may also be violated in some respects without causing profiles to appear anomalous (see section 1.3 below).

\section{2 PREVIOUS INVESTIGATIONS}

\section{$1.2 .1{ }^{210} \mathrm{~Pb}$ GEOCHEMISTRY IN THE MARINE ENVIRONMENT}

This summary of research on the geochemistry of ${ }^{210} \mathrm{~Pb}$ is not intended to be comprehensive, but rather it presents a synopsis of those studies of particular relevance to the freshwater environment.

In broad terms, the cycle of $210 \mathrm{~Pb}$ in the marine envixonment is characterized by supply or production of dissolved $21^{\circ} \mathrm{Pb}$ which is then taken up by solids and removed from the water column. The details of this cycle differ substantially in surficial sea water and in the deep sea. In the surface ocean $210 \mathrm{~Pb}$ is supplied mainly by atmospheric deposition rather than by support from its parent ${ }^{226} \mathrm{Ra}$. In this zone of relatively high biological productivity, ${ }^{210} \mathrm{~Pb}$ is taken up or sorbed by phytoplankton, which are then consumed by zooplankton and packaged into rapidly settling fecal pellets that carry the $210 \mathrm{~Pb}$ out of the surface ocean (NOZAKI et al. [1976], BACON et al. [1976]). The residence time of $210 \mathrm{~Pb}$ with respect to removal by particles is on the order of 2 years. 210 po is cycled in a similar fashion, except that 
average residence times are on the order of half a year, and much of the polonium is believed to be recycled from the fecal pellets before they can sink below the thermocline. The higher rate of $21^{\circ} \mathrm{Po}$ recycling in the thermocline results in excess ${ }^{210} \mathrm{Po}$ (i.e. unsupported by $210 \mathrm{~Pb}$ ) in that zone. It should be noted here and in subsequent discussions that a significant difference between marine and lacustrine environments is that in the ocean most particles are biogenic, whereas in lakes much of the particulate matter is clastic and is supplied from the watershed. In biologically productive regions of the ocean, such as coastal areas or equatorial upwelling zones, the residence time of $21^{\circ} \mathrm{Pb}$ and $2^{2} \mathrm{Po}$ in surface water decreases compared to mid ocean values (SCHELL [1977], NOZAKI et a1. [1976]).

In the deep ocean, ${ }^{210} \mathrm{~Pb}$ is supplied mainly by radioactive decay of its parent, ${ }^{226} \mathrm{Ra}$. In this zone of low production of biogenic particles, $210 \mathrm{~Pb}$ seems to be removed largely by scavenging at ocean boundaries rather than by scavenging by suspended particles and plankton (BACON et al. 1976). Boundary scavenging is thought to be linked to adsorption or coprecipitation with Fe or Mn oxides. (BACON et al. 1976, CARPENTER et al. 1981). ${ }^{210} \mathrm{~Pb}$ residence times in the deep ocean are on the order of 100 years.

We now turn to two special marine environments: anoxic basins and nearshore areas. The Cariaco Trench is an enclosed marine basin containing permanently anoxic water. The top of the basin is located at a depth of 250 meters and at this level the anoxic water of the basin contacts overlying oxygen rich water. In this interface zone the cycling of $210 \mathrm{~Pb}$ and $210 \mathrm{Po}$ seems to be closely associated with that of $\mathrm{Fe}$ and $\mathrm{Mn}$. Soluble reduced $\mathrm{Fe}$ and Mn diffuse upwards, encounter the 
interface, are oxidized, and precipitate, forming a thin zone with a high concentration of particulate $\mathrm{Fe}$ and $\mathrm{Mn}$. Dissolved $210 \mathrm{~Pb}$ seems to be removed by coprecipitation with $\mathrm{MnO}_{2}$ and $\mathrm{Fe}(\mathrm{OH})_{3}$ located just above the oxic-anoxic interface. Within the anoxic basin itself, ${ }^{210} \mathrm{~Pb}$ is deficient with respect to its parent ${ }^{226} \mathrm{Ra}$. The calculated residence time in this zone is only about 2 years, much smaller than the hundred year value for oxygenated deep ocean water. This difference most probably reflects removal via formation of insoluble $\mathrm{Pb}$ sulfide. The oxic waters above the trench contain a substantial excess of ${ }^{210}$ Po over $210 \mathrm{~Pb}$. The most likely source of this excess is advection of ${ }^{210} \mathrm{Po}$ released from sediments in shallow areas along the adjacent Venezuelan coast. Such release of ${ }^{210}$ Po from sediments seems to be fairly common in the marine environment (LI et dl. [1981], TANAKA et al. [1983]). SCHELL (1977) found that $210 \mathrm{~Pb}$ residence times were lower in coastal and estuarine locations than in the open ocean. For example, in the Strait of Juan de Fuca the residence time was measured to be 58 days, compared to $2.6 \mathrm{y}$ for an open ocean location in the same study. CARPENTER et a1. (1981) found that inventories of $210 \mathrm{~Pb}$ in the sediments of the Washington shelf and slope were many times greater than could be accounted for by the combination of atmospheric supply and support by radium in the overlying water column. The excess they attributed to efficient stripping of $210 \mathrm{~Pb}$ from water masses advected onto the shelf. The removal mechanism was judged to be sorption by iron and manganese oxides near the sediment-water interface rather than biological processes in surface waters.

SANTSCHI et aI. (1979) studied Narragansett Bay, R.I., and found that ${ }^{210} \mathrm{~Pb}$ concentrations and mean residence times varied seasonally, 
being higher in summer than in winter. They attributed the higher summer concentrations to either remobilization of $2{ }^{\circ} \mathrm{Pb}$ out of the sediments or stabilization by formation of complexes with organic compounds. Whatever mechanism(s) cause the elevated summertime concentrations, it must overcompensate for the competing process of increased scavenging caused by an elevated rate of sediment resuspension. This processes causes thorium to be removed more rapidly during the warm months.

\section{$1.2 .2{ }^{210} \mathrm{~Pb}$ GEOCHEMISTRY IN FRESH WATERS}

Information on the geochemistry of $21{ }^{\circ} \mathrm{Pb}$ in freshwater comes from studies in a variety of study sites: aquifers, rivers, and lakes. Results of these studies are sometimes supported by related investigations of stable lead and by research carried out in experimental systems and estuaries.

\subsubsection{Groundwater Studies}

HOLTZMAN (1964) presented the earliest data on $210 \mathrm{~Pb}$ in groundwaters. His measurements on well waters in Illinois averaged 11.3 $\mathrm{dpm} / 100 \mathrm{~kg}$ and ranged from 0 to $47 \mathrm{dpm} / 100 \mathrm{~kg}$ with $2{ }^{10} \mathrm{~Pb}$ deficient relative to ${ }^{226} \mathrm{Ra}$ in all samples $(\mathrm{n}=25)$. KRISHNASWAMI et al. (1982) measured a number of $U$ and $T h$ decay series radionuclides in several Connecticut aquifers including glacial drift and crystalline and sandstone bedrock. $210 \mathrm{~Pb}$ varied from 4.9 to $280 \mathrm{dpm} / 100 \mathrm{~kg}$, but these values are upper limits since ingrowth from $22^{2} \mathrm{Rn}$ was not prevented before the measurements. A second sample, drawn from the same we11 that yielded the $280 \mathrm{dpm} / 100 \mathrm{~kg}$ sample, was measured after stripping ${ }^{22} \mathrm{Rn}$ and was found to have only $28 \mathrm{dpm} / 100 \mathrm{~kg}$. Based on their data, Krishnaswami and coworkers estimated a retardation coefficient of 43,000 for $210 \mathrm{~Pb}$ in 
one of the bedrock aquifers. BENOIT and HEMOND (1987a) found that streams in their study watershed carried levels of $2{ }^{20} \mathrm{~Pb}$ that were higher than would be expected for precipitation that had passed through and been subjected to scavenging by the soil profile and aquifer matrix. They concluded that the majority of $210 \mathrm{~Pb}$ in the streams was supplied by recoil from aquifer solids or by ingrowth from recoil-supplied $222 \mathrm{Rn}$. NORTON et al. (1985) found $210 \mathrm{~Pb}$ inventories in the sediments of high altitude Colorado lakes that were up to 20 times greater than could be accounted for by atmospheric and runoff inputs. These lakes had elevated levels of ${ }^{22} \mathrm{Rn}$, and they attributed the high ${ }^{210} \mathrm{~Pb}$ inventories to ingrowth from ${ }^{22} \mathrm{Rn}$ supplied by groundwater to the lake water column.

\subsubsection{River Studies}

RAMA et a1. (1961) presented the earliest measurements of $210 \mathrm{pb}$ in river waters. They found decreasing values of 1470, 100, and 29 dpm/100kg for locations on the Colorado River that were progressively further downstream. They believed that the change in concentration reflected removal processes taking place in the river.

LEWIS (1977) studied the Susquehanna River system, measuring ${ }^{210} \mathrm{~Pb}$ in soil profiles, springs, headwater streams, and the river itself. One branch of the river, influenced by acid mine drainage, had a low pH (4 4.5) and relatively high levels of $210 \mathrm{~Pb}$ and dissolved manganese. Where this branch mixed with another high in alkalinity, the $\mathrm{pH}$ increased rapidly (to $6.5-7$ ) precipitating $\mathrm{MnO}_{2}$ and scavenging dissolved $210 \mathrm{~Pb}$, with a mean residence time of $0.7 \mathrm{~d}$. At the lower $\mathrm{pH}$, the residence time with respect to scavenging was immeasurably long, and iron hydroxides, though present, were ineffective scavengers. This study underscores the efficiency of $210 \mathrm{~Pb}$ removal by sorption/coprecipitation 
with manganese oxides. $210 \mathrm{~Pb}$ in neutral river water ranged from 7 to $107 \mathrm{dpm} / 100 \mathrm{~kg}$, mainly in the particulate fraction, and this is equivalent to about 0.3 to $5 \%$ of the quantity of $210 \mathrm{~Pb}$ contained in rain (corrected for evaporation). Two of three springs tested contained about $100 \mathrm{dpm} / 100 \mathrm{~kg}$ total ${ }^{210} \mathrm{~Pb}$ (i.e. dissolved plus particulate fractions), high levels compared to most surface waters.

BENNINGER (1978) prepared a mass balance for the Long Island Sound estuary including measurements of the Connecticut River, which drains 71.8 of the Sound's watershed. Total $210 \mathrm{~Pb}$ levels in the river ranged from 10 to $80 \mathrm{dpm} / 100 \mathrm{~kg}$ with a constant $5 \mathrm{dpm} / 100 \mathrm{~kg}$ of that total calculated to be in the dissolved form. Variations in concentration resulted from variations in the river's suspended sediment load, which had a constant specific $210 \mathrm{~Pb}$ activity. Overall, total ${ }^{210} \mathrm{~Pb}$ in the river was equivalent in magnitude to about 18 of the amount supplied to the watershed by precipitation.

SERVANT and DELAPART (1979) presented $210 \mathrm{~Pb}$ measurements for one small and two medium sized rivers in southwestern France. For all three the average total ${ }^{210} \mathrm{~Pb}$ level was close to $40 \mathrm{dpm} / 100 \mathrm{~kg}(\mathrm{n}=15)$ with variation by a factor of 8 about this mean. Highest activities were measured during flood flows.

CARPENTER et al. (1981) included measurements of the Columbia River in their investigation of $210 \mathrm{~Pb}$ in Washington coastal sediments. Particulate $210 \mathrm{~Pb}$ measured on 26 samples collected over a three year period averaged $11.2 \mathrm{dpm} / 100 \mathrm{~kg}$ (range $2.0-51.0$ ), and showed an approximately linear dependence on flow (Figure 1.2a). Dissolved $210 \mathrm{~Pb}$ was not measured, but was presumed to be negligible. A simple mass balance showed that an amount equivalent to about 28 of the atmospheric 
FIGURE $1.2 \mathrm{a}$ PARTICULATE $210 \mathrm{~Pb}$ IN THE COLUMBIA RIVER, WASHINGTON, AS A FUNCTION OF DISCHARGE

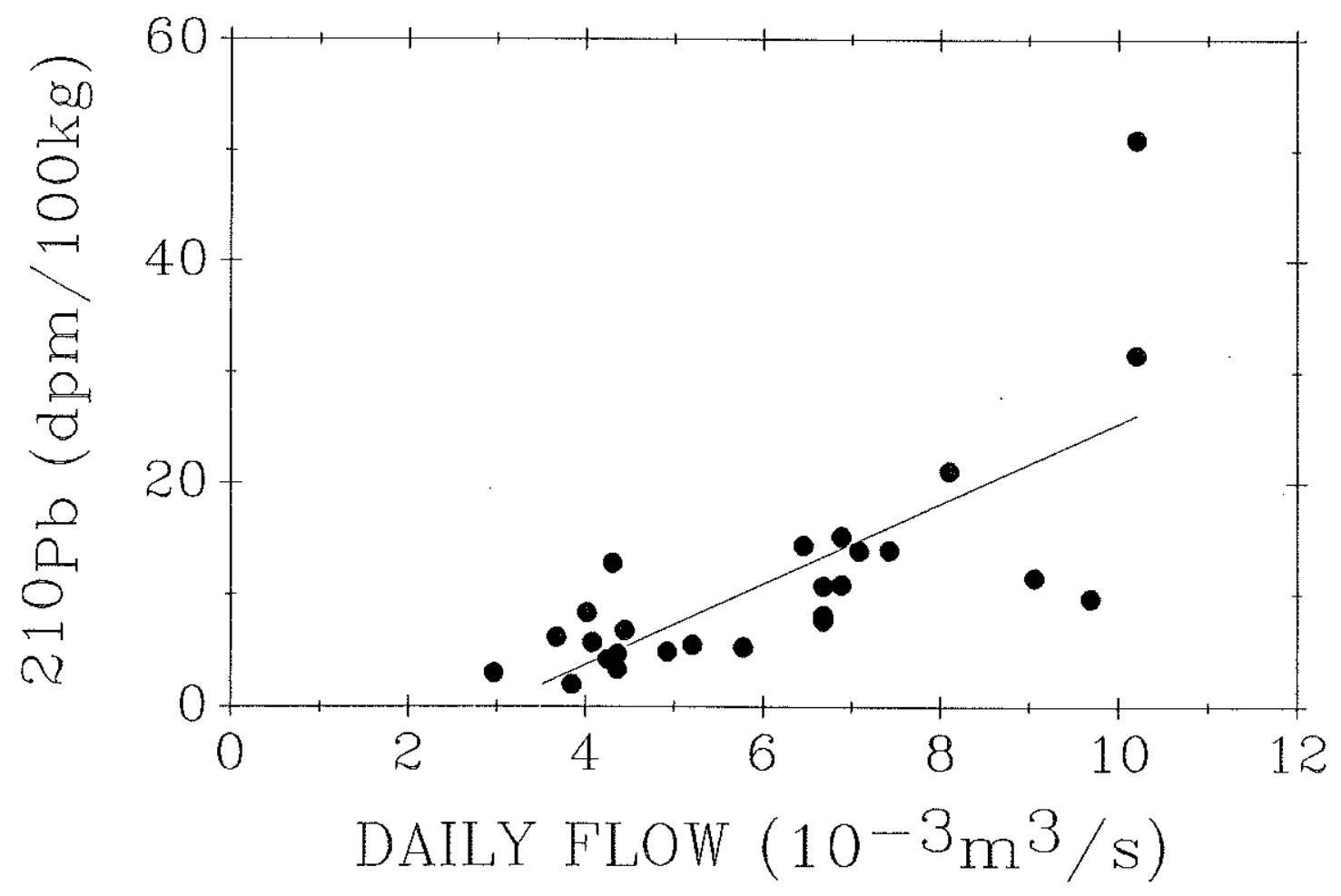

Data from CARPENTER et a1. (1981) 
delivery to the watershed was carried by the river to its mouth. Four of the river water samples had significant excesses of ${ }^{210} \mathrm{Po}$ over ${ }^{210} \mathrm{~Pb}$ suggesting that some $210 \mathrm{~Pb}$ went unmeasured. One possible explanation is that dissolved forms of these radionuclides are not in fact negligible and that some of the excess particulate 210 Po is counterbalanced by dissolved $210 \mathrm{~Pb}$.

STILLER and IMBODEN (1986) prepared a mass balance for Lake Kinneret (Sea of Galilee), Israel, that included measurements of the Jordan River. They found that river borne $21^{\circ} \mathrm{Pb}$ accounted for more than twice the input attributable to direct atmospheric deposition to the lake's surface. The riverine input term may be only a lower limit since it includes only $210 \mathrm{~Pb}$ on particles separable by decanting.

BENOIT and HEMOND (1987a) measured dissolved and particulate $210 \mathrm{~Pb}$ in three streams in Massachusetts. In their twelve monthly samples they found that $210 \mathrm{~Pb}$ was consistently near $10 \mathrm{dpm} / 100 \mathrm{~kg}, 80 \%$ in the dissolved form. Concentration showed little variation with changing flow. These results differ from those of BENNINGER (1978), who found that most $210 \mathrm{~Pb}$ was particulate (but the Connecticut River also has much higher levels of suspended particulate matter). Neither CARPENTER et a1. (1981) nor STILLER and IMBODEN (1986) measured dissolved $210 \mathrm{~Pb}$. LEWIS (1977) measured dissolved $2{ }^{\circ} \mathrm{Pb}$ in headwater streams and found levels that were an order of magnitude lower than measured by BENOIT and HEMOND (1987a). He did not measure particulate $21^{\circ} \mathrm{Pb}$.

\subsubsection{Lake Studies}

\section{Genera1}

The majority of $210 \mathrm{~Pb}$ studies published to date involve use of the radionuclide as a geochronometer rather than as the object of 
geochemical investigation. Still, some of these studies provide insights into the behaviors of $210 \mathrm{~Pb}$ and $210 \mathrm{Po}$. EVANS and RIGLER (1983) analyzed cores collected from throughout the basins of two Canadian lakes. They found that bulk sediment and ${ }^{210} \mathrm{~Pb}$ were both focused from shallower to deeper parts of the lake, such that bulk sediment accumulation rates increased linearly with overlying water depth. They also observed that in shallow areas of the lake, where only coarse sediment was accumulating, $210 \mathrm{~Pb}$ had penetrated to depths greater than could be explained by sediment accumulation alone. They attributed this phenomenon to mixing of a small amount of fine-grained sediment high in $210 \mathrm{~Pb}$ downward into the coarser sediments.

EVANS et al. (1986) presented additional data on the same lakes studied by EVANS and RIGLER (1983). They showed that total ${ }^{210} \mathrm{~Pb}$ inventories increased approximately linearly with the depth of the overlying water column, but there is enough scatter in their data that other functionalities cannot be ruled out. The increase with depth suggests that $210 \mathrm{~Pb}$ is focused from shallow to deep parts of the lake in the same manner as bulk sediment. The same conclusion holds for stable lead in the data of DILLON and EVANS (1982). In contrast, CORNETT et al. (1984) found only a weak correlation between sediment $210 \mathrm{~Pb}$ inventories and water column depth for the seven lakes that they studied (none significant at the 958 level).

In the lake studied by Evans and Rigler, the average inventory of $210 \mathrm{~Pb}$ in the sediments, calculated by weighting each depth increment by its relative area, was $1.1 \mathrm{dpm} / \mathrm{cm}^{2} \mathrm{y}$. This value is not statistically different from estimates of direct atmospheric deposition alone. The watershed can be expected to supply additional $2{ }^{20} \mathrm{~Pb}$ (the ratio of 
watershed to lake area is about ten). The sediment inventory is thus deficient compared to all inputs to the lake, a deficit that reflects loss of $210 \mathrm{~Pb}$ from the lake by non-sedimentary processes, probably outflow.

HESSLEIN et al. (1980) measured the removal rate of metal radiotracers added to an entire lake in the Experimental Lakes Area, Canada. They found that removal seemed to obey first order kinetics, a conclusion verified in a marine microcosm (SANTSCHI et a1. [1983b]) and a shallow marine embayment (TODD [1984]). This could lead to relatively constant water column concentrations, since removal would be accelerated at times of high input (as during rain storms), and slowed at times of low concentration (BENOIT and HEMOND [1987a]).

BARNES et al. (1978) and BIRCH et al. (1980) studied $21{ }^{\circ} \mathrm{Pb}$ in the water column and sediments of six Washington state lakes in areas marked by levels of development ranging from pristine wilderness to extreme urbanization. Most of their cores show sharp inflections in $210 \mathrm{~Pb}$-depth profiles. Such inflections probably result when watershed development and consequent erosion cause a sudden increase in the rate of sediment accumulation in the lake. Watershed erosion may be accompanied by an increase in the supply of $21{ }^{\circ} \mathrm{Pb}$ as well (see section 1.1 .3 above). Since the rate of supply by atmospheric inputs has remained constant, such changes must be caused by changes in the total delivery of $2{ }^{\circ} \mathrm{Pb}$ by the watershed or changes in the efficiency of the lakes in trapping $210 \mathrm{~Pb}$ inputs. These investigators also calculated residence times for $210 \mathrm{~Pb}$ and stable lead in three of the lakes. Average values were 93, 210, and $250 \mathrm{~d}$ for Lake Washington, Lake Sammamish, and Chester Morse Reservoir, respectively. Using hydraulic residence times of $2.35,1.7$, 
and $0.25 \mathrm{y}$, we can calculate that 90,75 , and 258 of total $210 \mathrm{~Pb}$ inputs are trapped within the three lakes.

NORTON et al (1985) measured $2{ }^{\circ} \mathrm{Pb}$ distributions and inventories in four high altitude $(3200 \mathrm{~m})$ Rocky Mountain lakes. Sediment inventories exceeded values equivalent to steady-state support by atmospheric deposition by factors of 1.5, 2.8,4.5, and 20.6. Except for one of the lakes, the oversupply could not be explained by processes such as sediment focusing or surface supply from the watershed. Norton and his coworkers attributed the surplus to support by a high flux of $222 \mathrm{Rn}$ to the lake in groundwater. Very high levels of ${ }^{222} \mathrm{Rn}$ were measured in the water column of the lake that showed the greatest excess $210 \mathrm{~Pb}$ inventory. A similar high inventory $(10 \times)$ has been measured in at least one arctic lake (pers. comm., D. Evans, Environmental Center, Trent Univ., Ontario, 1987).

\section{3 REMOBILIZATION FROM SEDIMENTS}

An important assumption of all $210 \mathrm{~Pb}$ dating methods is that the radionuclide is immobile within sediments. Endorsement for this assumption comes from successful application of $210 \mathrm{~Pb}$ dating in cases where true ages can be determined by an independent method. It is also supported by the fact that both $210 \mathrm{~Pb}$ and stable lead are known to be highly particle-reactive, that is, that they have a strong tendency to be adsorbed by solids.

HEM (1976) presented a model showing that ion exchange sites on clays can limit and control lead solubility at sediment concentrations as low as $10 \mathrm{mg} / 1$. This model is probably an oversimplification of the real world, since soils and suspended particulate matter are heterogeneous, with many surfaces coated with iron and manganese oxides 
and organic matter (JENNE [1967]). LEWIS (1977), for example, found that $210 \mathrm{~Pb}$ was associated almost exclusively with the organic matter fraction of soil profiles, even though soils contain much greater amounts of clays than of organic matter. Nevertheless, Hem's mode1 indicates that even in the absence of iron, manganese, and organic matter, mineral soil material would be expected to limit lead solubility. In support of this, KRISHNASWAMI et al. (1982) found that $210 \mathrm{~Pb}$ was strongly bound by subsoil aquifer materials that presumably are fairly low in organic matter.

SUAREZ and LANGMUIR (1976) measured a number of heavy metals in Pennsylvania soils. They found that many metals, including lead, were associated with iron and manganese coatings on soil particles. These metals were released by treatment of the soils with synthetic reducing chemical solutions that dissolve iron and manganese oxides. Lead was also released in situ by acidic, reducing waters draining a landfill, but not as effectively as by the synthetic leach. Studies of the phase association of lead in sediments suggest that it is most commonly bound to transition metal oxides in spite of the fact that removal from the water column may often take place on biogenic particles. CARPENTER et al. (1981) found that $210 \mathrm{~Pb}$ was principally associated with hydrous $\mathrm{Mn}$ oxides in Washington continental shelf sediments. GUPTA and CHEN (1975) found that stable lead was released from nearshore sediments when treated with reducing leaches designed to solubilize iron and manganese oxyhydroxides. DOMINIK et al. (1983) performed sequential leaching on sediments from the Mediterranean and Lake Geneva. They found that most of the ${ }^{210} \mathrm{~Pb}$ and stable lead was released from the carbonate and reducible fractions of the sediments. SAKATA (1985) found that 808 of 
the stable lead in sediments from a lake was released by hydroxylamine (a reducing agent). SIGG et al. (1987) measured metal concentrations and other characteristics of particles caught in sediment traps in Lake Zurich. They found that stable lead correlated best with the concentration of iron in the particles, and hypothesized that biogenic particles scavenged iron oxide colloids which then in turned sorbed lead and carried it to the sediments.

TUREKIAN (1977) summarized information on $210 \mathrm{~Pb}$ cycling in the river-estuarine-ocean system. He pointed out that at every point along its journey to the sea, lead is removed from solution and sequestered by solids in "the great particle conspiracy". ${ }^{210} \mathrm{~Pb}$ in rain falling on soils is strongly bound by the organic matter fraction, and is only released from the soil profile by erosion. Any dissolved $210 \mathrm{~Pb}$ that does make it to streams is rapidly scavenged by particulate matter, so that only a small fraction of $2{ }^{\circ} \mathrm{Pb}$ in larger rivers is dissolved. Once in estuaries, any dissolved lead that remains, or that is displaced from particles upon encountering high ionic strength seawater, seems to be taken up very rapidly by particles and deposited within the estuary, which serves as a highly efficient trap.

Given that lead has such a high tendency to be sequestered by solids, it would seem that ${ }^{210} \mathrm{~Pb}$ should be, in fact, immobile in sediments, which have a high ratio of solids to solution. Complicating this simple picture, lead in the solid phase is frequently associated with iron and manganese oxyhydroxides as described above. Under the reducing conditions that predominate in most lake sediments, these solids are solubilized, releasing any metals that may be associated with them. If the metals are not rapidly re-adsorbed, they may be 
transported by diffusion and advection before being redeposited, and this can lead to mobility even for a particle-reactive metal like lead. Growing evidence supports this hypothesis.

SANTSCHI et al. (1983b) studied the behavior of a variety of radionuclides in the water column and sediments of MERL model ecosystems. One experiment measured the penetration of radionuclides into sediments, using radioactively tagged microspheres as indicators of purely physical transport processes. They found that $2{ }^{20} \mathrm{~Pb}$ had significantly greater mobility than the spheres in a $240 \mathrm{~d}$ test. By comparison, plutonium was no more mobile than the spheres. It was impossible to show whether the observed mobility would be great enough to affect the interpretation of natural ${ }^{210} \mathrm{~Pb}$ profiles in sediments.

TANAKA et al. (1983) measured water column profiles of several parameters including $210 \mathrm{~Pb}$ in a field study of Funka Bay, a large marine embayment in Japan. They found that ${ }^{210} \mathrm{~Pb}$ and $21{ }^{\circ} \mathrm{Po}$ levels were elevated in bottom waters collected during the summer, a time when the bay waters were strongly stratified and dissolved oxygen was partially depleted at depth. Remobilization from sediments was considered the most likely source of the radionuclides since even quantitative release from settling particulate matter could not account for the magnitude of the flux. Since the high ${ }^{210} \mathrm{~Pb}$ bottom waters were also high in phosphate and silica, it was believed that the increases were directly or indirectly related to the decomposition of marine organic matter. One possible indirect mechanism is that organic matter decomposition consumes oxygen thereby creating reducing conditions. HARADA and TSUNOGAI (1982) suggested that lead may be released from weakly reducing sediments when the redox potential is poised between that of iron 
reduction and sulfate reduction. Under these conditions divalent dissolved lead is much more soluble than at a lower redox potential where lead sulfide would precipitate.

ERTEN et al. (1985) presented evidence that $2{ }^{210} \mathrm{~Pb}$ remobilization had substantially altered the total distribution of the radionuclide in sediments of Lake Zurich. They found that ${ }^{210} \mathrm{~Pb}$ decreased exponentially with depth except in the upper $6 \mathrm{~cm}$, where activity was constant. Three lines of evidence suggest that this constancy could not be the result of sediment mixing. 1) The sediments showed annual laminae (varves) that would be destroyed by mixing. 2) ${ }^{7}$ Be was found only in the uppermost layer of sediment; mixing would transport it deeper into the sediment column. 3) The ${ }^{137} \mathrm{Cs}$ profile showed fine structure inconsistent with mixing, and showed a sharp maximum at a depth deposited in 1963 according to varves. The total $2{ }^{\circ} \mathrm{Pb}$ inventory in the sediments was low, and preliminary measurements showed that porewater ${ }^{210} \mathrm{~Pb}$ was high. Erten and coworkers interpreted these findings as evidence for chemical remobilization of $210 \mathrm{~Pb}$ and transport out of the sediments.

WAN et a1. [1987]) measured distributions and inventories of ${ }^{210} \mathrm{~Pb}$, ${ }^{7} \mathrm{Be},{ }^{137} \mathrm{Cs},{ }^{239,240} \mathrm{Pu}$, and ${ }^{90} \mathrm{Sr}$ in the sediments of Greifensee, Switzerland. Sediment accumulation rates based on fallout radionuclide peaks agreed with true rates inferred from varves. $210 \mathrm{~Pb}$ derived dates using either C.I.C. or C.R.S. models were low by about a factor of two. Wan and coworkers concluded that this error was probably the result of $210 \mathrm{~Pb}$ remobilization. Additional circumstantial evidence that this was happening is that dissolved $2{ }^{\circ} \mathrm{Pb}$ was high in porewaters (130 dpm/100kg) and that the total sediment inventory of ${ }^{210} \mathrm{~Pb}$ was low (388 of direct atmospheric input). 
BENOIT and HEMOND (1987) measured a high $210 \mathrm{~Pb}$ leve1 in anoxic water adjacent to bottom sediments in Bickford Reservoir. They attributed the high value to remobilization of $210 \mathrm{~Pb}$ from particulate or sedimentary iron and manganese oxyhydroxides under the influence of reducing conditions. In support of this hypothesis, high $210 \mathrm{~Pb}$ was not observed the following year, when complete anoxia failed to occur. WHITE and DRISCOLL (1985) studied stable lead in Dart Lake, NY, and found that lead in bottom water increased by about a factor of five over typical upper water column values during the summer. Although Dart Lake is substantially affected by acid precipitation, the bottom water ${ }^{210} \mathrm{~Pb}$ increment was accompanied by an increase in $\mathrm{pH}$ and a reduction in dissolved oxygen, suggesting that the effect is related to oxygen depletion rather than acidification.

Additional circumstantial evidence for remobilization of stable lead in sediments is found in the existence of porewater concentration gradients that could lead to diffusive transport. Such gradients have been measured by GAILLARD et al. (1986) in nearshore marine sediments and by SAKATA (1985) in a small lake. The latter author also measured the transport of lead out of the sediments using a simple, unstirred flux chamber and found that lead increased in the device during the first day of the experiment and decreased thereafter. Sulfides were not detected.

SIGG et al. (1987) studied details of the $\mathrm{Mn}, \mathrm{Fe}$, and redox cycles and their relation to the behavior of heavy metals in the water column of Lake Zurich. They found that a significant amount of Mn was released from sediments and entered the water column, where it precipitated as oxides. Settling of these oxides caused an orders-of-magnitude increase 
in the Mn flux to sediment traps located near the sediment-water interface at all times during the year. $\mathrm{Zn}$ and $\mathrm{Cu}$ fluxes in deepwater sediment traps were also somewhat higher, suggesting that they accompany Mn. In contrast, Fe was not higher at depth. The difference between the behavior of iron and manganese probably reflects the difference in potential of the respective redox reactions and the kinetics of oxidation of the two elements. Specifically, manganese reduction (and remobilization) occurs at a higher redox potential, and manganese oxidation (and precipitation) takes much longer at low $\mathrm{pH}$ than iron oxidation. The net result is that manganese can be expected to be released under conditions that are less reducing and to penetrate higher into the water column before reoxidation. Neither $\mathrm{Pb}$ nor $\mathrm{Cd}$ levels were elevated in bottom sediment traps, so these metals are either not associated with manganese in the sediments, or they are rapidly rescavenged near the sediment water interface by other phases such as iron hydroxides.

Additional indirect evidence for $210 \mathrm{~Pb}$ remobilization is contained in LI et al. (1981). In their study of the New York Bight they concluded that high levels of $21{ }^{\circ} \mathrm{Pb}$ and $21^{\circ} \mathrm{Po}$ indicated regenerational inputs from sediments or bottom waters. $21{ }^{\circ}$ Po was regenerated to a much greater extent than $210 \mathrm{~Pb}$, as has been observed in other marine studies (see section 1.2 .1 above).

\subsection{LAKE MASS BALANCES}

One of the most effective ways to investigate the geochemistry of a compound is by means of a mass balance, an accounting of all inputs, outputs, and changes in standing stock for the given material. Lakes are especially well suited to this approach since they have well defined 
boundaries, and inputs and outputs can be accurately monitored with minimal effort.

TALBOT and ANDREN (1984) prepared a detailed mass balance for Crystal Lake, WI, during parts of two summers. The study site is a sma11, oligotrophic seepage lake with no inflowing or outflowing streams and a water residence time of about $20 \mathrm{y}$. In Crystal Lake, the removal rate of $210 \mathrm{~Pb}$ and ${ }^{210} \mathrm{Po}$ varied a great deal depending on biological productivity. The most rapid delivery of $210 \mathrm{~Pb}$ and $210 \mathrm{Po}$ to sediments occurred during and just after plankton blooms, at least during the warm months when data were collected. Radionuclide levels increased in the water column as blooms developed, and then decreased rapidly immediately afterwards.

Several differences were noted in the behavior of the two radionuclides. $210 \mathrm{~Pb}$ had a shorter average residence time (35 d) compared to $21{ }^{\circ} \mathrm{Po}(95 \mathrm{~d})$. The difference was thought to be the result of a greater degree of $2{ }^{\circ} \mathrm{Po}$ recycling in the water column and sediments of the lake. Indeed, it was found that $2{ }^{\circ}$ po was remobilized from sediments to the extent that at times there was a net increase in the water column, that is, regeneration from the sediments exceeded the sedimentation flux. This higher rate of ${ }^{210}$ Po recycling compared to lead is consistent with a number of marine studies (section 1.2.1 above).

For ${ }^{210} \mathrm{~Pb}$, an additional, non-biological removal mechanism was observed in association with fall overturn. At that time ${ }^{210} \mathrm{~Pb}$ levels fell rapidly, and Talbot and Andren believe that this phenomenon may be connected with $\mathrm{Fe}$ and $\mathrm{Mn}$ redox cycling. They also suggested that ${ }^{210} \mathrm{~Pb}$ and ${ }^{210}$ Po may be carried by different particle types, since ${ }^{210}$ Po levels 
increased slightly during overturn. In Crystal Lake, boundary scavenging (direct sorption onto bottom sediments) did not seem to be important as a removal mechanism judging from a lack of $210 \mathrm{~Pb}$ depletion near the sediment water interface.

CORNETT et a1. (1984) calculated approximate mass balance for seven small lakes located in the Canadian shield. Through their research they hoped to test rigorously the assumption of the $210 \mathrm{pb}$ dating method that there is a negligible loss of ${ }^{210} \mathrm{~Pb}$ as outflow. They found that the inventory of $210 \mathrm{~Pb}$ in the lake sediments ranged from 37 to $83 \%$ of the amount supplied by atmospheric deposition. When an estimate of $210 \mathrm{~Pb}$ supplied by streams was added, capture in the lakes was in the range of only 17 to $80 \%$ of total inputs. Clearly some of these lakes were not efficient at trapping $210 \mathrm{~Pb}$. Cornett and coworkers also calculated scavenging removal rates and found that they were lower than values measured for most other lakes. This apparent difference they attributed to the fact that their own calculations reflect year-long averages, whereas all previous measurements were made during the summer, a period of higher than normal productivity and biological scavenging processes. This hypothesis is not consistent with the work of SANTSCHI et al (1979), who found lower scavenging rates for $21^{\circ} \mathrm{Pb}$ in the summer in the Narragansett Bay estuary (Section 1.2.1).

STILLER and IMBODEN (1986) prepared a mass balance for Lake Kinneret, Israel. They found that direct atmospheric input accounted for 258 , rivers $55 \%$, and radioactive support $20 \%$ of all $210 \mathrm{~Pb}$ supplied to the lake. The relatively high ratio of riverine to atmospheric inputs is caused in part by the arid climate at this study site. Very low precipitation reduces wet deposition of $21^{\circ} \mathrm{Pb}$ to the lake's surface 
and increases erosional supply by the rivers. Residence time in the water column was $1-2 \mathrm{y}$ in the dissolved phase and only $0.1 \mathrm{y}$ in the particulate phase. The average residence time was 0.5 years, less than the sum of dissolved and particulate values because a large part of the input to the lake is already on particles.

BENOIT and HEMOND (1987a) prepared a year-long, detailed mass balance for Bickford Reservoir, MA. Measurements of streamwater over the course of the year showed that 808 of $210 \mathrm{~Pb}$ occurred in the dissolved form, and that total concentration changed little with large variations in flow, $210 \mathrm{~Pb}$ in the streams came mainly from alpha-recoil off of aquifer matrix materials rather than from meteoric sources. In terms of the total mass balance of the lake, streams and atmospheric deposition each provided half of total inputs while radioactive support and groundwater contributed negligible amounts. Within the lake, the residence time for scavenging onto particles and sedimentation totaled 80 d. Because the sedimentation residence time was of the same order as the hydraulic residence time, only half of total ${ }^{210} \mathrm{~Pb}$ inputs were captured by sedimentation; the remainder were lost as outflow.

Benoit and Hemond noted that total stream inputs and outputs were highly correlated and approximately equal in magnitude. As a result, sediment inventories were almost exactly equal to atmospheric deposition alone. It almost seems as if the fraction of total $210 \mathrm{~Pb}$ inputs that is supplied by streams behaves conservatively, only leaving the lake when it is flushed out. If this were indeed the case, then one possible explanation would be if $210 \mathrm{~Pb}$ speciation were different in the two inputs. It is interesting that a similar equivalence of stream inputs 
and outputs was documented by WHITE and DRISCOLL (1985) for stable lead in Dart Lake, NY.

$21{ }^{\circ} \mathrm{Po}$ scavenging and sedimentation was significantly slower than that of $210 \mathrm{~Pb}$ (average residence time $135 \mathrm{~d}$ ). A mass balance model showed that 210 Po was released from sediments to the water column, especially under suboxic conditions in the hypolimnion. Both of these conclusions are consistent with previous studies in freshwater and marine environments. Based on the relative concentrations of the particulate radionuclides and on their relative sedimentation rates, Benoit and Hemond were able to show that sedimentation of $210 \mathrm{~Pb}$ and 210 Po could not be modeled as simple settling of undifferentiated suspended particulate matter.

\subsection{THIS RESEARCH}

As described in section 1.1 above, the main goal of this research is to test assumptions of $210 \mathrm{~Pb}$ dating methods in order to facilitate better informed interpretation of $210 \mathrm{~Pb}$-depth profiles in sediments. A further objective is to provide information on the lacustrine geochemistry of stable lead, a substantial, ubiquitous, and highly toxic contaminant of the global environment. In order to achieve those aims, I focused on several components of the ${ }^{210} \mathrm{~Pb}$ geochemical cycle in lakes:

a) Refined mass balance: Previous research at this site featured a mass balance that was used to calculate ${ }^{210} \mathrm{~Pb}$ scavenging and sedimentation fluxes. In order to refine that approach, sediment traps were installed in the lake water column that would allow closure of the material budget and evaluation of the reliability of the measurements. Variations of $210 \mathrm{~Pb}$ and of the quantity and biogeochemical characteristics of sediment trap material can 
provide valuable information on scavenging and on sediment resuspension and redistribution processes.

b) Solid phase speciation: Scavenging of dissolved matter in the water column depends critically on the nature of the particles involved. Sequential leaching techniques were used to determine, at least operationally, the chemical characteristics of both suspended and rapidly settling particulate matter fractions with which $210 \mathrm{~Pb}$ and $210 \mathrm{Po}$ were associated.

c) $210 \mathrm{~Pb}$ remobilization: An important and surprising finding of previous research at this site was the discovery that substantial amounts of $210 \mathrm{~Pb}$ were released to the water column under reducing conditions. A major target of this investigation was to measure in detail the occurrence of this phenomenon in space and time, and to understand its causes.

d) Early diagenesis and porewater reactions: Once incorporated into sediments, ${ }^{210} \mathrm{~Pb}$ may undergo a number of reactions. Sequential leaching measurements were used to investigate the solid phase association of the radionuclide and how it changes with depth. Porewater concentration measurements revealed the partitioning of lead between solids and solution and permitted estimation of diffusive fluxes within the sediments. Solid phase distribution of ${ }^{210} \mathrm{~Pb}$ combined with the known history of the lake basin were used to interpret the record of sedimentation and mixing.

e) Water column physics: The occurrence of ${ }^{210} \mathrm{~Pb}$ fluxes out of the sediments gave rise to important questions concerning the hydrodynamic regime of the lake. Enclosures were used to test whether the measured maxima were the product of vertical or 
horizontal transport. The possibility that diffusion might limit radionuclide transport across a stagnant film at the sediment water interface was tested by direct measurement of its thickness. Eddy diffusion $\left(\mathrm{K}_{Z}\right)$ in the water column was evaluated using heat as a conservative tracer after correcting for radiant thermal inputs and heat losses to sediments.

f) Dating and sediment redistribution: Bickford Reservoir has had a complex history of anthropogenic alterations. A final task of this research was to use measured $210 \mathrm{~Pb}$ profiles to reconstruct the record of its development from a bog to a reservoir in two phases of dam building. Also, cores collected from throughout the lake basin were analyzed to test whether sediment focusing was active in the redistribution of either $210 \mathrm{~Pb}$ or bulk sediment. 


\section{CHAPTER 2 STUDY SITE}

Bickford Pond is an oligotrophic, dimictic lake located in central Massachusetts on the western flank of Mt. Wachusett (maximum height 611 $\mathrm{m})$ at $42^{\circ} 29^{\prime} \mathrm{N}$ latitude and $71^{\circ} 56^{\prime} \mathrm{W}$ longitude at an altitude of 319 $\mathrm{m}$. The lake's area is $58.8 \mathrm{ha}$, the average depth is $5.7 \mathrm{~m}$, and the maximum depth is $13 \mathrm{~m}$. The history of the lake can be divided into three separate periods. During the first, the lake, probably of glacial origin, occupied a depression that corresponds roughly to the area deeper than $8 \mathrm{~m}$ on the bathymetric map (Figure 2a). That lake gradually filled in, producing a bog whose peat-like material is still found on the bottom of the northern part of the present-day lake. In the second stage, sometime during the last century, a stone dam was constructed (see Figure 2b), flooding the bog to a depth of about $2 \mathrm{~m}$ (Andy Provencial, Fitchburg, Massachusetts, Water Dept., pers. comm.). The most recent period began in 1970 when the lake was enlarged to its present size by the addition of two earthen dams. Enlargement also captured a much larger watershed, causing streams to begin draining into the lake and presumably causing a large increase in the input of allochthonous material.

The basic form of the lake includes a broad, almost perfectly flatbottomed basin at a depth of $8 \mathrm{~m}$ in the north (the former bog), as well as a smaller, deeper $(13 \mathrm{~m})$ basin in the southwest. The southeast is a broadly sloping, irregular surface over which part of the now-submerged course of Provencial Brook once flowed. This section gradually increases in depth from 2 to about $5 \mathrm{~m}$ from east to west. The lake occupies a depression in glacial till that varies in thickness from a few meters to as much as $20 \mathrm{~m}$ in places. 


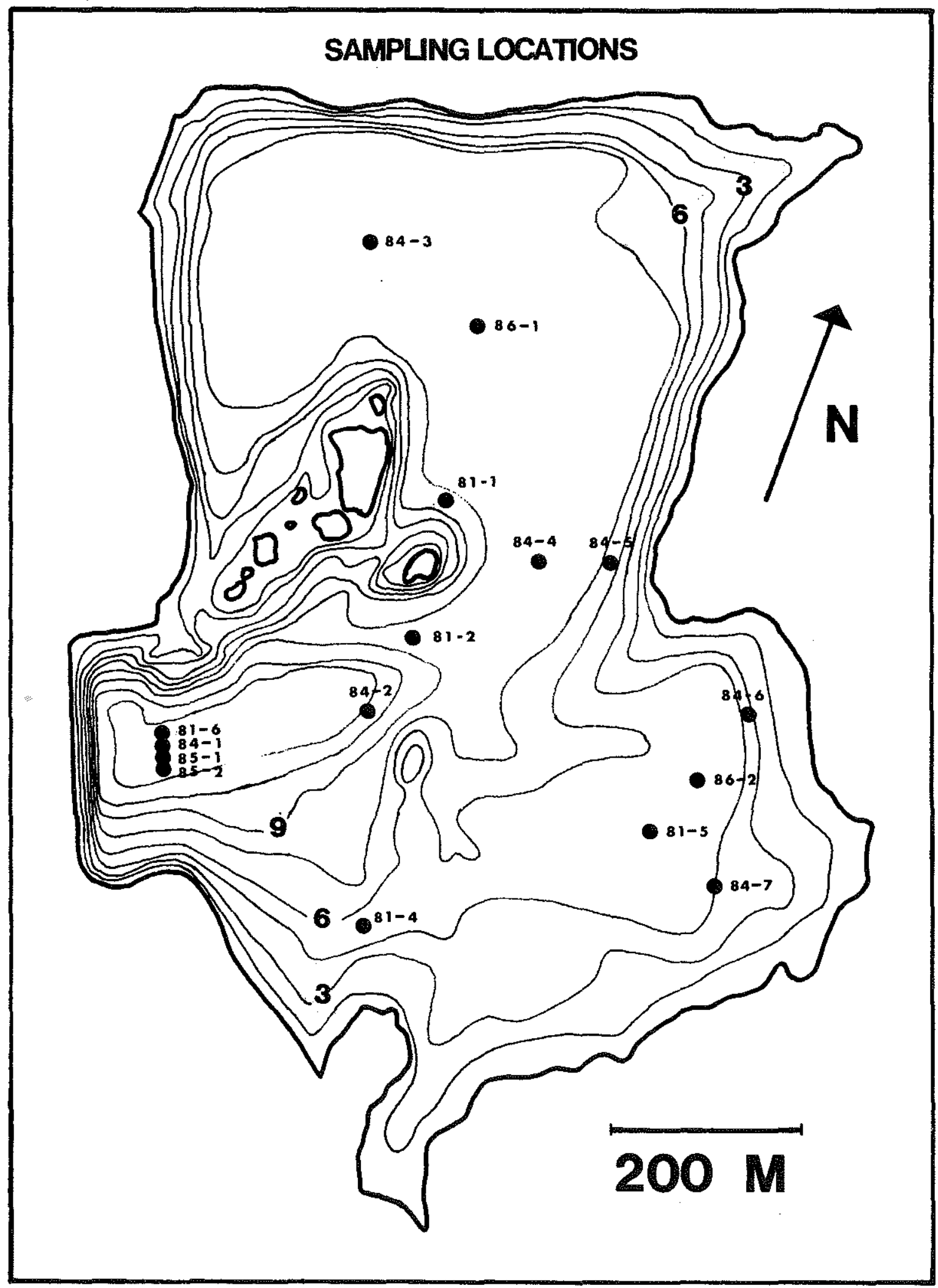

\section{BICKFORD POND CONTOUR INTERVAL $1.5 \mathrm{~m}$}




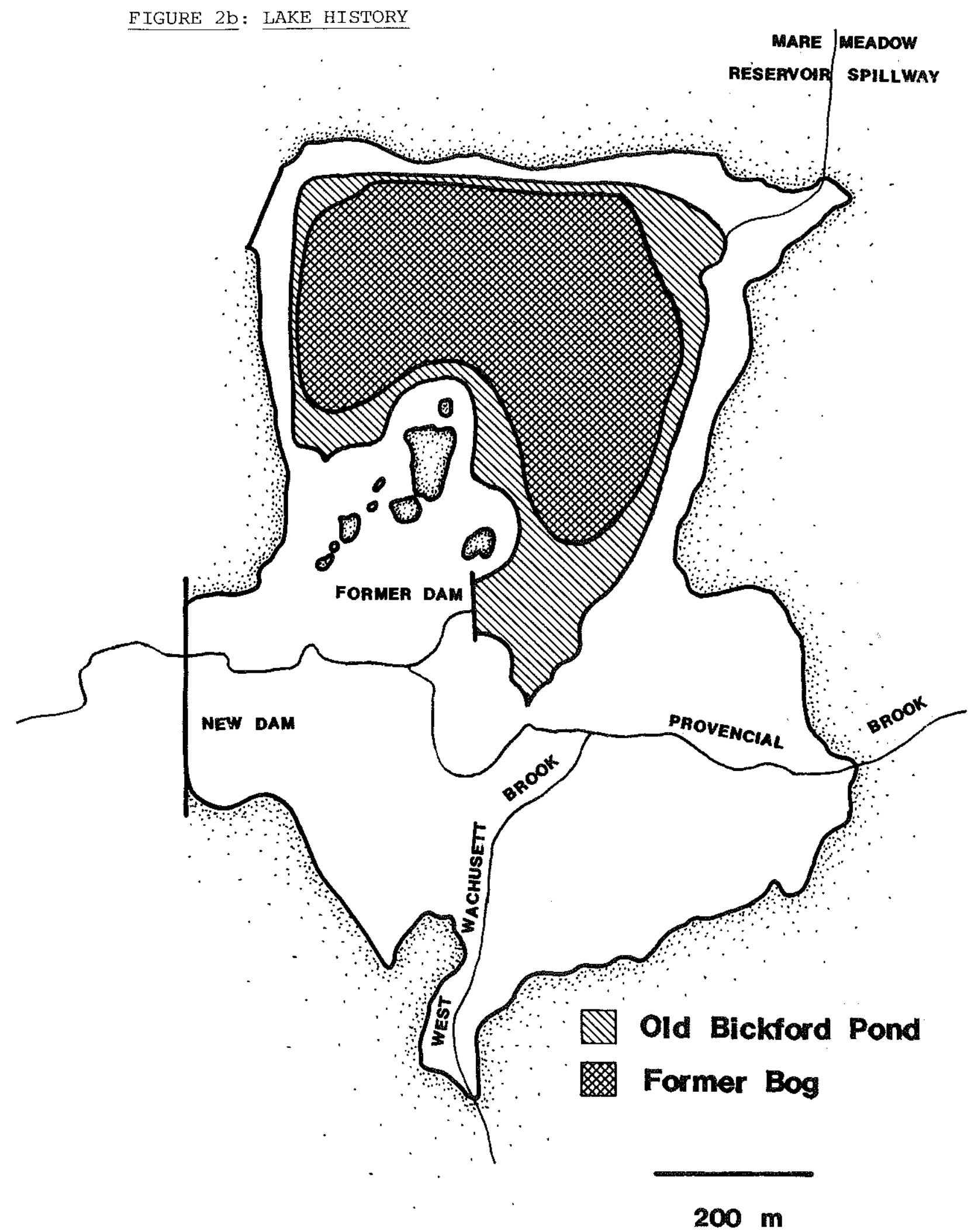


The lake is fed by two streams which drain the 760 ha watershed as well as by the overflow from Mare Meadow Reservoir and its 770 ha catchment. West Wachusett Brook receives drainage from $73 \%$ of the watershed while Provencial Brook drains the remaining $27 \%$ (Figure 2c). The Mare Meadow Reservoir is a municipal water supply reservoir. During periods of heavy pumping, flow from this source to Bickford Pond is diminished or completely stopped. Bickford Pond serves as a backup water supply reservoir for the town of Fitchburg, Massachusetts, and for that reason its mostly-forested watershed is partially protected from development; there are at present only a few households within that area. No public roads reach the lake, access to which is limited to water department personnel.

Bickford Pond has been the subject of an ongoing study to determine the impact of acid precipitation (ESHLEMAN [1985]). That study, which established a mass balance of all major ions and water during the period from July 1981 to July 1985, has shown that thus far Bickford has responded very differently from systems in the ILWAS study (Adirondacks, NY) and in the Hubbard Brook study (White Mountains, NH). In particular, acid deposition has not had as great an impact on the Bickford Pond system as on the watersheds in the above mentioned studies, and a nitric acid pulse is not observed at the time of spring snowme1t. Consequently, the cycles of $210 \mathrm{Po}$ and $210 \mathrm{~Pb}$ are probably similar in Bickford Pond and in many lake-watershed systems that are not receiving acid deposition.

The major ion chemistry of the brooks feeding the lake are typical of uncontaminated streams draining granitic terranes elsewhere. The water has a low ionic strength $(0.4 \mathrm{mM})$ and dissolved solids content (20 


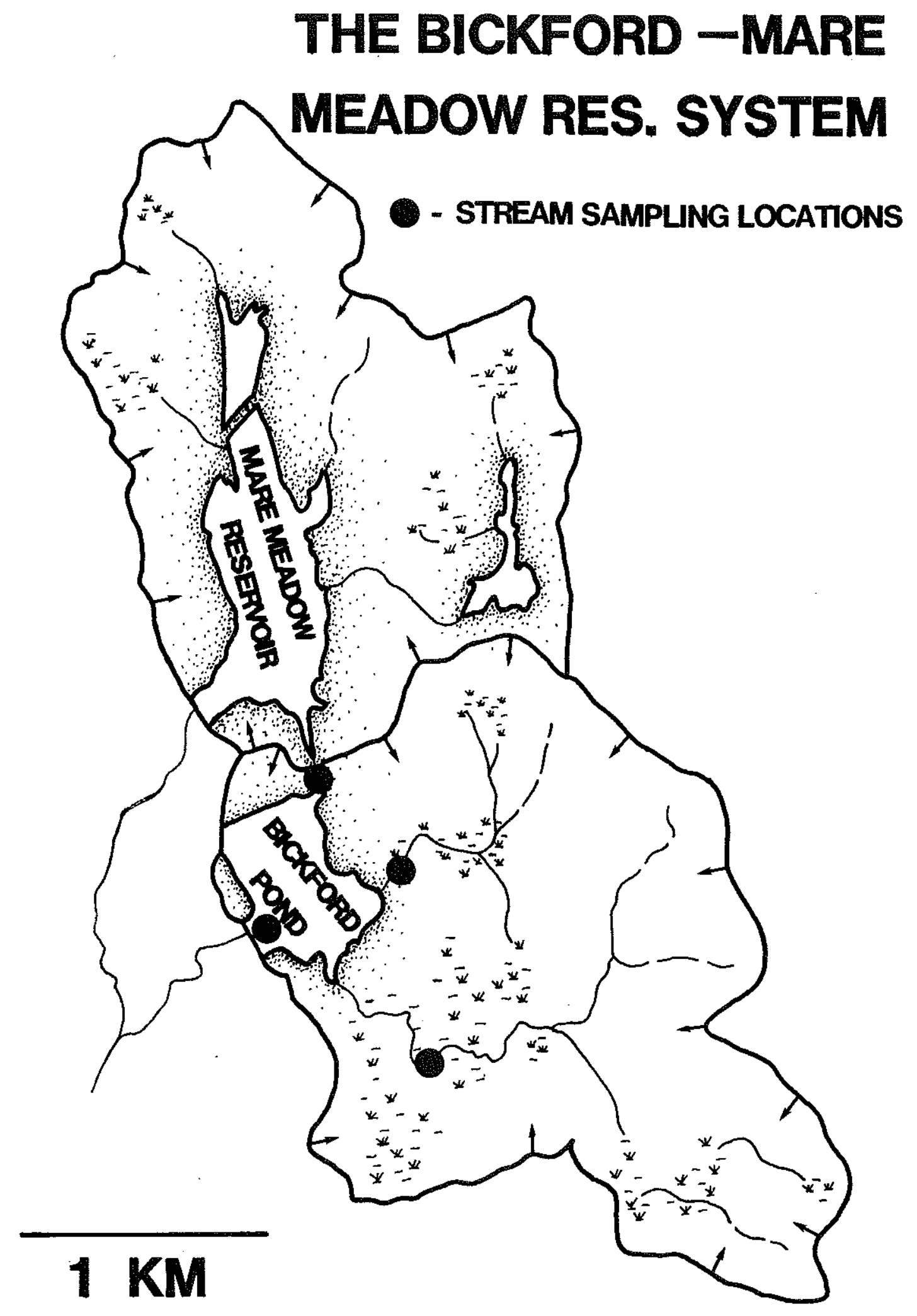


$\mathrm{mg} / 1 \mathrm{tter}$ exclusive of silica) which is composed mostly of the cations $\mathrm{Ca}^{2+}$ amd $\mathrm{Na}^{+}$and the anions $\mathrm{SO}_{4}{ }^{2-}$ and $\mathrm{Cl}^{-}$. Average $\mathrm{pH}$ is near 6 , but may fall as low as 4 during infrequent severe storm events. Lake water resembles stream water except that the $\mathrm{pH}$ is typically about 6.5. The lake has a volume of $3.37 \times 106 \mathrm{~m}^{3}$ and receives $0.71 \times 10^{6} \mathrm{~m}^{3}$ of rainfall each year along with $13.66 \times 106 \mathrm{~m}^{3}$ of runoff. The water residence time in the lake therefore averages $\left(3.37 \times 10^{6} \mathrm{~m}^{3} / 14.37 \times 10^{6}\right.$ $\left.\mathrm{m}^{3}\right)=0.23 \mathrm{y}$. This is an average value for the entire lake. When stratification takes place, the hydraulic residence time of water in the epilimnion alone is about $80 \mathrm{~d}$. 


\section{CHAPTER 3 METHODS}

\subsection{SAMPLE COLLECTION}

Rain was collected in funnels made from inverted glass bottles (15 cm I.D.) with their bottoms removed. Water from the funnel passed into an acid-washed, glass, collection bottle through a loop of PVC tubing which served as a barrier to evaporation. Dry deposition present on the surface of the funnel was added to the rain sample by rinsing with dilute $\mathrm{HCl}$. Rain was collected at an open site adjacent to the lake at its northeastern corner. The mouth of the funnel was at a height of 2 m. Collections averaged 20 days in length during which time $5 \mathrm{~cm}$ of rain typically accumulated. The collection intervals were the same as those for measurements on the lake water column (see Table 4.3.7a). Lake water samples for $210 \mathrm{Po}$ and $210 \mathrm{~Pb}$ analysis were collected by pumping from the required depth through PVC tubing of 1/4" I.D. through an in-1ine $142 \mathrm{~mm}$ diameter filter holder and into a 20 liter Nalgene polyethylene carboy by means of a battery-driven peristaltic pump. The filter-holder, which contained a $0.45 \mu$ Millipore ${ }^{T M}$ Durapore filter, was positioned between the pump and the carboy. In most cases it took from two to four filters to collect ten to twenty liters of lake water. The pumping rate was about one liter per minute. Back pressure on the filter was monitored with a gauge in order to circumvent the increase in filtering efficiency that can result from partially clogged filters (DANIELSON [1982]). This method of collection has the advantage that samples are filtered at in situ temperatures and before exposure to the atmosphere. Throughout this thesis the term "dissolved" refers to material that passes a $0.45 \mu$ filter, including both colloids and 
material that is in true solution. Similarly "particulate" means simply any material that is trapped on a $0.45 \mu$ filter.

Suspended particulate matter (SPM) was determined by measuring material collected on preweighed $.45 \mu \times 47 \mathrm{~mm}$ Durapore ${ }^{\mathrm{m}}$ filters mounted in in-line holder. Filtration took place during collection as described above in the $210 \mathrm{~Pb} / \mathrm{Po}$ sampling methodology.

Stream water samples for $210 \mathrm{~Pb}, 210 \mathrm{Po}$, and SPM analyses were collected using the same scheme described above for lake waters. In the case of stream waters, the mouth of the collection tube was placed in the deepest part of the stream at $2 / 3$ of the distance from the bottom to the surface. Samples were collected just upstream from the lake on 4 and 24 July, 14 August, and 19 and 24 October 1985.

Sediments $210 \mathrm{~Pb}$ analysis were collected by a SCUBA divers using 2.4 or $3.0 \mathrm{~cm}$ diameter metal tubing, $3.9 \mathrm{~cm}$ diameter plastic tubing, and $12.7 \mathrm{~cm}$ diameter PVC tubing. Details of each type of core are described in section 5.2. In general, the tubes were carefully pushed into the sediment, capped on the bottom by the diver's gloved hand, and then slowly withdrawn, taking care not to disturb the sediment water interface. Cores taken in this manner were sealed with plastic end-caps and carried in a vertical orientation back to the laboratory. Cores in metal tubes collected in 1981 were frozen until further analysis. Other cores were sectioned immediately after return to the laboratory into $1 / 2$ to $1 \mathrm{~cm}$ thick sections. The weight of each section was measured and its exact length recorded in order to determine in situ density. Al1 exposed surfaces were sliced away exposing fresh sediment, and the remaining material from each depth interval was homogenized before a 0.5 to $1.0 \mathrm{~g}$ subsample was taken for $210 \mathrm{~Pb}$ analysis. The sample was then 
dried in an oven at $105{ }^{\circ} \mathrm{C}$ and reweighed in order to determine the water content before further analysis. The sediment was then transferred to a teflon beaker and treated successively with hot concentrated nitric and hydrofluoric acids, which caused complete dissolution. It was then brought to dryness twice with dilute $\mathrm{HCl}$ to eliminate any traces of the $\mathrm{HF}$.

Settling particulate matter was collected in a sediment trap made from a polyethylene crankcase oil filler funnel glued to the bottom of a $12 \mathrm{~cm}$ diameter by $12 \mathrm{~cm}$ length of PVC pipe. The inside of the trap was painted with antifouling paint to prevent the growth of biota. The top of the trap was filled with $10 \mathrm{~cm}$ lengths of plastic drinking straws held under their own elastic tension in a space-filling honeycomb pattern. This design gave the sediment trap an effective aspect ratio greater than 5:1 as recommended by HARGRAVE and BURNS (1979). The lower end of the funnel was glued into a hole cut in the cap of a $100 \mathrm{~m} 1$ Nalgene ${ }^{\text {MM }}$ wide-mouth jar. SCUBA divers harvested the particulate matter by screwing a new jar in place of the cup. Design of the trap followed the recommendations of HARGRAVE and BURNS (1979) and BLOMQUIST and HAKANSON (1981).

\subsection{SAMPLE PREPARATION}

All water samples for $210 \mathrm{~Pb} /{ }^{10} \mathrm{Po}$ analysis were preserved in the field by the addition of concentrated $\mathrm{HCl}$ at a dosage of $4 \mathrm{~m} 1 / 1$ iter $(0.05$ molar final concentration). After return to the laboratory, water samples were spiked with ${ }^{208} \mathrm{Po}$ and stable $\mathrm{Pb}$ in order to monitor recovery of $210 \mathrm{~Pb}$ and $210 \mathrm{Po}$ respectively. Samples were allowed to equilibrate with the yield monitors for at least $24 \mathrm{~h}$ with stirring. At the end of the equilibration period, dissolved $\mathrm{Po}$ and $\mathrm{Pb}$ were 
concentrated from solution by precipitation with Cobalt-ADPC (BOYLE and EDMOND [1975]) and filtration through GF/C glass fiber filters. APDC precipitate that was formed in water samples from West Wachusett and Provencial Brook was very fine, unlike the coarser precipitate in lake samples. Almost all of these solids passed through GF/C filters even after standing for several days. For stream samples, prefiltration through a GF/C filter and subsequent filtration through an $0.45 \mathrm{~m}$ Durapore filter was employed.

GF/C filters from the APDC precipitation were leached with warm $6 \mathrm{~N}$ $\mathrm{HNO}_{3}$ in a beaker in order to redissolve the precipitate. Any glass fibers that broke loose from the filter during this step were either dissolved in $\mathrm{HF}$ or removed by filtration in order to obtain a clear plating solution. The sample was then brought to dryness on a hot plate, redissolved in $2 \mathrm{~N} \mathrm{HCl}$, and brought to dryness a second time. Recovery of yield monitors was routinely greater than 908 by this ne thod.

Durapore membranes that had been used to filter lake water in the field were treated with hot $6 \mathrm{~N} \mathrm{HNO}_{3}$ in order to liberate $210 \mathrm{~Pb}, 210 \mathrm{Po}$ and particles adhering to the filters. The filters were placed in a beaker, covered with $6 \mathrm{~N} \mathrm{HNO}_{3}$ and heated to $90{ }^{\circ} \mathrm{C} .208 \mathrm{Po}$ and stable $\mathrm{Pb}$ yield monitors were added to the beakers and allowed to equilibrate with the filters and their sediment load for at least one hour. The filters were then removed from the beakers and rinsed with $6 \mathrm{~N} \mathrm{HNO}_{3}$, the washings being added to the oxiginal leachate. Microscopic examination of filters treated in this manner showed them to be free of particles. Next the sample was boiled to dryness on a hot plate and the residual solids were redissolved in $2 \mathrm{~N} \mathrm{HCl}$ and brought back to dryness two times 
in order to eliminate any remaining $\mathrm{HNO}_{3}$ which might attack the silver planchets that are used in the plating step.

Methods of plating and counting are described in section 3.4 .

A sequential leaching procedure was used to divide solid-bound metals into operationally defined fractions according to which chemical treatment solubilized them. The goal of sequential leaching analysis is to treat solids with chemical solutions that maximize dissolution of more or less specific compounds. The method is not exact because: 1) solids tend to be composed of amorphous rather than well-defined, pure phases (e.g. amorphous iron oxyhydroxides as opposed to hematite, magnetite, limonite, etc.), 2) a given solid may be partially soluble in more than one solution depending on grain size, the physical characteristics of the surface, and the temperature, length, and degree of agitation of the treatment, 3) one type of solid may be coated and protected by another material (e.g. organic matter or transition metal oxide films), 4) metals liberated by one solution may immediately resorb to another solid that is refractory to the current treatment, 5) in nature solids are subject to low levels of chemical attack acting over long periods of time, and these are imperfectly simulated by strong reagents acting for a short time. In spite of these problems, sequential leaching can give high specificity of dissolution of major solid phases in both synthetic and natural substrates, and the method has been widely used to provide evidence on solid phase speciation of metals. Though flawed, it is the best technique available. Materials collected from sediment traps, filtered from the water column, or taken from sediment cores were subjected to sequential leaching immediately after return to the laboratory to avoid potential 
artifacts (RAPIN et al. [1986]). Anoxic sediments were maintained under a nitrogen atmosphere until step 4 of the sequential leach to prevent possible changes in speciation due to oxidation.

Table $3.2 \mathrm{a}$ 1ists the reagents used, their composition and strength, the order in which they were used, and the duration, temperature, and degree of agitation employed. The method selected was based in large part on the methodologies of TESSIER et al. (1979) and SALOMONS and FORSTNER (1980). The selectivity of this method for a number of pure synthetic compounds as we11 as metals phases occurring naturally in marine and lacustrine sediments has been evaluated by RAPIN and FORSTNER (1983) and shown to be effective. The sodium acetate-ammonium acetate step (usually between steps 1 and 2) was not included because the sediments of soft-water Bickford Reservoir are free of carbonates. In its place, the reducing step was split into two parts in an attempt to separate $\mathrm{Mn}$ and $\mathrm{Fe}$ oxides, which are solubilized by weak and strong reducing conditions, respectively. This division was based on the findings of CHAO (1972) who removed $85 \%$ of the Mn but only 58 of the iron from sediments by a mild reducing step. The stronger reducing step is equivalent to the recommendation of the original method and should solubilize all remaining labile $\mathrm{Fe}$ and $\mathrm{Mn}$.

Extractions were effected in $50 \mathrm{ml}$ polypropylene centrifuge tubes at reagent to sediment ratios of from 10:1 to $25: 1$ for sediments and about 10 times these values for the much smaller masses of trapped and filtered particulate matter. Centrifugation at $1000 \mathrm{G}$ was insufficient to completely separate solid and liquid phases between steps in some cases (some treated solids seemed positively buoyant). In these cases, 
TABLE 3.2a SEQUENTIAL LEACHING PROTOCOL

REAGENT

1) $1 \mathrm{M} \mathrm{MgCl}_{2} @ \mathrm{pH} 7$

2) $0.1 \mathrm{M} \mathrm{NH}_{2} \mathrm{OH} \cdot \mathrm{HCl}$ in $0.01 \mathrm{M} \mathrm{HNO}_{3}$

3) $0.25 \mathrm{M} \mathrm{NH}_{2} \mathrm{OH} \cdot \mathrm{HCl}$ in $0.25 \mathrm{M}$ Acetic acid

4) $308 \mathrm{H}_{2} \mathrm{O}_{2}$ in $0.02 \mathrm{M} \mathrm{HNO}_{3}$

5) $25 \mathrm{M} \mathrm{HF}$
CONDITIONS

TARGET SOLID

Sorbed

Wash with $\mathrm{dH}_{2} \mathrm{O}$

Shake $45 \mathrm{~min} @ 20{ }^{\circ} \mathrm{C}$

Mn(IV) oxides

Wash with $\mathrm{dH}_{2} \mathrm{O}$

$5 \mathrm{hr}$ @ $95{ }^{\circ} \mathrm{C}$

Fe(III) oxides

Wash with $\mathrm{dH}_{2} \mathrm{O}$

$5 \mathrm{hr} @ 85^{\circ} \mathrm{C}$

Organic matter $\&$ Wash w/1 $\mathrm{M} \mathrm{NH}_{4} \mathrm{Ac}$ in $68 \mathrm{HNO}_{3}$ sulfides

$175{ }^{\circ} \mathrm{C}$ until dissolved

Residua1 (silicates) 
phases were separated by passage through Whatman GF/C glass fiber filters, with addition of the filters to subsequent leaching steps.

\section{3 METHODS OF ANALYSIS}

Porewater seepage velocities were calculated using a seepage meter described by LEE (1977). The device consists of the upper $20 \mathrm{~cm}$ of an ordinary metal barrel, which is pressed into soft sediments until a good seal is formed all the way around. A flexible plastic tube attached to the opening on the top of the barrel leads to a plastic bag partially filled with a known volume of water. Changes in the volume of water in the bag over time can then be converted to average seepage velocities in the sediments. In Bickford, I consistently found negative velocities (flow from the lake into the aquifer). Concerned that this might be caused by the elastic force of the collection bag squeezing water into the sediments, a control was run consisting of a filled and disconnected bag deployed near a seepage meter for a period of two weeks. The bag lost no volume in that time, indicating that it was not causing the observed pore water flows.

Dissolved oxygen and temperature profiles were measured in the field using an Orbisphere ${ }^{\text {mM }}$ temperature/Do meter. Critical, near-zero values of dissolved oxygen were verified by Winkler titration.

Suspended particulate matter was determined in duplicate, gravimetrically, after drying the preweighed $47 \mathrm{~mm}$ Durapore filters for at least 24 hours in a dessicator. Blanks run using distilled water showed that the filters lost an insignificant amount of weight because of wetting. The average error for analysis of all lake waters was $15 \%$ of the mean. 
$210 \mathrm{Po}$ and $210 \mathrm{~Pb}$ were measured by alpha spectrometry of silver planchets prepared according to the method described in section 3.4 . The one standard deviation statistical counting error for 210 Po was less than $10 \%$ in every case and was generally about 58 . The counting error for $210 \mathrm{~Pb}$ was occasionally greater than 108 but was rarely over $12 \%$. Duplicate samples had identical activities within the limits of the statistical error. (Statistical counting error is given by $(1 / \mathrm{N} 1+$ $1 / \mathrm{N} 2)^{1 / 2}$, where $\mathrm{N} 1$ and $\mathrm{N} 2$ are the total number of ${ }^{208} \mathrm{Po}$ (or ${ }^{209} \mathrm{Po}$ ) and 210 Po counts recorded for a given sample.)

Resolution of 50 Kev F.W.H.M. or better was achieved using Ortec ${ }^{\text {M }}$ surface barrier detectors having an area of $450 \mathrm{~mm}^{2}$. In all cases, the peaks of ${ }^{208} \mathrm{Po}(5.114 \mathrm{MeV})$ and ${ }^{210} \mathrm{Po}(5.305 \mathrm{MeV})$ were completely separated. Measured activities were corrected for background and reagent blank activities.

Sulfide was measured by the methylene blue colorimetric method. Fe, Mn, and stable lead were measured by graphite furnace atomic absorption spectrophotometry. Alkalinity was determined by acidimetric titrimetry monitored on a $\mathrm{pH}$ meter to an end point characterized by a maximum in $\mathrm{d}(\mathrm{pH}) / \mathrm{d}(\mathrm{acid})$. 


\title{
3.4 METHODS OF $210^{\circ} \mathrm{PO}$ AND $210 \mathrm{~Pb}$ ANALYSIS
}

Improved Methods for the Measurement of ${ }^{210} \mathrm{Po},{ }^{210} \mathrm{~Pb}$, and ${ }^{226} \mathrm{Ra}{ }^{1}$

\author{
Gaboury Benoit and Harold F. Hemond \\ Room 48-320, Department of Civil Engineering \\ Massachusetts Institute of Technology \\ Cambridge, Massachusetts 02139
}

Accepted for publication in Limnology and Oceanography

${ }^{1}$ This research was supported in part by the U.S. Geological Survey, the National Science Foundation, the Massachusetts D.W.P.C., the National Wildlife Federation, and the Geological Society of America. 


\begin{abstract}
$210 \mathrm{~Pb}$ and $210 \mathrm{Po}$ have been measured by alpha spectrometry following room temperature plating in ordinary wide-mouthed sample jars. Use of two different isotopes of polonium $\left({ }^{208} \mathrm{Po}\right.$ and $\left.20{ }^{2} \mathrm{Po}\right)$ as yield monitors facilitates measurement of $21{ }^{\circ} \mathrm{Pb}$ and $2{ }^{\circ} \mathrm{Po}$ when both must be determined on the same samples. Hot $\mathrm{HCl}$ leaching/plating improves the resolution of alpha spectra for samples high in interfering iron. ${ }^{226} \mathrm{Ra}$ can be quantitatively electrodeposited from aqueous solution onto steel disks in disposable plating cells using an inexpensive $9 \mathrm{~V}$ "battery eliminator" as a power supply. The resulting source can be measured directly by alpha spectrometxy, eliminating the need for a separate detector system when determining supported $210 \mathrm{~Pb}$ activity.
\end{abstract}


The naturally occurring radionuclides ${ }^{210} \mathrm{Po},{ }^{210} \mathrm{~Pb}$, and ${ }^{226} \mathrm{Ra}$ have been used extensively to determine the ages of recently deposited sediments (eg. review by Oldfield and Appleby 1984) and also as tracers of particle-reactive metals (Benninger et al. 1975; Lewis 1977; Santschi et a1. 1979; Carpenter et a1. 1985) and particulate matter (Barnes et a1. 1978). The usual method for measuring total $2{ }^{10} \mathrm{~Pb}$ is through alpha spectroscopy of its granddaughter, $21{ }^{\circ}$ Po, after spontaneous deposition onto silver planchets with ${ }^{208}$ Po yield monitor (Flynn 1968). Radioactive support of $2{ }^{10} \mathrm{~Pb}$ by its long-1ived progenitor ${ }^{226} \mathrm{Ra}$ is most commonly determined via alpha scintillation counting of the short-1ived intermediary ${ }^{22} \mathrm{Rn}$ or by direct gamma spectroscopy.

A number of disadvantages are inherent to this measurement strategy. First, when $210 \mathrm{Po}$ and $210 \mathrm{~Pb}$ are in disequilibrium (as is the case with many water samples and plankton), samples must be stored for several ${ }^{210}$ Po half-lives $\left(138 \mathrm{~d}\right.$ ) before ${ }^{210} \mathrm{~Pb}$ can be determined. In some cases, 210 Po may be in excess by a factor of 100 or more (Turekian et al. 1974; Kharkar et al. 1976); thus even after storage for 2 years, $210 \mathrm{Po}$ activity could still be 2 or more times as great as $210 \mathrm{~Pb}$ activity. Second, when both radionuclides need to be measured, the sample must be first plated to measure Po, stored to allow ingrowth of new $210 \mathrm{Po}$, and then replated to determine $210 \mathrm{~Pb}$. In this case, if the initial plating is not 1008 effective, then ${ }^{208} \mathrm{Po}$ yield monitor and 210 Po that are not removed initially will be included in the later measurement and may cause a significant error in the inferred value for $210 \mathrm{~Pb}$. Third, the rate at which samples can be processed is limited by the number of plating assemblies that are available. Fourth, supported $210 \mathrm{~Pb}$ (as indicated by ${ }^{226} \mathrm{Ra}$ ) is measured using a different detection 
system (alpha scintillation) from that used for $210 \mathrm{~Pb} /{ }^{20} \mathrm{~Pb}$ (surface barrier detectors) and it requires building special gas stripping units, transfer boards, and gas scintillation cells.

In the course of measuring hundreds of samples for $210 \mathrm{Po},{ }^{210} \mathrm{~Pb}$, and ${ }^{226} \mathrm{Ra}$ we have developed a number of refinements to the standard measurement techniques. Room temperature plating is effected in the same jars used to store samples, eliminating the need for special plating cells and reducing analyst time. Use of two different Po yield monitors ( ${ }^{208} \mathrm{Po}$ and $\left.{ }^{209} \mathrm{Po}\right)$ allows precise assessment of "leftover" Po and permits shorter ingrowth time before replating. Electrodeposition of ${ }^{26} \mathrm{Ra}$ after a one or two step ion chromatographic purification yields disks that can be measured using the same surface barrier detectors used for $210 \mathrm{~Pb}$ and requiring no other special equipment.

We would like to thank Dr. Roy Carpenter, University of Washington, in whose laboratory G.B. was a visitor when the Ra plating method was developed.

LOW TEMPERATURE PLATING PROCEDURE

After spiking with ${ }^{208}$ Po yield monitor, completely dissolve sediment samples by fuming sequentially with $\mathrm{H}_{2} \mathrm{O}_{2} / \mathrm{HNO}_{3}$, concentrated $\mathrm{HF}$ (in Teflon beakers), and $\mathrm{HCl}$. For water column samples, which typically contain low levels of silicates, the HF step can be eliminated. Transfer the dried residue to a $125 \mathrm{ml}$, large-mouthed polyethylene jar using two $5 \mathrm{ml}$ portions of concentrated $\mathrm{HCl}$. Add $5 \mathrm{ml}$ of $20 \%$ hydroxylamine hydrochloride and $2 \mathrm{ml}$ of $25 \%$ sodium citrate, then adjust the $\mathrm{pH}$ to between 1.0 and 2.0 with concentrated ammonium hydroxide. Polish one surface of a $1.9 \mathrm{~cm}$ diameter silver disk (5 or $10 \mathrm{mil}$ thickness), then coat the other surface with a thin film of silicone 
grease (Dow Corning ${ }^{\circledR}$ high vacuum grease, or equivalent) and stick it to the inside of the cap. Seal and store the inverted jar for 7 to 10 days, preferably on a surface that will impart a slight vibration (e.g. the top of a refrigerator or laminar flow hood), thereby assuring that the plating process is not diffusion limited. At the end of the plating period remove the disk from the cap, rinse with distilled water, and wipe the back clean of grease. Samples treated in this way plate quantitatively in a week or less (Figure $3 a$ ). No equipment is required other than the jars in which samples are stored, and samples need not be tended while plating. For those samples that later will be replated in order to determine $210 \mathrm{~Pb}$ as well as $210 \mathrm{Po}$, the jars can be stored for an additional week with a small piece of scrap silver to assure complete removal of Po isotopes. Samples treated in this way had an average residual 208 Po activity that was less than 18 of the original amount of 208 Po yield monitor corrected for decay.

\section{IRON-RICH SAMPLES}

Ferric iron interferes with Po deposition on silver. A number of reducing and complexing agents have been recommended in order to circumvent this interference (Figgins 1961; Millard 1963; Flynn 1968; Bennet and Carpenter 1979; Dillard and Hobbs 1980). In spite of such precautions, iron-rich samples may still occasionally produce a darkbrown or black deposit on the silver disk, degrading resolution of the alpha spectrum and reducing the yield significantly. Planchets of this type can usually be saved by means of a hot HCl leaching/plating procedure.

Coat the back of the disk with a thin layer of silicone grease and stick it to the bottom of a $50 \mathrm{ml}$ beaker. Add $10 \mathrm{ml}$ of concentrated 
FIGURE 3a INFLUENCE OF PLATING TIME ON ROOM TEMPERATURE PLATING EFFICIENCY OF POLONIUM

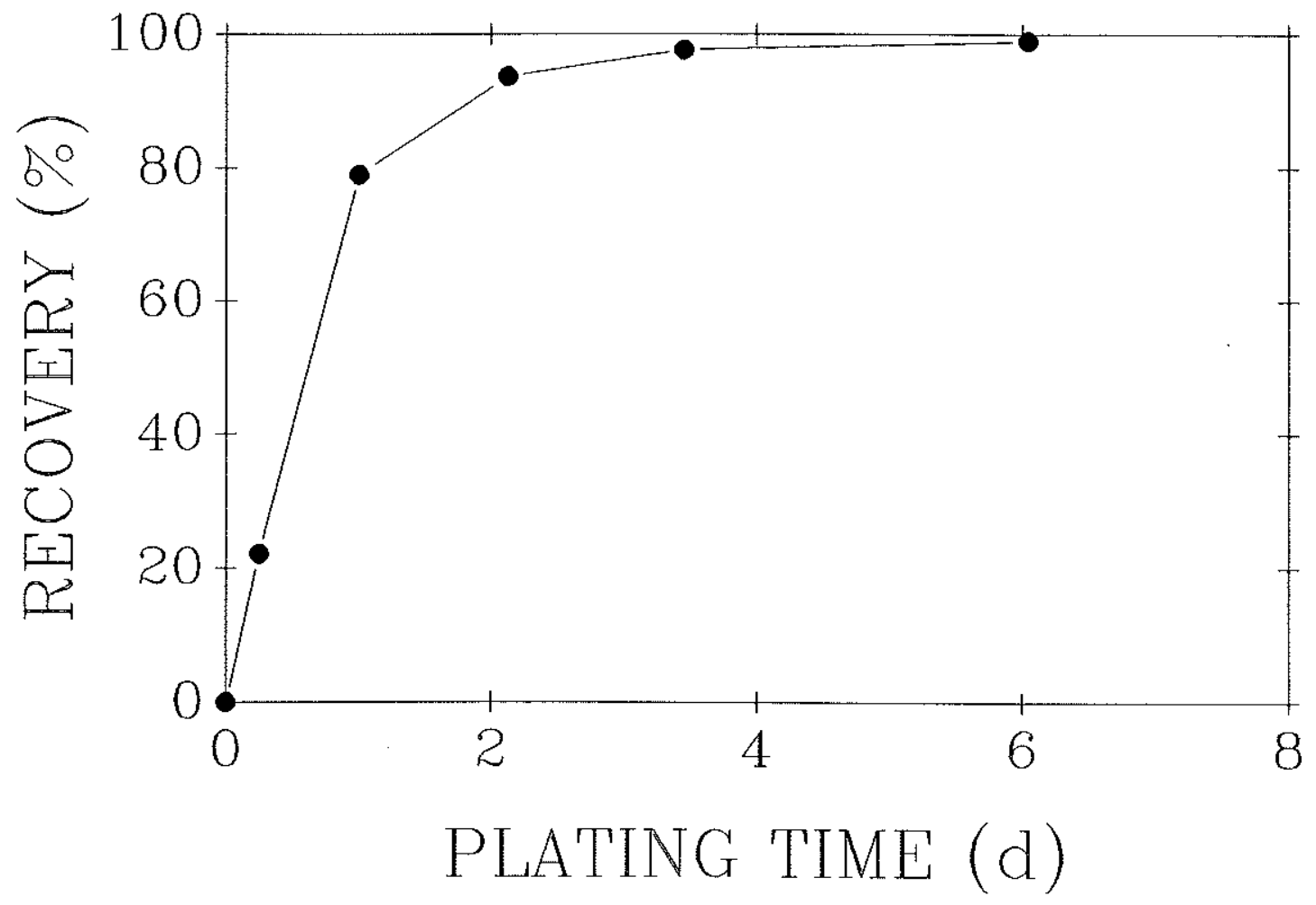


FIGURE 3b EFFECT OF HOT HC1 TREATMENT ON AN IRON COATED PLANCHET

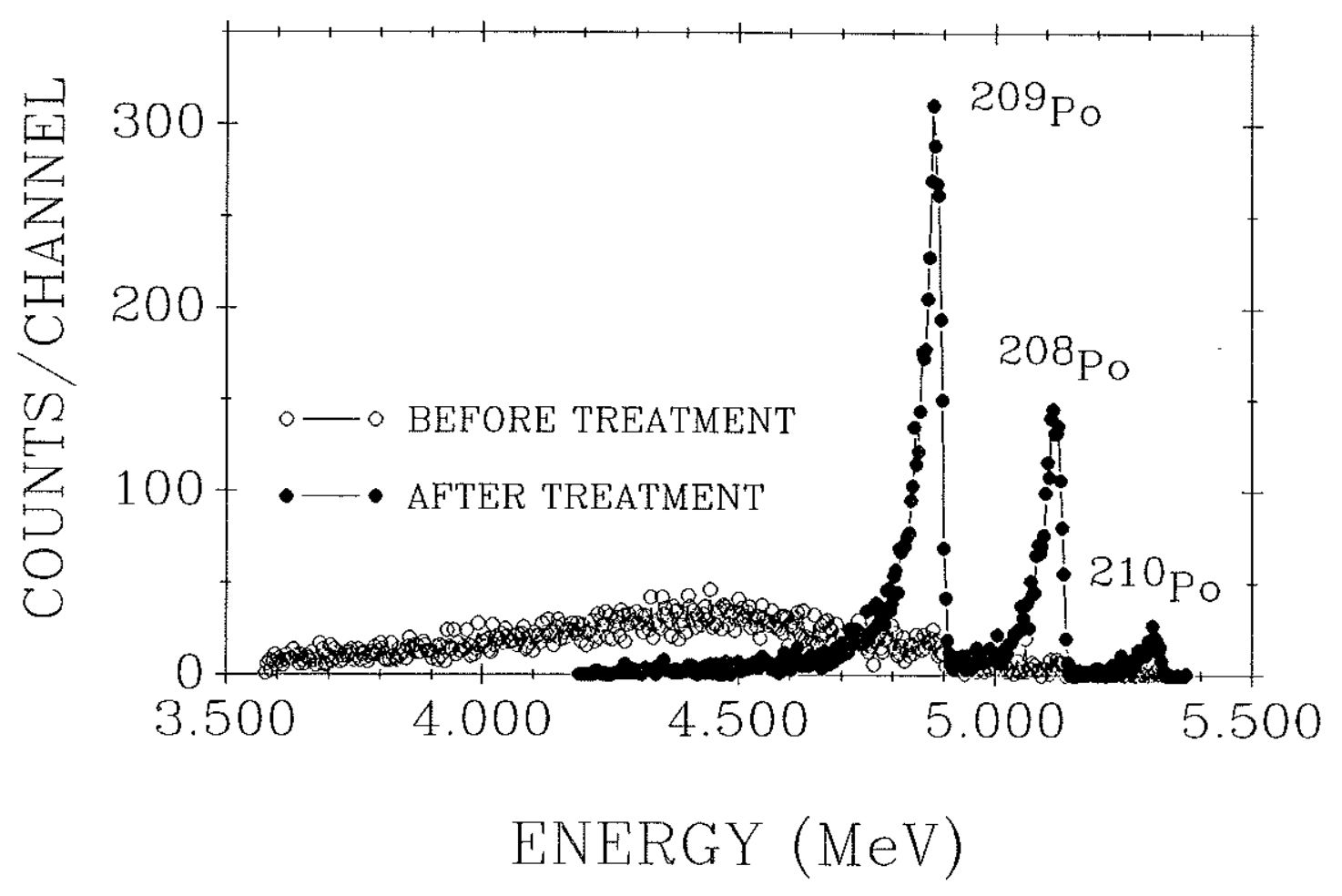


$\mathrm{HCl}$, cover with a watch glass, and heat to just below the boiling point for one hour. The surface of the disk will become bleached and appear du11. Rinse with distilled water, remove the grease, and count the disk in the usual manner. Figure $3 b$ shows the effect of this treatment on a badly iron coated planchet. Before treatment the peak was resolved to only about $850 \mathrm{KeV}$ F.W.H.M. with the resulting broad maximum shifted from $4.882 \mathrm{MeV}$ down to $4.47 \mathrm{MeV}$. After $\mathrm{HCl}$ treatment, resolution improved to $40 \mathrm{KeV}$ so that three peaks were resolved and the maxima were at the correct energies.

DOUBLE YIELD MONITOR TECHNIQUE

While a combined plating/stripping procedure removes virtually all polonium from most samples, the most accurate results require exact knowledge of the quantity of residual ${ }^{210}$ Po in samples that are replated for $210 \mathrm{~Pb}$ measurement. This can be accomplished by using two different Po isotopes as yield monitors in each of the two ${ }^{210} \mathrm{Po}$ plating steps. Samples are first spiked with known quantities of ${ }^{208}$ Po (half-1ife $138 d$ ) and stable lead yield monitors. After plating, $21^{\circ}$ Po is determined in the ordinary manner by comparison of the ${ }^{208} \mathrm{Po}$ and ${ }^{210} \mathrm{Po}$ decay peaks at 5.114 and $5.305 \mathrm{MeV}$. The plating solution is then stored and additional 210 Po grows in from $21{ }^{\circ} \mathrm{Pb} .{ }^{209} \mathrm{Po}$ yield monitor (half life $103 \mathrm{y})$ is then added and the sample replated. Measurement of stable lead by atomic absorption spectrometry gives an indication of $210 \mathrm{~Pb}$ losses during sample handling. The Po isotope data can then be used to calculate ${ }^{210} \mathrm{~Pb}$ activity accounting for the efficiency of the second plating and including a correction for any ${ }^{210}$ Po that may have escaped the initial plating. That value is calculated as follows: 
$210^{\circ} \mathrm{Po}_{\text {res }}={ }^{208} \mathrm{Po} \times \mathrm{R} \times \mathrm{e}^{-\Delta \lambda \times \mathrm{t}}$

Where: $\quad 210$ Pores $\equiv$ residual ${ }^{210}$ Po leftover from initial activity and not coming from decay of $210 \mathrm{~Pb}$ during the ingrowth period.

${ }^{208} \mathrm{Po} \quad \equiv$ counts under the $5.114 \mathrm{MeV}$ peak (final plating).

$\mathrm{R} \quad$ = ratio of the $5.305 \mathrm{MeV}$ to 5.114 peaks (initial plating)

$\left.\Delta \lambda \quad \equiv \lambda_{(208 \mathrm{Po})}-\lambda_{(210} \mathrm{Po}\right) \simeq 0.00436 \mathrm{~d}^{-1}$

$t \quad \equiv$ time between counting the initial and final platings.

Residual 210 Po calculated in this manner is then subtracted from total 210 Po activity before calculation of $210 \mathrm{~Pb}$ using the ratio of the 5.305 to $4.882 \mathrm{MeV}$ peaks corrected for ingrowth time. Figure $3 \mathrm{~b}$ illustrates the spectrum obtained from the final plating of one sample containing an unusually large Po residual. In this case, 718 of the observed $21^{\circ}$ Po peak was calculated to be from ingrowth and $29 \%$ from residual activity. For most samples, the correction is less than the detector background $\approx 1 \%$ ). Using this method, $210 \mathrm{~Pb}$ can be measured after ingrowth for as little as one 210 Po half-1ife. ${ }^{226} \mathrm{Ra}$ DETERMINATION BY DIRECT ALPHA SPECTROSCOPY

Radium can be electrodeposited onto stainless steel disks after resin chromatographic separation. In this way, the same detection system that is used to measure total ${ }^{210} \mathrm{~Pb}$ activity can be used to measure supported $210 \mathrm{~Pb}$. 
${ }^{226} \mathrm{Ra}$ ISOLATION: Radium is separated from all but the alkaline and alkaline earth metals and Al (III) using anion exchange resin and acetic acid medium. The method was developed using data contained in Van Den Winke1 et a1. (1971).

Slurry $1.6 \mathrm{~g}$ (dry weight equivalent) of Bio-Rad ${ }^{\oplus}$ AG 1-X8 (100 - 200 mesh) resin with glacial acetic acid and pour into an $0.5 \mathrm{~cm} \mathrm{I.D.} \mathrm{column}$ (Bio-Rad Econo Column ${ }^{\circledR}$ or equivalent). Wash the resin with several column volumes of glacial acetic acid at a flow rate no greater than 0.2 $\mathrm{ml} / \mathrm{min}$. Here and in all subsequent steps, keep the pore spaces saturated with liquid by not allowing the acid to drain below the upper end of the resin column. Meanwhile add ${ }^{223} \mathrm{Ra}$ yield monitor (prepared according to the method of Koide and Bruland 1975) to a 200 to $1000 \mathrm{mg}$ sample of dried sediment and digest in the same manner as for ${ }^{210} \mathrm{~Pb}$ determination. Redissolve the dried residue in two $2.5 \mathrm{ml}$ portions of concentrated acetic acid, transferring each in turn to the column. Elute at a flow rate of no greater than $0.2 \mathrm{ml} / \mathrm{min}$ until all of the acid has just entered the resin and then add and continue to elute an additional $10 \mathrm{ml}$ of acid. The elutriate may be a pale yellow due to colored organic compounds thrown by the anion exchange resin, but it should not be a deep orange color, which indicates the presence of dissolved iron. Evaporate the elutriate, which should leave behind a very small quantity of dried residue. If instead there is a copious residue of calcium, other alkaline earths, or aluminum, these can be separated from radium by means of a second ion chromatographic step using cation exchange resin and eluting wi.th EDTA or CDTA in HCl (Duyckaerts and Lejeune 1960; Gleason 1980). 
${ }^{226} \mathrm{Ra}$ PLATING: The isolated radium is plated onto stainless steel disks using a procedure adapted from Roman (1984). The resulting alpha spectra can be resolved to $30 \mathrm{KeV}$ F.W.H.M., obviating the need to correct for tailing of the ${ }^{223} \mathrm{Ra}$ peak into the ${ }^{226} \mathrm{Ra}$ peak as required by the method of Koide and Bruland (1975).

The plating cell can be fashioned from a $30 \mathrm{ml} \mathrm{Nalgene^{ \circledR }}$ sample bottle following the design of Talvitie (1972). One half of a copper rivet inserted through a hole drilled in the cap serves as an electrical contact for the $1.7 \mathrm{~cm}$ diameter polished stainless steel disk that is sandwiched between the cap and bottle neck. The anode is formed by bending the end of an approximately $10 \mathrm{~cm}$ length of $0.16 \mathrm{~cm}$ diameter platinum wire into a ring concentric with the axis of the rest of the wire. The circle should be as open as possible to prevent the trapping of bubbles that might reduce the effective electrode area. The anode is held in place by a slightly snug fit in a hole drilled through the center of a plug turned from a piece of PVC or Teflon. Additional holes should be drilled for the escape of generated gases and for the introduction of a thermometer, whose immersion depth in the plating solution can be controlled by the position of an undersized o-ring. Alligator clips connect the cell to the D.C. power supply. (Archer ${ }^{\circledR} \mathrm{AC}$ Adapter, Cat. no. 273-1651A, nominal output 9V, $500 \mathrm{~mA}$, or equivalent).

Adjust the distance between the anode and cathode to $3 \mathrm{~mm}$, then add $10 \mathrm{ml}$ of $0.4 \mathrm{M}$ ammonium acetate adjusted to $\mathrm{pH} 5$ with $\mathrm{HNO}_{3}$ and check for leaks. Dissolve the residue from the radium separation in $1 \mathrm{ml}$ of $0.5 \mathrm{M}$ $\mathrm{HCl}$ and transfer to the cell. Begin plating and monitor the current and voltage using an ordinary Volt-Ohm meter. Voltage starts near 9 and gradually decreases to about $7.5 \mathrm{~V}$. Current should fall in the range 
from 400 to $500 \mathrm{~mA}$. Adjust the inter-electrode spacing if conditions depart substantially from these values. If necessary, immerse the lower end of the plating cell in a container of water to maintain the temperature no higher than $60^{\circ} \mathrm{C}$. Continue plating for 5 hours, then remove the steel disk, rinse with distilled water, and air dry. ${ }^{226} \mathrm{Ra}$ COUNTING: After storing the disk for 25 days to allow the alpha emitter ${ }^{224} \mathrm{Ra}$ to decay to negligible activity, determine the alpha spectrum using a surface barrier detector/multichannel analyzer system. $226 \mathrm{Ra}$ activity is the sum of peaks at $4.781 \mathrm{MeV}(94.58)$ and $4.598 \mathrm{MeV}$ (5.58). 96.98 of the ${ }^{223} \mathrm{Ra}$ activity falls between $5.538 \mathrm{MeV}$ and 5.870 $\mathrm{MeV}$ with at least 5 of the total of 6 particle energies resolved. (The remaining 3.18 of the $223 \mathrm{Ra}$ activity coincides with the ${ }^{22} \mathrm{Rn}$ peak at $5.486 \mathrm{MeV})$. Other radionuclides that can be resolved include ${ }^{218}$ Po $(6.002 \mathrm{MeV}),{ }^{211} \mathrm{Bi}(6.278$ and $6.622 \mathrm{MeV})$, and ${ }^{219} \mathrm{Rn}(6.423,6.551$, and 6.817 MeV); these do not overlap with the peaks of interest and can be ignored.

Occasionally the steel disk will begin to darken after about $3 \mathrm{hr}$ of plating. Contrary to the results of Roman (1984), these runs have yielded lower plating recoveries than did ordinary unstained disks (Figure $3 c$ ), so plating should be discontinued in these cases. Darkened disks have the same high resolution alpha spectra as undarkened ones, so the loss of activity seens to be due to remobilization of Ra from the cathode surface rather than a covering over of Ra by some kind of coating (which would likely degrade resolution). The platinum electrode sometimes develops a brassy sheen that is not removed by boiling with concentrated $\mathrm{HNO}_{3}$, but it does not correlate with cathode darkening, and seems to have no effect on the success of plating. 
FIGURE 3c LOSS OF RADIUM FROM STEEL PLATING DISK ON DARKENING

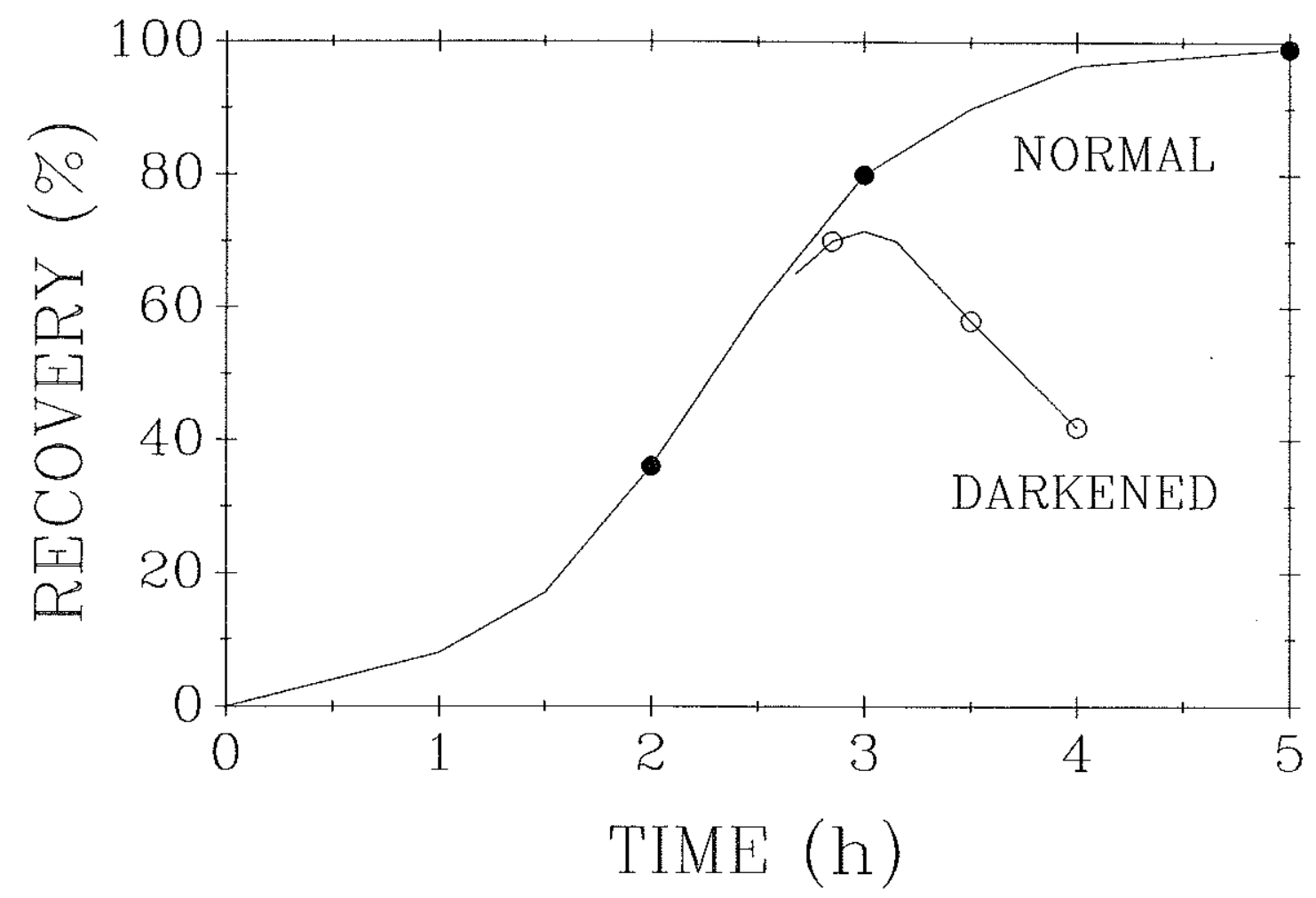


It is interesting to note that polonium isotopes can be electrodeposited under conditions similar to those used for radium plating (Roman [1984].) It would seem then that ${ }^{210} \mathrm{Po}$ and ${ }^{226} \mathrm{Ra}$ could be measured simultaneously after these two elements are separated from $U$ and Th. In this way both total and supported $210 \mathrm{pb}$ (assuming equilibrium with $21^{\circ} \mathrm{Po}$ ) could be determined in a single alpha counting step. 


\section{CHAPTER 4 THE WATER COLUMN}

\subsection{INTRODUCTION}

The cycling of $210 \mathrm{~Pb}$ in the water column can have a critical influence on $2{ }^{20} \mathrm{~Pb}$ dating. If the removal rate is comparable to the hydraulic residence time, then only a fraction of total ${ }^{210} \mathrm{~Pb}$ inputs will be captured within the lake (BENOIT and HEMOND [1987], CORNETT et a1. [1984], BIRCH et a1. [1980]). If the capture efficiency were then to change significantly, delivery of $210 \mathrm{~Pb}$ to the sediments would be altered, in violation of ${ }^{210} \mathrm{~Pb}$ dating assumptions. This chapter describes the behavior of $210 \mathrm{~Pb}$ in the water column, focusing special attention on the observed remobilization of $210 \mathrm{~Pb}$ and ${ }^{210} \mathrm{Po}$ from sediments into reducing bottom waters during summer stratification.

\subsection{METHODS}

Methods of sample collection, handling, and analysis were described in Chapter 3. Several key points should be re-emphasized. Samples were collected at approximately $20 \mathrm{~d}$ intervals from June through October 1985, though more frequent sampling was carried out whenever radionuclide levels changed rapidly, either as the result of anoxia or fast erosion of the metalimnion. Samples were collected from all levels in the water column, but the sampling interval spacing was widest in the upper mixed part of the water column where concentration changed very little, and it was quite short (10 cm or even less) near the oxic-anoxic interface where radionuclide concentration and solid-liquid partitioning changed rapidly. Fine-scale sampling was carried out using the same

procedure described in Chapter 3 (pumping from depth with a peristaltic pump) The position of the end of the collection tube with respect to temperature and dissolved oxygen gradients was monitored carefully with 
the temperature/DO meter, whose probe was attached to the end of the tube.

Many of the samples were anoxic or suboxic, and special care was taken to filter these samples during collection, before exposure to atmospheric oxygen. This precaution is crucial in order to avoid transition metal precipitation and changes in particle size distributions (LAXEN and CHANDLER [1982]), especially as would be caused by precipitation of iron and manganese oxides.

\section{3 RESULTS AND DISCUSSION}

\subsubsection{TEMPERATURE}

As in most lakes in the temperate region, temperature plays a critical role in the biogeochemical cycles of Bickford Reservoir. During the warm months, vertical temperature variations cause density differences that effectively separate the water column into two zones, an upper, mixed layer and a lower, stratified layer. The upper layer, or epilimnion, circulates freely and remains fully oxygenated throughout the summer. In deep lakes, the lower zone consists of two parts: a region where temperature decreases rapidly with depth (metalimnion) and below it a region of nearly constant low temperature (hypolimnion). Although there is little density stratification in the hypolimnion, water circulates very slowly since it is isolated from the direct influence of the wind. In Bickford, as can be seen in Figure 4.3.1a, the greatest depth $(13 \mathrm{~m})$ is at a level corresponding to the intersection of the metalimnion and hypolimnion, so that density increases virtually to the very bottom.

The pattern of temperature distribution displayed by Figure 4.3.1a is ordinary except for the truncation of the bottom of the profiles as 
TEMPERATURE $\left\langle{ }^{\square} \mathrm{C}\right\rangle$

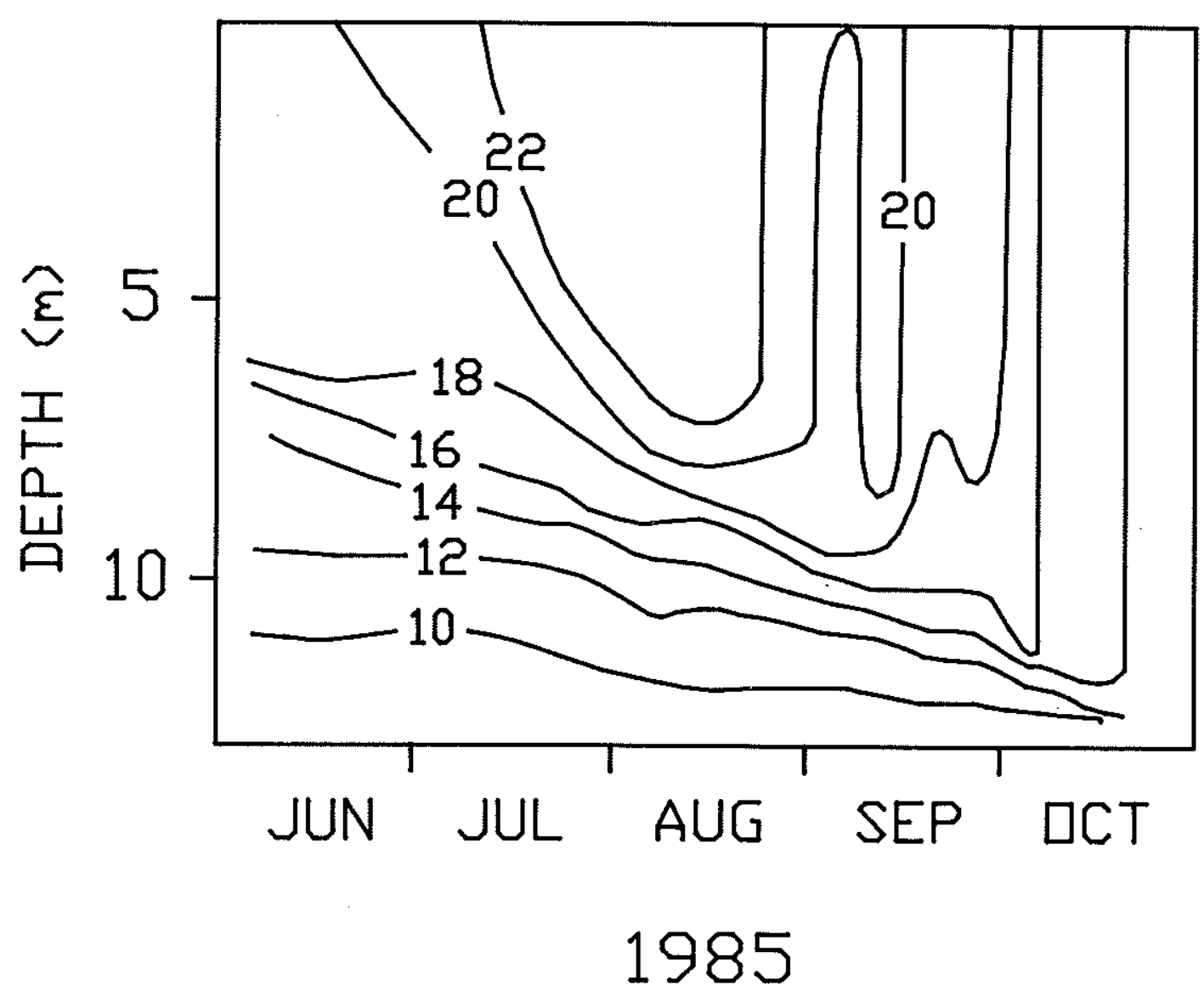


described in the preceding paragraph. Bickford's spring circulation takes place in April, so at the beginning of the study period in June, the lake was already stratified and the epilimnion extended from the surface to a depth of $6 \mathrm{~m}$. Throughout the rest of the summer, the depth of the epilimnetic-metalimnetic boundary deepened approximately linearly with time, reaching a depth of about $12 \mathrm{~m}$ just before fall overturn on about the 1st of November (Figure 4.3.1b). An exception to the gradual deepening was the rapid exosion of the thermocline that took place as a result of mixing caused by Hurricane Gloria on 26 September 85 . That Gloria did not cause complete mixing of Bickford attests to the extreme stability of the temperature gradient. Similarly, Linsley Pond was not completely mixed by the much stronger hurricane of 21 September 1938 (Hutchinson [1975] p.452).

Temperature profiles in the early summer show the bottom meter of the water column to be nearly isothermal, suggesting that this zone forms an extremely abbreviated hypolimnion. The occurrence of a hypolimnion at this depth is in agreement with data from other small lakes, where the top of the hypolimnion is found between 5 and $12 \mathrm{~m}$ (e.g. Linsley Pond, CT - 8 m, Lake Mendota, WI - 10 m, Lake Quassapaug, CT - $12 \mathrm{~m}$, HUTCHINSON [1975]; Lawrence Lake, MI - $5 \mathrm{~m}$, Little Crooked Lake, IN - $6 \mathrm{~m}$, Little Round Lake, ON - $6 \mathrm{~m}$, Martin Lake, IN - $9 \mathrm{~m}$, Crooked Lake, IN - $10 \mathrm{~m}$, WETZEL [1975]; Esthwaite Water - $5 \mathrm{~m}$, DAVISON ET AL. [1982]; Crystal Lake, WI - $10 \mathrm{~m}$, TALBOT [1981]). The upper boundary of the hypolimnion at Bickford is deeper than for any of these other lakes of comparable profundity. This may be a result of the water's clarity, which permits radiational heating to an unusually great depth. 
FTGURE $4.3 .1 \mathrm{~b}$ DEPTH OF THE BASE OF THE EPILIMNION AND OF THE OXIC-ANOXIC INTERFACE OVER TIME

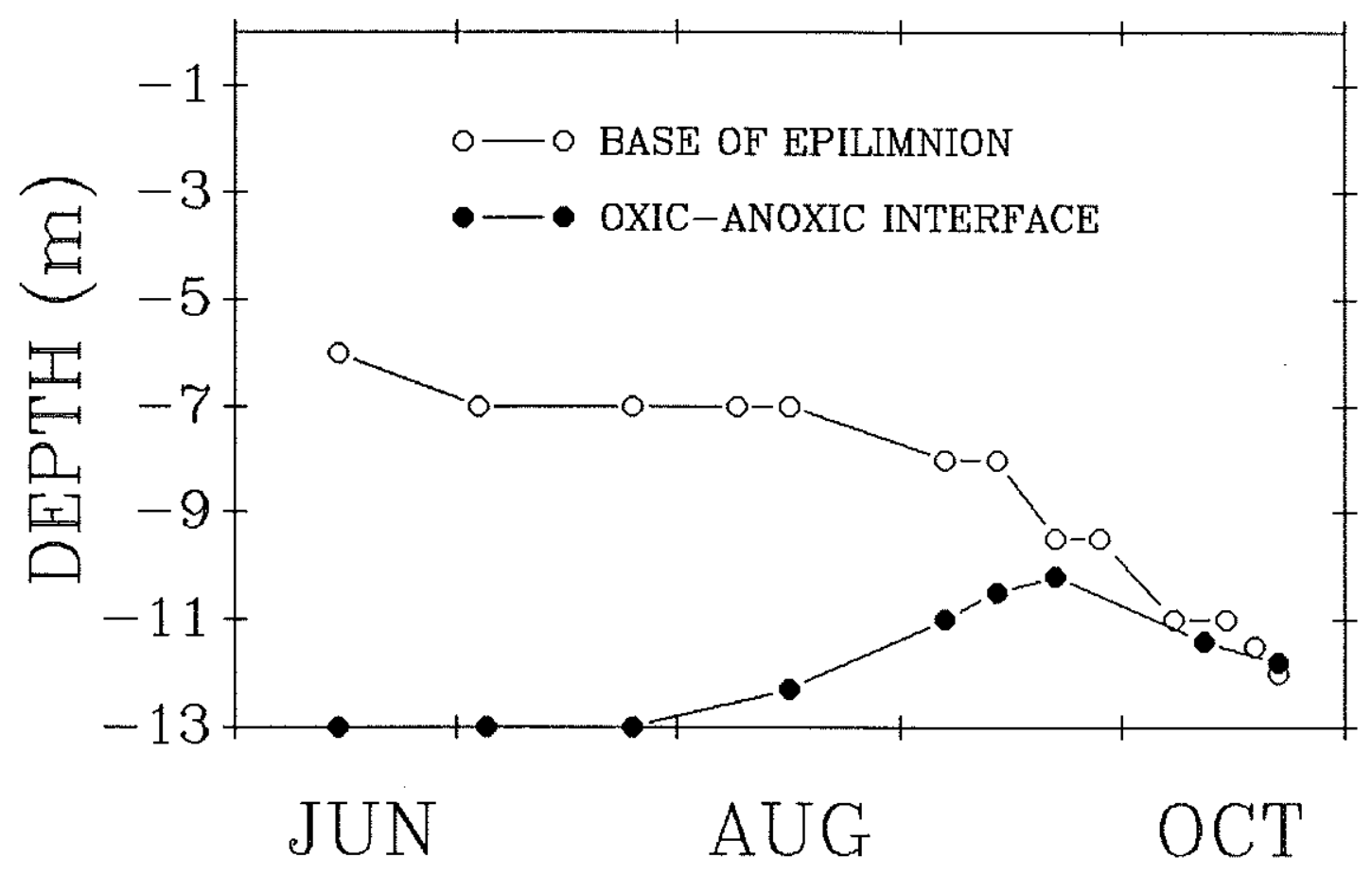


From the point of view of geochemical cycling, the significance of a temperature gradient extending virtually to the sediment-water interface is that it causes a great resistance to mixing, diminishing the rate of eddy diffusion, and helping to reduce the rate at which material released by the sediments can be transported higher in the water column. This will be described in greater detail in section 4.5 .3 .

\subsubsection{DISSOLVED OXYGEN}

Bacteria in the metalimnion, hypolimnion, and sediments consume oxygen when they metabolize the organic detritus settling from above. Since the deeper part of the water column is isolated from the atmosphere, the depleted oxygen is not replenished (until fall overturn), and the concentration of dissolved oxygen decreases. The resulting pattern of oxygen concentration -- decreasing with depth and time - - is shown in Figure 4.3.2a. Anoxia starts near the bottom in mid-August and continues until fall overturn, reaching progressively higher levels in the water column until attenuated by erosion of the metalimnion. Full anoxia was attained in four of the five years for which we have collected data at Bickford (including the year of this study). In the other year, oxygen decreased but never dropped below 1 $\mathrm{mg} / 1$, even at the sediment water interface. This interyear variation is probably caused by the the small volume of water below the epilimnion compared to the rest of the lake (only $6 \%$ of the lake's volume is found below $10 \mathrm{~m}$ ). Organic matter produced throughout the lake is focused, in part, to the deepest location. Small differences in total productivity or in the degree of focusing are thus magnified and cause relatively large changes within the small volume of metalimnetic and hypolimnetic 
FIGURE 4.3.2a ISOPLETHS OF DISSOLVED OXYGEN IN THE WATER COLUMN

DXYGEN (mg/liter)

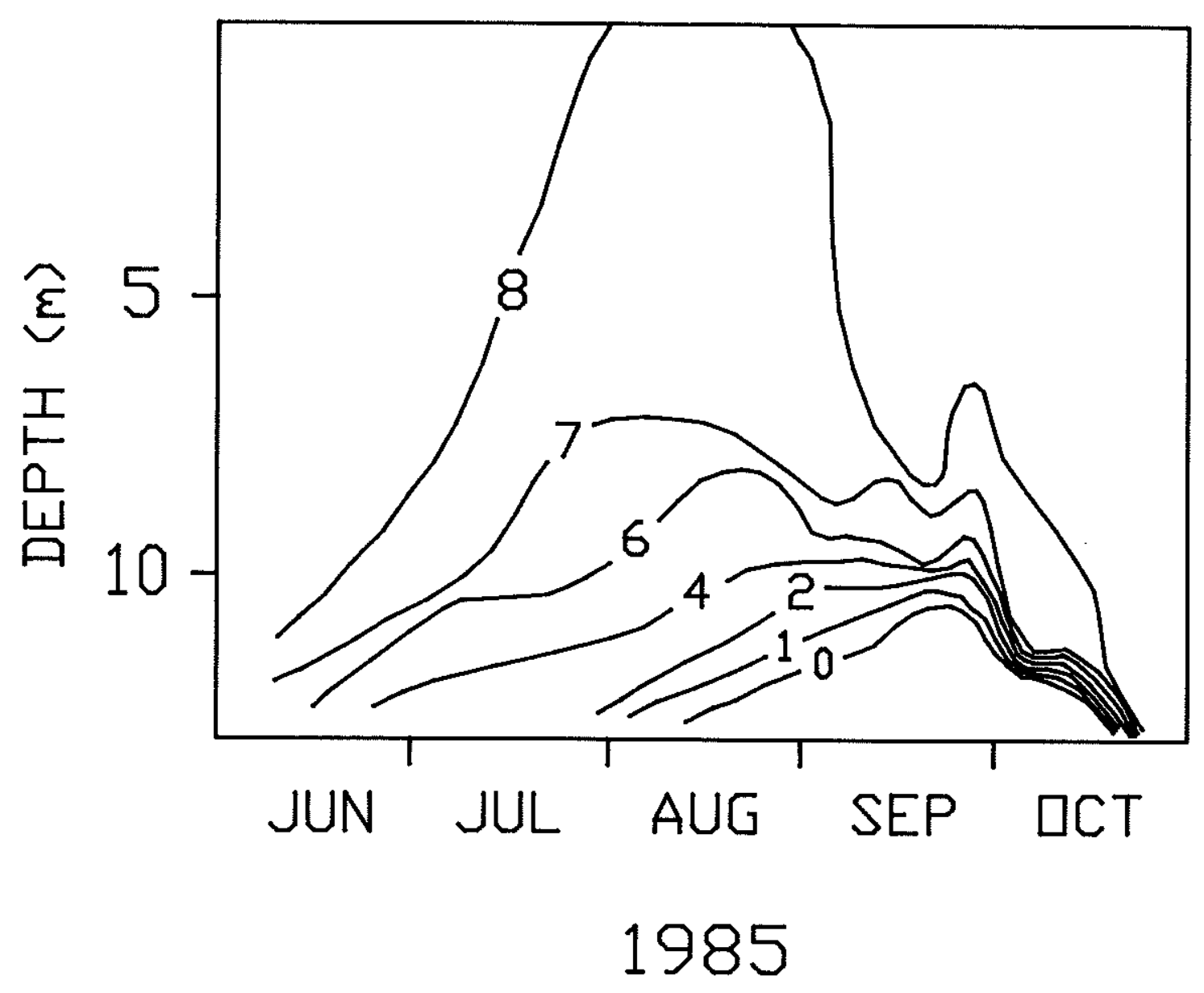


water. Without focusing, and without the relatively small volume of the hypolimnion, it is unlikely that the bottom waters of such an oligotrophic lake would ever become anoxic.

The failure of the bottom water to go anoxic in the summer of 1983 can probably be explained by the greater volume of stratified water that year. The hypo-metalimnion was thicker that year (compare Figure 4.3.1a with Figure 2 in BENOIT and HEMOND [1987]) and thus contained a greater total amount of dissolved oxygen. The reason for the shallow thermocline in 1983 is not known, but it probably was related to the local meteorological conditions at the end of the spring circulation. The shallow thermocline may then have been protected from solar heatinginduced deepening by a higher than usual water opacity (see next section)

\subsubsection{LIGHT}

Transmission of visible light was measured on 4, 11, and 19 September 1985. The results presented in Figures 4.3.3a and 4.3.3b for the first and last dates are similar. As in most lakes, there was an exponential decrease in transmitted light as a function of depth, in accordance with Bouguer's law:

$$
I_{z} / I_{0}=e^{-\eta z}
$$

where $I_{z}$ is the light intensity at depth $z, I_{0}$ is the intensity at the surface, $z$ is the depth in the water column, and $\eta$ is the extinction coefficient. In theory, this law is only applicable for monochromatic light, but in practice it seems to work reasonably well for broadband 
FIGURE 4.3.3a LIGHT ATTENUATION IN THE WATER COLUMN - 4 SEPT 85

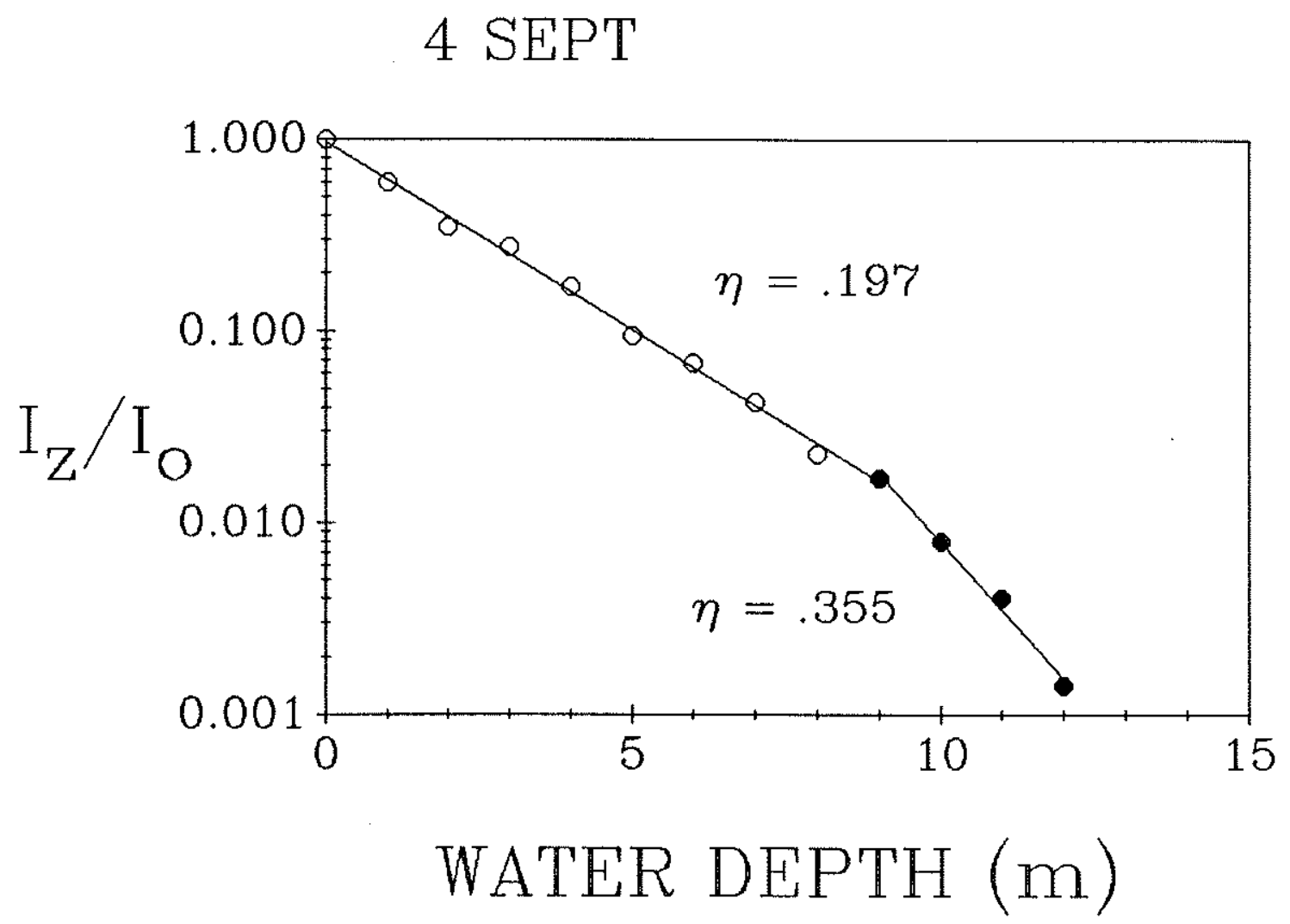


FIGURE 4.3.3b LIGHT ATTENUATION IN THE WATER COLUMN - 19 SEPT 85

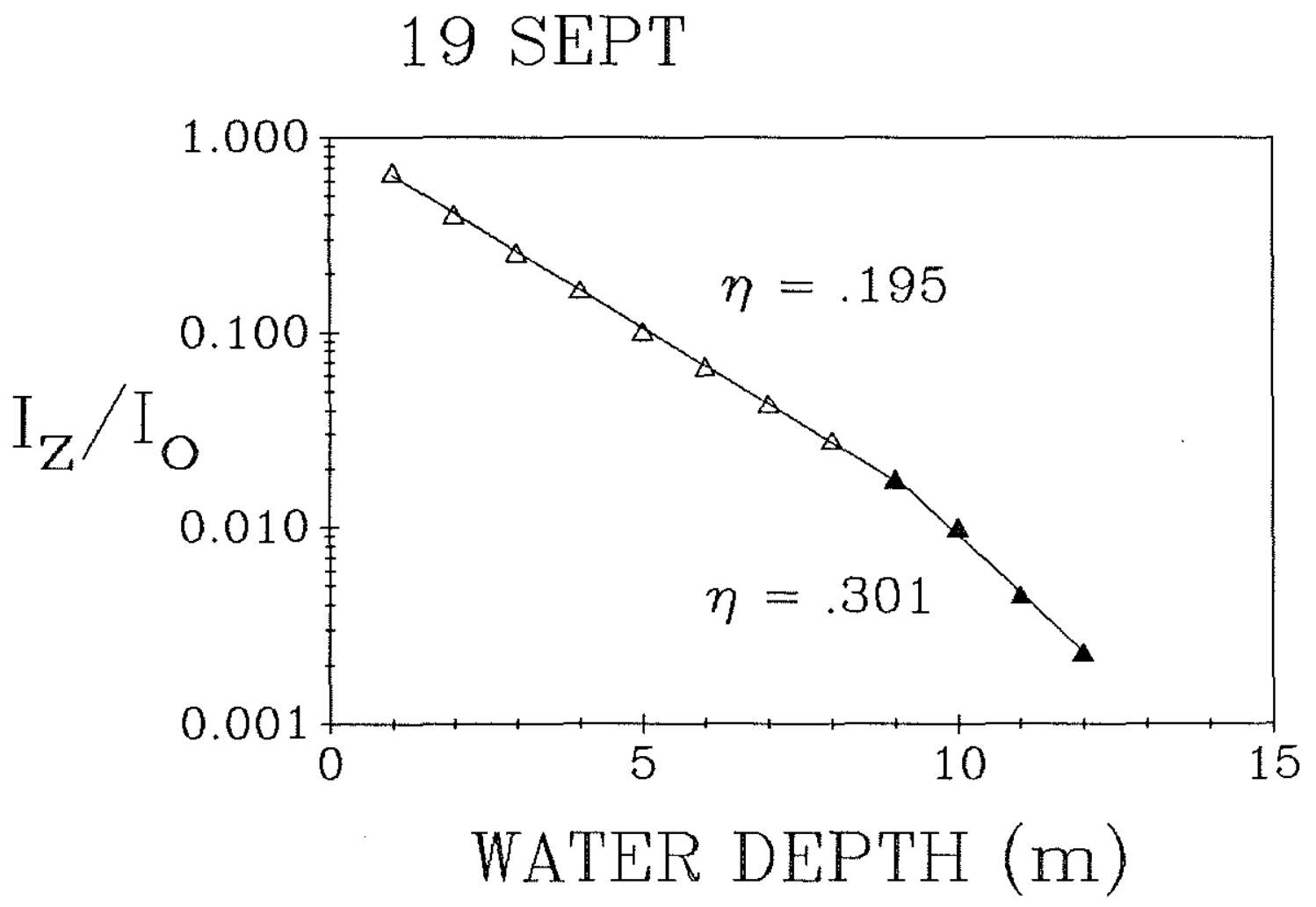


sunlight, after infrared and ultraviolet wavelengths are filtered out in the upper meter of the water column.

The value of the extinction coefficient, $\eta$, averaged 0.39 in the epilimnion $(n=9, r=.9999)$. (For comparison, pure water has an extinction coefficient averaging about 0.060 for light between 5000 to 6000 A.) This value is near the lower end of the range found by Birge and Juday in a survey of Wisconsin lakes, indicating that the water in Bickford Reservoir is clearer than most. The offshoot of the low extinction is that light penetrates to greater depth, heating deeper waters, and causing the metalimnion to occur at a somewhat greater depth than in an equivalent lake with less transparent water.

Light transmission dropped markedly in the metalimnion, where suspended particulate matter (SPM) increased sharply. On 4 September 1985, $\eta$ increased with depth from 0.396 to 0.714 , on 11 September from .389 to .573 , and on 19 September it increased from 0.382 to 0.589 . An equivalent increase in extinction coefficient due to suspended particulate matter in the hypolimnion of Crystal lake is evident in the data of Birge and Juday (according to HUTCHINSON [1975] p.393). In Bickford, SPM increased from less than $1.0 \mathrm{mg} / 1$ iter in the epilimnion to greater than 2.0 in the metalimnion. Such an increase in light absorption is consistent with theory, which states that extinction due to pure water, particulate matter, and color should be additive, such that:

$$
\eta_{\mathrm{t}}=\eta_{\mathrm{w}}+\eta_{\mathrm{c}}+\eta_{\mathrm{p}}
$$

where $\eta_{t}$ is the total extinction coefficient and $\eta_{\mathrm{w}}, \eta_{\mathrm{c}}, \eta_{\mathrm{p}}$, are those due to pure water, color, and particles respectively. In this case the value of $\eta_{p}$ increased by an average of .236. Anecdotally, the rapid 
decrease in light and increase in SPM was quite noticeable to SCUBA divers as they passed through the thermocline.

\subsubsection{IRON AND MANGANESE}

The behavior of iron and manganese in lakes and their sediments has been wel1 documented, first in papers by MORTIMER $(1941,1942)$, and more recently in work by DAVISON et al. $(1980,1982)$, TIPPING et a1. (1981), SHOLKOVITZ and COPLAND (1982), DUNCAN et al. (1983), SIGG et a1. (1987), and others. In general, there exists an oxic-anoxic interface above which iron and manganese are oxidized and largely particulate, and below which they are reduced and dissolved. In productive lakes, this surface passes out of the sediments and into the water column during the summer. This is the case for Bickford Reservoir, as was described in Section 4.3.2, and for the most part, Bickford conforms to the pattern of iron and manganese distribution and fluxes described by MORTIMER, DAVISON, SIGG and others. Concentration isopleths for total manganese, total and particulate iron, and SPM are shown in Figures $4.3 .4 \mathrm{a}, \mathrm{b}, \mathrm{c}$, and $\mathrm{d}$. Concentration-depth profiles for selected dates are included in Figures $4.3 .4 e, f, g$, and $h$.

Manganese

For both transition metals, concentrations increased in stratified bottom waters during the summer, but significant differences between iron and manganese were noted in the timing and magnitude of release. At $11 \mathrm{~m}$, manganese concentrations approximately doubled between 14 June and 24 July, doubled again by 14 August, and doubled once more by 19 September (Figure 4.3.4a). Completely anoxic conditions did not start in the lower water column until mid-August, and thus manganese increased even in well oxygenated water. Manganese showed little tendency to 
FIGURE 4.3.4a: TOTAL MANGANESE ISOPLETHS IN THE WATER COLUMN

\section{TOTAL MANGANESE ISOPLETHS}

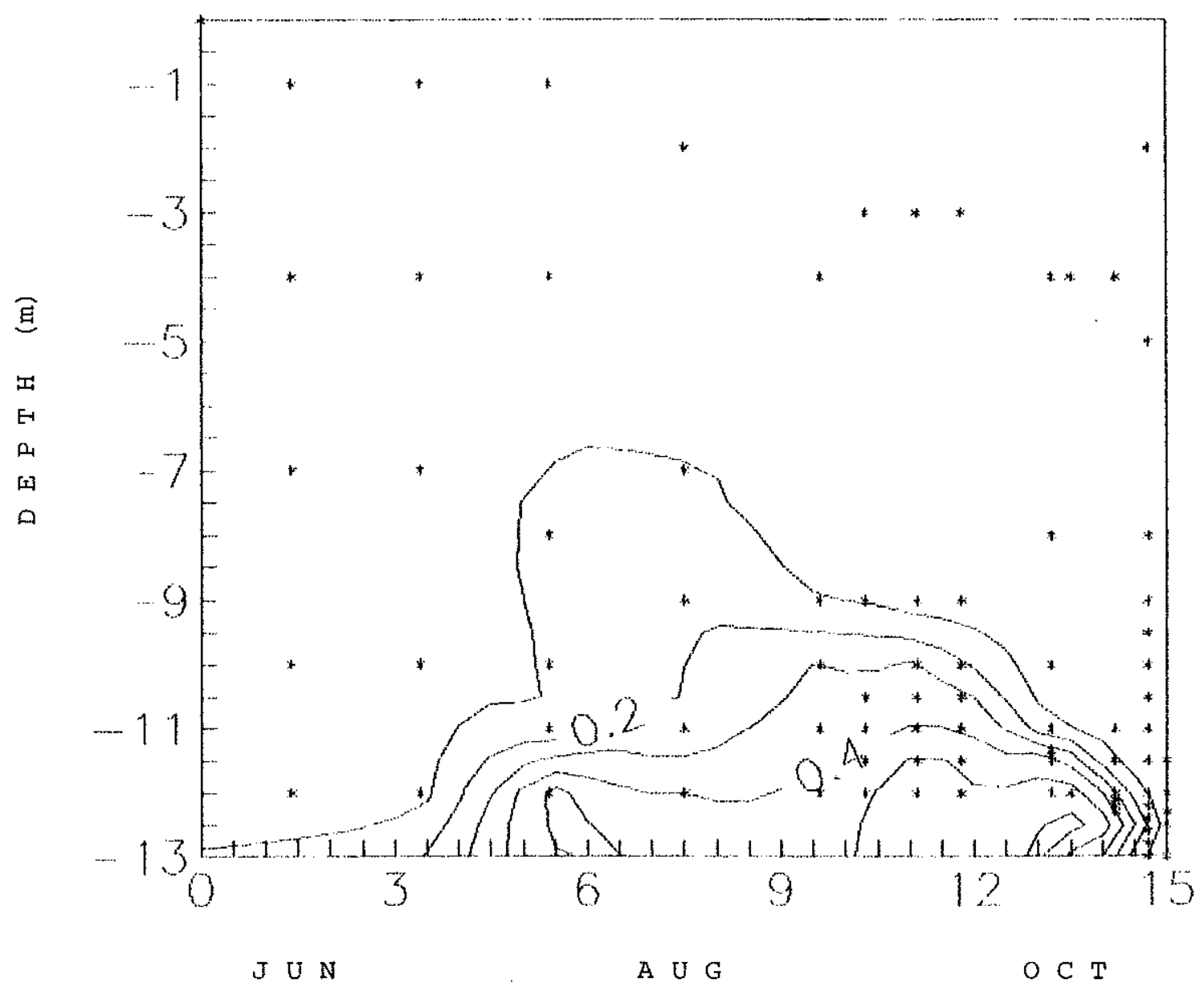

Contour interval: $0.1 \mathrm{mg} /$ liter 
reprecipitate on encountering the oxic-anoxic interface whether in the sediments or in the water column, and dissolved manganese was the predominant form measured at all depths in the water column and at all times throughout the summer (manganese dissolved $=94.6 \%$ of manganese total, average for all samples). Manganese increased steadily over time and did not show a tendency to increase rapidly at the onset of anoxic conditions in the water column. A small spurt was noted about a month before that time, perhaps when the anoxic-anoxic interface reached the sediment water interface.

Iron

In marked contrast to manganese, iron showed a complex pattern of distribution in time, in space, and between dissolved and particulate forms. Iron levels rose slightly in suboxic stratified bottom water, but the major increase was coincident with the the start of anoxic conditions in the water column in August (Figure 4.3.4b). Total iron (dissolved plus particulate) rose abruptly at that time, reaching concentrations near $8 \mathrm{mg} / 1$ by late September.

A simple mass balance for the period from 4 September to 19 September is illustrative. At the beginning of that time period, the total inventory of iron in the hypolimnion from $10 \mathrm{~m}$ to the bottom was $4.7 \times 10^{4} \mathrm{~g}$, and at the end it was $15.4 \times 10^{4} \mathrm{~g}$. These values were obtained in the following manner. A second-order polynomial regression was calculated for the total iron vs. depth profiles for each date. These were then multiplied by a expression for lake area as a function of depth, which is linear in the depth range of interest, and the product was integrated analytically over depth from $10 \mathrm{~m}$ to the bottom. The difference between the inventories on the two dates is $107 \mathrm{~kg}$, 
FIGURE $4.3 .4 \mathrm{~b}$ ISOPLETHS OF TOTAL IRON IN THE WATER COLUMN

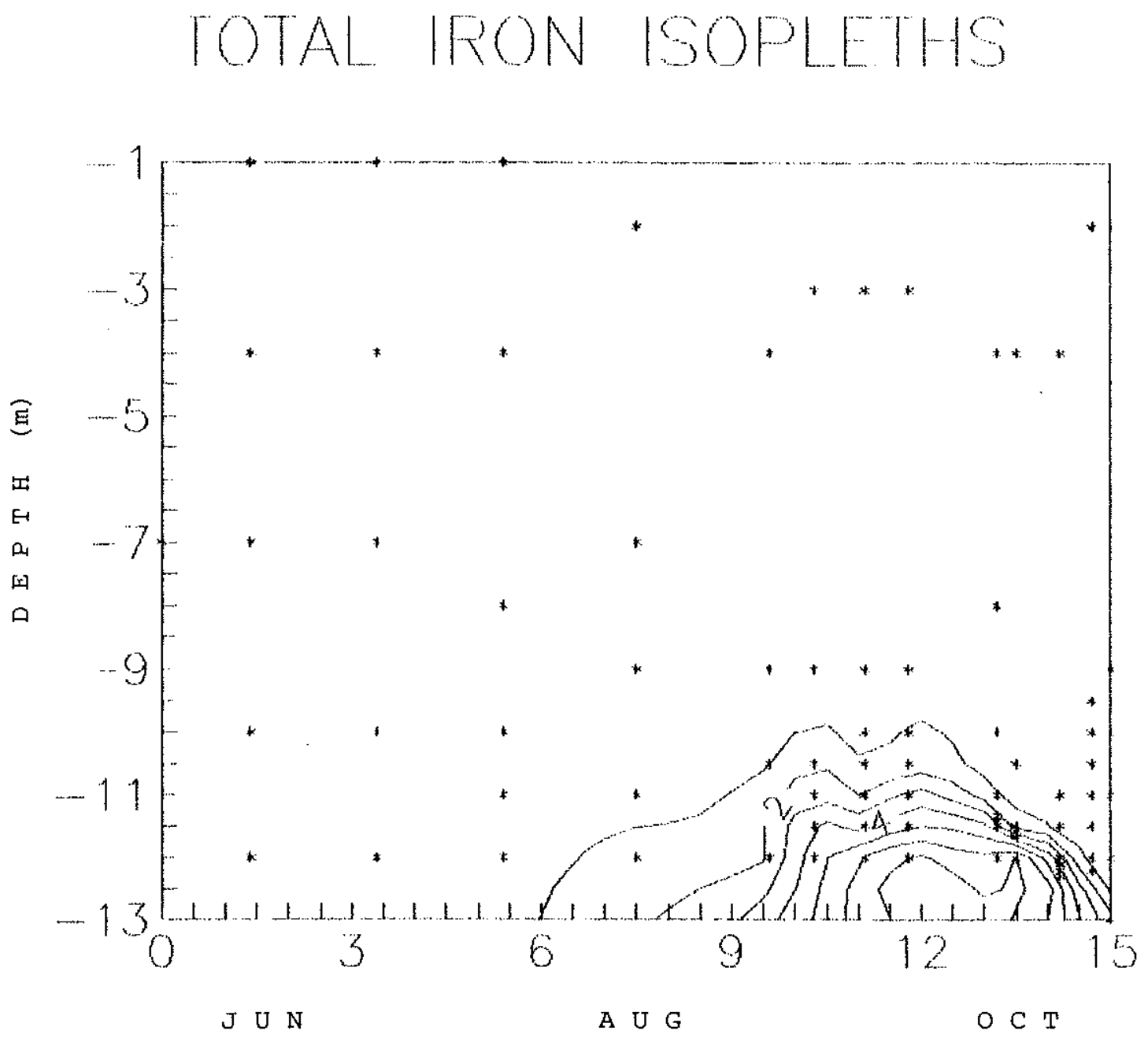

Contour interval: $1 \mathrm{mg} / 1$ iter 
which, divided by the time interval and the area of the basin at $10 \mathrm{~m}$ gives the average rate of net release from the sediments: $7.3 \mathrm{mg} / \mathrm{cm}^{2} \mathrm{y}$. This value is similar to one reported by DAVISON et al. (1981) for the hypolimnion of Esthwaite Water on 28 August: $2.3 \mathrm{mg} / \mathrm{cm}^{2} \mathrm{y}$ (their Table 2). Fluxes and transport mechanisms for total iron in the water column are discussed further in section 4.5 .2 below.

The Particulate Iron Maximum

Concomitant with the rapid increase in the level of total iron in near-bottom water were increases in particulate iron and SPM. Both of these parameters showed similar distribution patterns in time and space (Figures $4.3 .4 \mathrm{c}$ and 4.3.4d). They rose sharply in water adjacent to the sediment-water interface in mid-August, and then this maximum moved higher into the water column flanked by lower concentrations at both deeper and shallower water depths. The surface of maximum particulate iron and SPM reached its greatest height in late September, and thereafter descended toward the sediments, driven downward by thermocline erosion. The depth of the particulate iron peak corresponded to that of the oxycline, so the maximum probably resulted when dissolved iron released from reducing sediment was transported by eddy diffusion, encountered oxygen, and reprecipitated. The same sort of mid-water peak in particulate iron was described by DAVISON et al. (1980), and is well illustrated by their light attenuance-depth profiles.

Considering only measurements taken in the concentration peak, particulate iron comprised $27 \pm 138$ of the air dried SPM mass, similar to the 30 to $40 \%$ iron content of particulate iron formed in Esthwaite water (TIPPING et al. [1981]). Assuming that the precipitated ferric iron has 
FIGURE 4.3.4c ISOPLETHS OF PARTICULATE IRON IN THE WATER COLUMN

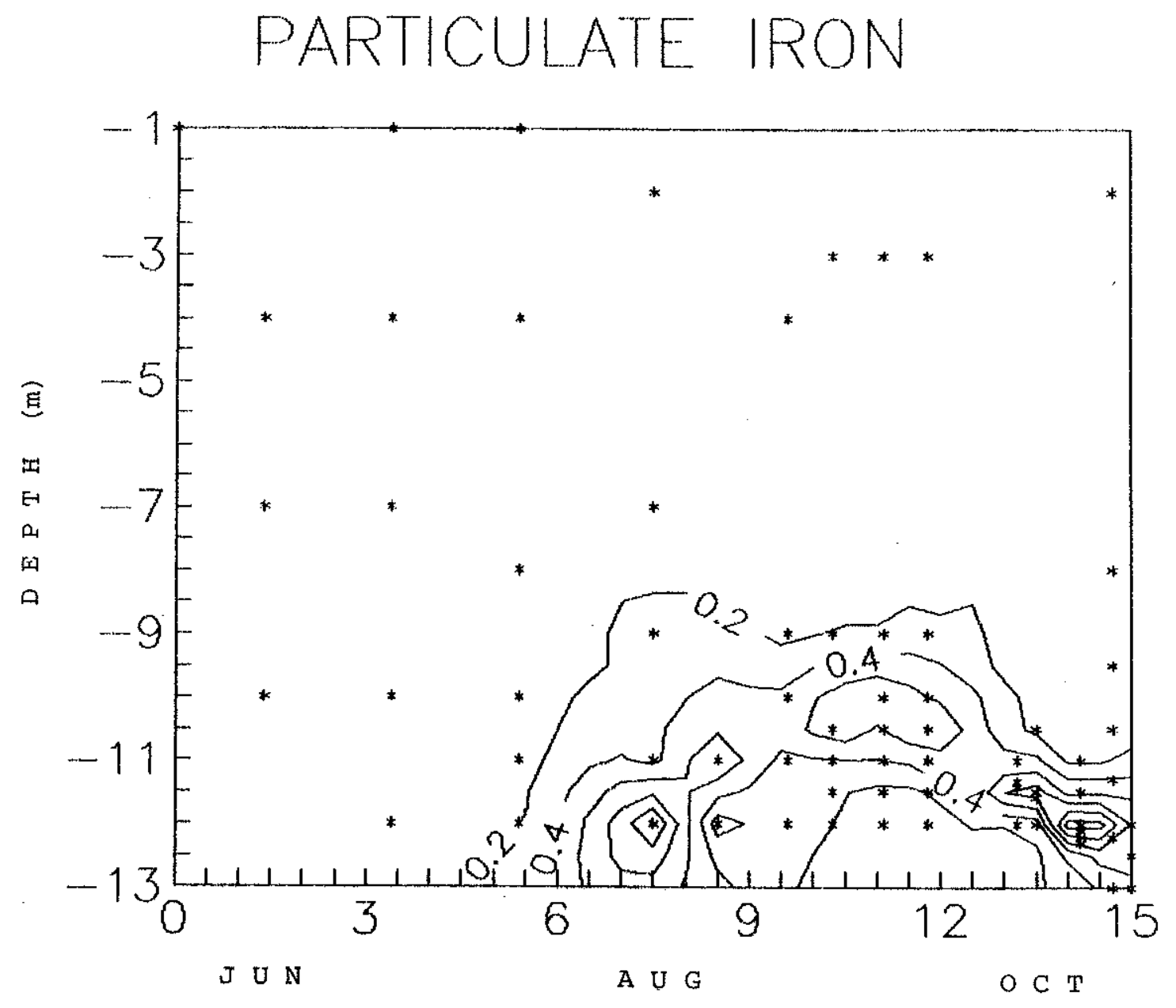

Contour interval: $0.2 \mathrm{mg} /$ liter 
FIGURE $4.3 .4 \mathrm{~d}$ ISOPLETHS OF SPM IN THE WATER COLUMN

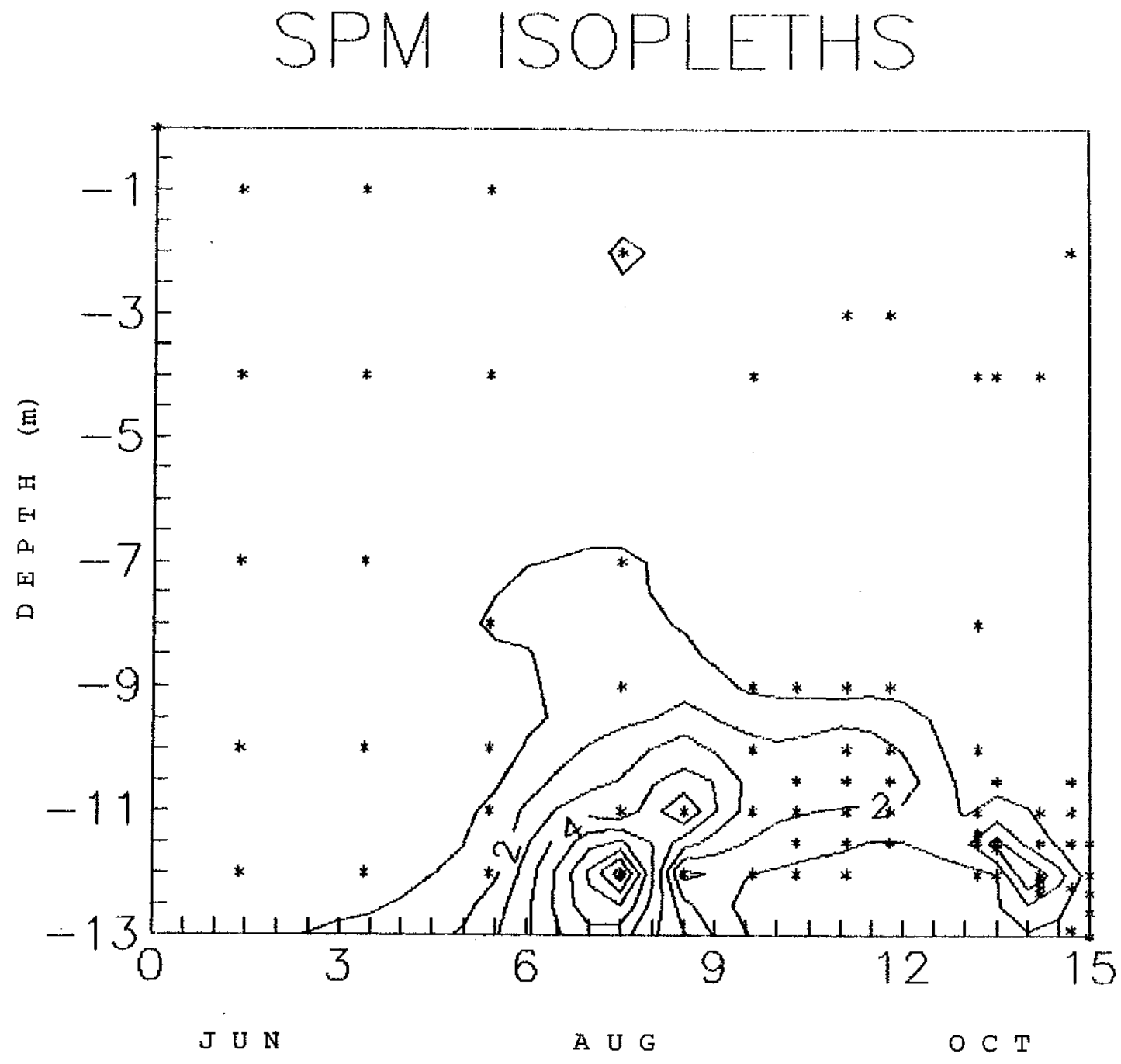

Contour interval: $1 \mathrm{mg} /$ liter 
the formula $\mathrm{Fe}(\mathrm{OH})_{3}, 528$ of the SPM's mass can be accounted for by iron oxyhydroxide. The remainder of the mass is probably composed of 1 ) water of hydration not removed by room temperature drying of the filters, 2) adsorbed organic natter (TIPPING [1981]), 3) co-flocculated silicate detritus, and 4) a small amount of manganese oxyhydroxides. The large proportion of the dry mass accounted for by iron oxyhydroxides probably means that bacteria are not quantitatively important in the iron-SPM peak. This is not surprising in view of the rapidity of iron oxidation even unaided by iron-bacteria (DAVISON and SEED [1983]).

As can be seen from Figure 4.3.4b, elevated total iron levels were limited roughly to the zone of anoxic water, and it is tempting to attribute this restriction solely to a barrier to upward transport posed by the mechanism of rapid oxidation, reprecipitation, aggregation, and settling of iron at the oxycline. Instead, the apparent barrier may be an artifact stemming from the extreme insensitivity of concentrationdepth profiles to fluxes upward into the epilimnion, due to the large ratio of epilimnetic to metalimnetic volume in Bickford. If, for example, a quantity of iron equal to the entire inventory in the anoxic part of the lake in mid-September were added instantaneously to the epilimnion, average concentration would increase by only $0.08 \mathrm{mg} / 1$. Because of this insensitivity one can not rule out upward mixing/dilution as a contributing cause of the rapid attenuation of high iron levels above the oxycline.

Beginning in late September 1985, the upward growth of the anoxic zone was halted by the downward erosion of the thermocline (Figure 4.3.1b). From then on the particulate iron/SPM maximum occurred at progressively greater depths and was increasingly pronounced (Figures 
4.3.4e and $f$ ). The particulate iron peak continued to define the upper limit of the zone of high total iron, and the erosion of the thermocline is evident in plots of total iron vs. depth (Figure 4.3.4g). Some of the iron in the region through which the thermocline descended may have been mixed upward into the epilimnion, but much of it was converted to particulate form and returned to the bottom. A sediment trap deployment from 26 September to 12 October 1985 at $9.1 \mathrm{~m}$ showed a reducible iron flux of $0.9 \mathrm{mg} / \mathrm{cm}^{2} \mathrm{y}$, while at $11.2 \mathrm{~m}$ it was $3.7 \mathrm{mg} / \mathrm{cm}^{2}$, an increase of $2.7 \mathrm{mg} / \mathrm{cm}^{2}$ (see dotted lines on Figure 4.3.4f for sediment trap depths in relation to the particulate iron maximum). This number is comparable to the decrease in the water column Fe inventory over the same depths and time, $0.24 \mathrm{mg} / \mathrm{cm}^{2}$, indicating that a large fraction of the iron was lost as settling particles. There was a similar, but much less dramatic increase with depth in the amount of iron trapped in Esthwaite Water, U.K. (DAVISON et a1. [1982]). SIGG et al. (1987) observed a similar effect for manganese, but not iron, in Lake Zurich, Switzerland, a much deeper lake $(135 \mathrm{~m})$ with virtually no anoxic water. The difference probably reflects the inability of iron to penetrate into the water column except under completely anoxic conditions. Also, because of the depth of Lake Zurich, dissolved reduced manganese was resident long enough to reoxidize and precipitate, unlike in shallower Esthwaite Water or Bickford Reservoir.

Like iron, elevated manganese levels were limited to the metalimnion of Bickford. This was definitely not due to reprecipitation on encountering oxygenated water, since no particulate manganese maximum was observed. Rather manganese that was transported to the base of the 
FIGURE 4.3.4e PROFILES OF PARTICULATE IRON IN THE WATER COLUMN SUMMER 1985

PARTICULATE Fe: SUMMER

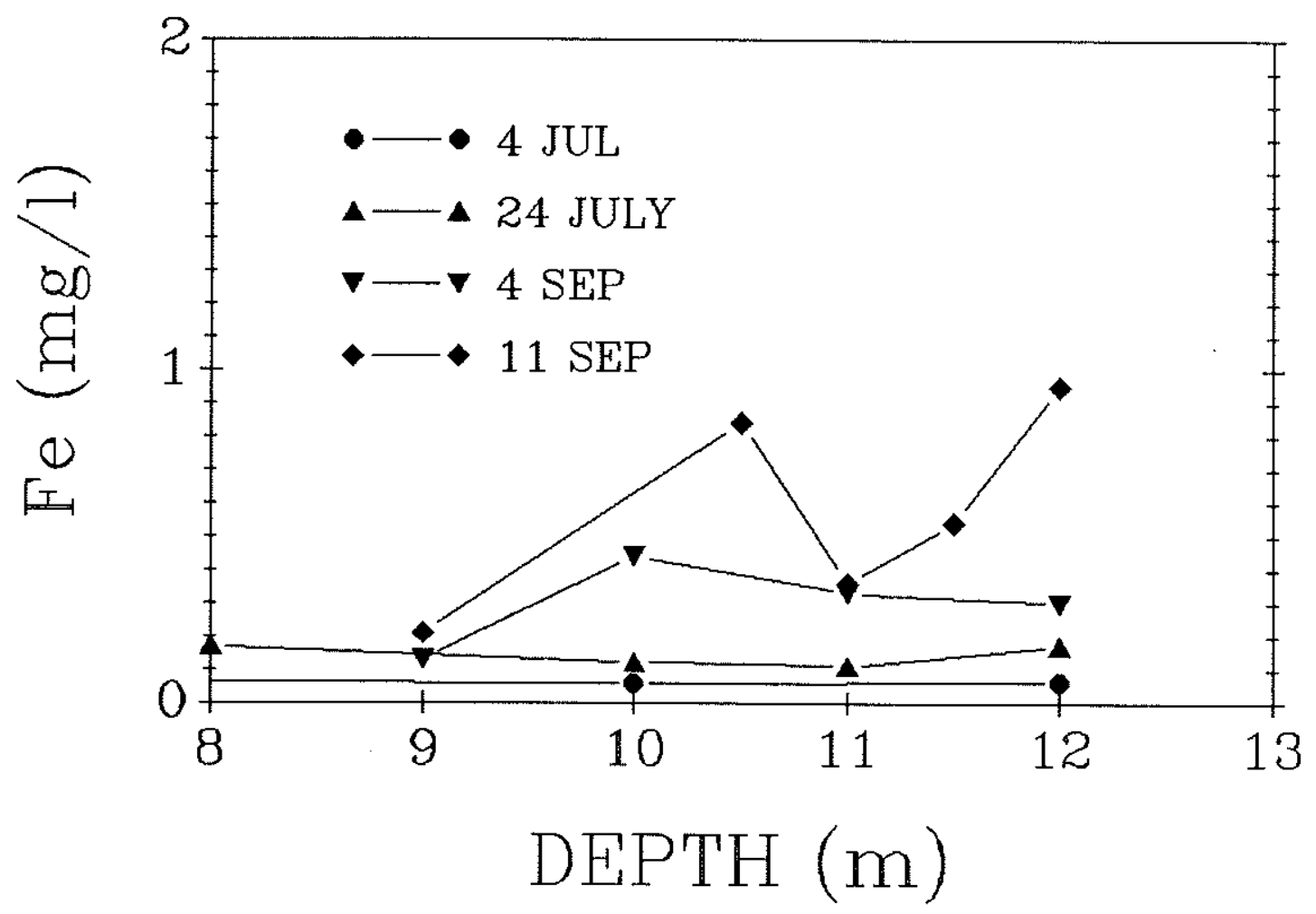


FIGURE 4.3.4f PROFILES OF PARTICULATE IRON IN THE WATER COLUMN FALL 1985

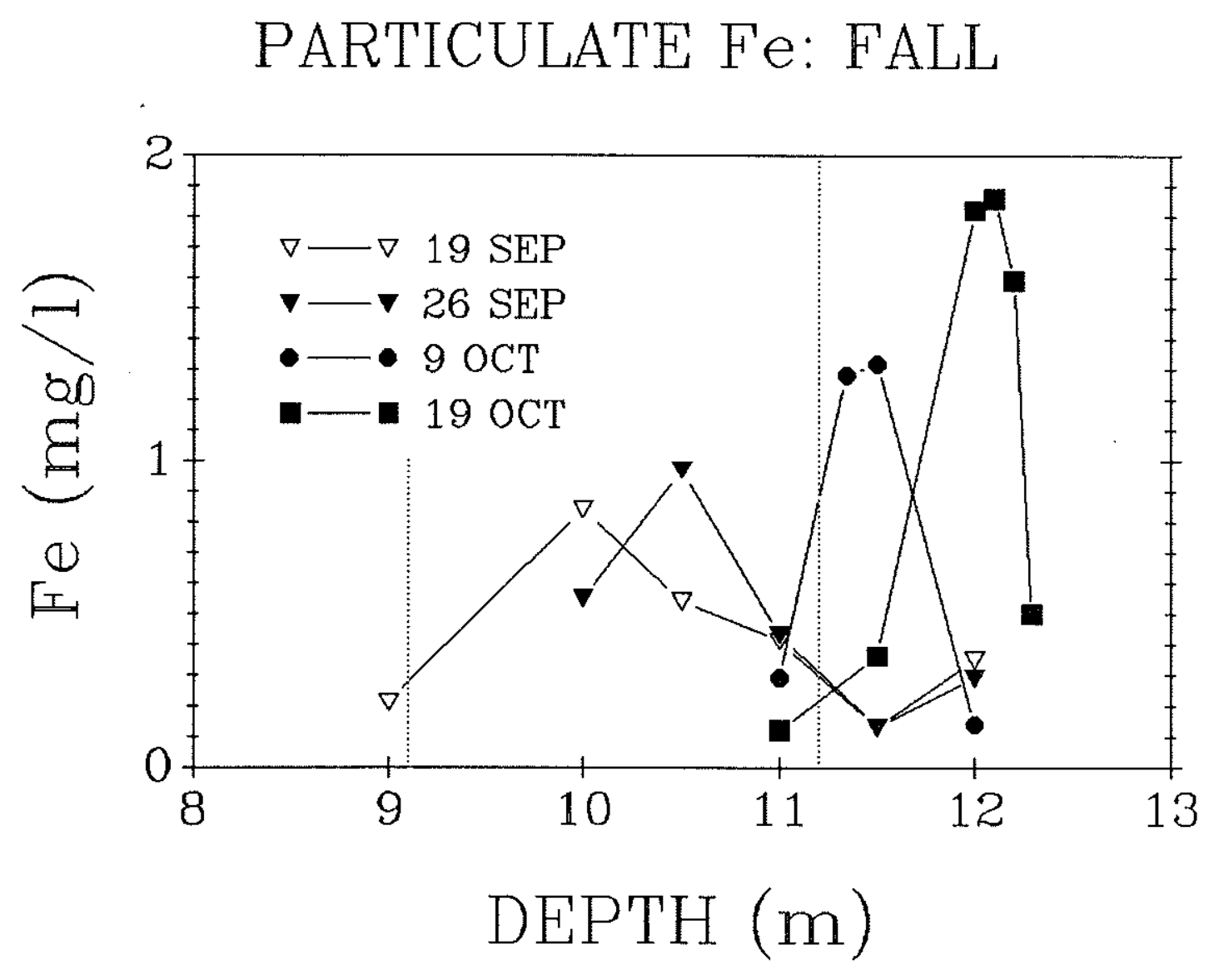


FIGURE 4.3.49 PROFILES OF TOTAL IRON IN THE WATER COLUMN

FALL 1985

TOTAL IRON: FALL

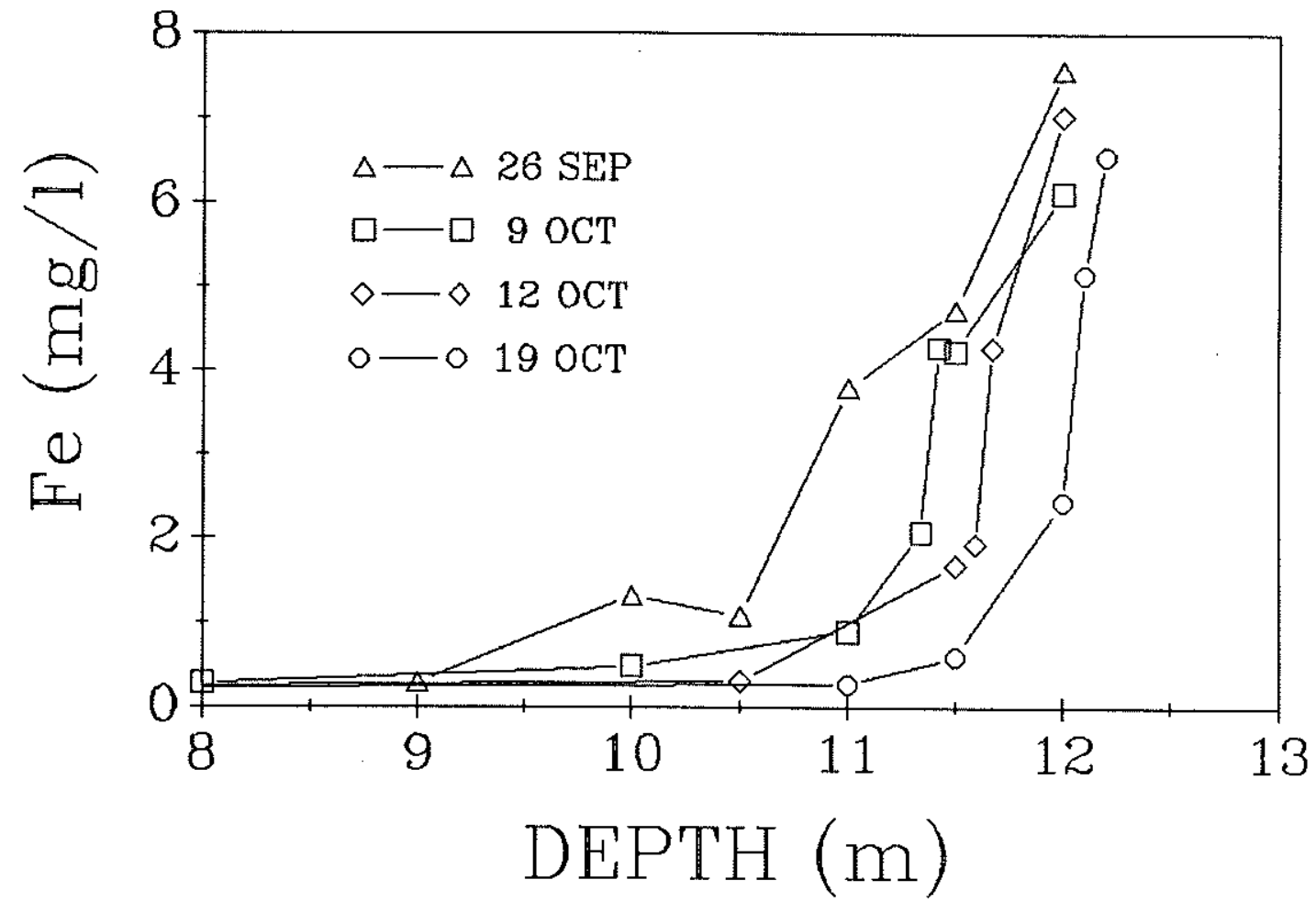


FIGURE $4.3 .4 \mathrm{~h}$ PROFILES OF TOTAL IRON IN THE WATER COLUMN SUMMER 1985

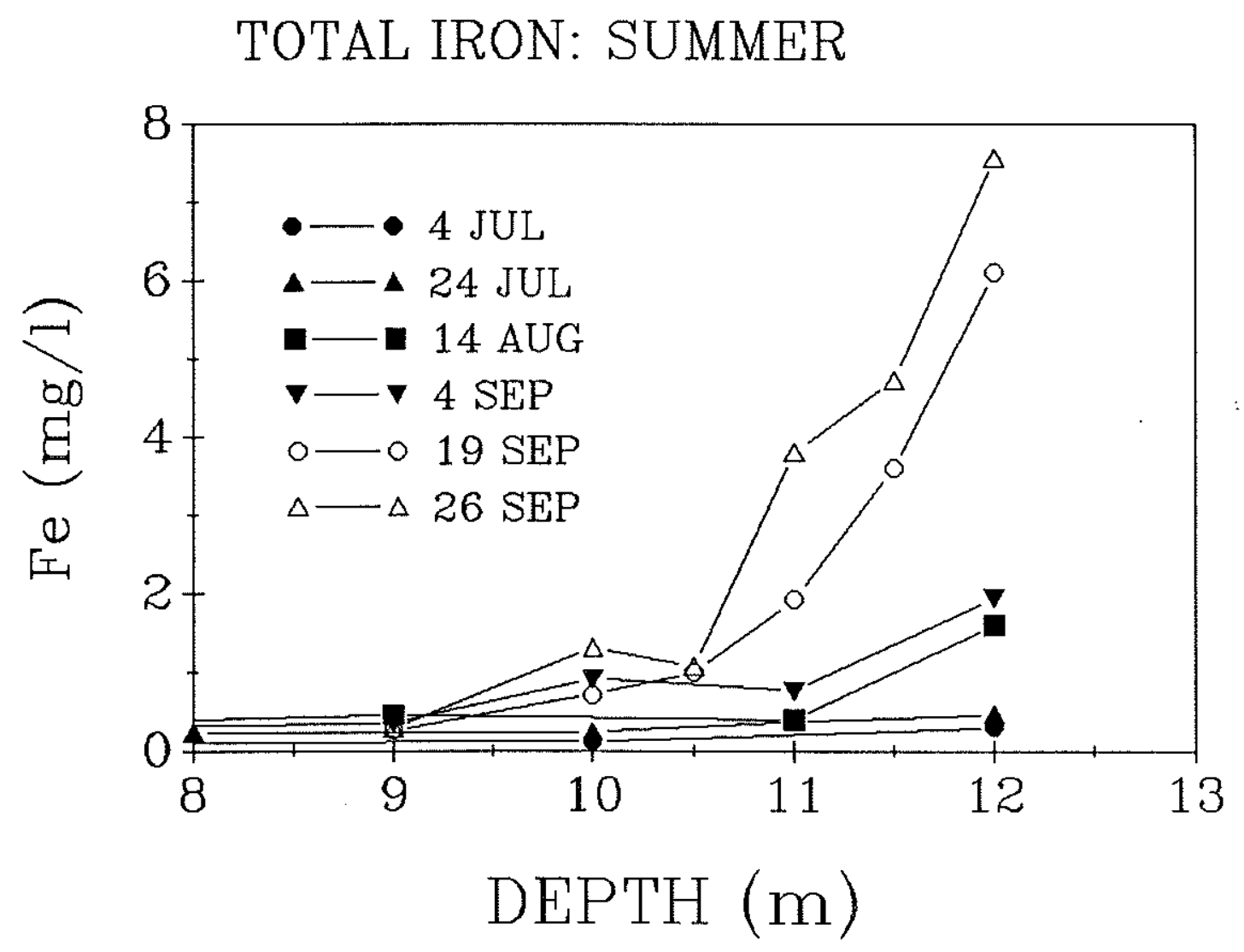


epilimnion was rapidly mixed through the much larger volume of that layer and quickly diluted. As will be described in a later section, much of this manganese is ultimately lost from the lake as outflow rather than being returned to the sediments.

\subsection{5 pH AND ALKALINITY}

Table 4.3.5a is a summary of data on $\mathrm{pH}$ and alkalinity in the water column. Measurements were made in the laboratory without special precautions regarding $\mathrm{CO}_{2}$ exchange with the atmosphere. The $\mathrm{pH}$ values may be high, since loss of $\mathrm{CO}_{2}$ from these oversaturated waters would tend to drive the $\mathrm{pH}$ upward. Alkalinities, of course, are unaffected by $\mathrm{CO}_{2}$ dissolution, but they may be low to the extent that iron oxidation took place in the sample during the time between collection and measurement. That reaction would cause a decrease in $\mathrm{pH}$, so the measured $\mathrm{pH}$ may be either higher or lower than in situ values depending on the relative rates of $\mathrm{CO}_{2}$ degassing and iron oxidation after sample collection.

Overall the pattern was one of micromolar alkalinity and $\mathrm{pH}^{\prime} \mathrm{s}$ near 5.7 in the epilimnion of the lake. With depth, $\mathrm{pH}$ increased toward neutrality and alkalinities increased toward millimolar values. From this data it is clear that the release of metals from the sediments was definitely not related to acidification, since $\mathrm{Fe}, \mathrm{Mn},{ }^{210} \mathrm{~Pb}$, and $210 \mathrm{Po}$ maxima were associated with high alkalinities and $\mathrm{pH}^{\prime} \mathrm{s}$. WHITE and DRISCOLL (1985) documented increases of stable lead in bottom waters of Dart Lake, NY. Even in this acidified Adirondack lake, the lead peak was associated with increased alkalinity and $\mathrm{pH}$.

The occurrence of elevated alkalinity in near-bottom waters is not surprising in view of the reducing conditions found there. Reactions 
TABLE 4.3.5a ALKALINITY AND $\mathrm{PH}$ IN THE WATER COLUMN

\begin{tabular}{|c|c|c|c|}
\hline DATE & $\begin{array}{l}\text { DEPTH } \\
\text { (m) }\end{array}$ & $\begin{array}{l}\text { ALKALINITY } \\
\text { (meq/liter) }\end{array}$ & $\begin{array}{l}\mathrm{pH} \\
--\end{array}$ \\
\hline 9 OCT 85 & 12.0 & .260 & 6.1 \\
\hline 12 OCT 85 & $\begin{array}{l}4.0 \\
10.5 \\
11.5 \\
11.59 \\
11.67 \\
12.0\end{array}$ & $\begin{array}{l}.016 \\
.020 \\
.053 \\
.048 \\
.100 \\
.161\end{array}$ & $\begin{array}{l}5.7 \\
5.7 \\
6.4 \\
5.7 \\
5.7 \\
6.2\end{array}$ \\
\hline 19 OCT 85 & $\begin{array}{l}4.0 \\
11.0 \\
11.5 \\
12.0 \\
12.1 \\
12.2 \\
12.29\end{array}$ & $\begin{array}{l}.016 \\
.016 \\
.025 \\
.081 \\
.100 \\
.190 \\
.209\end{array}$ & $\begin{array}{l}5.6 \\
5.7 \\
5.9 \\
5.9 \\
6.2 \\
6.2 \\
6.6\end{array}$ \\
\hline 27 SEP 86 & $\begin{array}{l}9.3 \\
10.0 \\
11.0 \\
11.5 \\
12.0 \\
12.29\end{array}$ & $\begin{array}{l}.070 \\
.064 \\
.140 \\
.300 \\
.380 \\
.380\end{array}$ & $\begin{array}{r}>5.6 \\
>5.6 \\
>6.0 \\
>6.2 \\
>6.4 \\
6.6\end{array}$ \\
\hline 11 OCT 86 & $\begin{array}{r}6.0 \\
10.0 \\
11.0 \\
11.5 \\
12.3\end{array}$ & $\begin{array}{l}.014 \\
.035 \\
.139 \\
.319 \\
.382\end{array}$ & $\begin{array}{l}5.7 \\
6.1 \\
6.5 \\
6.6 \\
6.7\end{array}$ \\
\hline
\end{tabular}

${ }^{1} \mathrm{pH}$ still drifting upward at indicated value at start of alkalinity titration. 
for the reduction of oxygen, nitrate, manganese, iron, and sulfate by organic matter all cause elevation of $\mathrm{pH}$ (under near-neutral conditions) and the production of alkalinity (Figure 4.3.5b). It is possible to check for a balance between the production of alkalinity and the reduction of these oxidants. Reduction of oxygen produces 0.14 equivalents of alkalinity per mole of bimolecular oxygen reduced, while each of the other oxidants produces two equivalents. These values can be multiplied by the number of moles of each reactant consumed, and the sum compared to measured alkalinity. A calculation for data from $12 \mathrm{~m}$ on 12 October 1985 is presented in Table $4.3 .5 \mathrm{c}$. The predicted alkalinity is greater than the measured value, $0.16 \mathrm{mEq} / \mathrm{liter}$. This could occur if the initial alkalinity at the time of stratification were $-0.18 \mathrm{mEq} / 1$ (i.e. net acidity), but this seems unlikely since such large negative alkalinities were not measured in this lake at any other time. Much of the difference probably came from $\mathrm{Fe}^{2+}$ oxidation and alkalinity consumption taking place in samples prior to the alkalinity titration. Other possibilities include errors in our assumptions about the nature of the redox reactions, the existence of unconsidered alkalinityconsuming reactions, or different transport rates for alkalinity compared to the products of the redox reactions. The calculation also shows that the reduction of iron dominates alkalinity production in these bottom waters because it is the second most abundant oxidant (after oxygen) and its reduction produces alkalinity at a higher rate.

\subsubsection{SULFIDE}

Measurements of total sulfide in the water column for sampling dates in 1985 and 1986 are presented in Table 4.3.6a. The data show that sulfide was generally absent from the water column except in the 
TABLE $4.3 .5 \mathrm{~b}$ STOICHIOMETRY OF ORGANIC MATTER OXIDATION REACTIONS

\section{$\triangle$ ALKALINITY}

1) OXYGEN REDUCTION

$0.14 \mathrm{eq} / \mathrm{mole} \mathrm{O}_{2}$

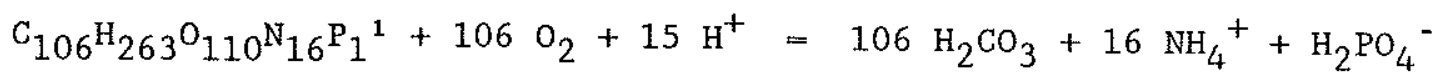

2) NITRATE REDUCTION

$$
2 \mathrm{eq} / \mathrm{mole} \mathrm{NO}_{3}{ }^{-}
$$

$$
2 \mathrm{CH}_{2} \mathrm{O}^{2}+\mathrm{NO}_{3}^{-}+\mathrm{H}_{2} \mathrm{O}+2 \mathrm{H}^{+}=2 \mathrm{H}_{2} \mathrm{CO}_{3}+\mathrm{NH}_{4}^{+}
$$

3) MANGANESE REDUCTION

$2 \mathrm{eq} / \mathrm{mole} \mathrm{MnO}_{2}$

$$
1 / 2 \mathrm{CH}_{2} \mathrm{O}+\mathrm{MnO}_{2}+2 \mathrm{H}^{+}=1 / 2 \mathrm{H}_{2} \mathrm{CO}_{3}+\mathrm{Mn}^{2+}+\mathrm{H}_{2} \mathrm{O}
$$

4) IRON REDUCTION

$$
2 \mathrm{eq} / \mathrm{mole} \mathrm{Fe}(\mathrm{OH})_{3}
$$

$$
1 / 4 \mathrm{CH}_{2} \mathrm{O}+\mathrm{Fe}(\mathrm{OH})_{3}+2 \mathrm{H}^{+}=1 / 4 \mathrm{H}_{2} \mathrm{CO}_{3}+\mathrm{Fe}^{2+}+5 / 2 \mathrm{H}_{2} \mathrm{O}
$$

5) SULFATE REDUCTION

$$
2 \mathrm{CH}_{2} \mathrm{O}+\mathrm{SO}_{4}^{2-}+2 \mathrm{H}^{+}=2 \mathrm{H}_{2} \mathrm{CO}_{3}+\mathrm{H}_{2} \mathrm{~S}
$$

${ }^{1 "} \mathrm{C}_{106} \mathrm{H}_{263} \mathrm{O}_{110} \mathrm{~N}_{16} \mathrm{P}_{1}$ " represents organic matter.

2 " $\mathrm{CH}_{2} \mathrm{O}$ " represents organic matter. Using the more complete form, " $\mathrm{C}_{106} \mathrm{H}_{263}{ }^{\mathrm{O}} 110^{\mathrm{N}} 16^{\mathrm{P}} \mathrm{P}_{1}$ ", would result in an unimportant correction (increase) in alkalinity production. 
TABLE $4.3 .5 \mathrm{c}$ ALKALINITY MASS BALANCE GALCULATION ${ }^{1}$

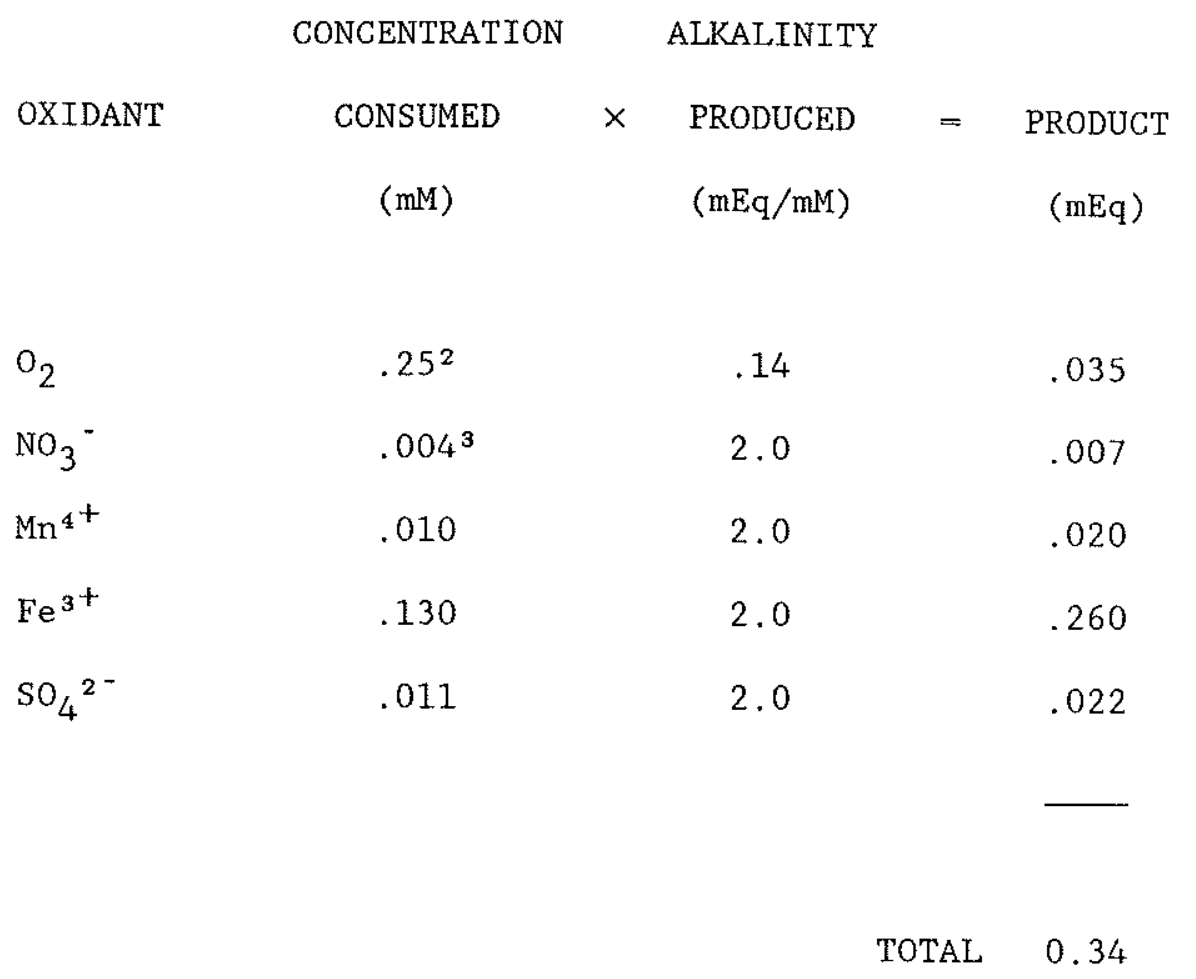

1 Based on data from $12 \mathrm{~m}$ on 12 october 1985.

${ }^{2}$ Decrease in oxygen concentration since the start of stratification.

${ }^{3}$ Weighted mean value for Bickford surface water (ESHLEMAN [1985]). 
TABLE $4.3 .6 \mathrm{a}$ SULFIDE IN THE WATER COLUMN ${ }^{1,2}$

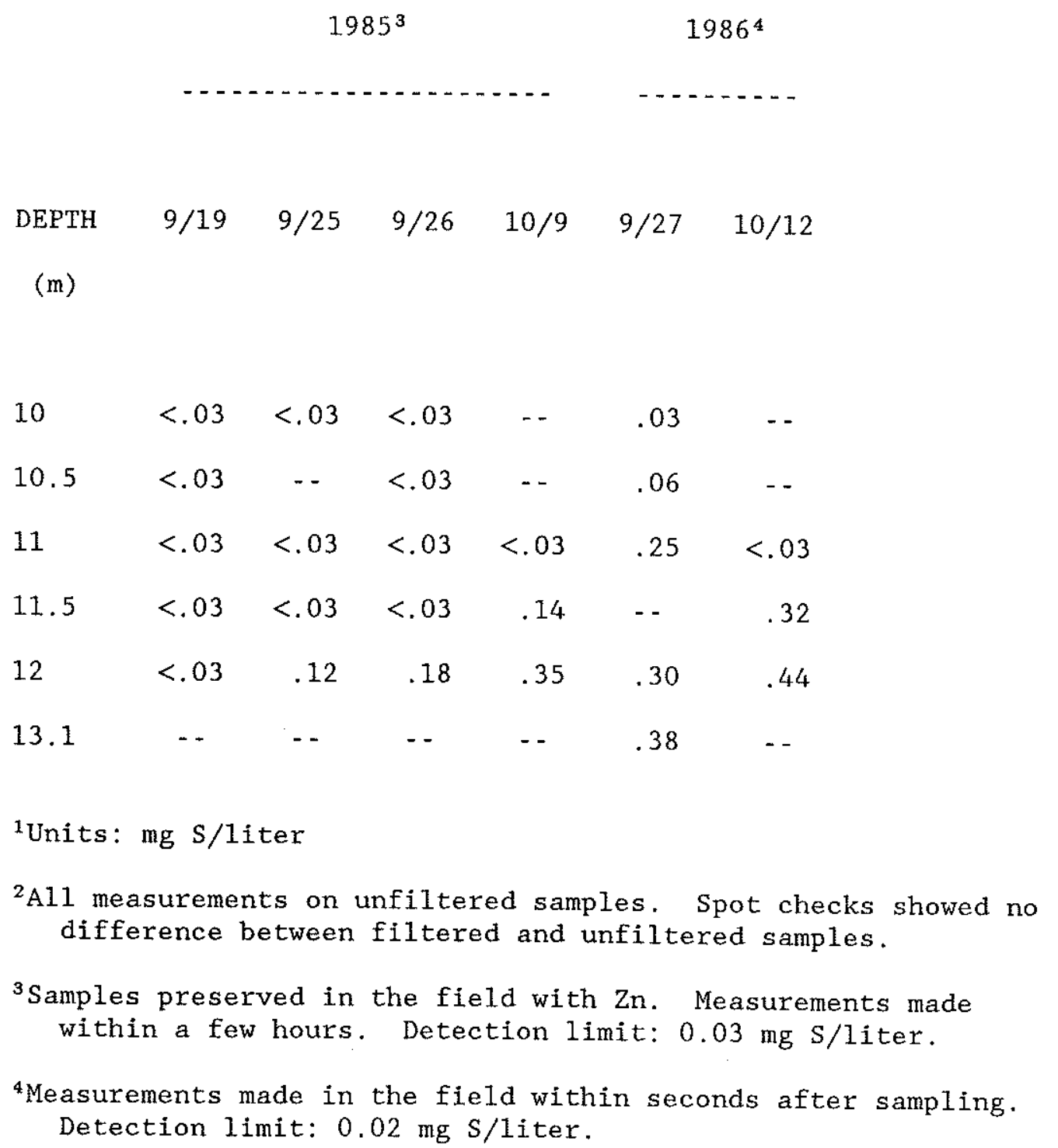


early fall near the sediment water interface, where levels rose to a few tenths of a milligram per liter. In 1985, no sulfide was detected in the water column until 25 September. Over the next two weeks, sulfide rose to a maximum concentration of $0.35 \mathrm{mg} / 1$ (11 $\mu \mathrm{M})$ and reached up to a depth of $11.5 \mathrm{~m}$. In 1986, sulfide levels were higher. The beginning of sulfide release from the sediments was not observed, but on 27 September bottom waters contained $0.38 \mathrm{mg} /$ liter $(12 \mu \mathrm{M})$, and traces of sulfide were detected up to $10 \mathrm{~m}$, within a few decimeters of the base of oxygenated water. Two weeks later, sulfide had increased by about 508 at depth, but had decreased higher up in the water column due to erosion of the thermocline.

DAVISON and HEANEY (1978) documented patterns of sulfide and ferrous iron distribution in Esthwaite water. They found that $\mathrm{Fe}^{2+}$ occurred at levels ranging up to $250 \mu \mathrm{M}$ near the sediment water interface and decreased to zero at the oxycline. The high levels of $\mathrm{Fe}^{2^{+}}$placed a limit on sulfide through precipitation of FeS. The sulfide distribution, limited at the top by oxidation and at the bottom by precipitation, had its maximum at mid depth. In Bickford Reservoir, pyrrhotite ( $\mathrm{FeS}$ ) saturation never occurred, probably because lower productivity caused $\mathrm{Fe}^{2+}$ and $\mathrm{S}^{2-}$ levels to rise later and more slowly. As a result, sulfide was always greatest close to the sediment water interface, which is presumably its source. Figure $4.3 .6 \mathrm{a}$ shows that pyrrhotite saturation was approached for only a few of the samples, all from 1986. Data in this figure have been corrected for the difference between $\mathrm{pH}$ in situ $\left(10^{\circ} \mathrm{C}\right)$ and that measured in the laboratory $\left(20^{\circ} \mathrm{C}\right)$. They have not been corrected for ionic strength effects, which should be quite small because of the low ionic strength of Bickford water. 
FIGURE 4.3.6a IRON AND SULFIDE IN THE WATER COLUMN -

FeS SATURATION STATUS

\section{PYRRHOTITE SATURATION}

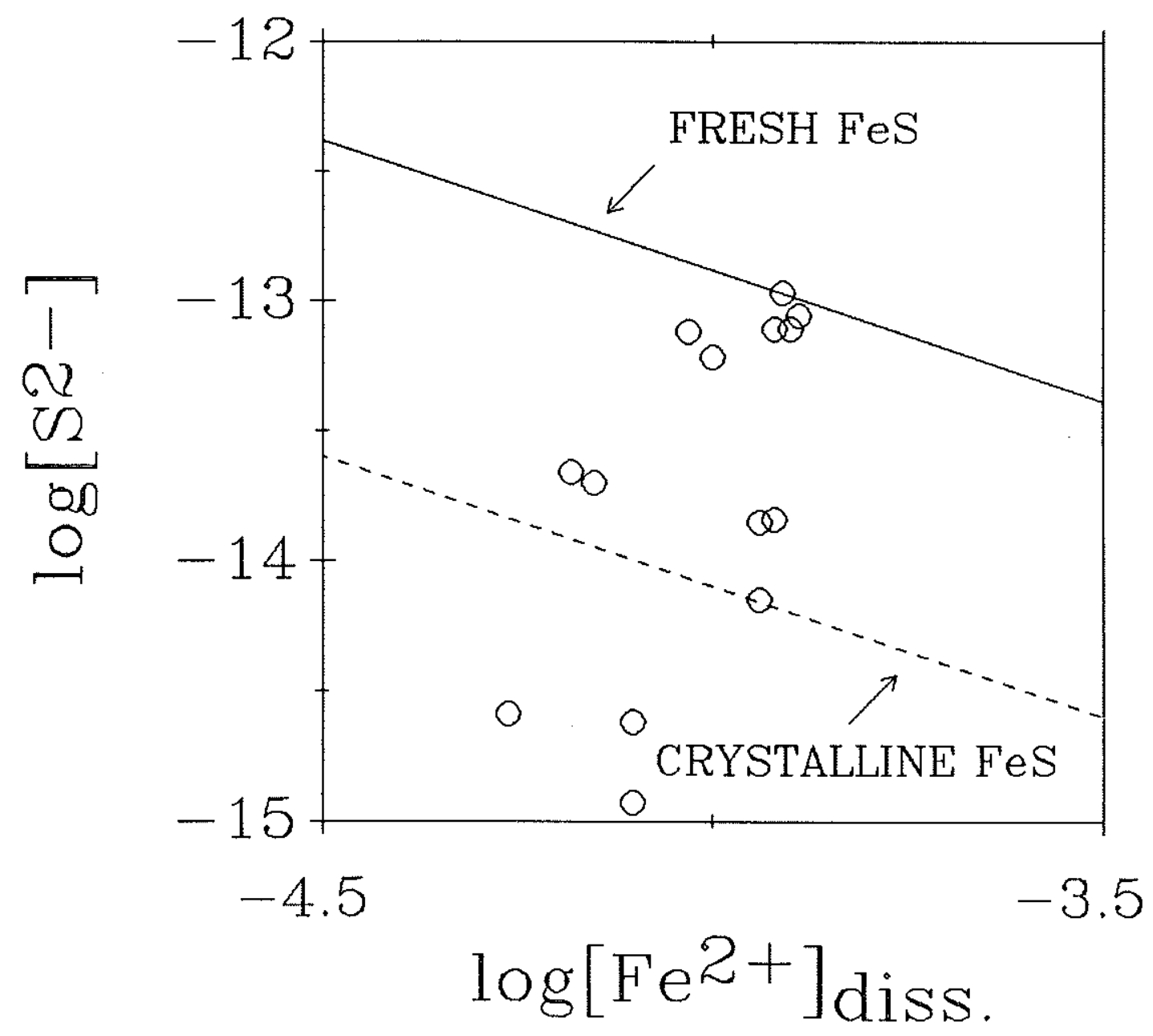




\section{$\mathrm{Pb}$-Sulfide Precipitation}

The presence of even traces of sulfide raises the possibility that $210 \mathrm{~Pb}$ may precipitate in the water column because of the extreme insolubility of galena, $\mathrm{PbS}$. Dissolved lead was not measured in the Bickford water column, but was probably in the nanomolar range (world average river water, MARTIN and MEYBECK [1979]). Detectable sulfide levels ranged from 1 to 200 femtomolar. The ion product is in the range from $10^{-24}$ to $10^{-22}$, greatly exceeding $\mathrm{PbS}$ saturation $\left(\mathrm{K}_{\mathrm{Sp}}=10^{-27.5}\right.$, SMITH and MARTELL [1976]).

Despite this apparent supersaturation, there was not a shift of $21{ }^{\circ} \mathrm{Pb}$ from solution onto particles for those depth increments with measurable sulfide. Figure $4.3 .6 \mathrm{~b}$ is a plot of $2{ }^{\circ} \mathrm{Pb}$ partitioning as a function of SPM concentration. The data conform to a linear relationship implying that $\mathrm{K}_{\mathrm{D}}$ is constant in the water column. Four data points, identified by filled circles on the graph, correspond to intervals with measurable sulfide. All four lie on or below the regression line, indicating that in sulfidic water $210 \mathrm{~Pb}$ had a lower than average tendency to partition onto particles. There are several possible explanations for this ostensible lack of $\mathrm{PbS}$ precipitation under apparently supersaturated conditions. 1) PbS did, in fact, precipitate, but the particles were small enough to pass through $0.45 \mu$ filters. 2) Lead in the water column was bound to colloids or complexed by ligands that outcompete $\mathrm{S}^{2-}$ 3) Freshly precipitated $\mathrm{PbS}$ may have a higher $\mathrm{K}_{\mathrm{sp}}$ value than does the well crystallized mineral (as is the case for FeS, DAVIS and HEANEY [1978]). 4) Precipitation may be kinetically hindered by the very low concentrations of the two reactants, by a lack of nucleation sites, or by other factors. It is impossible to choose 
FIGURE $4.3 .6 \mathrm{~b} 210 \mathrm{~Pb}$ PARTITIONING IN THE HYPOLIMNION

$210^{\mathrm{Pb} \text { PARTITIONING v. SPM }}$

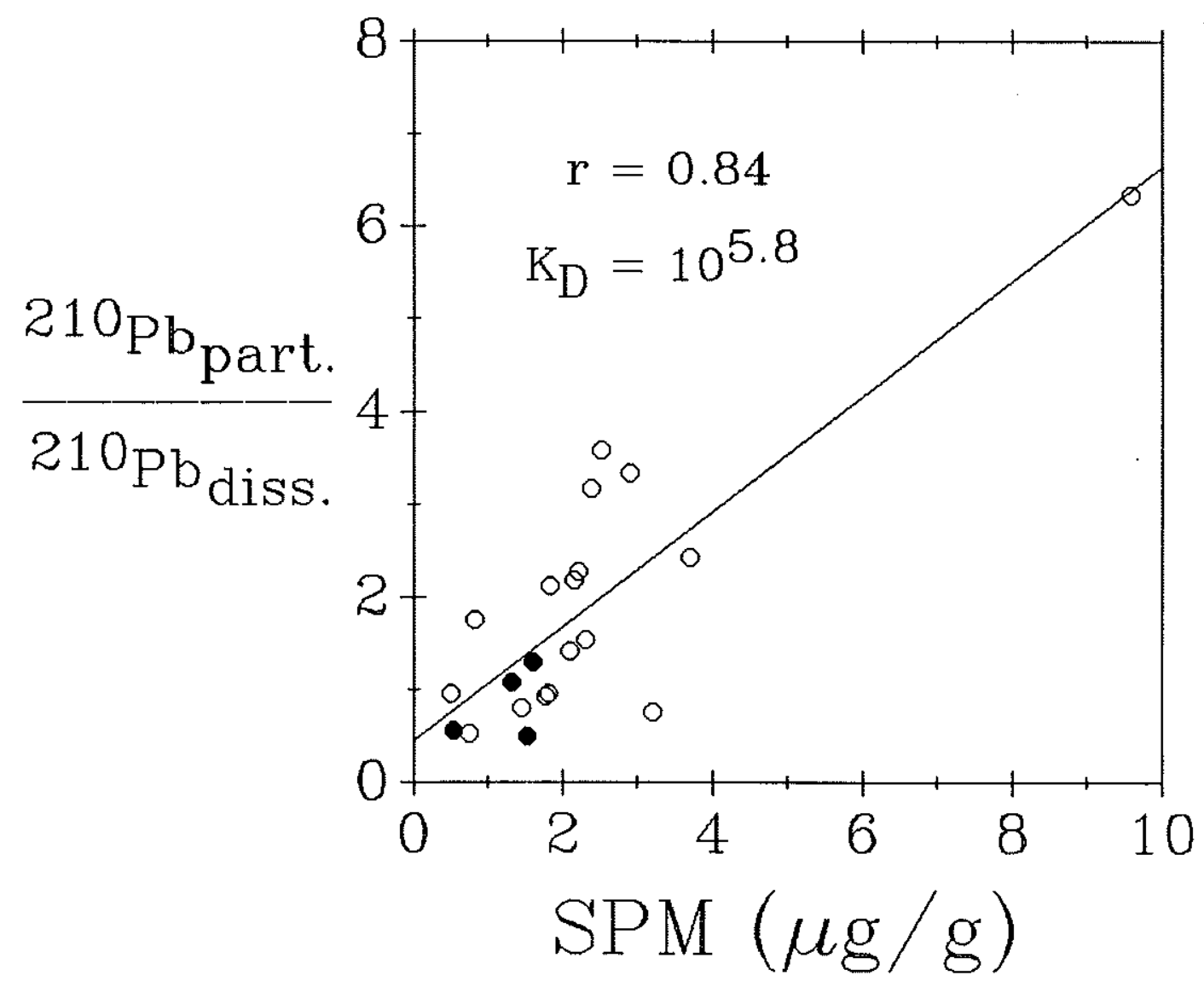


the operative mechanism(s) based on the available data. It should be pointed out that any of the above explanations means that $21{ }^{\circ} \mathrm{Pb}$ is not rapidly removed from the water column by particle aggregation and settling. ${ }^{210} \mathrm{~Pb}$ thus would continue to be transported by eddy diffusion as if still dissolved.

\section{$4.3 .7^{210} \mathrm{~Pb}$}

Dissolved and particulate $2{ }^{10} \mathrm{~Pb}$ data are summarized in Table 4.3.7a and total $210 \mathrm{~Pb}$ in Figure 4.3.7a. In the upper water column, ${ }^{210} \mathrm{~Pb}$ was low and relatively constant, with a little less than half passing a 0.45 $\mu \mathrm{m}$ filter. The samples above $10 \mathrm{~m}$ had an average ${ }^{210} \mathrm{~Pb}$ concentration of $12.9 \pm 3.1 \mathrm{dpm} / 100 \mathrm{~kg} ; 32 \pm 98$ of that total was dissolved. This finding is in agreement with an earlier, year-long study at the same site (BENOIT and HEMOND [1987]).

The difference between total ${ }^{210} \mathrm{~Pb}$ levels in surface and bottom waters is evident in Figure $4.3 .7 \mathrm{~b}$. In the epilimnion, $210 \mathrm{~Pb}$ remained constant, while in the hypolimnion, it increased steadily and reached levels an order of magnitude higher than baseline values before fall turnover halted the rise. A single sample with elevated ${ }^{210} \mathrm{~Pb}$ and $210 \mathrm{Po}$ was reported in BENOIT and HEMOND for October 1982, but no anomalous levels were recorded in 1982, a year when bottom water did not become oxygen depleted. The co-occurrence of high $2{ }^{\circ} \mathrm{Pb}$ and anoxia, and the absence of elevated levels in 1983 support the interpretation that ${ }^{210} \mathrm{~Pb}$ is released from sediments under the influence of reducing conditions. These data are the first measurements of $210 \mathrm{~Pb}$ in anoxic freshwaters, and show that substantial remobilization is possible under these conditions. The nature and causes of $210 \mathrm{~Pb}$ release are described in section 4.5 .3 and in chapter 6 . 
TABLE $4.3 .7 \mathrm{a} \quad 210 \mathrm{~Pb}$ IN THE WATER COLUMN ${ }^{1}$

$$
\begin{aligned}
& \begin{array}{clllllllllll}
\begin{array}{c}
\text { DEPTH } \\
(\mathrm{m})
\end{array} & 14 & 4 & 24 & 14 & 4 & 11 & 19 & 26 & & \multicolumn{3}{c}{\text { JLY }} & \text { AUG } & \multicolumn{2}{c}{\text { SEP }} & 19 & 24
\end{array}
\end{aligned}
$$

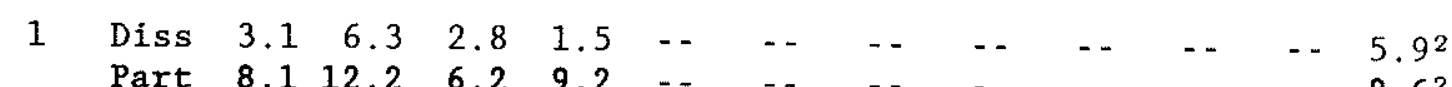

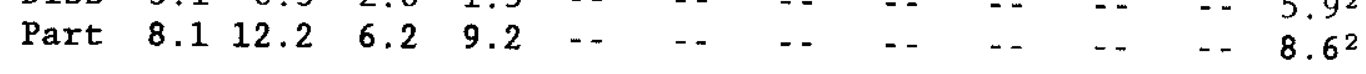

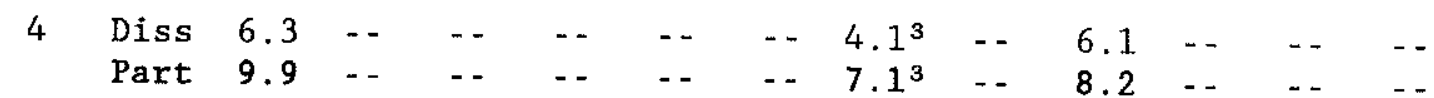

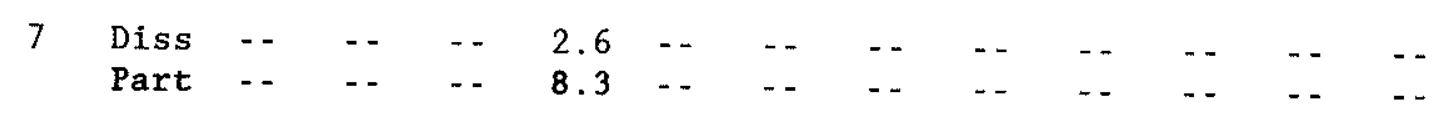

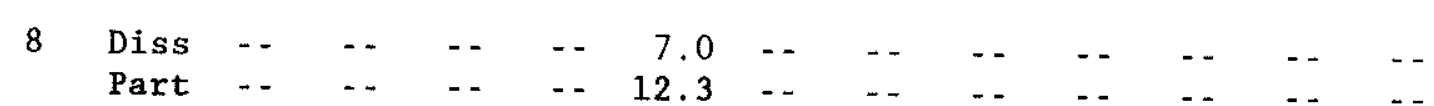

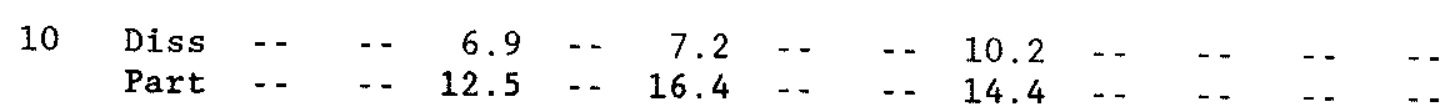

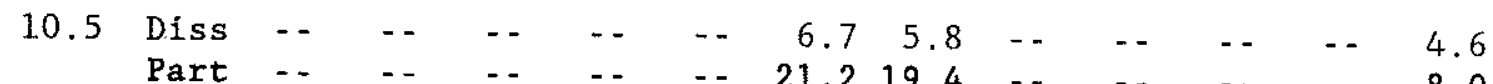

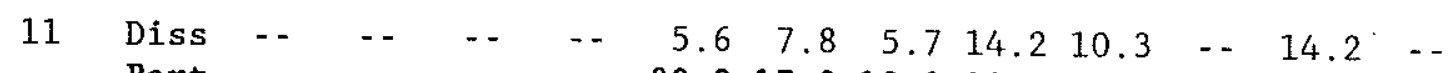

$$
\begin{aligned}
& \text { Part - . } \quad \ldots \quad \ldots \quad 20.017 .012 .213 .310 .0 \quad \ldots \quad 6.9 \quad \ldots
\end{aligned}
$$

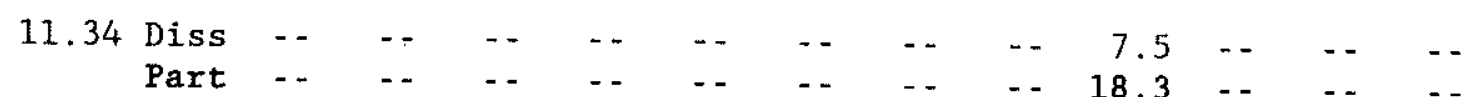

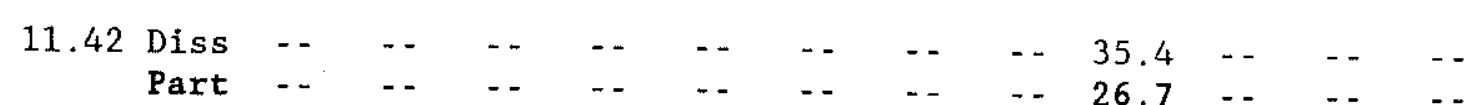

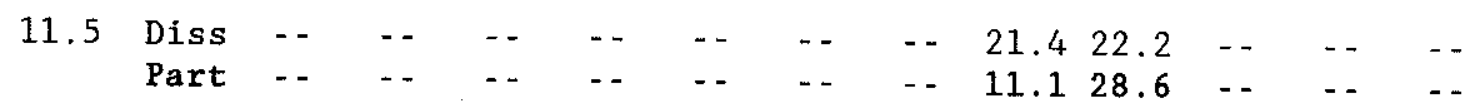

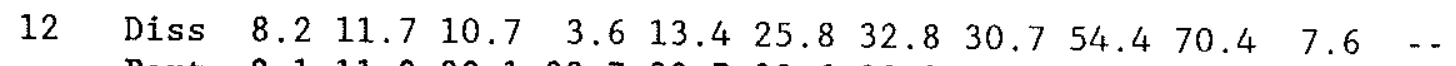

$$
\begin{aligned}
& \begin{array}{llllllllllllllll}
\text { Part } 8.1 & 11.8 & 20.1 & 22.7 & 20.7 & 20.6 & 30.2 & 33.0 & 30.4 & 35.2 & 18.5 & \text { - - }
\end{array}
\end{aligned}
$$

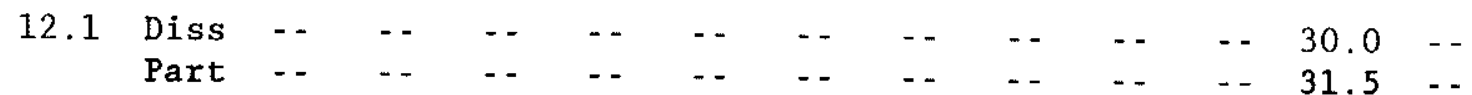

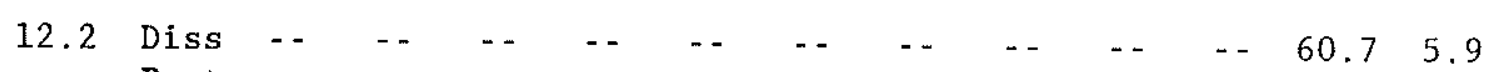

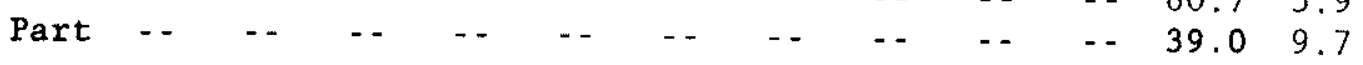

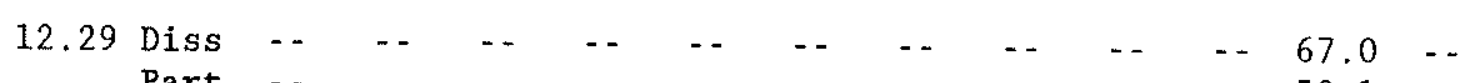

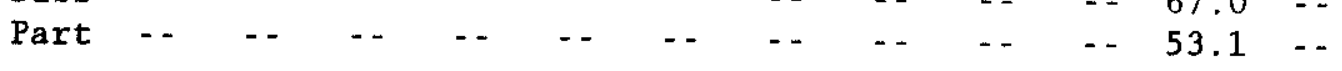


FIGURE $4.3 .7 \mathrm{a}$ ISOPLETHS OF TOTAL $210 \mathrm{~Pb}$ IN THE WATER COLUMN

$210 \mathrm{~Pb}(\mathrm{dpm} / 100 \mathrm{~kg})$

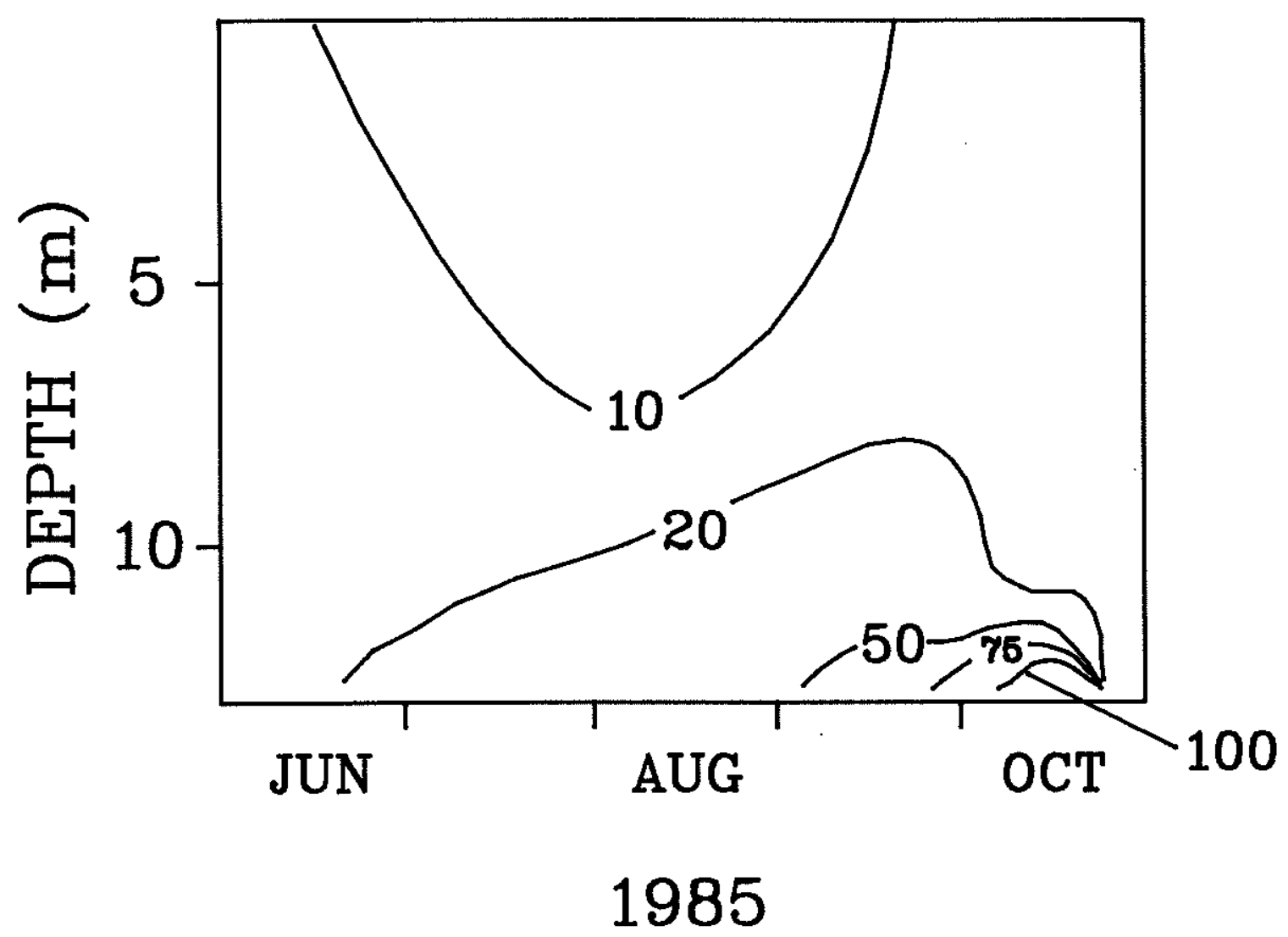


FIGURE $4.3 .7 \mathrm{~b}$ TOTAL $210 \mathrm{~Pb}$ LEVELS IN SURFACE AND BOTTOM WATERS

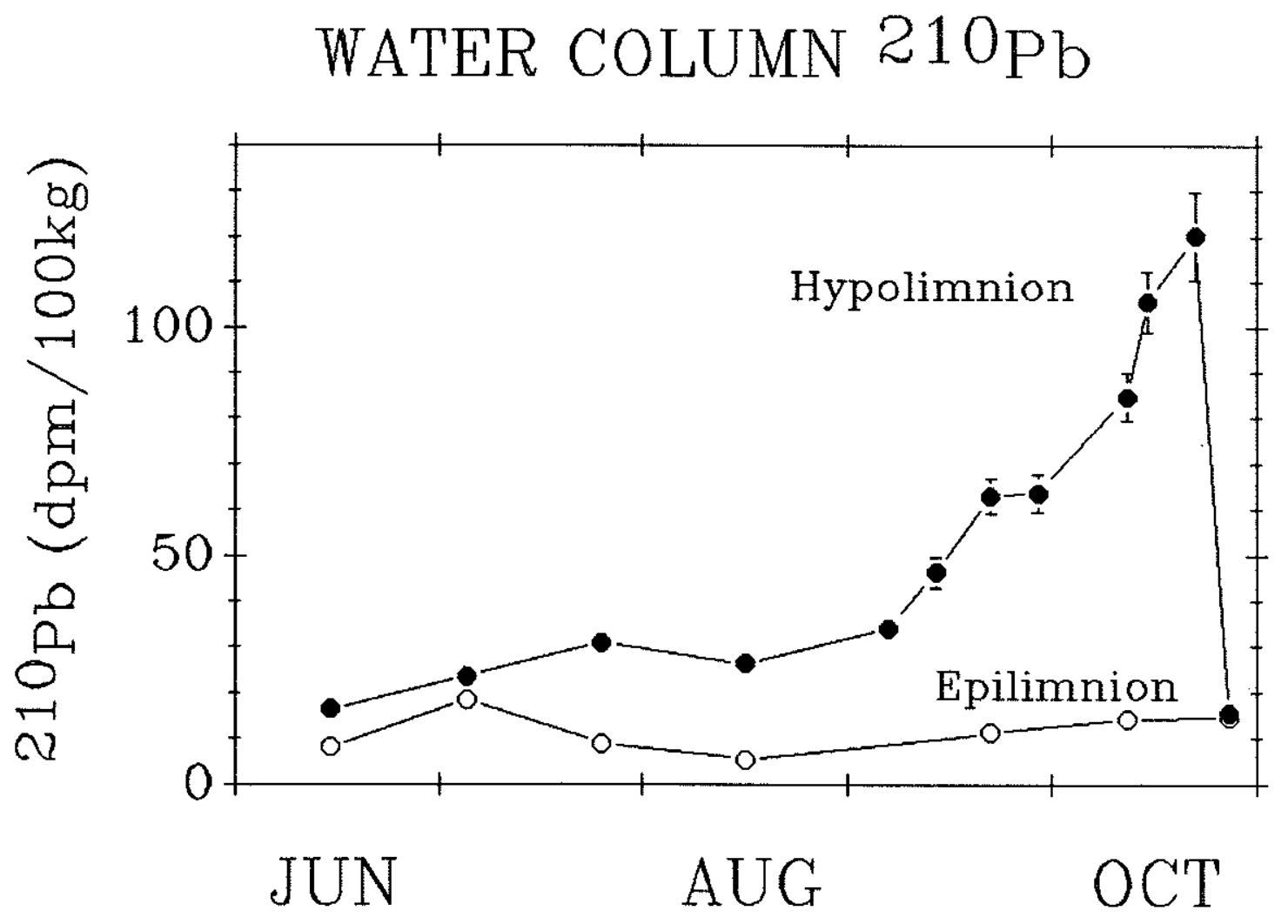




\section{$4.3 .8210 \mathrm{Po}$}

Dissolved and particulate water column 210 Po data are summarized in Table 4.3.8a and total ${ }^{210} \mathrm{Po}$ in Figure 4.3.8a. For the most part, ${ }^{210} \mathrm{Po}$ followed the same pattern as $210 \mathrm{~Pb}$, with low values in the epilimnion and levels increasing in the hypolimnion with time. In the epilimnion, $21{ }^{\circ} \mathrm{Po}$ was slightly lower than ${ }^{210} \mathrm{~Pb}(8.0 \pm 2.2 \mathrm{dpm} / 100 \mathrm{~kg})$, and it had a somewhat lesser tendency to be associated with particles (dissolved fraction $=47 \pm 10 \%$ ) than did ${ }^{210} \mathrm{~Pb}$.

In the epilimnion, total $2{ }^{\circ} \mathrm{Po}$ was never in excess of its progenitor, $210 \mathrm{~Pb}$, but in the metalimnion, ${ }^{210} \mathrm{Po}$ exceeded ${ }^{210} \mathrm{~Pb}$ by as much as a factor of 3.8 from at least mid-August through early September. The magnitude of this excess is proof that the high water column activities of the radionuclides did not derive from sediment resuspension, which would mobilize ${ }^{210} \mathrm{~Pb}$ and $2{ }^{\circ} \mathrm{Po}$ in equal amounts. The excesses mean that $2^{\circ}$ Po began to be released from the sediments earlier than was $210 \mathrm{~Pb}$, consistent with ${ }^{210} \mathrm{Po}^{\prime} \mathrm{s}$ lower scavenging rate in the epilimnion (section 4.4.3); ${ }^{210}$ Po seems to have a lower affinity for solids in general in this lake (exception noted below). The early release of $2{ }^{\circ} \mathrm{Po}$ also has precedents in a number of studies that have documented $2{ }^{\circ} \mathrm{Po}$ remobilization exceeding that of $210 \mathrm{~Pb}$ (BACON et al. [1976], BACON et al. [1980], LI et a1. [1981], TALBOT and ANDREN [1984]). It is somewhat surprising then that in the hypolimnion, ${ }^{210}$ Po had a greater tendency to be sorbed by solids than did ${ }^{210} \mathrm{~Pb}$. In the month from 11 September to 12 October 1985 at a depth of $12 \mathrm{~m}, 57 \pm 88$ of the $210 \mathrm{~Pb}$ but only $29 \pm 78$ of the $2{ }^{20} \mathrm{Po}$ passed a $0.45 \mu \mathrm{m}$ filter. Paradoxically, 210 Po had both a greater tendency to be released from sediments, and a higher affinity for solids once in the hypolimnetic 
TABLE $4.3 .8 \mathrm{a} \quad 210^{\circ} \mathrm{PO}$ IN THE WATER COLUMN ${ }^{1}$

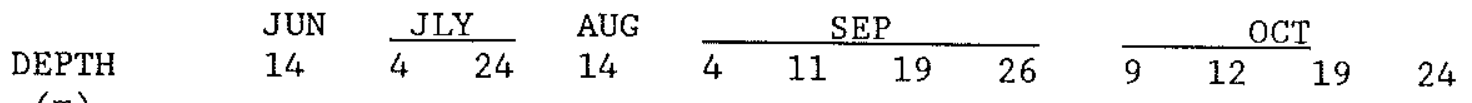

$$
\begin{aligned}
& (\mathrm{m})
\end{aligned}
$$

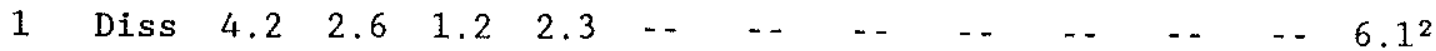

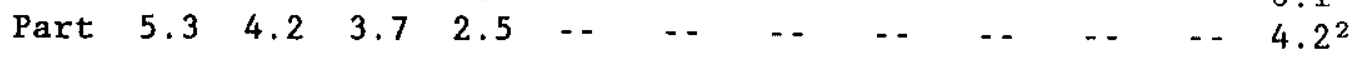

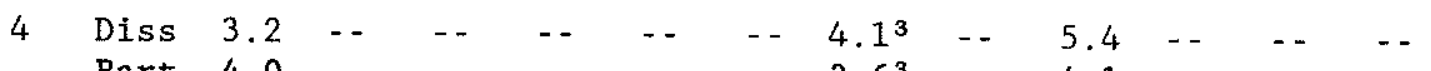

$$
\begin{aligned}
& \text { Part } 4.0 \quad \ldots \quad \ldots \quad \ldots \quad \ldots \quad \ldots 3.6^{3} \ldots-4.1 \ldots
\end{aligned}
$$

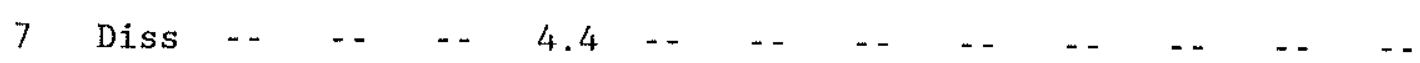

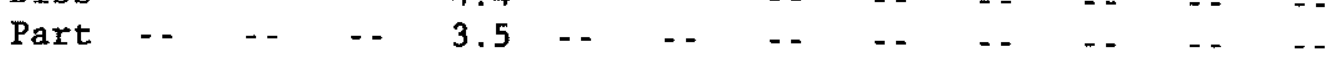

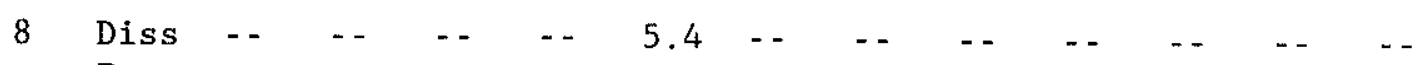

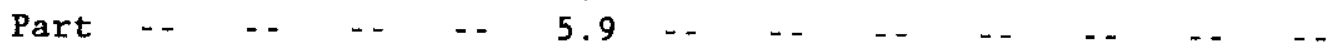

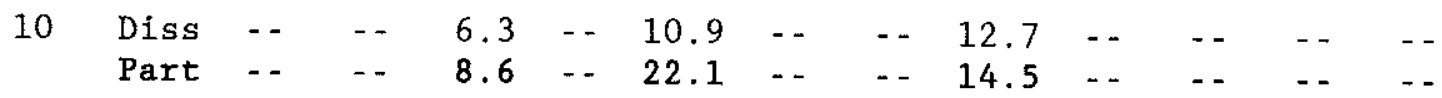

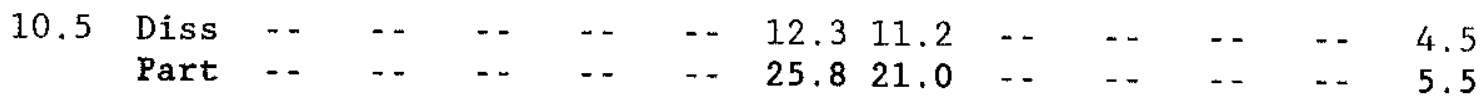

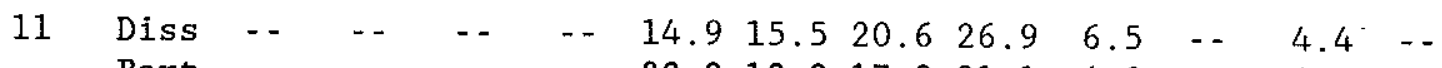

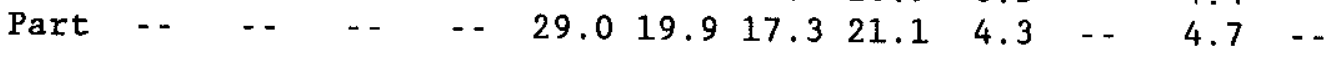

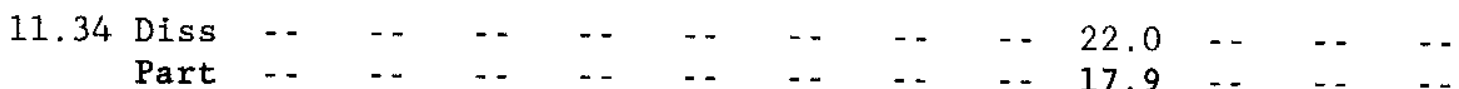

$$
\begin{aligned}
& \begin{array}{r}
11.42 \text { Diss } \\
\text { Part }
\end{array} \\
& \begin{array}{rllllllllllll}
11.5 & \text { Diss } & - & - & - & - & - & - & - & 32.938 .4 & - & \ldots & - \\
& \text { Part } & - & - & - & - & - & - & - & 25.334 .9 & - & \ldots & \ldots
\end{array}
\end{aligned}
$$

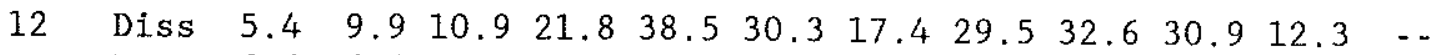

$$
\begin{aligned}
& \begin{array}{lllllllllllllll}
\text { Part } & 6.6 & 6.6 & 20.6 & 29.7 & 52.9 & 70.6 & 83.8 & 77.0 & 57.1 & 61.2 & 21.0 & \ldots
\end{array}
\end{aligned}
$$

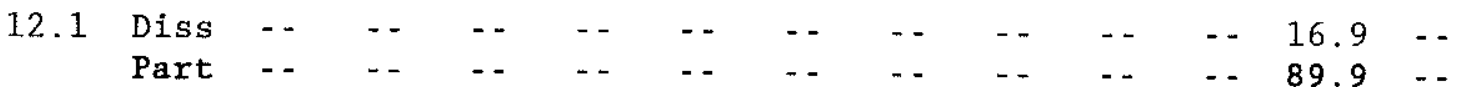

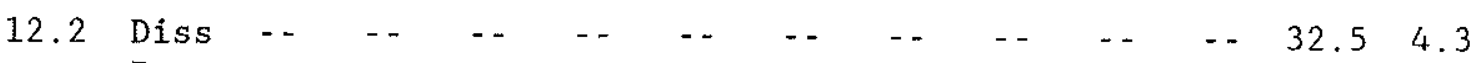

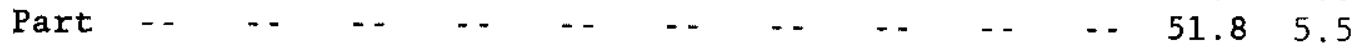

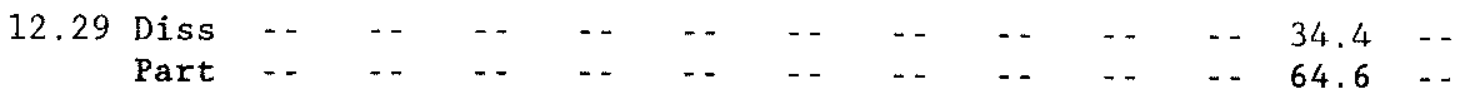

$$
\begin{aligned}
& \text { 1Units: dpm/100 kg } \\
& 22 \mathrm{~m} \\
& 33 \mathrm{~m}
\end{aligned}
$$


FIGURE $4.3 .8 \mathrm{a}$ ISOPLETHS OF TOTAL $210 \mathrm{~Pb}$ IN THE WATER COLUMN

210Po (dpm/100kg)

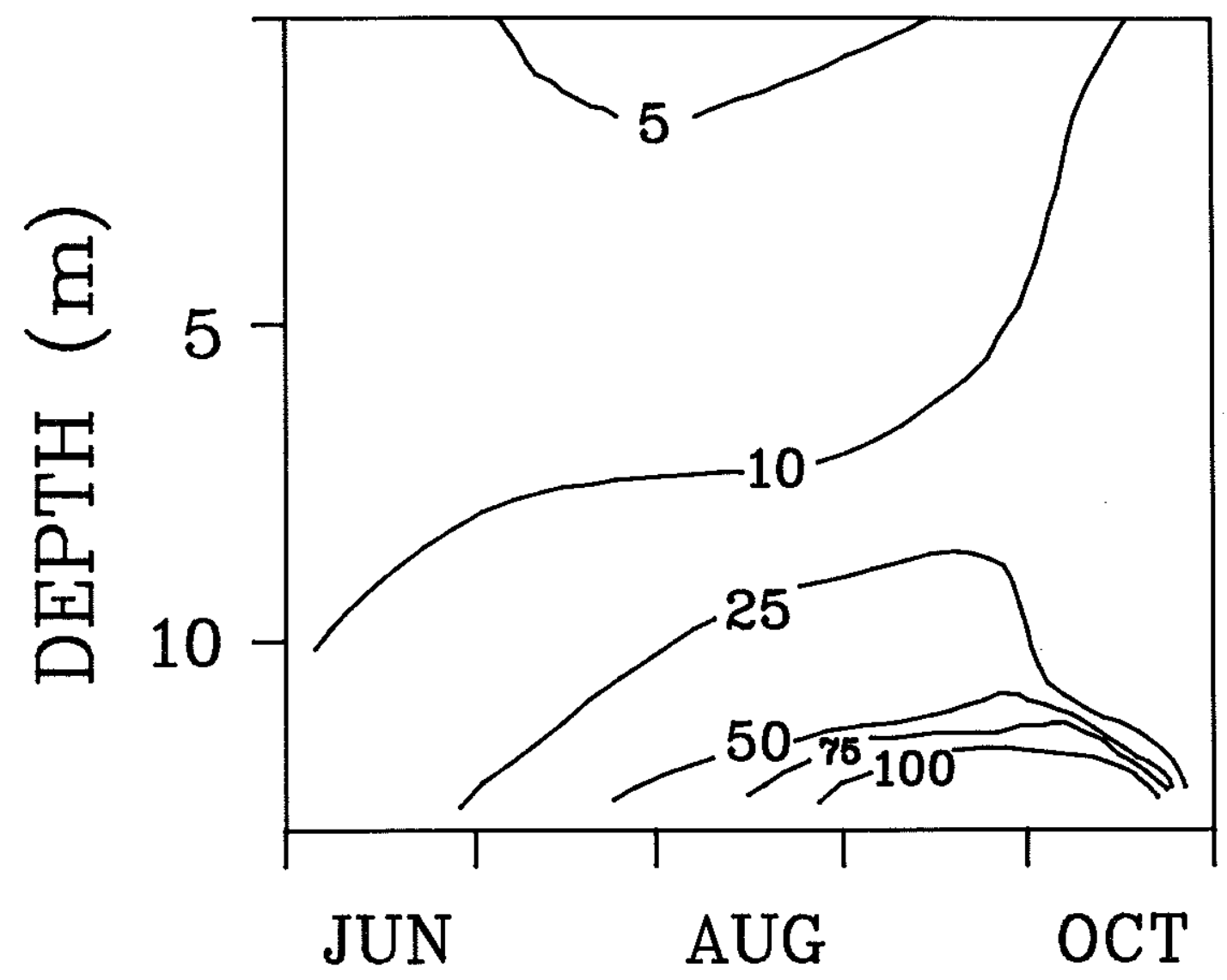


water column than did $210 \mathrm{~Pb}$. This and other aspects of $210 \mathrm{~Pb}$ remobilization are discussed in section 4.5 .3 and chapter 6 .

\subsection{THE EPILIMNETIC MODEL}

\subsubsection{MODEL DESCRIPTION}

$210 \mathrm{Po}$ and $210 \mathrm{~Pb}$ data collected on the water column, streams, and sediment traps at Bickford Reservoir were combined in an epilimnetic mass balance model to yield information on the rate of uptake and/or release of dissolved radionuclides by solids. The mass balance model is simply an accounting of all inputs, outputs, and changes in storage for the system. This information is combined using the mass conservation law to reveal uncertainties in the data or to evaluate loss or supply terms that are not easily measurable. As will be shown, the mass balances of the dissolved and particulate forms of the two radionuclides show that no important input or output terms have been overlooked, that stream fluxes are insignificant during the summer, that scavenging outputs correlate with rain inputs, that measurements of sediment settling fluxes are accurate, and that $2{ }^{20} \mathrm{~Pb}$ scavenging rates are much greater than ${ }^{210}$ Po scavenging rates.

The model used was a refinement of the one presented in BENOIT and HEMOND (1987). The improvements were that: 1) sedimentary fluxes were measured directly using sediment traps, 2) atmospheric deposition intervals were synchronized with those of water column and stream monitoring, 3) changes in the depth of the thermocline and the volume of the epilimnion were incorporated into the model, and 4) inputs into the epilimnion due to erosion of the thermocline and mixing upward of waters high in radionuclides were explicitly considered. The sediment traps provided a direct measurement of the settling particulate flux, which 
was also derived independently by the mass balance calculation.

Comparison of these two results verify the reliability of the data set and indicate whether other inputs or outputs have been overlooked.

Synchronous atmospheric deposition and lake water column measurements eliminated the need for extrapolations and increased the confidence in the results. Inclusion of the changing thermocline depth improved the accuracy of the model. Another important difference between BENOIT and HEMOND (1987) and this model is that, in the present study, data were collected intensively, but for a shorter time period (June through October). Consequently, the results should not be taken as typical of the full year, but rather reflect special conditions occurring during the summer as will be described below.

The epilimnetic mass balance for the dissolved form of radionuclides is described by the following equation:

CHANGE

IN = RAIN + INFLOW + SUPPORT + THERMOCLINE STORAGE

- SORPTION - OUTFLOW - DECAY.

The terms of this equation are defined as follows:

CHANGE IN STORAGE - the net increase or decrease in radionuclide concentration summed over the entire epilimnetic water column

RAIN

- direct deposition of radionuclide to the surface of the lake from either rain or dry deposition

INFLOW

- radionuclide delivered to the lake by the three influent streams

SUPPORT

- radionuclide supplied by radioactive decay of its parent in the water column 
THERMOCLINE

SORPTION

OUTFLOW

DECAY
- radionuclide supplied to the epilimnion by erosion of the metalimnion

- the net conversion of the dissolved radionuclide to particulate form by processes such as coagulation of colloids, precipitation, or uptake by suspended particles; it can also include direct sorption onto bottom sediments

- loss of radionuclide in the overflow from the lake

- radioactive decay of the radionuclide in the water column.

Details of the calculation of these terms is given in BENOIT and HEMOND

(1987). Rearranging we get:

SORPTION $=$ RAIN + INFLOW + SUPPORT + THERMOCLINE

CHANGE

- IN - OUTFLOW - DECAY. STORAGE

All of the terms were measured directly except sorption, which was obtained by difference.

For particulate forms the equation is:

CHANGE

IN = INFLOW + SUPPORT + THERMOCLINE + SCAVENGING

STORAGE

- SEDIMENTATION - OUTFLOW - DECAY.

The new terms in this equation are:

SCAVENGING - the conversion of dissolved radionuclide to the particulate form specifically by scavenging onto suspended particles. SCAVENGING is quantitatively different from SORPTION if direct uptake by bottom sediments is significant. 
SEDIMENTATION - loss of particulate radionuclide from the epilimnion via settling particles

The particulate mass balance equation can be rearranged to give:

SEDIMENTATION $=$ INFLOW + SUPPORT + THERMOCLINE + SCAVENGING

CHANGE

- IN - OUTFLOW + DECAY

STORAGE

For $210 \mathrm{~Pb}$, support and decay are insignificant because ${ }^{226} \mathrm{Ra}$ is not high and because the hydraulic residence time is much shorter than the $210 \mathrm{~Pb}$ half-life. For $21{ }^{\circ} \mathrm{Po}$, the radioactive input and output terms are significant, and were included in the mass balance.

The contribution of 210 Po by direct deposition was taken to be 0.04 times the precipitation input of $210 \mathrm{~Pb}$, the average value found by BENNINGER (1978). An assumed value was used because $21{ }^{\circ}$ Po from this source could not be measured directly since most of the ${ }^{210} \mathrm{Po}$ in the precipitation collectors came from ingrowth from $2{ }^{2} \mathrm{~Pb}$ in the funnel during the collection period. Since rainstorms were episodic and supplied rain with a varying initial ${ }^{210} \mathrm{Po}:{ }^{210} \mathrm{~Pb}$ ratio, correcting ${ }^{210} \mathrm{Po}$ in the collector for ingrowth would be overly complicated, especially in view of the relatively small magnitude of this input term. The value of 0.04 reflects the residence time of $210 \mathrm{~Pb}$ in the air mass from which the rain was derived; the older the air mass, the higher the factor would become. No realistic atmospheric residence time would yield a rainderived $21{ }^{\circ}$ Po contribution that would substantially alter the results of the dissolved mass balance presented in Table $4.4 .3 \mathrm{c}$

Inputs to the epilimnion from cross-thermocline mixing were low. Radionuclides levels in the hypolimnion were high, but ineffectual 
vertical eddy diffusion (section 4.5 .1 below) limited the magnitude of this flux. Later, erosion of the thermocline hastened transferal of radionuclides upwards. By October, erosion of the thermocline had penetrated down to a depth where $210 \mathrm{~Pb}$ and $210 \mathrm{Po}-\mathrm{rich}$ waters were mixed upward into the epilimnion. The contribution of this flux to the epilimnetic mass balance was evaluated and found to be small, but only because the area of the deep part of the lake is equivalent to just a few per cent of the lake's surface area. Without correcting for relative area, thermocline erosion would be the largest input to the epilimnion in early fall.

\subsubsection{ERROR ANALYSIS}

An error analysis was carried out in parallel with the mass balance model calculations. Uncertainties were measured or estimated for all the components of each term of the model, and these were then combined using standard propagation of error techniques to arrive at an overall uncertainty for the calculation. In general, the most important source of uncertainty was the statistical nature of the radioactivity measurements. An important exception was the uncertainty of the trapping efficiency of the sediment collectors. Substantial undertrapping by these devices was suspected, and the original design was compared to an improved instrument (baffle removed) in a 9 month deployment. This study served as a calibration, providing a correction factor that was applied to the sediment trap fluxes. The resulting data were judged to have an uncertainty of $\pm 30 \%$, substantially greater than the error of the radioactivity measurement on which they were based. 


\subsubsection{MODEL RESULTS}

Dissolved $210 \mathrm{~Pb}$

Results of mass balance model calculations for dissolved $210 \mathrm{~Pb}$ are presented in Table 4.4.3a. The goals of this mass balance were to calculate the rate of $210 \mathrm{~Pb}$ sorption by solids and to compare the magnitude of the various input and output terms. The lower array of numbers in this and the following three tables is composed of uncertainty values calculated as described in section 4.4.2). All units are $\mathrm{dpm} / \mathrm{cm}^{2} \mathrm{y}$. The results of the calculations are consistent with findings for the same location two years earlier (BENOIT and HEMOND [1987]). Sorption, the rate of conversion of dissolved radionuclide to particulate form, averaged $0.92 \pm .42 \mathrm{dpm} / \mathrm{cm}^{2} \mathrm{y}$ with a range from 0.32 to $1.55 \mathrm{dpm} / \mathrm{cm}^{2} \mathrm{y}$. Sorption was correlated with input by direct precipitation (regression significant at the $98 \%$ confidence level). During the summer, Bickford becomes a de facto seepage lake since evapotranspiration reduces stream inflow and outflow to negligible levels. As a result, the only important terms in the mass balance during this time are atmospheric input, sorption, and change in storage. That concentration remains fairly constant, and that sorption correlates with input suggests that removal may be first order in ${ }^{210} \mathrm{~Pb}$ concentration (HESSLEIN et a1. [1980], TODD [1984]). Particulate $210 \mathrm{pb}$

Table $4.4 .3 \mathrm{~b}$ gives mass balance model calculations for particulate ${ }^{210} \mathrm{~Pb}$. The chief object of this calculation was to compare calculated sediment trap fluxes to measured values, both as a verification of the sediment trap data and to test mass balance closure. In this budget, the interval from 19 September to 9 October produced a non-significant 
TABLE $4.4 .3 \mathrm{a}$ MASS BALANCE OF DISSOLVED $210 \mathrm{~Pb}$ IN THE EPILIMNION ${ }^{1}$

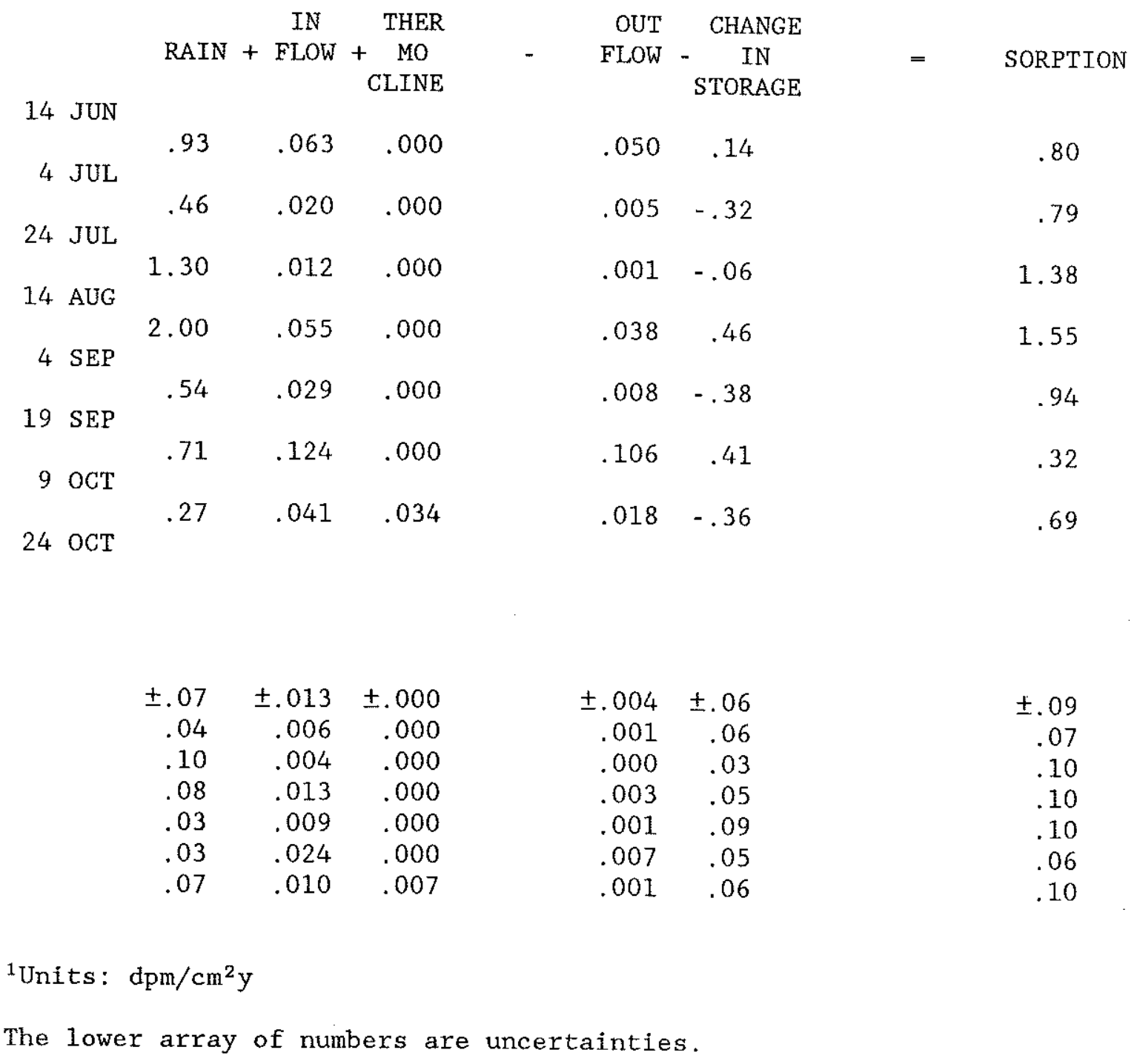


TABLE $4.4 .3 \mathrm{~b}$ MASS BALANCE OF PARTICULATE $210 \mathrm{~Pb}$ IN THE EPILIMNION ${ }^{1}$

\begin{tabular}{|c|c|c|c|c|c|c|c|c|c|}
\hline & \multirow{4}{*}{$\begin{array}{c}\text { IN } \\
\text { FLOW }+\end{array}$} & \multirow{4}{*}{$\begin{array}{c}\text { SCAV } \\
+\quad \text { EN } \\
\text { GING }\end{array}$} & \multirow{4}{*}{$\begin{array}{c}\text { THER } \\
+\quad \text { MO } \\
\text { CLINE }\end{array}$} & \multirow{4}{*}{$\begin{array}{c}\text { CHNG } \\
-\quad \text { IN } \\
\text { STOR }\end{array}$} & \multirow[b]{2}{*}{ OUT } & \multicolumn{4}{|c|}{ SEDIMENTATION } \\
\hline & & & & & & & & & \\
\hline & & & & & - FLOW & $=$ & CALC & $-\mathrm{MEAS}^{2}$ & $=\mathrm{DIFF}$ \\
\hline & & & & & \multicolumn{5}{|c|}{14 JUN } \\
\hline \multirow{2}{*}{$4 \mathrm{JUL}$} & .03 & .80 & .000 & .28 & .097 & & .45 & .59 & $-.13^{3}$ \\
\hline & 008 & 79 & 000 & -.54 & 012 & & 133 & 61 & 72 \\
\hline \multicolumn{10}{|l|}{$24 \mathrm{JUL}$} \\
\hline \multirow{3}{*}{14 AUG } & .004 & 1.38 & .000 & .23 & .006 & & 1.15 & .98 & $.17^{3}$ \\
\hline & & & & & & & & & \\
\hline & .02 & 1.55 & .000 & .34 & .067 & & 1.17 & 1.24 &.$- \theta 7^{3}$ \\
\hline \multicolumn{10}{|l|}{$4 \mathrm{SEP}$} \\
\hline \multirow{3}{*}{$19 \mathrm{SEP}$} & .012 & .94 & .000 & -.70 & .014 & & 1.64 & .76 & .88 \\
\hline & & & & & & & & & \\
\hline & .06 & .32 & .000 & .20 & .119 & & $(1.07)^{4}$ & .76 & $.31^{3}$ \\
\hline 9 OCT & .018 & .69 & .017 & -.04 & .028 & & .74 & .95 & $-.21^{3}$ \\
\hline$+\mathrm{OCT}$ & & & & & & & & & \\
\hline
\end{tabular}

$\begin{array}{lrrrrrrr} \pm .03 & \pm .09 & \pm .000 & \pm .10 & \pm .007 & \pm .14 & \pm .16 & \pm .21 \\ .007 & .07 & .000 & .10 & .001 & .13 & .16 & .21 \\ .003 & .10 & .000 & .06 & .000 & .12 & .26 & .29 \\ .02 & .10 & .000 & .10 & .004 & .14 & .33 & .36 \\ .009 & .09 & .000 & .16 & .001 & .18 & .20 & .27 \\ .06 & .06 & .000 & .09 & .009 & .43 & .20 & .48 \\ .015 & .10 & .003 & .10 & .002 & .14 & .26 & .29\end{array}$

${ }^{1}$ Units : $\mathrm{dpm} / \mathrm{cm}^{2} \mathrm{y}$

${ }^{2}$ Measured sediment trap flux for comparison with calculated value in previous column.

${ }^{3}$ Differences that are struck through are not statistically significant.

${ }^{4}$ The calculated result was not statistically significant. The number in parentheses is the average of the remaining six calculated values. 
calculated sediment trap flux, so the average of the significant values was used in its place for comparison purposes. The average of calculated particle fluxes was $1.08 \pm 0.42 \mathrm{dpm} / \mathrm{cm}^{2} \mathrm{y}$ with a range from 0.45 to $1.64 \mathrm{dpm} / \mathrm{cm}^{2} \mathrm{y}$. This average is not significantly different from the average measured sediment trap flux of $0.84 \pm 0.23 \mathrm{dpm} / \mathrm{cm}^{2} \mathrm{y}$ or the average scavenging rate described above.

The agreement of the calculated sedimentation with the average sediment trap data indicates the reliability of the latter measurements. Looking at specific time intervals, two of them produced calculated sediment settling fluxes that were significantly different from measured values ( $4-24$ July and 4 - 19 September). These intervals also had the largest change in storage terms, and these values (unlike any of the other five) were based on differences between only two water column measurements in each case. They thus may be somewhat less certain than is suggested by their calculated uncertainties. It is also possible, since the measured trap fluxes are lower than the calculated values, that there was some undercollection during these two intervals. Scavenging by SPM vs. Direct Uptake by the Bottom

The equality between scavenging and settling fluxes (second and seventh columns in Table 4.4.3b) means that, on average, all scavenged $210 \mathrm{~Pb}$ leaves the lake by means of particle settling. That in turn means that direct scavenging onto sediments plays only a small role in the epilimnion of Bickford Reservoir during the summer and presumably throughout the rest of the year. This conclusion agrees with the findings of TALBOT and ANDREN (1984) who saw no indication of ${ }^{210} \mathrm{~Pb}$ boundary scavenging in their data for Crystal Lake, WI. A lack of an important role for sediment scavenging as a removal mechanism for the 
metal lead contradicts HESSLEIN et al. (1980), who found that a large portion of the metals $\mathrm{Zn}, \mathrm{Hg}, \mathrm{Fe}$, and Co that were added to one of the ELA lakes were taken up directly by sediments. That conclusion was based on the fact that the rate of metal accumulation in sediment cores exceeded the measured sediment trap flux. The difference was judged to be material that bypassed the sediment settling step. Judging from the particle reactivity of lead, it would be expected to behave similarly to some of these other metals, notably $\mathrm{Hg}$ and Co. Why this discrepancy?

One possibility is that their sediment traps undercollected settling particles. The design involved a plastic bag anchored to the bottom but connected to a surface float by a line used to close the trap and retrieve it. Three potential design flaws exist. First, the plastic bag they used had an aspect ratio of only $2.3: 1$. Such a trap is likely to undercollect according to HARGRAVE and BURNS (1979), who found that quantitative trapping cannot be achieved with an aspect ratio less than 5. A second problem is that the line connecting the trap to the surface marker might cause the trap to pendulate, shaking trapped material free. Thirdly, the line, under the force of a strong wind on the float, might cause the trap to close prematurely. The high variability of their sediment trap results is consistent with the possibility of incomplete and variable collection efficiency of these devices.

If instead, the sediment trap data of Hesslein and coworkers are correct, there are a number of factors that could account for the differences between measurements at their study site and at Bickford. Following is a discussion of considerations that might affect the relative tendency for removal by direct sorption onto sediments and 
scavenging by SPM. Assuming perfect mixing and microscopic similarity of particles and sediments, the relative rate of uptake of $210 \mathrm{~Pb}$ by the two kinds of solids should be controlled by their relative surface areas. The area on particles suspended in a $1 \mathrm{~cm}^{2}$ water column can be calculated by making certain assumptions: 1) particles are approximately spherical, 2) average particle diameters range from 0.5 to $5 \mu, 3$ ) the concentration of particles is $1 \mathrm{mg} / 1$ iter, 4) the density of the particles ranges from 1.1 to $2.0 \mathrm{~g} / \mathrm{cm}^{2}$, and 5) the average depth of the water column is $12 \mathrm{~m}$. Based on these assumptions one can calculate a range in SPM surface area of from 7 to $130 \mathrm{~cm}^{2}$, or roughly from one to two orders of magnitude higher than that of the lake bottom at the base of the water column. The disparity can be reduced slightly if some of the assumptions are altered, but the room for improvement is small. For example, sediments are not a perfectly flat surface, but neither are particles smooth spheres. If particles had a much greater density, they would have a smaller surface area for the same mass, but they would also sink rapidly and not contribute to the standing stock. The size range used in the calculation is predicted by theory and observed in nature. Particles smaller than this quickly aggregate under the influence of Brownian diffusion, while larger particles aggregate and sink due to the combined effects of shear and differential settling (LAXEN and CHANDLER [1983]). Finally, SPM levels are unlikely to be much less than 1 $\mathrm{mg} / \mathrm{cm}^{2}$, since that was a typical value for Bickford, which is both oligotrophic and receives little or no allochthonous material during the summer.

In addition, both large and small scale hydrodynamic processes work against removal by sediments in the absence of irrigation by infauna. 
The lake is not perfectly mixed, and a stagnant film isolates the sediments from the water column. This film is a thin layer across which metal transport is limited by diffusion. Assuming a perfectly "sticky" surface (one for which every metal-surface collision is irreversible) and a diffusion coefficient of $7 \times 10^{-6} \mathrm{~cm}^{2} / \mathrm{s}$, the maximum rate of metal uptake by the sediments is controlled by the system geometry: the thickness of the diffusive boundary layer and the height of the water column. For Lake 224 the stagnant film thickness is about $0.1 \mathrm{~cm}$ (SANTSCHI et al. [1983a]) and the average water depth $12 \mathrm{~m}$. One can then calculate the half removal time in such a system, assuming an initial water column concentration of $\mathrm{A} / \mathrm{cm}^{3}$ :

$$
\begin{aligned}
& \text { Inventory }=\mathrm{A} / \mathrm{cm}^{3} \times 1200 \mathrm{~cm}^{3} / \mathrm{cm}^{2}=1200 \mathrm{~A} / \mathrm{cm}^{2} \\
& \text { Removal flux }=\mathrm{D} \times \mathrm{dC} / \mathrm{dz}=7 \times 10^{-6} \mathrm{~cm}^{2} / \mathrm{s} \times\left(\left(\mathrm{A} / \mathrm{cm}^{3}-0\right) / 0.1 \mathrm{~cm}\right) \\
& =7 \times 10^{-5} \times \mathrm{A} / \mathrm{cm}^{2} \mathrm{~s} \\
& \text { Residence time }=\text { Inventory/Removal flux }=1.7 \times 10^{7} \mathrm{~s}=200 \mathrm{~d} \text {, }
\end{aligned}
$$

or a half removal time of $140 \mathrm{~d}$.

Uptake by SPM would be faster than by sediments both in proportion to its greater surface area, and to the greater ease with which dissolved metals can approach the particle surface. Considering the factors that work against direct uptake by sediments, it is not surprising that scavenging by SPM seems to account for all removal of dissolved $210 \mathrm{~Pb}$ in Bickford. Nevertheless, there are several factors that may account for the apparent direct uptake of metal radiotracers by sediments in Lake 224. Two relate to experimental design. First, the metals were added as chlorides. These yield free dissolved ions, which 
are likely to be more reactive than and behave differently from the naturally occurring forms of metals, which might include organically or colloidally bound forms. Second, a spiking experiment is more sensitive to new additions of a substance to an environmental compartment than is a study that monitors nearly steady-state fluxes and distributions of a natural tracer, like ${ }^{210} \mathrm{~Pb}$. My error analysis indicates that, due to the uncertainty of the data, from 10 to $20 \%$ of the loss from the water column at Bickford could take place by some mechanism other than particle scavenging without being detected. Since there is already a large inventory of $210 \mathrm{~Pb}$ in sediments, addition of a small fraction more would not be a statistically significant change. On the other hand, since a radiotracer spike is an entirely new isotope, the addition of even a few percent to sediments is easily measured. Another factor that may be at work in Lake 224 is bio-irrigation, which would bypass the diffusive boundary layer and greatly increase water-sediment contact. Fina1ly, in Lake 224, bottom sediments may be "stickier" than SPM due to the effect of transition metal redox cycling near the sediment water interface.

To summarize this discussion, two major pathways for the removal of dissolved metals from lakes (excluding outflow) are direct uptake by sediments and scavenging by SPM. In Bickford Reservoir, more than $80 \%$ of ${ }^{210} \mathrm{~Pb}$ is removed by the latter mechanism. Geometry and hydrodynamics tend to discourage direct uptake by the bottom, and the following characteristics can increase the imbalance: high levels of SPM, great average depth, and low mixing rate and turbulence. Two factors that could result in increased levels of uptake by the bottom are 
bioirrigation and transition metal redox cycling near the sediment water interface.

Dissolved $21{ }^{\circ} \mathrm{Po}$

Mass balance calculations for dissolved 210 Po in the epilimnion are presented in Table $4.4 .3 \mathrm{c}$. The objects of this calculation were to compare the relative magnitude of the various input and output terms, to determine the rate of ${ }^{210}$ Po uptake by solids, and to compare this rate to that for ${ }^{210} \mathrm{~Pb}$. The behavior of ${ }^{210}$ Po differs from that of ${ }^{210} \mathrm{~Pb}$ both because of its different means of introduction to the lake, and its different chemical behavior once in the lake. During the summer, streamflow is meager and, except after infrequent storms, it is limited to baseflow levels having small absolute changes in magnitude. Since ${ }^{210} \mathrm{Po}$ is negligible in rain, streamflow combined with support by $210 \mathrm{~Pb}$, another steady source, provide 768 of all inputs. The result is a relatively constant rate of removal from the water column. Only four of the calculated scavenging rates were significant at the $95 \%$ confidence level, but these four showed little variation (average $=.210 \pm .012$ $\mathrm{dpm} / \mathrm{cm}^{2} \mathrm{y}$, a 68 standard deviation). The high frequency of nonsignificant results probably stems from the combination of many nearly equal terms; the difference of inputs and outputs tend to cancel while the uncertainties always add. The average dissolved $2{ }^{\circ}$ Po scavenging rate was 238 of $210 \mathrm{~Pb}$ scavenging despite their nearly equal water column concentrations $\left({ }^{210} \mathrm{Po}:{ }^{210} \mathrm{~Pb}=0.96 \pm 0.43\right)$. This difference reflects fundamentally different cycling of the two elements, with Po either having a lower tendency to be scavenged or a greater tendency to be regenerated. TALBOT and ANDREN (1984) concluded that the lower scavenging flux for $210 \mathrm{Po}$ compared to ${ }^{210} \mathrm{~Pb}$ in Crystal Lake, WI, 
TABLE $4.4 .3 \mathrm{C}$ MASS BALANCE OF DISSOLVED 210 PO IN THE EPILIMNION ${ }^{1}$

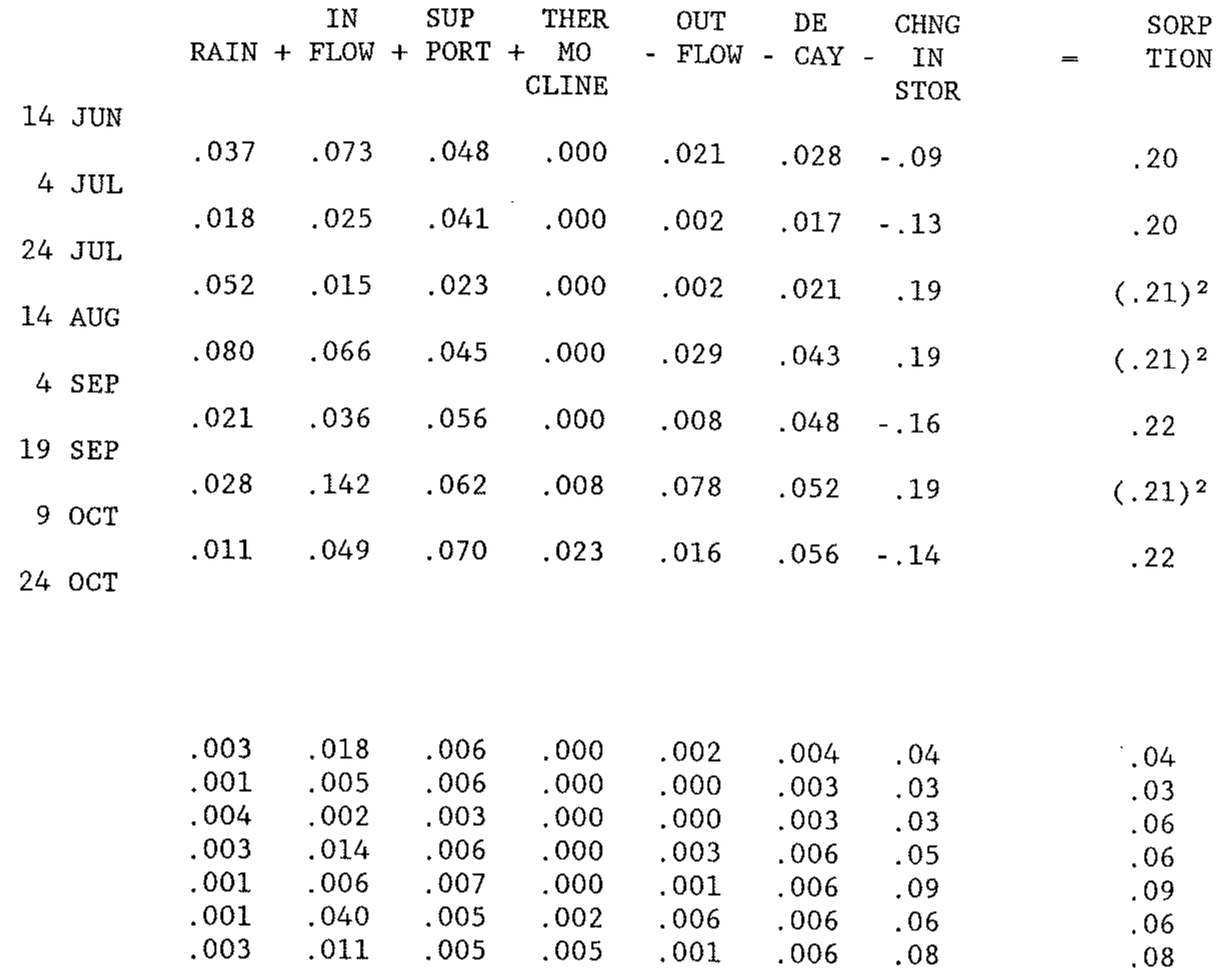

\footnotetext{
${ }^{1}$ Units: dpm $/ \mathrm{cm}^{2} \mathrm{y}$

${ }^{2} \mathrm{Calculated}$ result was not statistically significant. Number in parentheses is the average of the four significant values.
} 
reflected a greater degree of recycling. Perhaps they based this judgment, in part, on previous studies of $\mathrm{Po}$ and $\mathrm{Pb}$ geochemistry in the marine environment, where $2{ }^{2} \mathrm{Po}$ has a lower residence time in surface water than does $210 \mathrm{~Pb}$, but is regenerated at mid-depths, producing excesses relative to ${ }^{210} \mathrm{~Pb}$ in the thermocline (BACON et al. [1976]). The simplest interpretation of both our data and that of Talbot and Andren is that $210 \mathrm{~Pb}$ is simply more rapidly scavenged than is ${ }^{210} \mathrm{Po}$, without any water column recycling of $21{ }^{\circ} \mathrm{Po}$ in lakes (release from bottom sediments being excluded). Scavenging of $2{ }^{10} \mathrm{~Pb}$ averaged 2.7 times greater than that of ${ }^{210}$ Po in Crystal Lake and 4.4 times greater in Bickford. The ratio of $210 \mathrm{~Pb}$ to ${ }^{210} \mathrm{Po}$ in settling sediments was 3.2:1 in Bickford and 2.4:1 in Crystal Lake (TALBOT [1981]). There were no consistent occurrences of excess ${ }^{210}$ Po in either lake except resulting from releases from the bottom (section 4.3.8). Based on this evidence, shallow lakes seem to differ from the ocean in that ${ }^{210} \mathrm{~Pb}$ is preferentially scavenged compared to $21{ }^{\circ}$ Po by particulate matter in surface waters, and may not be regenerated in the water column, but only in sediments.

Particulate $210 \mathrm{Po}$

Results of mass balance model calculations for particulate ${ }^{210}$ Po are presented in Table 4.4.3d. The object of these calculations was to verify the sediment trap measurements and to check for unaccounted for input or output terms. Two of the calculated sediment settling fluxes were not significant at the 958 confidence level. Substituting the average of the remaining significant values in their places and comparing to the measured sediment trap fluxes reveals only one time interval for which the difference between the measured and calculated 
TABLE $4.4 .3 \mathrm{~d}$ MASS BALANGE OF PARTICULATE 210 PO IN THE EPILIMNION ${ }^{1}$

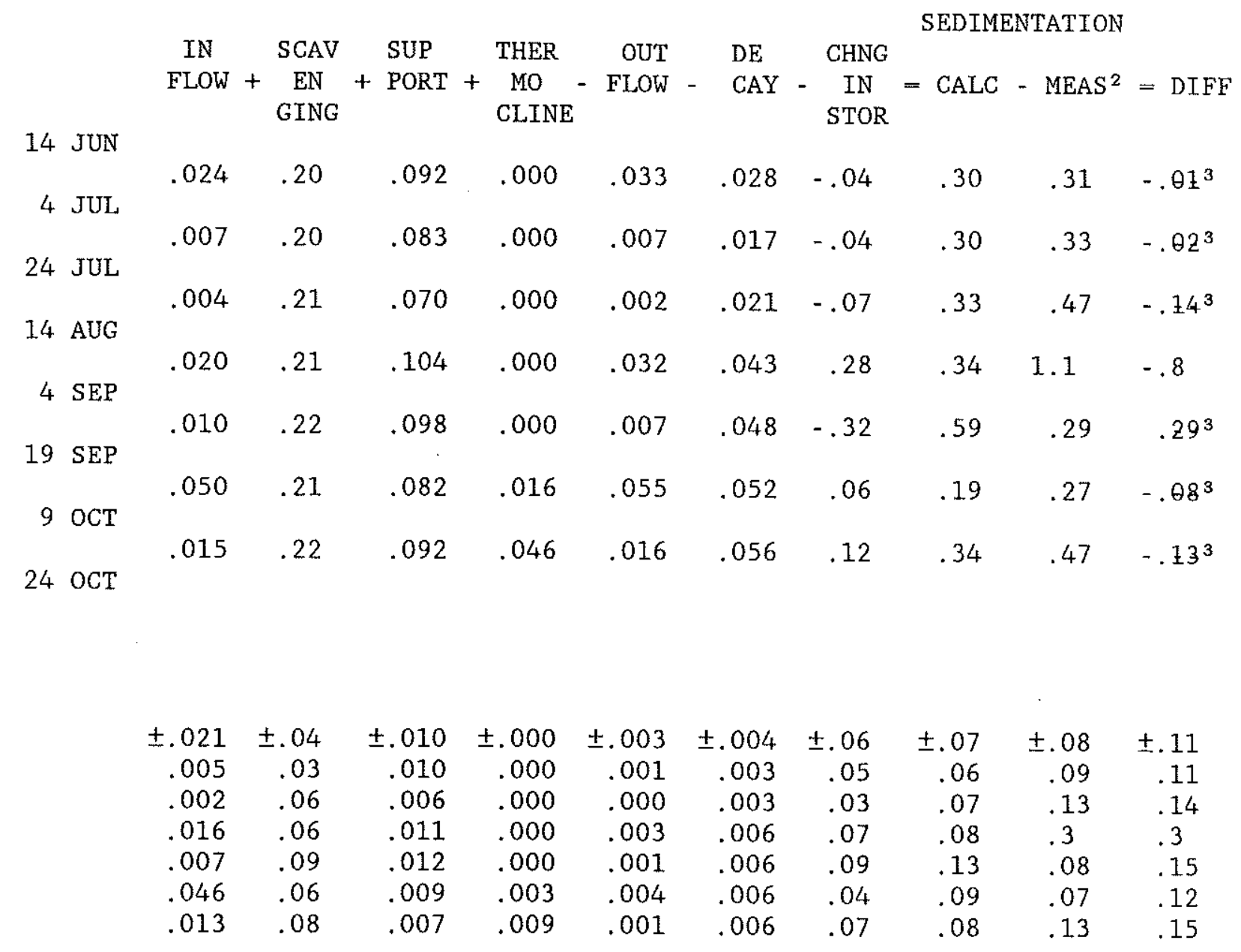

\footnotetext{
IUnits: $\mathrm{dpm} / \mathrm{cm}^{2} \mathrm{y}$

${ }^{2}$ Measured sediment trap flux for comparison with calculated value in previous column.

${ }^{3}$ Differences that are struck through are not statistically significant.
} 
values of the sediment trap flux is significant. On this date the measured sediment trap flux was different from the average of the other intervals by 9 times the standard deviation. On this basis, that measurement was excluded as an outlier. The agreement of the rest of the data (calculated $=.34 \pm .15$, measured $=.36 \pm .09$ ) is further verification of the reliability of the mass balance model and the sediment trap flux measurements. The average of the ${ }^{210}$ Po scavenging flux is not significantly different from the particle settling flux, indicating that other pathways for the loss of particulate ${ }^{210} \mathrm{Po}$ are relatively unimportant. This expectation is confirmed, as outflow accounts for only 58 and decay only 98 of total losses. This is in sharp contrast to conditions during the cooler months, when outflow was equal to settling as a sink (BENOIT and HEMOND [1987]). In addition, the successful closure of the mass balance calculation indicates that there are no significant ${ }^{210}$ Po inputs or outputs that have been ignored by the model.

\subsection{THE HYPOLIMNION}

\subsubsection{EDDY DIFFUSION}

The mass balance model presented above for cycling of $21^{\circ} \mathrm{Pb}$ and $21{ }^{\circ}$ Po rests on the assumption of rapid mixing. The epilimnion is viewed as a homogeneous reactor (a "black box") where input and output fluxes act uniformly at all points in space; it is a zero-dimensional model. Such a simple paradigm may not be physically accurate, but it is justified insofar as radionuclide concentrations were virtually invariant as a function of vertical and horizontal position in the mixed layer (Figure 4.3.7a, Figure 4.3.8a, and BENOIT [1985]). By contrast, the hypolimnion is not well mixed and vertical concentration gradients 
are evident. Here a one-dimensional (at least) model is required, and in order to explain radionuclide distributions, transport rates must be explicitly considered. In the hypolimnion of lakes, transport seems to be controlled by large scale Fickian transport, termed eddy diffusion.

In order to understand the geochemical cycling of radionuclides as reflected by their fluxes and patterns of distribution within the hypolimnion, it is first necessary to know the magnitude of eddy diffusion as a function of depth and time.

Calculation of the Eddy Diffusion Coefficient

Eddy diffusion is characterized by the eddy diffusion coefficient, $\mathrm{K}_{z}$, which is analogous to the molecular diffusion coefficient and can be used in Fick's laws in the same way. The eddy diffusivity can be calculated from changes in the temporal and spatial distribution of a conservative tracer, such as heat, by the flux gradient method (Jassby and Powel1 [1975]). Since the flux of heat is proportional to the temperature gradient and eddy diffusivity, eddy diffusion can be calculated by dividing the increase in heat below a given surface by the temperature gradient at that surface. The equation to be used is:

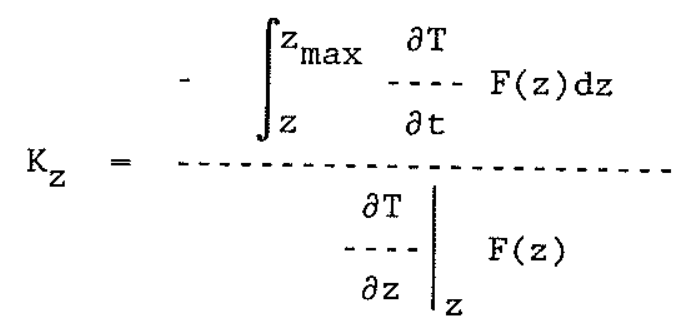

Where:

$$
\begin{aligned}
& T=\text { temperature } \\
& t=\text { time } \\
& z=\text { depth }
\end{aligned}
$$




$$
F(z)=\text { lake area at depth } z
$$

Temperature profiles were measured at Bickford once every 10 to 15 days during the study period. The stratified water column was divided into 1.0 or $0.5 \mathrm{~m}$ thick slices and a polynomial describing $\mathrm{T}(\mathrm{t})$ determined for each stratum using a least squares method (Figure 4.5.1a). Differentiation of these equations yielded the $\partial \mathrm{T} / \partial \mathrm{t}$ terms. Likewise the lower part of each temperature profile was fitted with a polynomial describing $\mathrm{T}(\mathrm{z})$ in order to evaluate $\partial \mathrm{T} / \partial \mathrm{z}$. Lake area as a function of depth was determined from a bathymetric map prepared ealier using a recording depth meter.

This simple formulation assumes that eddy diffusional transport is the only way that the heat content of the stratified portion of the water column can change. In fact, at least two other process can have a significant impact: cooling by sediments and radiant heating by sunlight. These terms enter the equation as corrections to the heat integral term in the numerator. Preliminary calculations showed that for Bickford these additional terms were large and could not be ignored. Correction for Radiant Heating

Radiant heating was determined at each depth for each of the ten intervals using calculations of the magnitude and angle of incidence of solar radiation, information on per cent cloud cover, and field measurements of the optical transmission of Bickford lake water. In practice, this was accomplished by writing a FORTRAN program, RADHEAT. To allow for rapid seasonal changes, each day within a given interval was calculated separately. Also, since the changing solar altitude throughout the day causes large changes in the optical path in the lake 
FIGURE 4.5.1a TEMPERATURES AT FIXED DEPTHS IN THE WATER COLUMN AS A FUNCTION OF TIME

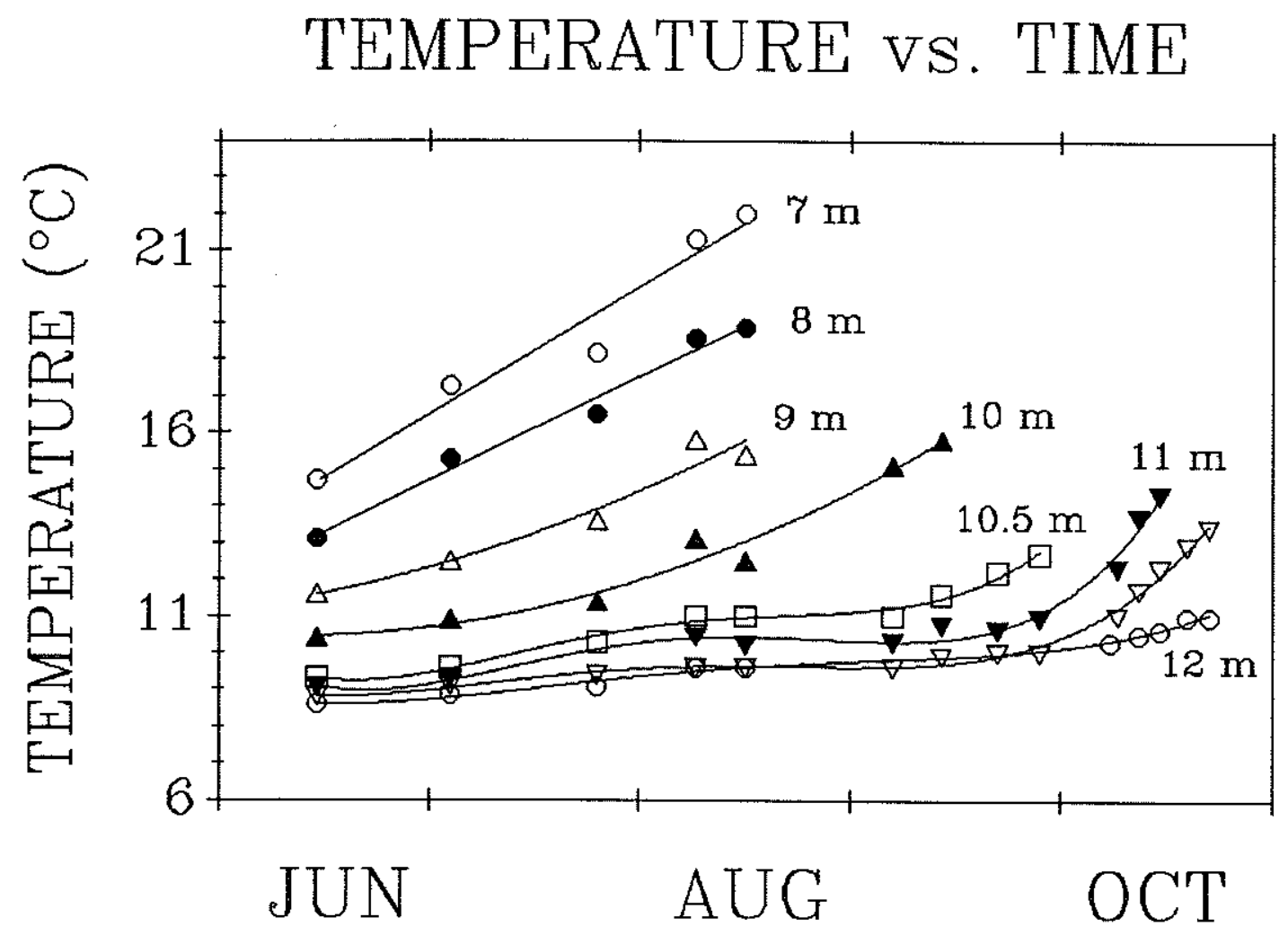


(and attendant absorption), each day was broken into half hour intervals (typically 25 or 30 per day). For a given half hour interval, direct and diffuse solar radiation terms were calculated from the widely used model of the American Society of Heating, Refrigeration, and Airconditioning Engineers (FARBER and MORRISON [1977], hereafter referred to as "ASHRAE"). The improved parameters recommended by IQBAL (1983) were used, and the clearness number (CN) was taken to be equal to the value at Blue Hill, MA, given in THRELKELD and JORDAN (1958). Direct solar radiation was corrected by a factor of cos(zenith angle) to correct for oblique incidence on the horizontal lake surface. An additional correction factor was applied to eliminate all infrared and ultraviolet radiation (538 of total, IQBAL [1983]), which is absorbed in the top meter of the water column. A path length correction factor was derived from the mid-interval zenith angle and the law of sines (refraction) with an average value of 1.33 for the refractive index of visible light in water. The result was introduced into Bouguer's law, using extinction coefficients described in section 4.3 .3 , to derive the radiant energy as a function of depth in the lake. To complete the calculation, all the half hour intervals were summed to give a total for the day, and all the days were combined to give an average for each period.

Diffuse radiation was treated somewhat differently from direct radiation. A constant path length correction of 1.19 was used (HUTCHINSON [1975]). On sunny days, diffuse radiation amounts to about $10 \%$ of direct radiation, and was calculated exactly by the ASHRAE model. For partly sunny conditions the following correction was made; it was assumed that the sun was obscured for a fraction of time equal to the 
per cent sky cover and that the radiation received when the sun was behind clouds was one third of the clear sky value:

$$
R_{t}=R_{b}+R_{c}=(1-f) \times \text { ASHRAE }+.333 \times f \times \text { ASHRAE } .
$$

Where:

$$
\begin{array}{ll}
\mathrm{R}_{t} & =\text { Total radiation on a given day } \\
\mathrm{R}_{\mathrm{b}} & =\text { Bright sun radiation for the day } \\
\mathrm{R}_{\mathrm{c}} & =\text { Cloudy radiation for the day } \\
\mathrm{f} & =\text { Fraction of sky obscured by clouds } \\
\text { ASHRAE } & =\text { The ASHRAE calculated global solar radiation value }
\end{array}
$$

Values of $f$ were taken from the Local Climatological Data Summary for Worcester, MA (National Climatic Data Center, Asheville, NC) and a path length correction of 1.19 was applied to the cloudy radiation. As a test of the assumptions, the calculation was carried out for a one year period using data for Montreal contained in IQBAL (1983) and was found to be within 48 of the measured value on average. This is a much better approximation than the formula of BLACK (1956), which has the added disadvantage that it cannot be used when sky cover exceeds $80 \%$. It is interesting to note that in the winter, when the sun is low in the sky, cloudy days may deliver a greater amount of solar energy to the depth of lakes than do sunny ones. Although light intensity is reduced by a factor of three on cloudy days, it arrives less obliquely, resulting in smaller cosine and path length correction terms. At the winter solstice, the minimum zenith angle at Bickford is $71^{\circ}$, corresponding to a path length factor of 1.42 and cosine correction of 0.33 . At $10 \mathrm{~m}$ in 
Bickford, a cloudy day would deliver 2.5 times as much energy at noon as would a sunny day, and the difference would be even greater away from the noon hour.

Considering the high precision with which solar parameters can be calculated, and the reliability of the ASHRAE model (especially for the period from April to September), the insolation calculations are probably accurate to much better than $\pm 10 \%$. Additional error may be introduced due to variation of the water column extinction coefficient, $\eta$, over time. In the mixed part of the water column $\eta$ seems to be quite constant; it varied by less than 18 in three series of measurements spanning a 15 day period in September. Its value may have changed by a greater amount in the 82 days before the first measurement and the 30 days after the last measurement. Still, the time of greatest interest for eddy diffusive transport is the period of anoxia from mid-August to mid-October, and it seems unlikely that $\eta$ would be completely invariant when measured in September, but highly variable in the two or three weeks before and after. Overall, the calculated radiant heat term was judged to have an uncertainty of \pm 10 o where suspended particulate matter was less than $1 \mathrm{mg} /$ liter.

A greater problem arises in the stratified portion of the water column where particles cause an increase in the value of $\eta$ (Figure 4.3.3a and $\mathrm{b})$. The three measurements in September showed a standard deviation in $\eta_{\mathrm{p}}$ (the extinction attributable to particles) of 308 . Some of this variation is real, but some of it probably comes from difficulty in estimating the value based on only 3 or 4 data points. Also, the distance over which particles contribute significantly to light attenuation is short, never more than $2.5 \mathrm{~m}$. Finally, $\eta_{\mathrm{p}}$ is only about 
one third of total attenuation. Based on these considerations, radiant heating, even in the high SPM zone, is probably certain to better than $\pm 20 \%$.

The output from RADHEAT is a tabulation of average daily values of radiant heating at depths of $7,8,9,10,11,11.5,12$, and $12.5 \mathrm{~m}$ in the water column for each of the ten time periods between 14 June and 19 October 1985. The range in values is from 0.2 to $9.2 \mathrm{cal} / \mathrm{cm}^{2} \mathrm{~d}$. As would be expected, heating decreased rapidly with depth on a given date and gradually with time at a fixed depth. As will be shown below, radiant heating was always smaller than heat transported by turbulence, though sometimes by a small margin. Correction for Water Column Cooling by Sediments

The heat budget of the hypolimnion is influenced by thermal exchange with the sediments as well as by radiant heating and eddy diffusion. Over the course of the year, the temperature of bottom water varies between warm and cool values roughly sinusoidally, and the temperature of surficial sediments tracks that of the bottom water fairly closely. In the winter the water rapidly cools the sediments and in the summer it rapidly warms them. Propagation of this temperature cycle downward deeper into the sediments is damped by their limited thermal conductivity, so that at a depth of a few meters the sediments are practically isothermal throughout the year. Nevertheless, for lakes whose zone of stratified water is thin, heating sediments can be a significant thermal sink during the summer.

No measurements of heat exchange with the sediments were made, but rough calculations indicated that the value was too high to be ignored 
in the determination of the eddy diffusion coefficient. One method of estimation is to calculate the heating as (Nyffeler [1983]):

$$
J=\mathrm{C} \times \mathrm{F} \times \frac{\partial \mathrm{T}}{\partial \mathrm{z}_{\max }}
$$

Where:

$$
\begin{aligned}
& \mathrm{J} \quad=\text { heat flux } \\
& \mathrm{C} \quad=\text { thermal conductivity of sediments } \\
& \mathrm{F} \quad=\text { area of sediments } \\
& \mathrm{T} \quad=\text { temperature } \\
& \mathrm{z}_{\max } \quad=\text { maximum depth in the water column }
\end{aligned}
$$

This method has the disadvantages that it assumes, probably inaccurately, that the temperature gradient in the upper sediments is identical to that in the adjacent water. It also depends critically on precise knowledge of that gradient, which may depart from values extrapolated on the basis of temperatures measured at a distance from and unaffected by the hydrodynamically unique domain near the sediment water interface.

Instead I decided to make a numerical model of sediment heating (MUDHEAT). The governing partial differential equation is:

$$
\begin{array}{ccc}
\partial \mathrm{T} & \mathrm{C} & \partial^{2} \mathrm{~T} \\
-\cdots & \cdots \times \mathrm{k} & \partial \mathrm{z}^{2}
\end{array}
$$

Where:

$$
\begin{aligned}
& \mathrm{T}=\text { temperature } \\
& \mathrm{t}=\text { time } \\
& \mathrm{C}=\text { thermal conductivity }\left(\mathrm{cal} / \mathrm{cm} \times \mathrm{s} \times{ }^{\circ} \mathrm{C}\right)
\end{aligned}
$$




$$
\begin{aligned}
& \rho=\text { density }\left(\mathrm{g} / \mathrm{cm}^{3}\right) \\
& \mathrm{k}=\text { heat capacity }\left(\mathrm{cal} / \mathrm{g} \times{ }^{\circ} \mathrm{C}\right) \\
& \mathrm{z}=\text { depth }
\end{aligned}
$$

The depth and time intervals used were $1 \mathrm{~cm}$ and $.001 \mathrm{~d}$. The short time interval was necessary to prevent instability in the model. Assumptions used were: 1) that thermal conduction is the only method of heat transport, 2) that the sediment profile was isothermal at the average annual temperature of overlying water on the date that the overlying water was at that temperature, 3) that the temperature of sediments at the sediment-water interface is equal to that of the overlying water column (Figure 4.5.1b), and 4) that the thermal conductivity could be calculated as a linear combination of the values for water and rock in the proportions that they occur at depth in sediment profiles (568 water, 448 detritus).

An evaluation of the reasonableness of these assumptions follows. 1) The only means to transport heat through the sediments other than conduction is by advection of pore waters. Measurements in the summer of 1985 showed that seepage velocities averaged $0.06 \mathrm{~cm} / \mathrm{s}$ (range 0.03 $0.10)$. Approximating the depth of diffusional transport as $(2 \mathrm{D} \times t)^{1 / 2}$, we can estimate that conduction transports heat to a depth of $4 \mathrm{~m}$ fifteen times faster than does advection in these sediments. For a $1 \mathrm{~m}$ depth it is sixty times faster. 2) Measured temperature profiles of the sediments of Lake Mendota (BIRGE et al. [1927]) show that sediments do pass through a point when they are approximately isothermal at the average annual water temperature, and that this occurs on about the same 
FIGURE 4.5.1 $1 \mathrm{~b}$ LONG-TERM VARIATION IN THE TEMPERATURE OF THE WATER COLUMN AT $12 \mathrm{~m}$

\section{HYPOLIMNETIC TEMPERATURE}

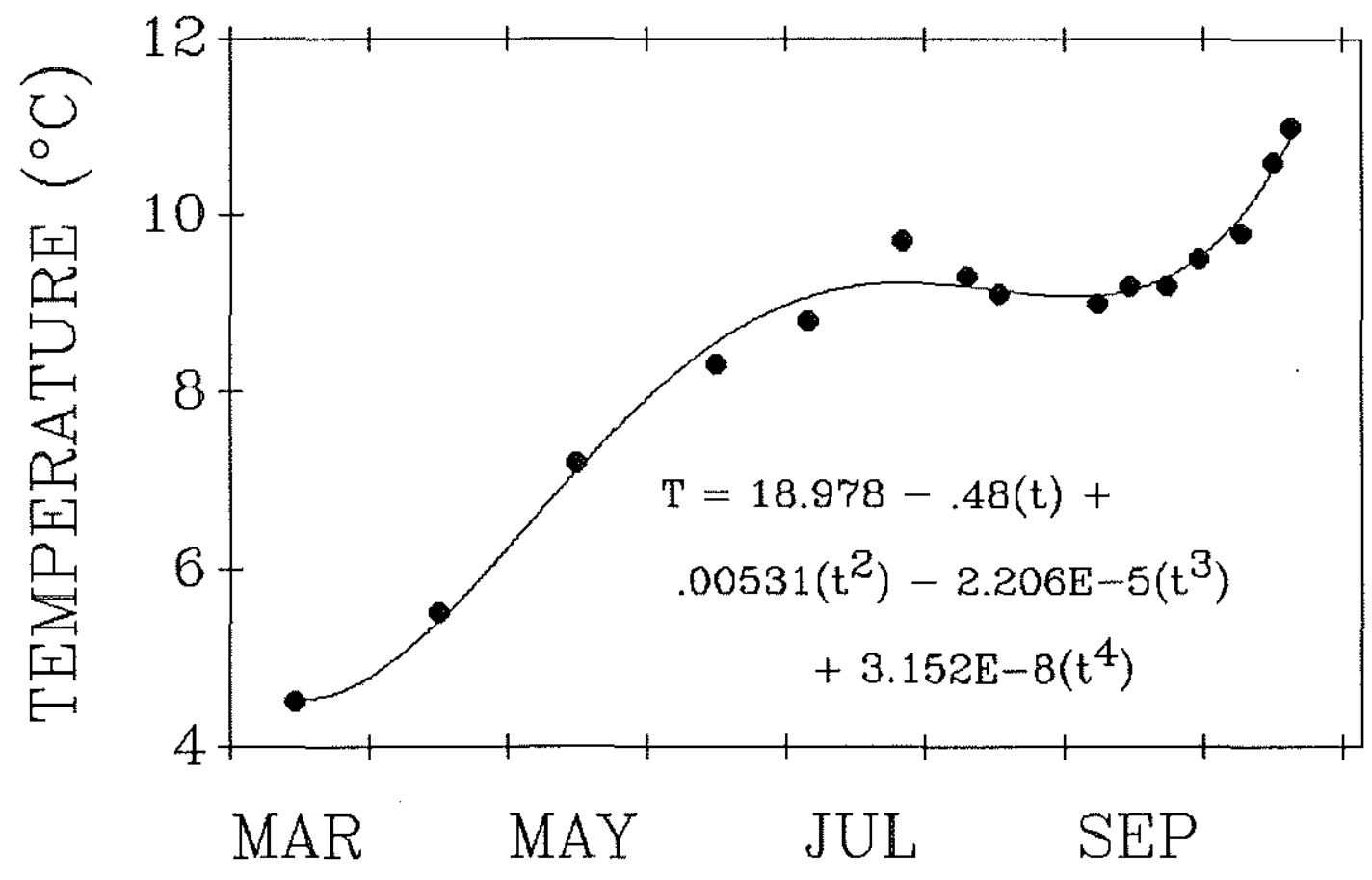


date that the overlying water is at this temperature. It should also be noted that MUDHEAT runs begin on a date that is more than a month before the beginning of the study period. During this period, diffusion will tend to smooth out any kinks in an initially non-isothermal temperature profile. 4) The final assumption yields a value for thermal diffusivity (thermal conductivity divided by density and heat capacity) of .0040 $\mathrm{cm}^{2} \mathrm{~s}$, similar to measured values for Lake Mendota, .0033, and Lake Hula, .004 (HUTCHINSON [1975]). The mode1 was relatively insensitive to changes in the assumed solids to water ratio; varying the ratio changes the heat capacity and thermal conductivity in opposite senses so that they tend to cancel each other. For example, nearly halving the bulk density and using a ratio of 248 detritus to 768 water caused only a $15 \%$ change in the output of the mode1.

As a further verification of the model, temperature profiles were generated for comparison with measurements on sediments at a $12 \mathrm{~m}$ water depth in Lake Mendota in the summer of 1919 (BIRGE et al. [1927]). The starting condition was a measured temperature profile on 18 April. The heat capacity and density of the sediments were inferred from the measured thermal diffusivity. First it was assumed that diffusivity was a linear combination of values for water and rock, and a solid;water ratio derived $(878: 138)$. That ratio was then applied to the heat capacity and density of rock $\left(0.2 \mathrm{cal} / \mathrm{g}^{\circ} \mathrm{C}\right.$ and $\left.2.5 \mathrm{~g} / \mathrm{cm}^{3}\right)$ and water to get combined values for the sediment for use in the model. The results of the model (open symbols) are compared to measurements (line and filled symbols) in Figure 4.5.1c, and show very good agreement. Integrating the heat inventory in the profile on the various dates shows 
FIGURE $4.5 .1 \mathrm{C}$ LAKE MENDOTA SEDIMENT HEATING SIMULATION

\section{LAKE MENDOTA SIMULATION}

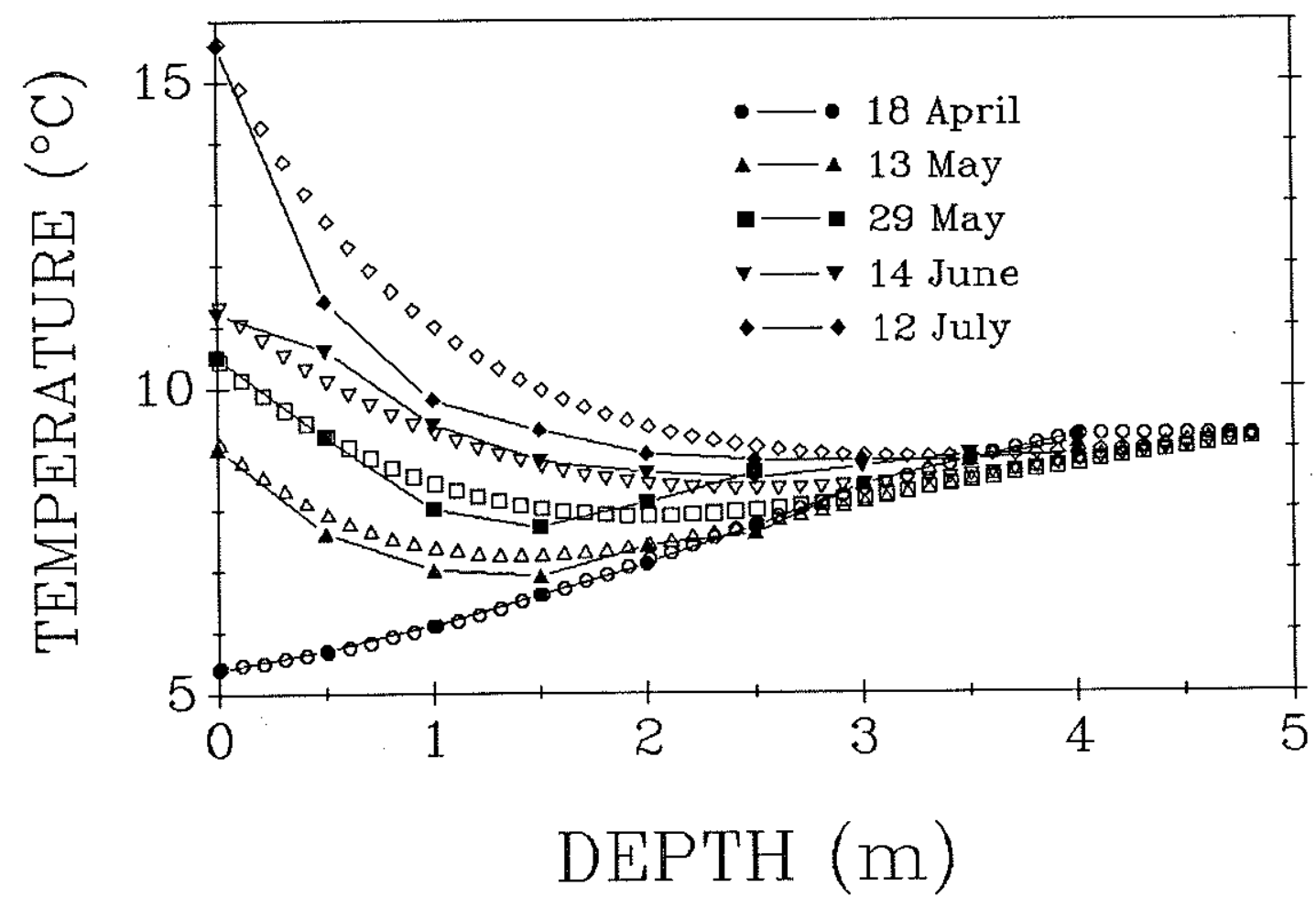

Measurements of the temperature of Lake Mendota sediments as a function of depth are indicated by the solid symbols and lines. The open symbols are the predicted temperatures derived using the model MUDHEAT as described in the text. 
that the model predicts sediment heating to an average accuracy of better than \pm 108 .

Calculation of the Eddy Diffusion Coefficient

A least squares polynomial fit to the temperature data at depths of $7,8,9,10,11,11.5,12$, and $12.5 \mathrm{~m}$ was used to express $\mathrm{T}(\mathrm{t})$ (Figure 4.5.1a), which was then differentiated with respect to time to derive $\partial \mathrm{T} / \partial t$. Likewise, temperature profiles were fit with a polynomial to get $T(z)$ and differentiated to get $\partial T / \partial z$. The value of $\partial T / \partial z$ used in the calculation was the average of values at the given depth on the dates at either end of the period. The results of the calculation are average daily values of eddy diffusivity for the 8 specified water depths during the 10 time intervals spanning the period from 14 June to 19 October 1985. Results were not calculated for any depth-date combinations that fell in the epilimnion due to descent of the thermocline. Results of the Eddy Diffusion Calculation

The relative contribution to the metalimnetic heat budget of the three terms - eddy diffusion, radiant heating, and cooling by sediments -- varies with time and depth. As would be expected, solar heating drops rapidly with depth and more slowly with time, decreasing by a factor of 10 over $5.5 \mathrm{~m}$ and a factor of 3 over 4 months (normalized to area). The effect of sediment heating on the heat budget of the water column has a complex pattern, decreasing with water depth monotonically but first decreasing then increasing at a fixed depth. This pattern is a function of the rate of change of temperature at any depth since changing water temperature drives sediment heating. Between 7 and $9 \mathrm{~m}$, temperature increased rapidly and continuously, while at greater depth, it increased more slowly overall and went through a minimum during the 
middle of the study period (Figure 4.5.1a). The decrease in $\mathrm{K}_{\mathrm{z}}$ was as great as 20 times over depth (time constant) and as much as a factor of 6 over time (depth constant). Comparing the relative magnitude of the three terms, sediment heating was always greatex than radiant heating by a factor ranging from 2 to 60 . Bickford is a relatively clear lake, where radiant heating at depth is substantial. It is significant, therefore, that the common practice of ignoring sediment heating (HUTCHINSON [1975], JASSBY and POWELL [1975]) would have a greater effect on calculated eddy diffusivities than would ignoring radiant heating. The flux of heat transported by eddy diffusion downward from the epilimnion (calculated by difference) was typically twice as great as the amount of heat entering sediments at the bottom of the metalimnion. Near the sediment water interface the amount of heat carried downward by turbulence was approximately equal to the amount of heat taken up by sediments.

That heating of sediments was comparable to heating of the stratified water column may seem surprising until the following factors are considered. First the relative volume of material affected was about equal: metalimnion thickness $=1$ to $5.5 \mathrm{~m}$, heated sediment thickness 3 to $4 \mathrm{~m}$. Second, the heat capacities were equivalent: water $=1.0 \mathrm{cal} / \mathrm{cm}^{3}{ }^{\circ} \mathrm{C}$, sediment $=1.08 \mathrm{cal} / \mathrm{cm}^{3}{ }^{\circ} \mathrm{C}$. Third, the thermal diffusivities were similar: water $=.005 \mathrm{~cm}^{2} / \mathrm{s}$ (typical eddy diffusivity), sediment $=.004 \mathrm{~cm}^{2} / \mathrm{s}$ (molecular thermal diffusivity). Finally, the temperature gradients were comparable, and usually greater in the sediment near the interface. The net result was that much of the heat that reached the sediment water interface was taken up by sediments. The extreme importance of sediment heating to the heat 
budget of the stratified portion of this lake arises in large part from the near absence of a hypolimnion. Still, ignoring sediment heating should cause a significant error when using thermal analysis to calculate eddy diffusion coefficients for lakes with combined metalimnetic plus hypolimnetic thicknesses up to 15 or $20 \mathrm{~m}$. That should include virtually all lakes up to $25 \mathrm{~m}$ depth and many deeper lakes that have profound thermoclines due to relatively transparent water column, late stratification, high average wind shear, or other causes.

The results of the eddy diffusion calculations fall in the range from 0.001 to $0.01 \mathrm{~cm}^{2} / \mathrm{s}$ (Table 4.5.1a). For each value, $0.0012 \mathrm{~cm}^{2} / \mathrm{s}$ is attributable to thermal conduction by water. An approximate error analysis was carried out in parallel with the eddy diffusivity calculations. Uncertainty as to the cross-sectional area of the basin as a function of depth was assumed to contribute negligible error. The $\partial \mathrm{T} / \partial \mathrm{t}$ and $\partial \mathrm{T} / \partial \mathrm{z}$ terms (numerator and denominator in the governing equation) were judged to be uncertain to $\pm 5 \%$ since they are derived from many measurements each of which is accurate to about \pm 28 . Above the depth of high SPM, the radiant heating term was taken to be uncertain to \pm 108 and to $\pm 20 \%$ below this level for reasons described above. The sediment heating term was taken to be uncertain to $\pm 20 \%$. This number is more than twice the average error determined in the verification run; the doubling is intended to allow for the less precise knowledge of the initial temperature profile in Bickford compared to Lake Mendota. Using these liberal error estimates and standard propagation of error techniques (BEVINGTON [1969]) the range in total uncertainty was from 9 
TABLE 4.5.1a EDDY DIFFUSION COEFFICIENTS AND UNCERTAINTIES

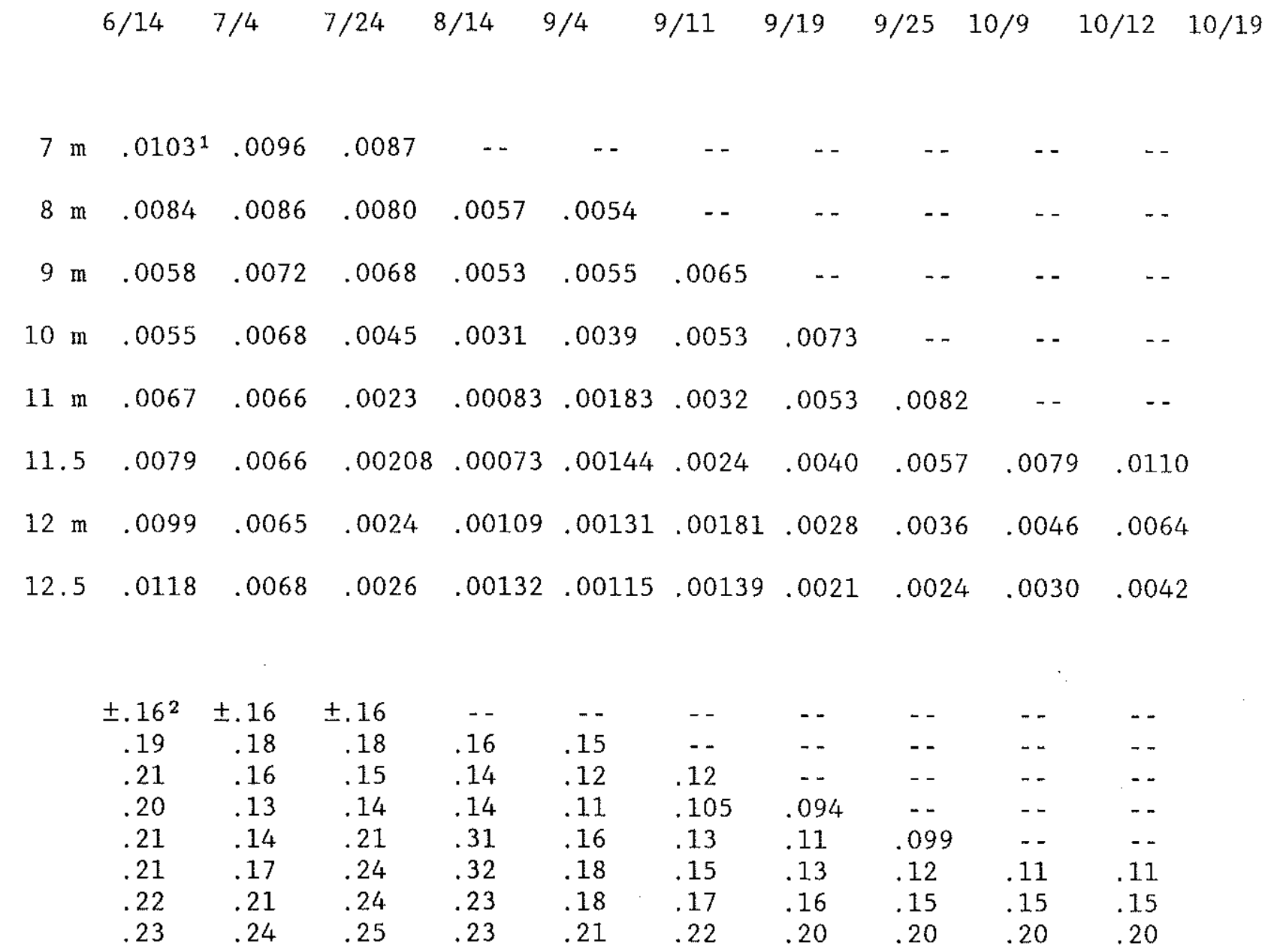

\footnotetext{
${ }^{1}$ Top array contains eddy diffusion coefficients $\left(K_{z}\right)$. Units $=\mathrm{cm}^{2} / \mathrm{s}$.

${ }^{2}$ Bottom array contains fractional uncertainty values (e.g. . $16= \pm 168$ uncertainty in corresponding upper array value).
} 
to 308 of the calculated $\mathrm{K}_{\mathrm{z}}$ values. 10 of the 59 calculated values were not significantly different from the molecular thermal diffusivity of heat by water. The average of the remaining 49 values was $.0059 \pm .0025$ $\mathrm{cm}^{2} / \mathrm{s}$. Without including a correction for sediment heating, the calculations would have been substantially in error, with derived values often low by one or two orders of magnitude and sometimes negative.

A number of investigators have reported values for the eddy diffusivity of lakes. HUTCHINSON (1975) used the flux gradient heat method and calculated $\mathrm{K}_{\mathrm{z}}$ values for Linsley Pond ranging from 0.0021 to $0.0059 \mathrm{~cm}^{2} / \mathrm{s}$ (corrected for thermal conduction). Hutchinson did not correct for sediment heating, so these values represent lower limits. ORLOB and SELNA (1970) using heat as a tracer calculated eddy diffusivities ranging from 0.02 to $1.7 \mathrm{~cm}^{2} / \mathrm{s}$ in and below the thermocline of four large lakes with depths up to $490 \mathrm{~m}$. These values are higher than those for the metalimnion of Bickford in agreement with the general trend of $\mathrm{K}_{\mathrm{z}}$ increasing with lake area MORTIMER (1941,1942). JASSBY and POWELL (1975) used heat to measure the eddy diffusivity in and below the thermocline of high altitude Castle Lake $(1706 \mathrm{~m})$, and found a range from .0040 to $.054 \mathrm{~cm}^{2} / \mathrm{s}$. Their calculations included a correction factor for radiant heating, but used extinction coefficients of pure water. This means that they probably overestimated the magnitude of this term at depth, and as a result their estimates of $\mathrm{K}_{z}$ are probably too low. They also do not consider sediment heating, which would also cause errors in the direction of underestimation (total depth $=25 \mathrm{~m}$ ). QUAY et al. (1980) used both tritium and heat to measure diffusivities in two small Experimental Lakes Area ponds. Values in the thermoclines were .0018 and $.0039 \mathrm{~cm}^{2} / \mathrm{s}$ using the heat method. The 
former value is almost certainly an underestimate since heating of sediments was not considered and the maximum depth of this lake was only $10 \mathrm{~m}$. DAVISON et al. (1980) used the flux gradient method without correction for sediment heating. They found an average of 0.01 and a range from negative values to $0.05 \mathrm{~cm}^{2} / \mathrm{s}$ for depths below $9 \mathrm{~m}$ in Esthwaite water. The negative values must in part represent values that are not statistically different from zero, though they may also be attributable to a failure to correct for sediment heating. IMBODEN and EMERSON (1978), using radon as a tracer, found values of $\mathrm{K}_{z}$ in Greifensee ranging from 0.05 to $0.20 \mathrm{~cm}^{2} / \mathrm{s}$. COLMAN and ARMSTRONG (1987) calculated eddy diffusivities using radon as a tracer. Their study of 7 lakes in Wisconsin and Michigan focused on the benthic boundary layer under ice-covered conditions. They found a range of $\mathrm{K}_{\mathrm{z}}$ from .0005 to $0.027 \mathrm{~cm}^{2} / \mathrm{s}$. These values match the lower end of the range of values calculated for Bickford, which seems reasonable since their study sites were protected by ice from wind shear. To summarize these comparisons, eddy diffusivities in Bickford are in agreement with values calculated for other lakes of similar size. The correspondence is best when one considers only metalimnetic measurements and allows for errors in previous studies that may exist due to a failure to consider sediment heating.

As shown by Figure 4.5.1d, in Bickford, $K_{z}$ tended to increase with depth and decrease with time. The highest values were found near the sediment water interface at the beginning of the study period and the lowest values were higher in the water column and later in the year. An exception to this pattern are depths within two meters of the base of the descending epilimnion; here $\mathrm{K}_{z}$ was higher. The overall trend in $\mathrm{K}_{z}$ 
FIGURE $4.5 .1 \mathrm{~d}$

WOPLETHS OF EDDY OIFFUSMITY IN THE WATER COIUMN

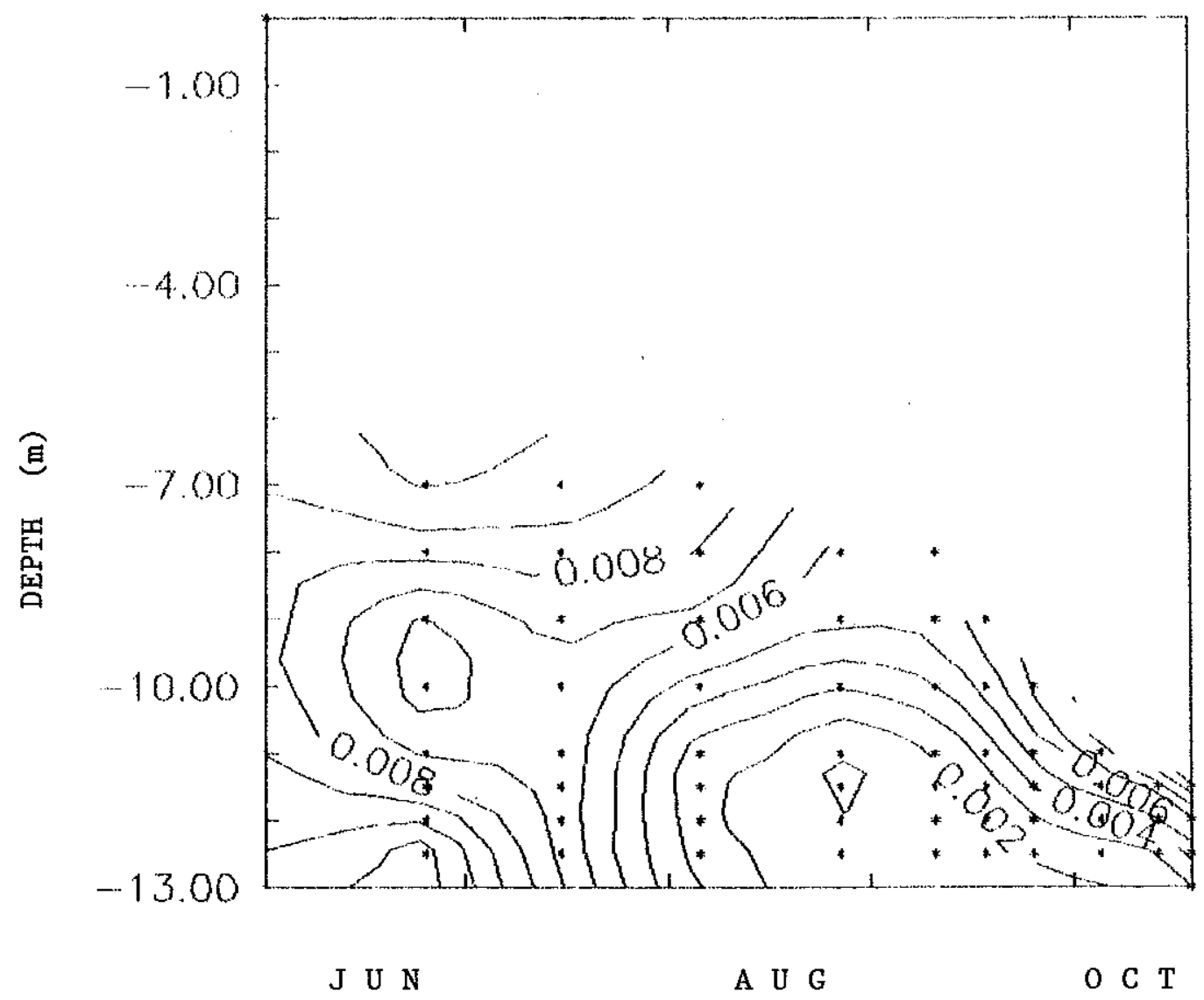


was in opposition to that of the density gradient, $\partial \rho / \partial z$, which decreased with depth and increased with time. Many authors have found a correlation between eddy diffusivity and the stability of stratification as expressed by the rate of change of density with depth. To test this hypothesis, $\mathrm{K}_{z}$ was plotted against the square of the Brunt-Vaisala frequency, $\mathrm{N}^{2}$ (defined as $(\mathrm{g} / \rho)(\partial \rho / \partial \mathrm{z})$ ). For the purpose of this calculation the density gradient was assumed to depend only on temperature. Ignoring the effect of solutes in this way is reasonable for an oligotrophic lake like Bickford. The results are presented in Figure 4.5.1e. Clearly there is a pronounced tendency for eddy diffusion to decreases with increasing water column stability, as seems intuitively reasonable. The regression of the log transformed variables conform to the relation $\mathrm{K}_{\mathrm{z}}=1.9 \times 10^{-4} \times\left(\mathrm{N}^{2}\right)^{-0.48}(\mathrm{r}=0.848$, confidence level >998). WELLANDER's (1968) theoretical analysis predicts that $\mathrm{K}_{z}$ will be proportional to $\left(\mathrm{N}^{2}\right)^{-1}$ when turbulence is caused by a cascade of energy down from large scale motions and to $\left(\mathrm{N}^{2}\right)^{-1 / 2}$ for turbulence generated by local shear stress. In Bickford, the coefficient on $\mathrm{N}^{2}$ is close to 0.5 as it was in field studies by QUAY et a1. (1980) and JASSBY and POWELL (1975). BROECKER and PENG (1982) have pointed out that the buoyancy flux (the product of $\mathrm{N}^{2}$ and $\mathrm{K}_{\mathrm{Z}}$ ) is a nearly constant $4 \times 10^{-6}$ for systems ranging from the deep sea to small lakes. The data for Bickford agree well with this observation, having an average value near $5 \times 10^{-6}$ Data that were either close to the epilimnion or uninterpretable because they were not significantly different from molecular diffusivity were excluded from this regression. Eddy diffusivities in the upper metalimnion were greater than expected based on the given level of density stability, and may reflect special processes taking place near 
FIGURE 4.5.1e $\mathrm{K}_{Z}$ AS A FUNCTION OF DENSITY STABILITY

$\mathrm{K}_{\mathrm{Z}}$ vs. DENSITY STABILITY

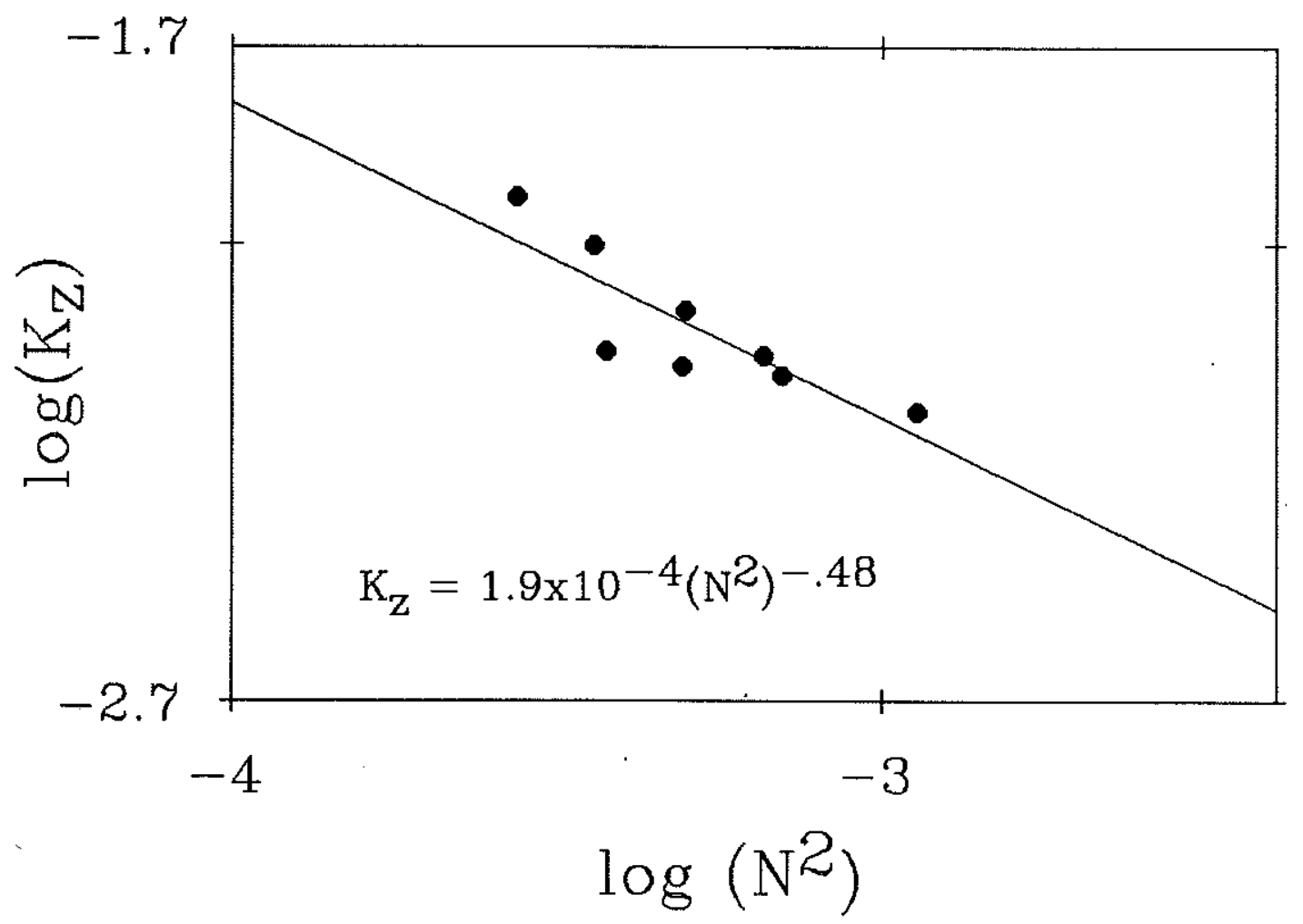


the interface of the epilimnion and metalimnion. Possible mechanisms are heat transport caused by heat interchange with sediments during seiching (DUTTON and BRYSON [1962]) or by breaking of internal waves (QUAY et al. [1980]). The possible magnitude of such processes has not been evaluated for Bickford, but to the extent that they are Fickian their action in the upper metalimnion can be included in subsequent eddy diffusive mass transport calculations.

As was stated at the beginning of this section, the purpose of calculating diffusive transport rates is to be able to trace the origin of element concentration distributions in the water column. In that way, insight is gained into geochemical cycling. As will be seen in the next section, the information produced by the present analysis of eddy diffusion yielded a largely "negative" result; during much of the summer, $\mathrm{K}_{\mathrm{z}}$ was so low that vertical turbulent transport was not an important contributor to the measured water column concentration increases. Still that conclusion could not be made without information gained by going through the calculations. Furthermore, (as will be shown in the following sections) the inconsequence of vertical turbulence points to the importance of such processes as horizontal turbulence and vertical transport by particles.

\subsubsection{IRON DISTRIBUTION AND TRANSPORT}

Possible Sources of the Water Column Iron: Desorption from Particles

The rate of increase of iron in the water column can be used to help identify its source. One possibility is that iron desorbs from particulate matter settling into the metalimnion from above. For Bickford the magnitude of this input flux was measured in two different ways: sediment traps and sediment profiles. Sediment trap collections 
for two fifteen day periods ending 19 September and 12 October 1985 had reducible iron contents of 1.00 and $0.92 \mathrm{mg} / \mathrm{cm}^{2} \mathrm{y}$, respectively. This agrees with an estimate of $1.5 \mathrm{mg} / \mathrm{cm}^{2} \mathrm{y}$, based on the amount of reducible iron in core $85-2(18 \mathrm{mg} / \mathrm{g})$, and its sedimentation rate $\left(0.085 \mathrm{~g} / \mathrm{cm}^{2} \mathrm{y}\right.$, see chapter 5). The estimate based on the sediment profile data reflects a year-long average, including periods with high stream inputs, so it is not surprising that it is higher than short-term values measured in sediment traps during the low flow period. These data indicate that even if reducible iron on particles was solubilized quantitatively, it could not account for even 158 of the total water column inventory increase during September. It thus seems that release from sediments must be the principal source.

Release of iron from particles was believed by DAVISON et a1. (1980) to be an important contributor to the hypolimnetic $\mathrm{Fe}$ distribution of Esthwaite water. However, their analysis was based on several assumptions, two of which are problematic: 1) that in the short term steady state conditions prevailed, and 2) that $\mathrm{K}_{\mathrm{z}}$ was constant over depth and time. Assumption 1: analysis of their data shows that changes in concentration at a given depth are typically as great as all other fluxes and cannot be neglected. Assumption 2: theory predicts and observation confirms that $\mathrm{K}_{z}$ varies with wind energy input into a lake's surface and with changes in the density gradient with depth. In Bickford, for example, $\mathrm{K}_{\mathrm{z}}$ varied by more than an order of magnitude. In summary, it is quite possible that their estimate of iron supplied to the hypolimnion of Esthwaite Water needs to be revised. 
Possible Sources of the Water Column Iron: Vertical Turbulent Transport

The calculations of eddy diffusivity described in the previous section (4.5.1) were carried out with the expectation that vertical turbulent transport was a primary mechanism controlling elemental distributions in the hypolimnion. In order to test that hypothesis, an attempt was made to recreate the distribution of iron using the measured eddy diffusivities and water column concentration gradients plugged into Fick's first 1aw. The computation was carried out by dividing the water column into half-meter intervals and calculating eddy diffusive fluxes into and out of every depth increment during each of the periods for which $\mathrm{K}_{\mathrm{z}}$ had been determined. The value of the iron concentration gradient as a function of depth was derived by differentiation of a second order polynomial regression of the iron-depth profiles. The model was only run on data through 26 September 1985 because, after this date, the iron profiles were strongly influenced by thermoclinal erosion, whose effect was not easily accommodated into the model.

The results of these calculations indicated that, during the summer of 1985, vertical turbulent mixing was not an important pathway for transport of iron away from the sediment water interface to higher levels in the water column. In most cases, the calculated Fickian flux of iron to a given depth interval was much less than the measured increase in iron. In some instances negative values were calculated, indicative of net losses for certain depth-time intervals. This came about because eddy diffusion sometimes decreased more rapidly than did the iron gradient. To some extent the mismatch between prediction and measurement may have been an artifact of the iron concentration data. In most instances, the depth resolution of the iron profiles was low, 
with samples typically spaced every $50 \mathrm{~cm}$. This was insufficient to allow accurate assessment of $\mathrm{d}(\mathrm{Fe}) / \mathrm{dz}$ in many cases, especially in the critical zone near the sediment water interface. On the other hand, the shortfall in the predicted iron flux was so substantial and widespread that some additional transport process must be active. Sources of the Water Column Iron: Horizontal Turbulent Transport Iron not supplied by either remobilization from settling particles or by vertical eddy diffusive transport from sediments must be supplied from sediments via horizontal turbulent diffusion. To test this hypothesis, a simple model was developed based on the following assumptions: 1) there was a constant rate of iron release from sediments exposed to anoxic bottom water, 2) there was no release from other sediments, 3) the lake was rapidly mixed in the horizontal, and 4) there was no removal of iron from the water column and no vertical transport. Assumption \#1 means that iron release was a step function, with no release before overlying water went anoxic (DO $<0.05 \mathrm{mg} / 1 \mathrm{iter}$ ), and constant release thereafter. Given these assumptions, the iron content at any depth in the water column should be directly proportional to the time of anoxia and to the ratio of sediment area to water column volume. Figure $4.5 .2 \mathrm{a}$ is a plot of all the water column iron data in the anoxic zone. In this figure total iron is plotted as a function of the product of the two factors that should influence its concentration: time of anoxia and the ratio of sediment area to water column volume. The abscissa can be thought of as a time axis, with the data normalized by a dilution factor characteristic of each depth layer. The straight line plot of the data (through the end of September) suggests that this 
FIGURE $4.5 .2 \mathrm{a}$ and $\mathrm{b}$ THE CONSTANT FLUX, RAPID HORIZONTAL MIXING MODEL FOR IRON AND $210 \mathrm{~Pb}$
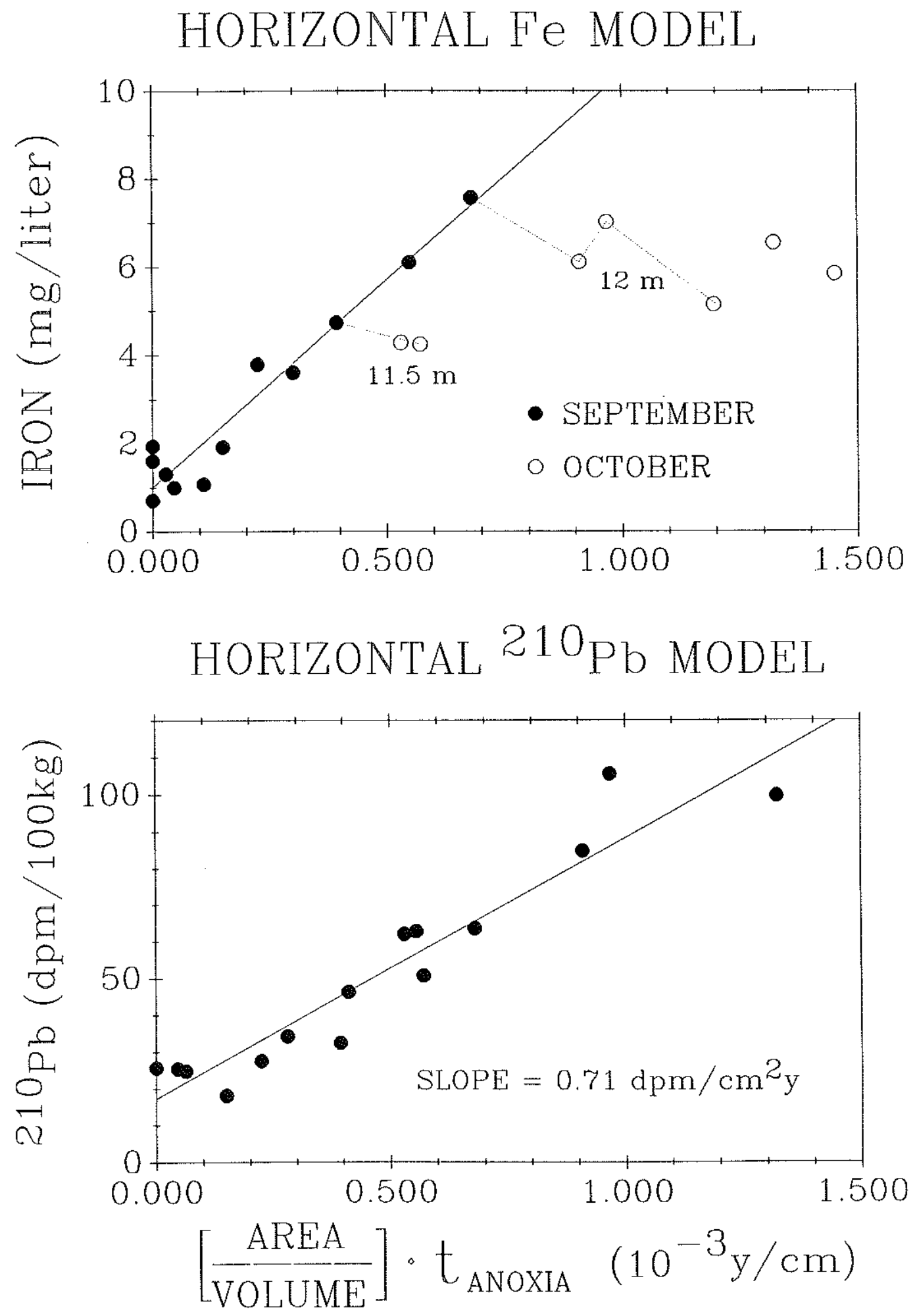
simple model can explain virtually all of the variation in water column iron. In October, data points fall below the line, implying an iron deficiency that could result either from a competing removal process or from a slowing or cessation of the rate of iron release by the sediments. Iron oxidation and precipitation cannot be the cause since all the data are from below the oxycline. Also, it has been shown (section 4.3.6) that FeS was not forming to a significant extent in Bickford in the summer of 1985. No other removal mechanism is evident, so instead, the lower iron in the October samples must reflect a reduction in the iron supply rate. This conclusion is consistent with the observed evolution of water masses at a constant depth. Water begins with negligible iron and increases up the solid diagonal line as time progresses. Beginning about the 1st of October, iron was depleted at all depths, and data from a single depth track to the right (as illustrated for the 11.5 and $12 \mathrm{~m}$ water masses by dotted lines on Figure 4.5.2a). The slight downward slope of the post-depletion tracks indicates limited removal of iron from the water column during this period.

The slope of the regression 1 ine, $10.2 \mathrm{mg} / \mathrm{cm}^{2} \mathrm{y}$, is the apparently constant rate of iron release under reducing conditions, and is an order of magnitude greater than the delivery of iron to the sediment water interface by settling particles. The high rate of $\mathrm{Fe}$ release means that the equivalent of an entire year's input of reducible iron can be remobilized during a one month period of anoxia in the summer. Iron thus seems to be like manganese in that it is quantitatively reduced and released from sediments. The important difference between the two metals is that iron reprecipitates on encountering the oxycline and is 
returned to the sediments, while the very slow oxidation rate of manganese allows it to enter the mixed water column and flow out of the lake.

On average, the vertical distance to the bottom is much less than the horizontal distance. This means that if the water column distribution of iron is more strongly influenced by horizontal transport than vertical transport, then $\mathrm{K}_{\mathrm{x}}$ must be much greater than $\mathrm{K}_{\mathrm{z}}$. This effect is magnified by the fact that average Fickian transport distances are proportional to the square root of the diffusion coefficient; a hundredfold increase in $\mathrm{K}_{z}$ causes only a tenfold increase in diffusive transport, on average. To evaluate the significance of this fact, one must look at the shape of the lake basin. The hypsographic curve (Figure 4.5.2c) shows that Bickford's area decreases at a constant rate with depth below $9 \mathrm{~m}$. The bathymetric map (Figure 2a) reveals that the deep basin can be approximated by a rectangle with an aspect ratio of about $3: 1$. Equating the expression for the lake's cross-sectional area as a function of depth to that of a rectangle with dimensions of $\mathrm{x}$ and $3 x$, rearranging, and differentiating with respect to $z$ gives an expression of the average slope of the bottom as a function of depth. Results are given in Table 4.5.2a along with the ratio of $\mathrm{K}_{\mathrm{x}}$ to $\mathrm{K}_{\mathrm{z}}$ needed to cause equal transport in the horizontal and vertical. As expected, the slope $(1 /[\mathrm{dx} / \mathrm{dz}])$ decreases with depth, so $\mathrm{K}_{\mathrm{x}}$ must be increasingly greater than $\mathrm{K}_{\mathrm{z}}$ deeper in the lake. The table lists values for which vertical and horizontal transport would be just equal, so the ratio of $\mathrm{K}_{\mathrm{x}}$ to $\mathrm{K}_{\mathrm{z}}$ must substantially exceed the tabulated value for horizontal transport to be dominant, as it evidently was in September 1985. IMBODEN and EMERSON (1978) measured both vertical and horizontal 
FIGURE $4.5 .2 \mathrm{c}$ HYPSOGRAPHIC CURVE FOR BICKFORD RESERVOIR

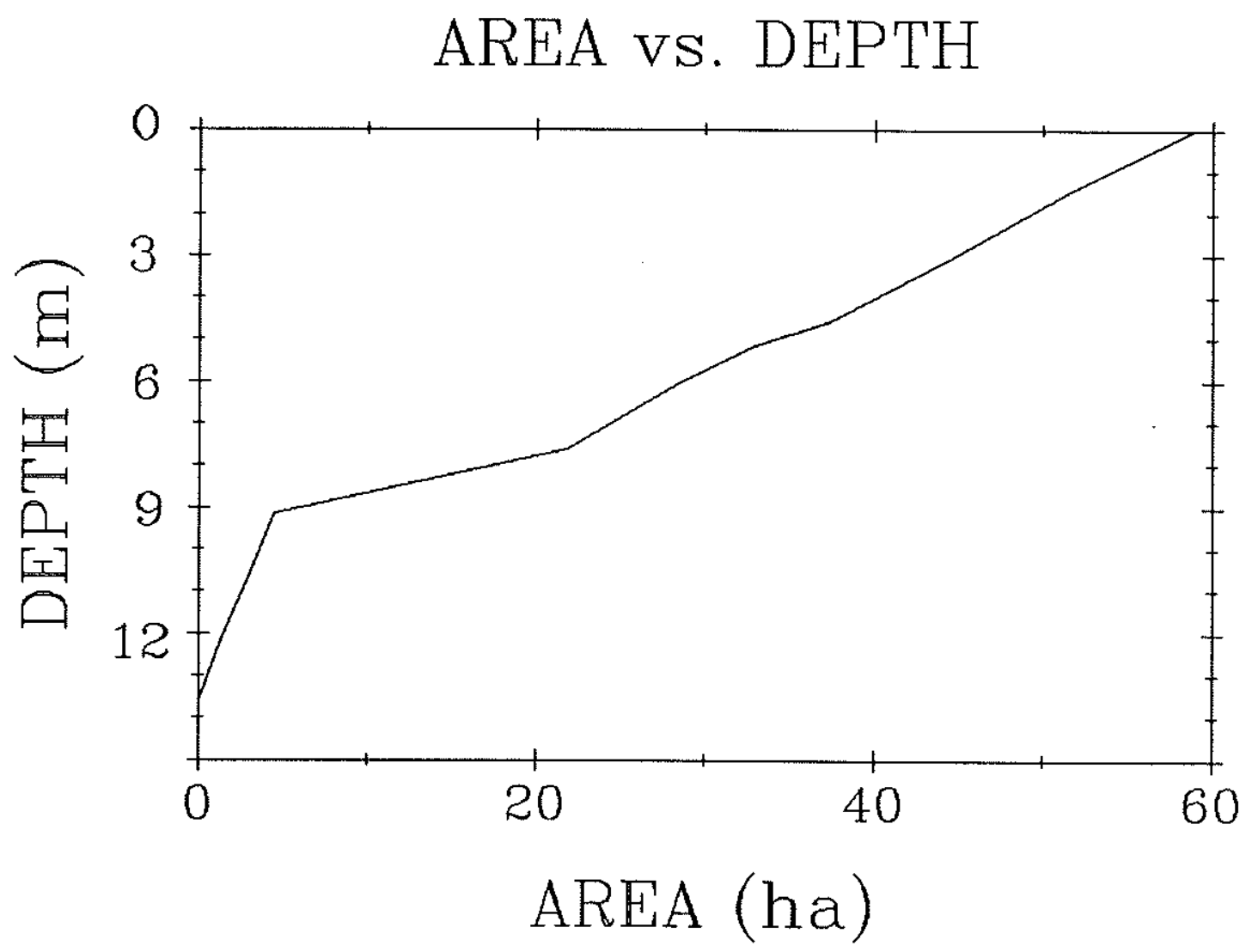


TABLE $4.5 .2 \mathrm{a}$ AVERAGE BOTTOM SLOPE AS A FUNCTION OF DEPTH

$\begin{array}{ccc}\text { DEPTH } & \mathrm{dx} / \mathrm{dz} & \mathrm{K}_{\mathrm{x}} / \mathrm{K}_{\mathrm{z}}{ }^{1} \\ (\mathrm{~m}) & - & - \\ 9 & 23 & 530 \\ 10 & 26 & 680 \\ 11 & 31 & 960 \\ 12 & 40 & 1600 \\ 13 & 65 & 4200\end{array}$

${ }^{1}$ Ratio of $\mathrm{K}_{\mathrm{x}} / \mathrm{K}_{\mathrm{z}}$ for which the magnitude of horizontal and vertical turbulent transport would be just equal. 
eddy diffusion coefficients in Greifensee, Switzerland, and found that the ratio ranged from 600 to 6,000 , close to values in Table 4.5.2a. Unless the ratio is substantially greater in Bickford, it seems that conditions are barely within the realm of dominance by horizontal transport. At times of the year when $\mathrm{K}_{\mathrm{z}}$ is greater than average, vertical turbulent transport may still be significant. At such times, iron would be expected to penetrate more rapidly and to higher levels in the water column than it did during the study period.

\section{Limnocorral Experiments}

In order to further test the relative importance of vertical and horizontal turbulent transport, limnocorral experiments were conducted in the summer of 1986. The limnocorral consisted of a $1 \mathrm{~m}$ diameter polyethylene enclosure, anchored at the bottom in $13 \mathrm{~m}$ of water, and open at the top, which floated $6 \mathrm{~m}$ above the bottom with no connection to the surface. Measurements of temperature, dissolved oxygen, alkalinity, iron, sulfide, $210 \mathrm{~Pb}$, and $2{ }^{10} \mathrm{Po}$ showed no difference between the water column inside and outside the enclosure. This implies that vertical transport was just as important as horizontal transport during the study period from August through October 1986. This difference between 1985 and 1986 is further evidence that Bickford is on the borderline between dominance by vertical and horizontal transport.

As described above in the section entitled Horizontal Turbulent Transport, the release rate of iron from sediments was constant throughout September, but it decreased in october. What factors control the rate of iron release? There would seem to be three potential limiting steps: 1) the rate of transport away from the sediment water interface, 2) the rate of transport across the benthic boundary layer, 
and 3 ) the rate of iron reduction in the sediments. Considering the first possibility, recall that the horizontal eddy diffusive flux, $F$, is given by:

$$
F=-K_{x}(d c / d x)
$$

Assuming that $\mathrm{K}_{\mathrm{X}}$ was approximately constant, this requires that the horizontal concentration gradient in the water column was constant as we11. An attempt was made to measure these gradients, but it proved impossible; the very steep vertical concentration gradients demanded prohibitively precise control of vertical position when sampling.

Nevertheless, it seems unlikely that water column transport was the rate limiting step, since one would expect concentration gradients that decreased with time to slow sediment releases progressively. First to decline would be deep sections, with a high area to volume ratio and an earlier onset of anoxia, while shallow sections would show the effect later. In fact, the iron flux from sediments was constant and did not change with depth.

The second possibility for a rate limiting process is molecular diffusion across the benthic boundary layer, a thin film of quiescent water immediately adjacent to the sediment water interface. The existence of such a zone is predicted by fluid mechanical theory, and its existence has been measured in both laboratory (JORGENSEN and REVSBECH [1985]) and field studies (SANTSCHI et al. [1983a]). At Bickford, the thickness of the diffusive boundary layer was measured using the alabaster plate method (SANTSCHI et al. [1983]) during two deployments (Table 4.5.2b). The results indicate 1 ) that the boundary layer is of the order of $1000 \mu \mathrm{m}, 2$ ) that conditions are similar inside 
TABLE $4.5 .2 \mathrm{~b}$ DIFFUSIVE BOUNDARY LAYER MEASUREMENTS

DATE

$12-21$ Oct 1986

6 - 12 Nov 1986
LAYER THICKNESS

$(\mu \mathrm{m})$

Water Column Enclosure

$1500^{1}$

$3000^{2}$

$1300^{1}$

${ }^{1}$ Plate covered with a very thin layer of sediment when recovered.

${ }^{2}$ Plate overlain by about $2 \mathrm{~mm}$ of sediment on recovery.

${ }^{3}$ Plate clean when recovered. 
the lake enclosures and in the open water column, and 3) that surficial sediments pose about the same barrier to diffusion as does an equal thickness of still water (cf. ANDREWS and BENNET [1981]). Using the approximation that the average diffusion distance is given by $z=$ $(2 \mathrm{Dt})^{1 / 2}$, substituting the measured thickness (1100) $\mu \mathrm{m}$, and solving for $t$, shows that the diffusion time across the boundary layer is only about $15 \mathrm{~min}$. This means that any variations in the rate at which iron is regenerated from surficial sediment solids is almost immediately transmitted to the water column, so this cannot be the rate limiting step.

The final possibility, selected by default, is that the pace of iron reduction limits the rate at which iron is released from the sediments. The speed of this process depends on a number of factors including the character and abundance of organic substrate, the nature of iron reducing bacteria, temperature, and the availability of nutrients, among others. Until the end of August, the availability of oxygen, an energetically more favorable oxidant, inhibits iron reduction (also, any reduced iron diffusing from depth is quickly oxidized and precipitated within the sediment profile). After anoxia begins, reduction of ferric iron becomes important and quickly reaches steady state (filled circles in Figure 4.5.2a). Finally, the near-surface supply of easily reducible metal is exhausted, and iron release stops (open circles). The iron redox cycle in the hypolimnion involves a dynamic pool of easily reducible iron that is supplied by inputs on settling particles and consumed by outputs of burial/mixing and diagenesis to less amorphous, more thermodynamically stable, less easily reducible compounds. The annual cycle of growth and decline of anoxia 
leads to a redistribution of the reducible iron pool within the zone of zero oxygen. Iron is released from sediments at all depths within this zone as the oxycline climbs. Then when thermocline erosion causes reprecipitation and settling of the metal, iron from shallower sediments is delivered to deeper locations. The net result is that a greater amount of reducible iron is found in deeper sediments, and this helps to explain the apparently simultaneous depletion of iron in surficial sediments at different depths.

\section{5 .3 CONTROLS ON $210 \mathrm{~Pb}$ DISTRIBUTIONS AND FLUXES}

Source of Water Column $210 \mathrm{~Pb}$

The occurrence of high levels of total ${ }^{210} \mathrm{~Pb}$ in the stratified water column (Figure 4.3.7a) indicates the likelihood of substantial $21^{\circ} \mathrm{Pb}$ release from sediments. To the extent that this release may cause lead redistribution, it may compromise the ${ }^{210} \mathrm{~Pb}$ dating method. It is therefore critical to understand the timing, mechanism, and magnitude of that release as well as the ultimate fate of the ${ }^{210} \mathrm{~Pb}$.

Although it seems likely that the high levels of ${ }^{210} \mathrm{~Pb}$ in the hypolimnion derive from bottom sediments, the possibility exists that it comes from desorption off of settling particles. For iron it was possible to rule out this source because the rate of buildup exceeded the total delivery by particles by a factor of ten. For $210 \mathrm{~Pb}$, the difference between the two fluxes is not as great, but it is still significant. The epilimnetic model, sediment trap measurements, and inventoxies in sediment profiles all point to an average $210 \mathrm{~Pb}$ flux on settling particles of about $0.9 \mathrm{dpm} / \mathrm{cm}^{2} \mathrm{y}$ (section 5.6 ). The observed rise in hypolimnetic $210 \mathrm{~Pb}$ was coincident with and contingent upon the onset of anoxic conditions (see also BENOIT and HEMOND [1987]), so the 
fraction of $210 \mathrm{~Pb}$ released from particles should be related to that released by the reducing steps of the sequential leaching experiments. The results of those studies (chapter 6) show that a consistent $50 \%$ of all the $210 \mathrm{~Pb}$ in sediment trap material was liberated by the combination of weak and strong reducing leaches. Conditions in the water column might only be sufficient to remobilize a portion of this total reducible fraction. By this reasoning, less than half of the measured rise in ${ }^{210} \mathrm{~Pb}$ could have been supplied by remobilization from settling particles. Three additional lines of evidence support the hypothesis that bottom sediments are the dominant source. First, the maximum in the ${ }^{210} \mathrm{~Pb}$ distribution is located adjacent to sediment water interface, and this proximity strongly implies provenance. Second, the correlation of $\mathrm{Fe}$ and $210 \mathrm{~Pb}$ implies that they come from a common source, and the rise in iron has been definitively linked with bottom sediments. Finally, as will be seen in the next section, ${ }^{210} \mathrm{~Pb}$ release is described successfully by the horizontal transport model. $210 \mathrm{~Pb}$ Releases in Relation to Transition Metals Comparison of figures 4.3.2a and 4.3.7a shows that ${ }^{210} \mathrm{~Pb}$ releases occurred only in conjunction with anoxia. There is no direct way in which reduction would remobilize lead, so the release of $210 \mathrm{~Pb}$ is probably linked to redox cycling of the transition metals iron and manganese. As would be expected, there was a correlation between $210 \mathrm{~Pb}$ and iron buildups (compare Figures 4.3.7a and 4.3.4b). Given that there appears to be such a linkage, the ${ }^{210} \mathrm{~Pb}$ data were tested for conformance with the horizontal transport model developed for iron in section 4.5.2; the results are plotted in Figure $4.5 .2 \mathrm{~b}$. The $2{ }^{\circ} \mathrm{Pb}$ data do fall close to a straight line, implying that the series of assumptions listed in 
section 4.5.2 describe the behavior of $210 \mathrm{~Pb}$ as well as iron. It should be mentioned in regards to both of these elements that the plots show only that $210 \mathrm{~Pb}$ and iron concentrations are proportional to the time of anoxia and sediment surface area, and are inversely proportional to the volume of water at a given depth. To some extent, other models would have similar dependence on these same factors; that is, concentration would increase with time and decrease with dilution. It is the failure of other models to account for the magnitude of measured total mass releases that makes the horizontal model attractive.

Two important differences should be noted between Figures 4.5.2a and $\mathrm{b}:$ 1) the slope of the ${ }^{210} \mathrm{~Pb}$ line is less steep, and 2) the ${ }^{210} \mathrm{~Pb}$ data continue to fit the model throughout the entire anoxic period and do not drift to the right of the line late in the season. The slope of the $210 \mathrm{~Pb}$ curve is equivalent to a constant ${ }^{210} \mathrm{~Pb}$ release rate from sediments of $0.7 \mathrm{dpm} / \mathrm{cm}^{2} \mathrm{y}$, about equal to the average total input on particles, not ten times higher than input as was the the case for iron. Plotting total iron vs. total ${ }^{210} \mathrm{~Pb}$ (Figure $4.5 .3 \mathrm{a}$ ) shows that these two constituents are present in the water column (filled circles and solid regression line) at about the same ratio as that of their release rates (dashed 1ine). Some of the ${ }^{210} \mathrm{~Pb}$ data, in the region of high iron concentration, fall above the line, indicating excess ${ }^{210} \mathrm{~Pb}$ relative to Fe in these cases. Those points - indicated in Figure 4.5.3a by open circles - - resulted when $210 \mathrm{~Pb}$ continued to be released at a constant rate in October (Figure 4.5.2b), while iron did not (Figure 4.5.2a). The reason for the continued release of $210 \mathrm{~Pb}$ after iron was exhausted is twofold. First, since ${ }^{210} \mathrm{~Pb}$ was released at a slower rate (relative to annual input) than iron, it seems reasonable that it would take a 
FIGURE 4.5.3a TOTAL $210 \mathrm{~Pb}$ VS. TOTAL IRON IN THE WATER COLUMN

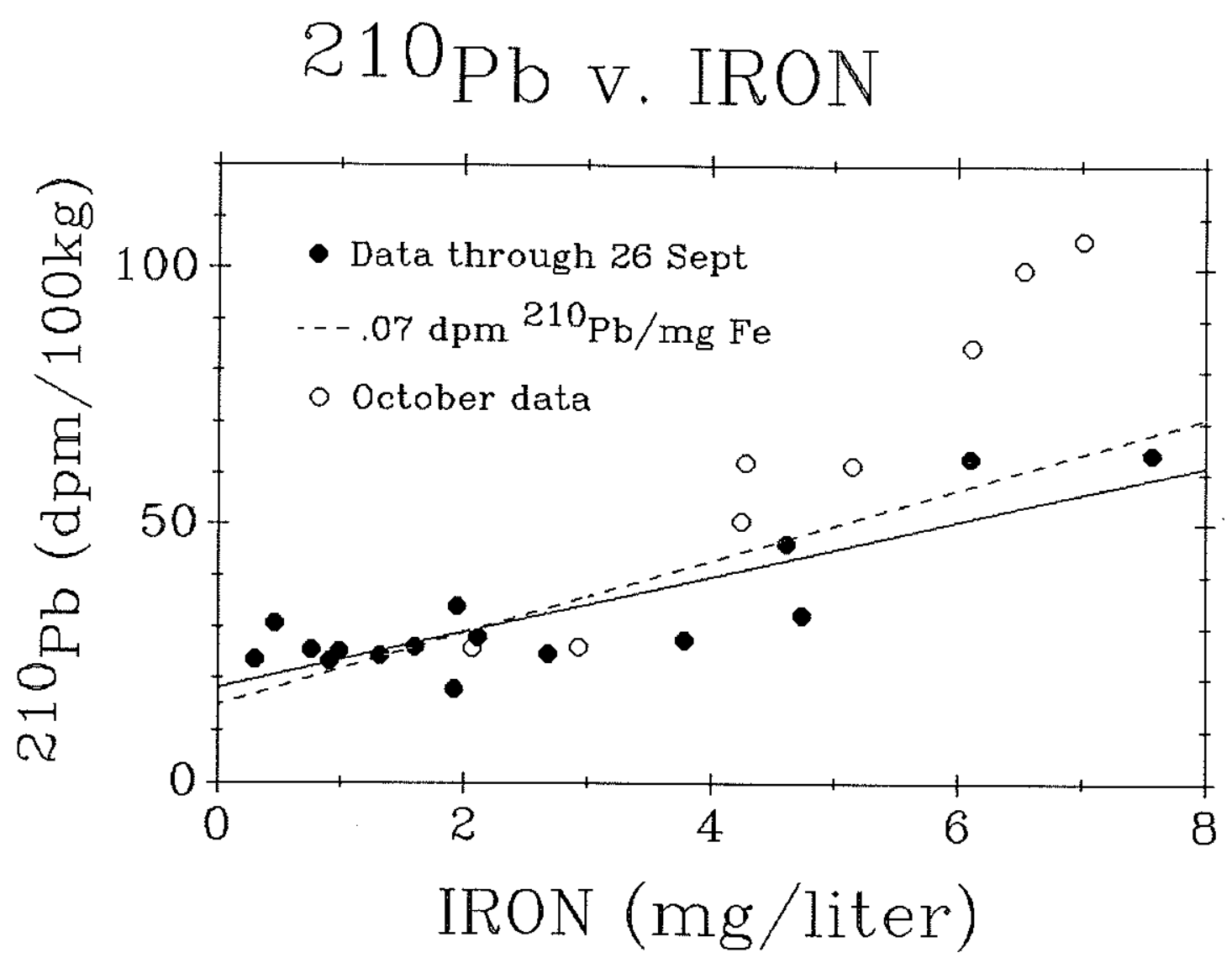


longer time to deplete the supply available in surficial sediments. Second, as will be shown in section 6.3 .2 , pore water concentration gradients were sufficient to supply a significant diffusive flux of $210 \mathrm{~Pb}$ but not of iron.

Near the oxycline, freshly precipitated iron oxyhydroxide can be expected to sorb $210 \mathrm{~Pb}$, and the partitioning of the radionuclide between dissolved and particulate fractions should reflect particulate matter leve1s. Figure $4.3 .6 \mathrm{~b}$ shows that the ratio of particulate to dissolved $210 \mathrm{~Pb}$ increases linearly with SPM, supporting the idea that ${ }^{210} \mathrm{~Pb}$ uptake can be described in terms of a simple $\mathrm{K}_{\mathrm{D}}$ approach (see section 6.3.2). The slope of the regression line gives the numerical value of the partition coefficient as $\mathrm{K}_{\mathrm{D}}=630,000$ for uptake by $\mathrm{SPM}$. Since $\mathrm{Fe}$ constitutes $27 \%$ of $\mathrm{SPM}, \mathrm{K}_{\mathrm{D}}=2,300,000$ expressed in relation to particulate iron. A plot of $210 \mathrm{~Pb}$ partitioning as a function of particulate iron gives a somewhat lower value for $K_{D}$ of $1,400,000$. Both of these plots show considerable scatter, but that is not surprising in view of the dynamic conditions in the zone of iron precipitation and the limitations of the measurements. For one thing, only total ${ }^{210} \mathrm{~Pb}$ on particles larger than $0.45 \mu \mathrm{m}$ was measured; some particles finer than the filter cutoff undoubtedly were included in the dissolved fraction. In addition some of the ${ }^{210} \mathrm{~Pb}$ on particles is not free to participate in sorption-desorption reactions, for example, that bound in the matrix of silicate detritus. Another problem is that a significant length of time may be required to establish equilibrium with the rapidly forming iron oxyhydroxides, and their sorptive characteristics may change rapidly on a short time scale as they age (SWALLow et al. [1980). 
The nearly constant partitioning of the radionuclide implies that iron particles that form at the oxycline and settle downward should carry $210 \mathrm{~Pb}$ with them. That expectation is confirmed by measurement, with enhanced accumulation of $210 \mathrm{~Pb}$ in sediment traps located below the oxycline. Table 4.5.3a summarizes sediment trap measurements of $210 \mathrm{~Pb}$ fluxes near the oxycline. For the period from 14 August to 4 September, both of the sediment traps were located above the top of the anoxic zone and show the same flux. During the next interval, the oxycline ascended until it was just above the lower trap, and there was a slight increase in the ${ }^{210} \mathrm{~Pb}$ flux in the lower compared to the upper. Between the 4 th and 19 th of September, the oxycline was well above the top of the lower sediment trap, and there was a significant increase in flux between the two. During the final deployment, thermocline erosion began to cause a deepening of the oxycline, and this process caused the largest measured difference between the ${ }^{210} \mathrm{~Pb}$ fluxes above and below the zero oxygen surface. These measurements suggest that the ascending oxycline constitutes a zone where iron is oxidized, precipitates, sorbs ${ }^{210} \mathrm{~Pb}$, aggregates, and settles to the bottom. When the oxycline begins to be eroded downward, this cycle is accelerated by the added supply of metals available in the zone swept out during the descent. The existence of this region of enhanced $2{ }^{10} \mathrm{~Pb}$ scavenging serves as a barrier at the top of the zone of anoxia and high $210 \mathrm{~Pb}$ levels, and may help to prevent ${ }^{210} \mathrm{~Pb}$ released by sediments from escaping into the mixed upper part of the lake. 
TABLE $4.5 .3 \mathrm{a}$ HYPOLIMNETIC $210 \mathrm{~Pb}$ SEDIMENT TRAP FLUXES

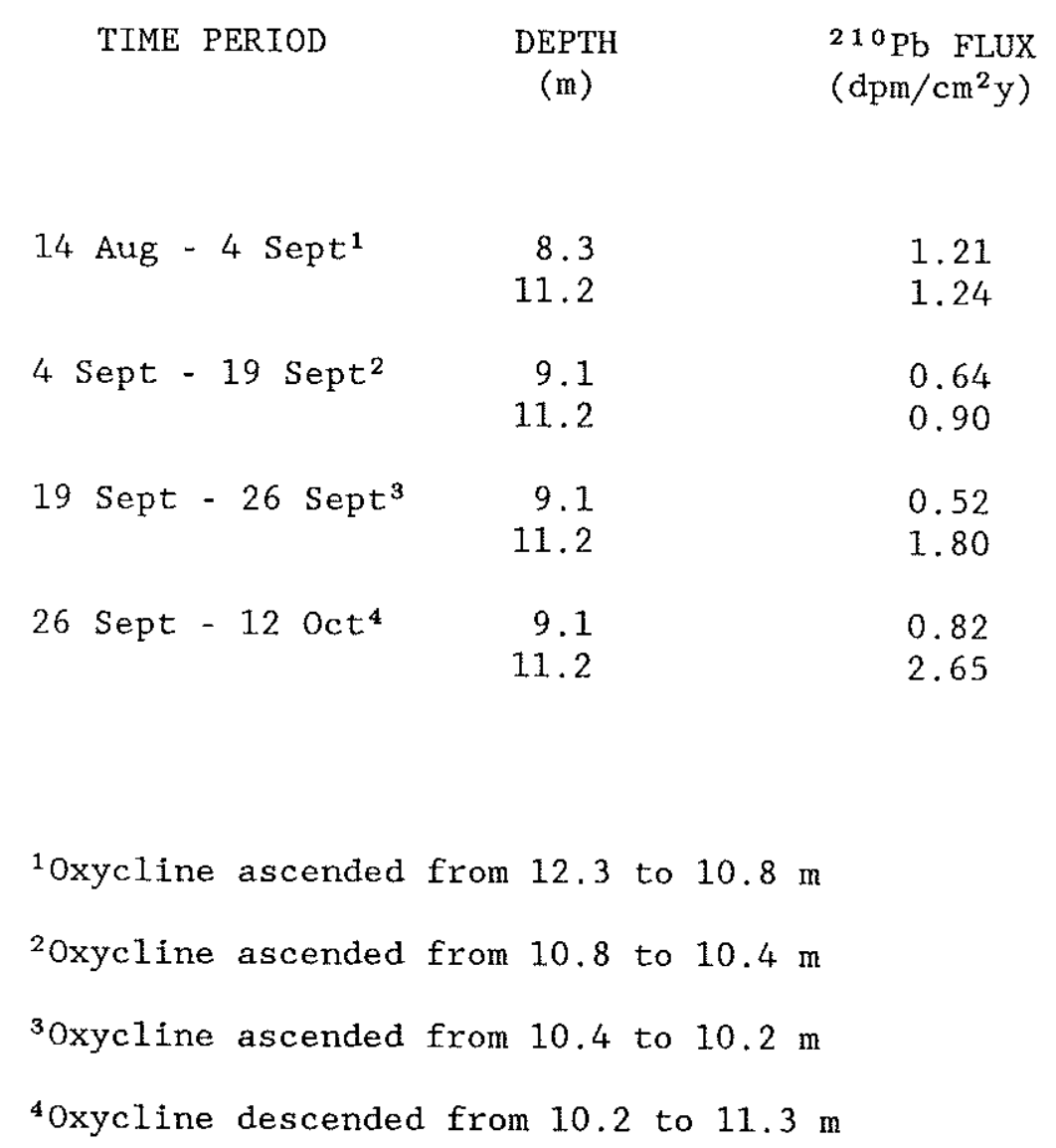




\subsubsection{CONTROLS ON ${ }^{210}$ PO DISTRIBUTIONS AND FLUXES}

General Pattern of 210 po Distribution

The overall pattern of $2{ }^{\circ}$ Po distribution in the stratified water column is similar to that of $210 \mathrm{~Pb}$, but with certain important differences. The similarity lies in the fact that ${ }^{210}$ Po increases rapidly beginning at about the time of bottom water anoxia, eventually reaching levels about an order of magnitude higher than in the epilimnion. The differences are that ${ }^{210}$ Po begins to be released earlier, and seems to bear a different relationship to iron release than does $210 \mathrm{~Pb}$.

As was described in section 4.3 .8 , the remobilization of $2{ }^{\circ}$ Po into partially oxygen depleted waters has already been seen in a number of studies in both marine and lacustrine environments (BACON et al. [1976], BACON et a1. [1980], LI et al. [1981], TANAKA et al. [1983], TALBOT and ANDREN [1984]). In this regard, the results from Bickford up until the time of anoxia follow a well-established pattern; $21{ }^{\circ}$ Po is released but not $210 \mathrm{~Pb}$, leading to excess $210 \mathrm{Po}$. Only under anoxic conditions does $210 \mathrm{~Pb}$ begin to increase, eventually exceeding $210 \mathrm{Po}$. This pattern is illustrated in Figure 4.5.4a for total radionuclides. Symbols on this graph indicate the "age" of the water stratum on which the measurement was made. Filled triangles are samples from well before the onset of anoxia; open circles are from 20 days before to 50 days after the start of anoxia; and filled circles are more than 50 days after oxygen was depleted. It is clear from this graph that before anoxia, ${ }^{210} \mathrm{~Pb}$ was low but greater than ${ }^{210} \mathrm{Po}$. (Note that for clarity much of the data from before the time of anoxia has been excluded form this graph. Additional data presented in As anoxia approached, ${ }^{210}$ Po was released at a much 
FIGURE $4.5 .4 \mathrm{a}$ TOTAL $210 \mathrm{PO}$ VS. TOTAL $210 \mathrm{~Pb}$ IN THE WATER COLUMN

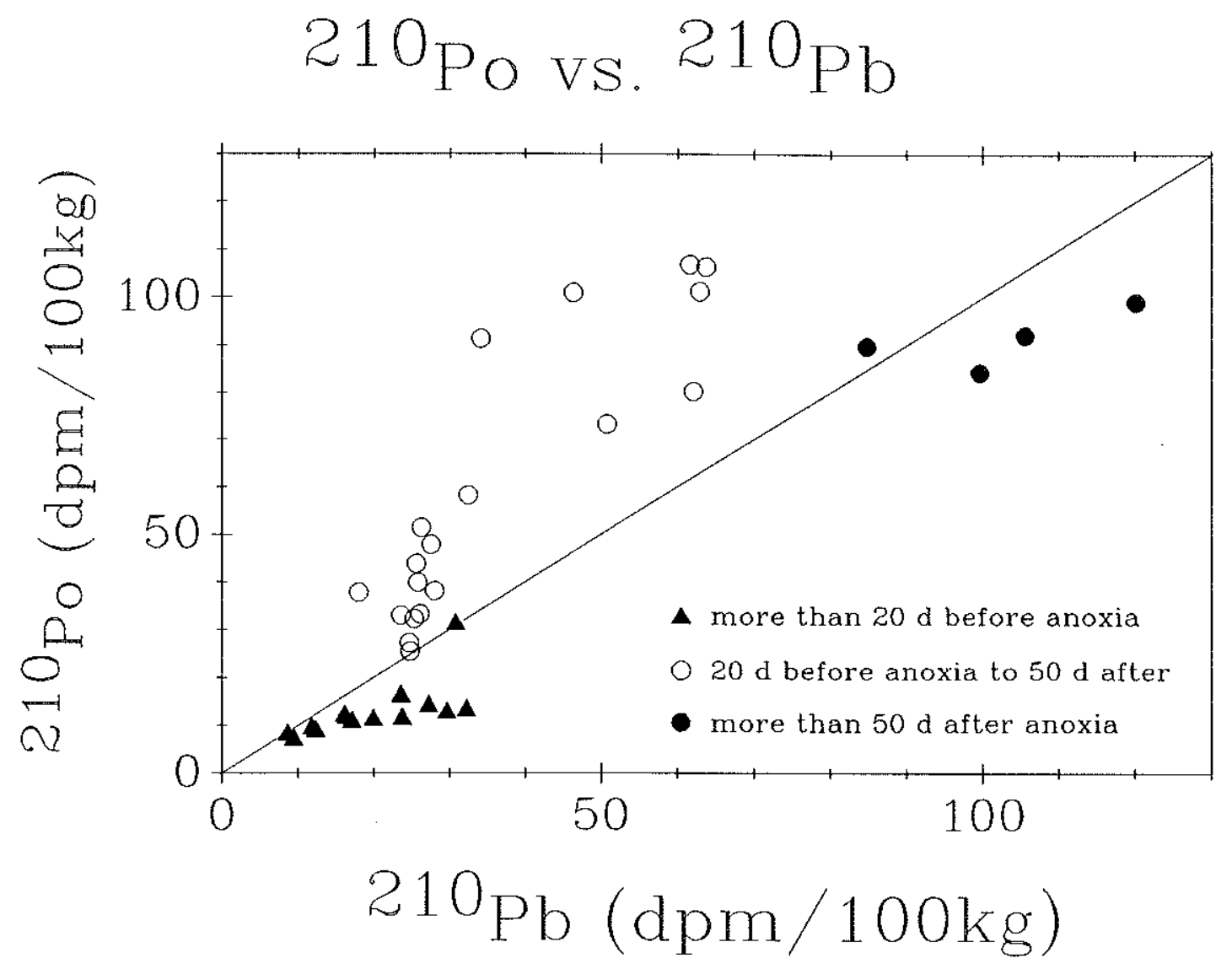


greater rate than $210 \mathrm{~Pb}$ and quickly exceeded secular equilibrium (indicated by the solid diagonal line). Eventually the situation was reversed -- with $210 \mathrm{~Pb}$ release exceeding that of ${ }^{210} \mathrm{Po}$ - - and the data points approach the equilibrium line and pass below it.

The early onset of $21^{\circ}$ Po release and the known association of 210 po and organic matter (TALBOT and ANDREN [1984], and many marine studies) raise the possibility that polonium is released, not from transition metal oxides, but from remineralized organic matter. To test this hypothesis, $21^{\circ}$ Po was plotted as a function of the amount of organic carbon oxidized (Figure 4.5.4b). The latter parameter was calculated from the sum of oxygen depletion and reduced $\mathrm{Mn}$ and $\mathrm{Fe}$ production, each weighted according to the stoichiometry of the appropriate reaction. As can be seen in Figure 4.5.4b, ${ }^{210}$ Po does increase linearly with organic matter mineralization, but the release rate accelerates dramatically as soon as the water column becomes anoxic (open circles to the left of the dotted line). Since there is no reason to expect organic matter oxidation to accelerate under anoxic conditions, the implication is that $210 \mathrm{Po}$ is associated more with some other phase than with organic matter. A likely candidate for the other phase is transition metals, whose rate of solubilization would increase with anoxia. ${ }^{210} \mathrm{Po}$ in Relation to Iron and Manganese

The difference between the timing of releases of $2{ }^{10} \mathrm{Po}$ and $2{ }^{20} \mathrm{~Pb}$ still needs explanation, and it is tempting to draw a parallel with the differential behavior of $\mathrm{Mn}$ and $\mathrm{Fe}$; manganese is reduced more easily and released somewhat earlier. Unfortunately, it is difficult to distinguish between the influence of these two metals since total $21^{\circ}$ Po shows a good correlation with either manganese (Figure 4.5.4c) or iron 
FIGURE $4.5 .4 \mathrm{~b}$ TOTAL 210 Po VS. CUMULATIVE ORGANIC MATTER OXIDATION

210 Po v. CARBON OXIDATION

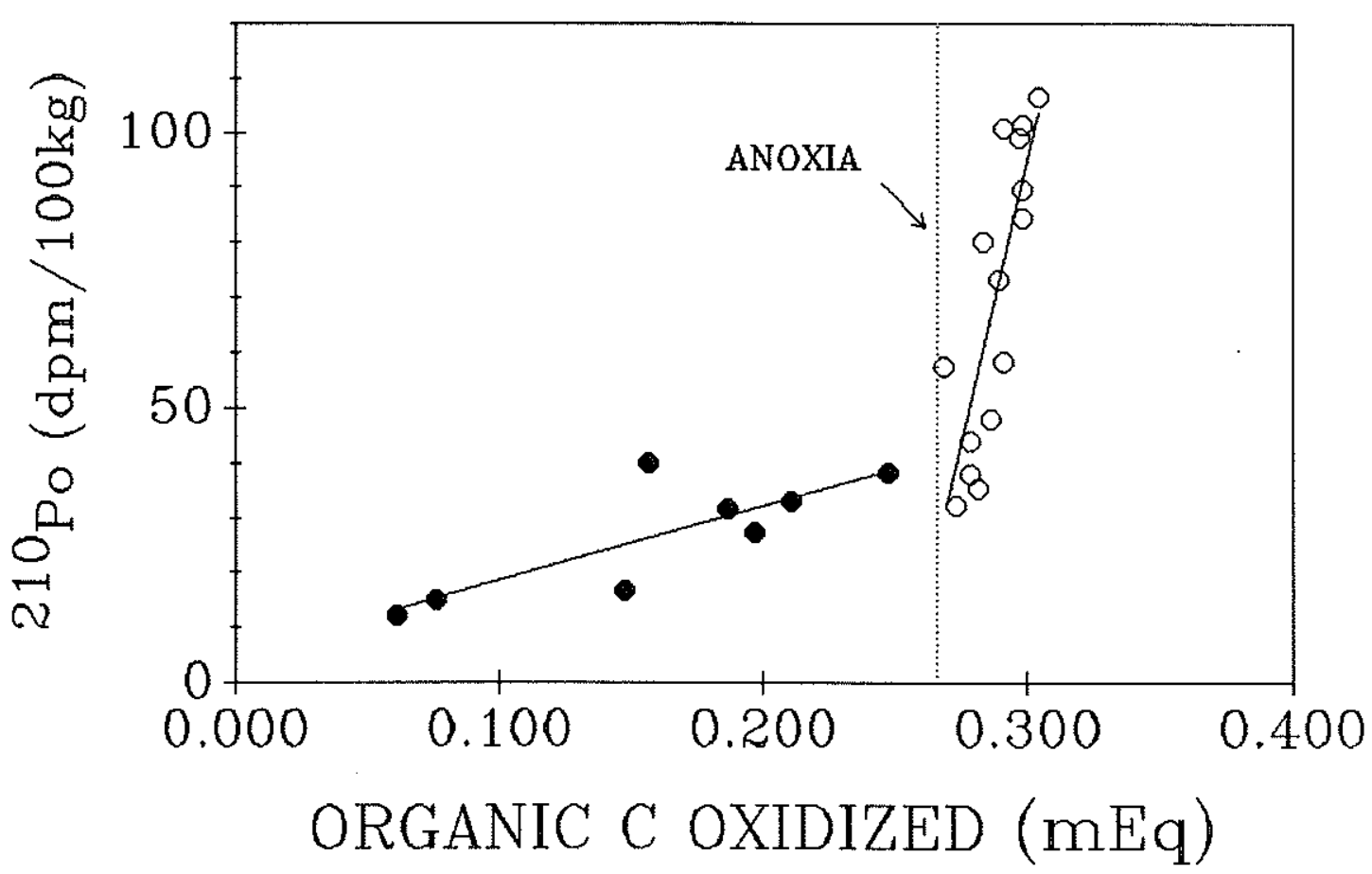


FIGURE $4.5 .4 \mathrm{c}$ and $\mathrm{d}$ : TOTAL 210Po VS. TOTAL MANGANESE AND TOTAL IRON IN THE WATER COLUMN

\section{Po v. MANGANESE}

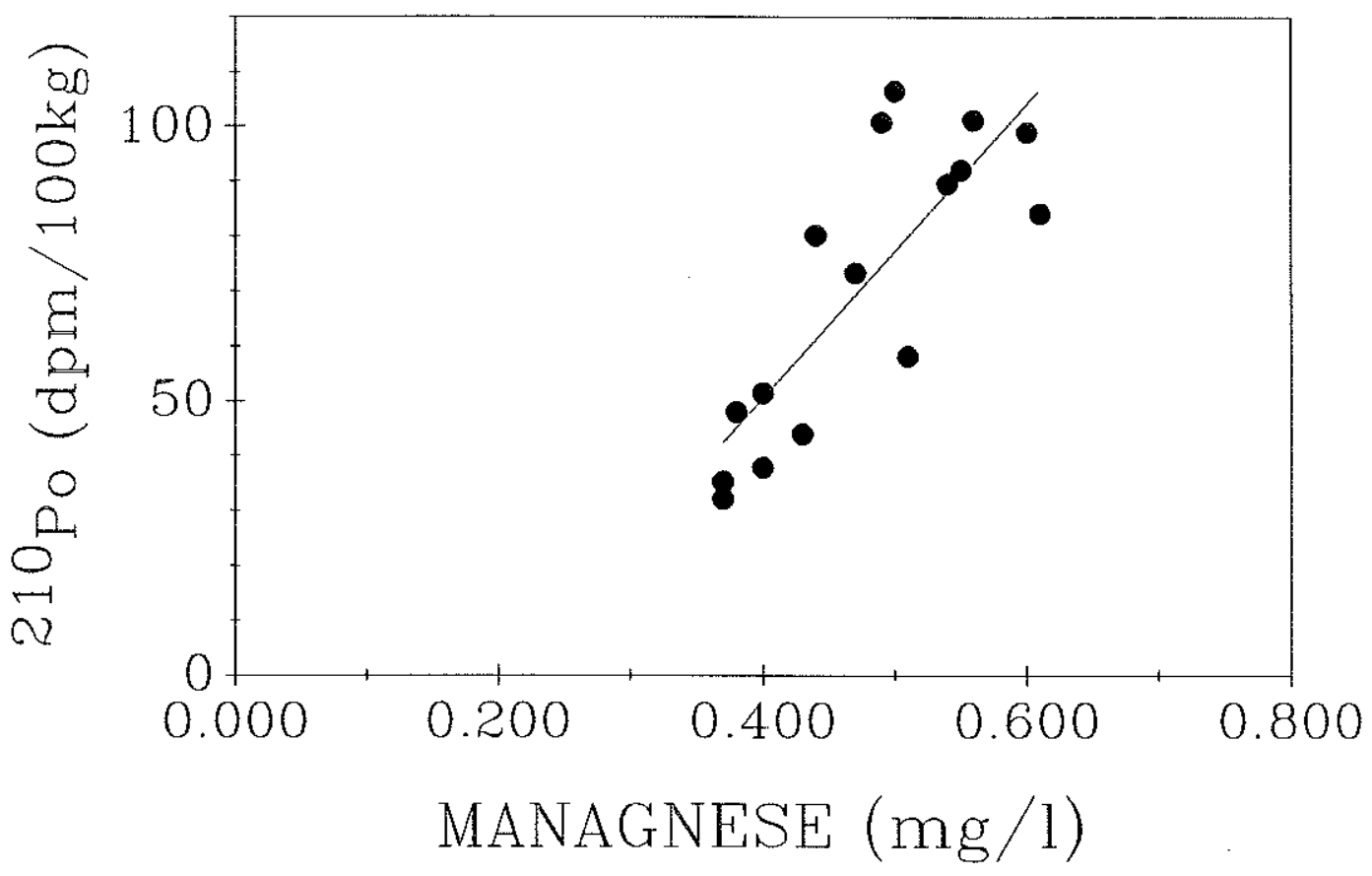

$210^{\text {Po v. IRON }}$

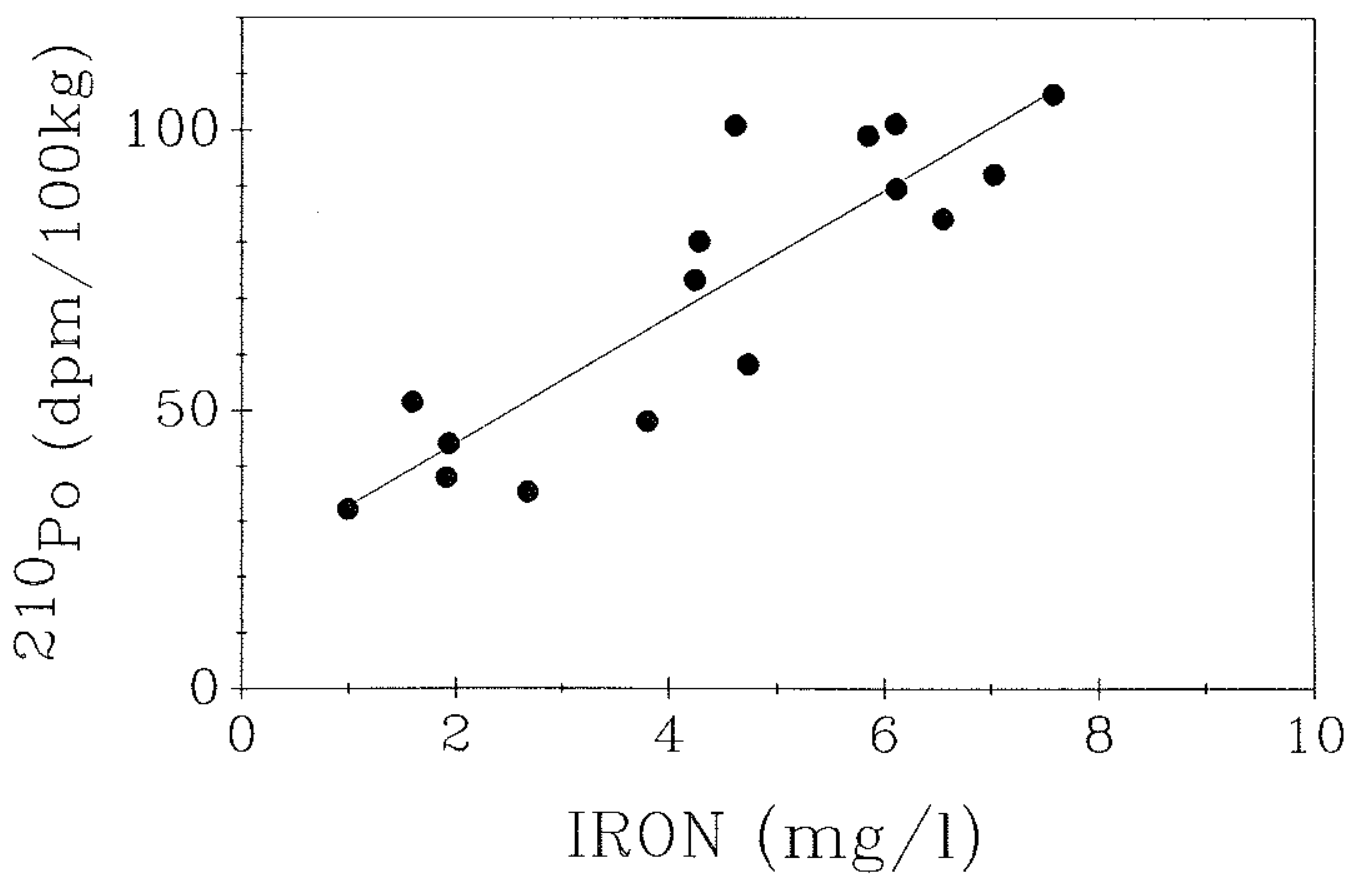


FIGURE 4.5 .4 e TOTAL IRON VS. TOTAL MANGANESE IN THE WATER COLUMN

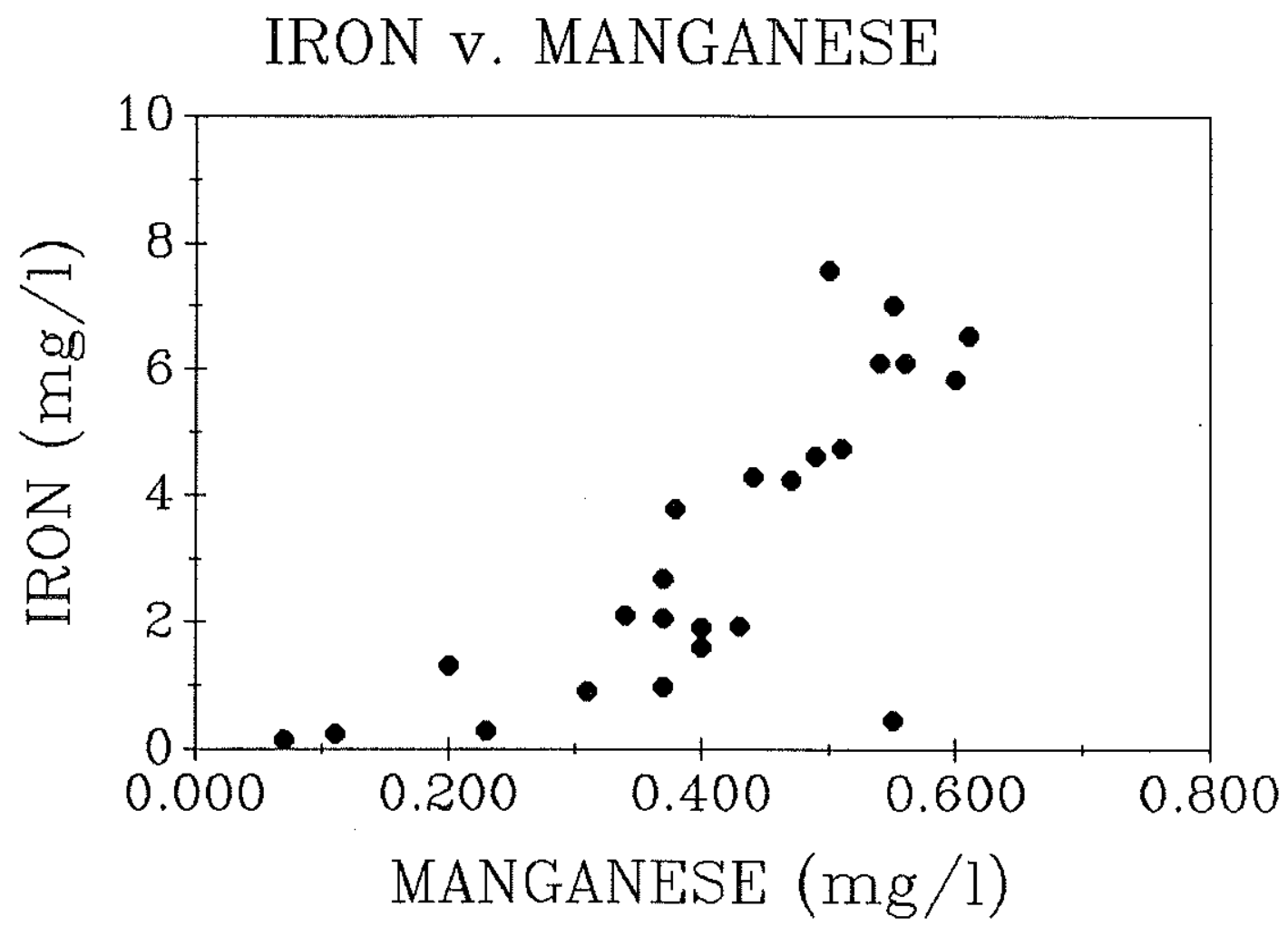


(Figure 4.5.4d). This result is not surprising since $\mathrm{Fe}$ and $\mathrm{Mn}$ are correlated with each other to some extent (Figure 4.5.4e). The sequential leaching data are of little help in determining which metal might control polonium. At all depths in the sediments, $21{ }^{\circ}$ Po was predominantly released by the $\mathrm{HF}$ treatment (averaging $80 \%$ ), and it seems probable that this is an experimental artifact. All of the sedimentary polonium is produced from $2{ }^{210} \mathrm{~Pb}$ via an energetic beta decay step. It seems unlikely that polonium, bound at a site originally occupied by $210 \mathrm{~Pb}$ and further "loosened" by beta decay, should be more tightly bound than its progenitor (which is predominantly released by reducing treatments and not $\mathrm{HF}$ ). Instead, I believe that $210 \mathrm{po}$ is mobilized by an earlier leaching step, but then sorbs strongly to the container walls or glass filter fibers, from which it is liberated by HF. The tendency for ${ }^{210}$ Po to stick to such surfaces is well known (FIGGINS [1961]). Another sequential leaching study has found the same curious results for $21^{\circ}$ Po (DOMINIK et a1. [1983]).

No firm conclusion can be drawn, but circumstantial evidence supports the possibility that $210 \mathrm{Po}$ is more strongly associated with iron than manganese. Plotting total water column levels of the two transition metals as a function of oxygen depletion, it is apparent that manganese reaches near maximal levels before anoxia (Figure 4.5.4f), while iron increases dramatically only after oxygen depletion (Figure 4.5.4g). The ${ }^{210}$ Po behavior illustrated in Figure $4.5 .4 \mathrm{~b}$ (rapid release following anoxia) thus seems to parallel iron (Figure $4.5 .4 \mathrm{~g}$ ) more than manganese (Figure 4.5.4f). Also, iron is much more abundant in sediments than is manganese, and the water column data show a better correlation for ${ }^{210}$ Po with Fe than Mn, especially when data from the 
FIGURE 4.5.4f TOTAL MANGANESE VS. WATER COLUMN OXYGEN CONSUMPTION

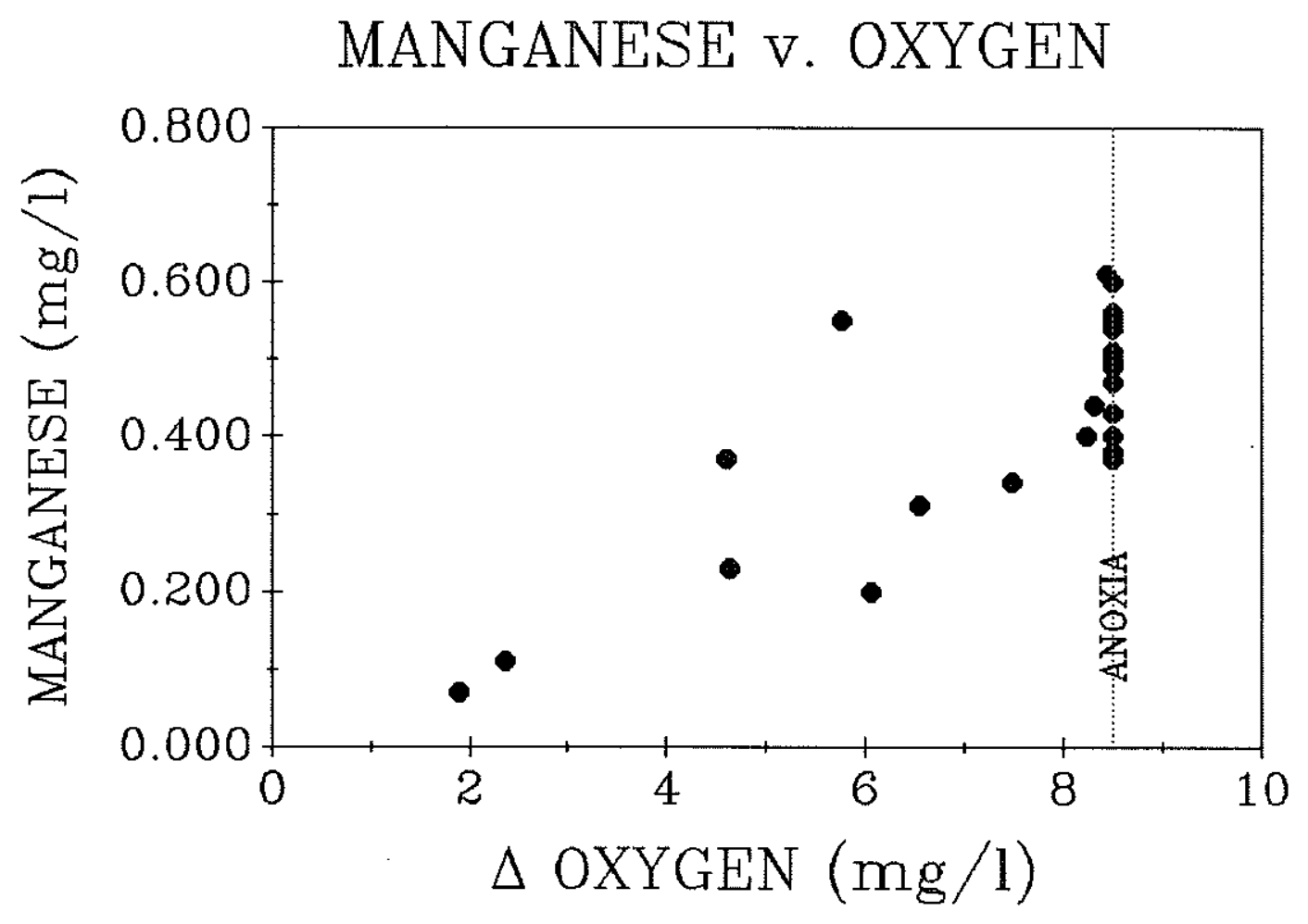


FIGURE $4.5 .4 \mathrm{~g}$ TOTAL IRON VS. WATER COLUMN OXYGEN CONSUMPTION

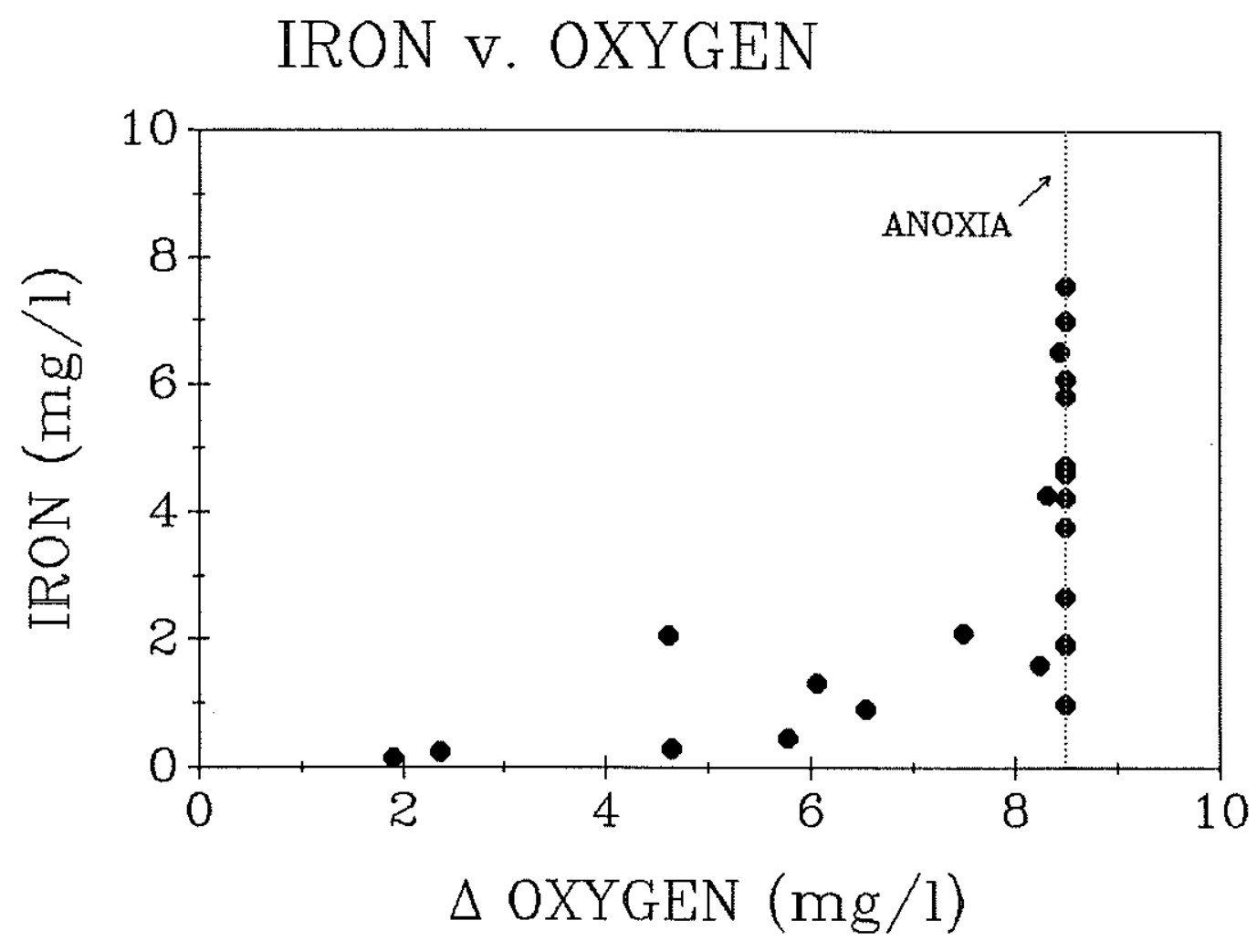


pre-anoxic period are included. Finally, for sediments, the sequential leaching data show that of the $20 \%$ of ${ }^{210}$ Po not liberated by HF, most was released by the strong reducing leach that solubilized $90 \%$ of the iron.

Failure of the Horizontal Model for $210 \mathrm{Po}$

An attempt to explain the distribution of ${ }^{210}$ Po by the constant flux-horizontal mixing model of section 4.5.2 was not successful.

Figure $4.5 .4 \mathrm{~h}$ shows that ${ }^{210}$ Po reached high levels before the onset of anoxia, and did not conform to a straight line relationship like Fe (Figure 4.5.2a) or ${ }^{210} \mathrm{~Pb}$ (Figure 4.5.2b). The failure of the horizontal model to describe 210 Po release means that one or more of its assumptions are invalid for this radionuclide. Clearly the assumption of no release from sediments overlain by oxic water is invalid, since $21{ }^{\circ}$ Po builds up to nearly half its maximum value before complete oxygen depletion. The other assumption that may be violated is that of no removal from the water column. If $21^{\circ}$ Po is rapidly scavenged by settling iron oxyhydroxides, the scatter of the data and the apparent slackening of ${ }^{210}$ Po release (data points on the right in figure $4.5 .4 \mathrm{~h}$ ) might be explained. Preferential removal of $2{ }^{20} \mathrm{Po}$ compared to ${ }^{210} \mathrm{~Pb}$ is consistent with the fact that it has a greater tendency to associate with particles (section 4.3.8).

This also recalls an apparent paradox mentioned earlier; ${ }^{210} \mathrm{Po}$ is released more readily from bottom sediments but is scavenged more effectively by suspended sediment. Two explanations seem possible. First, polonium may be released by one solid phase and rescavenged by another. As an example, $2{ }^{\circ}$ Po may arrive at the sediment water interface with organic matter or manganese oxyhydroxides. These could 
FIGURE $4.5 .4 \mathrm{~h}$ HORIZONTAL TRANSPORT MODEL FOR 210Po

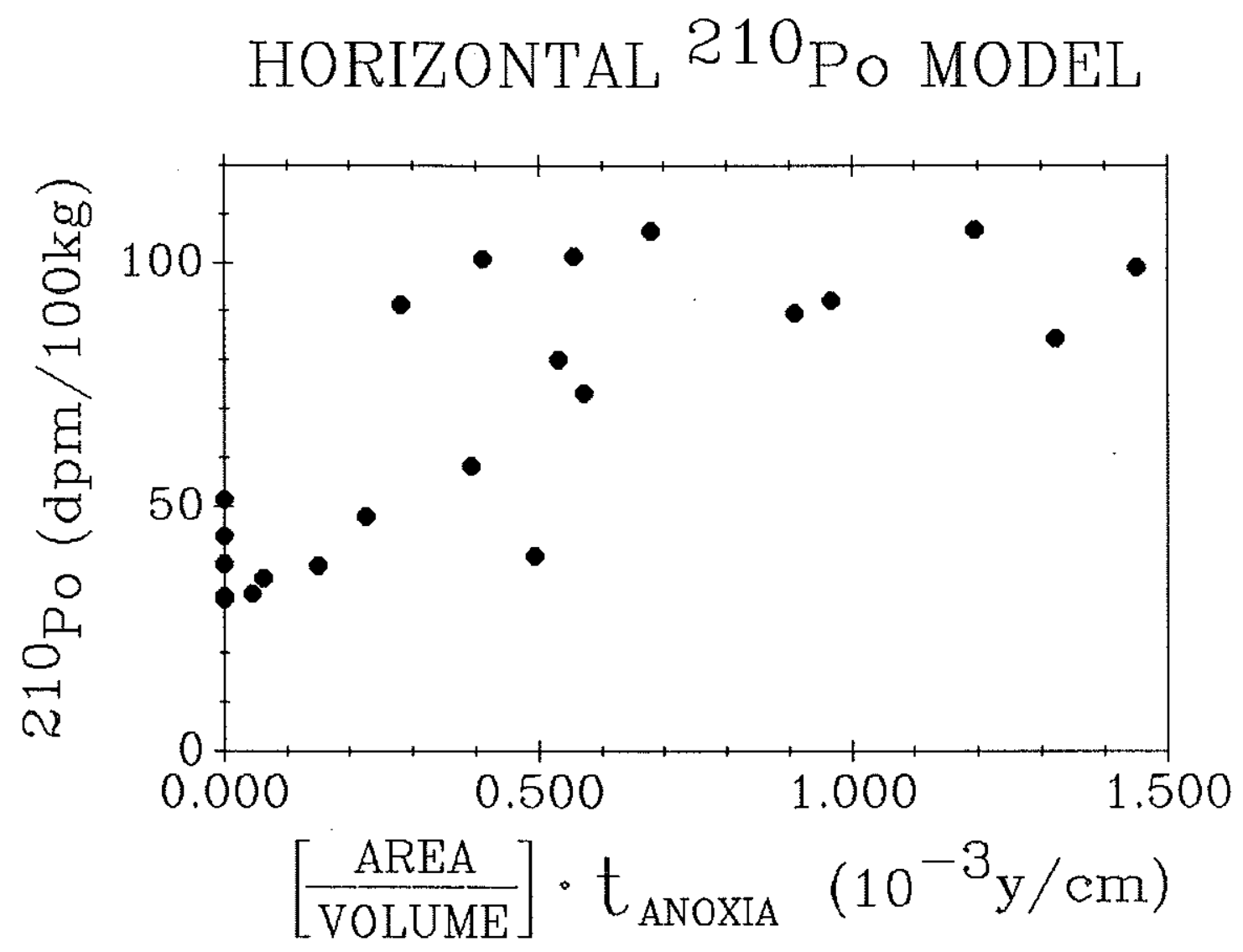


release their polonium burden in the early stages of oxygen depletion and at the same time be irreversibly lost from the system. ${ }^{210} \mathrm{~Pb}$ on the other hand seems to be associated with iron, which is released later. Then when iron oxides precipitate and settle to the bottom, they might scavenge ${ }^{210} \mathrm{Po}$ more effectively than ${ }^{210} \mathrm{~Pb}$. The second possibility is that polonium occurs in two diffexent oxidation states. In this scenario, $21^{\circ} \mathrm{Po}$ is directly reduced and remobilized. Then in the water column it is oxidized and reprecipitates. FIGGINS (1961) described the redox chemistry of polonium, which, under oxygenated conditions, occurs in the tetravalent state. Evidence exists for valences of $-2,+2,+4$, and +6 , but information on redox potentials is limited. Tetravalent polonium hydroxide is insoluble, so if reduction of $\mathrm{Po}^{4}$ to $\mathrm{Po}^{2}$ occurs near the same pe as that of the $\mathrm{Mn}^{2+} / \mathrm{Mn}^{4}{ }^{+}$couple and if bivalent polonium is soluble, then a mechanism could exist for precipitationremobilization. 
CHAPTER 5 SEDIMENTS I $210 \mathrm{~Pb}$ DISTRIBUTIONS AND INVENTORIES

\subsection{INTRODUCTION}

The main interest in $210 \mathrm{~Pb}$ is in relation to its use as a geochronometer of lake sediments. For that reason, determining sedimentation rates is the logical first step in studying the geochemical cycling of $210 \mathrm{~Pb}$ in the sediments of Bickford. In doing this we will take advantage of the transient (non-steady-state) nature of sedimentation at Bickford. Specific issues to be addressed are described in the following paragraphs.

Sediment focusing has been shown to have an important influence on the long-term, areal distribution of sedimentary components in a number of lake basins. Evidence for focusing of bulk sediment, stable lead, and $210 \mathrm{~Pb}$ has been found in some systems. Still, short term sediment trap studies have failed to see the effect for a number of metals in two studies. Also there is still only one study of $21^{\circ} \mathrm{Pb}$ focusing published to date. How has focusing influenced depositional patterns of $210 \mathrm{~Pb}$ and bulk sediment in the 15 years since the modern Bickford reservoir was filled? A total inventory of $210 \mathrm{~Pb}$ in the sediments of Bickford is prepared that closes and verifies the mass balances presented in chapter 4 of this thesis and in BENOIT and HEMOND [1987a]).

Vertical mixing in the sediment can create profiles that mimic distributions caused by purely depositional processes. We present a method that uses the known time of $210 \mathrm{~Pb}$ deposition to estimate the relative magnitude of mixing and sediment accumulation. It will be shown that the magnitude of non-depositional transport of $21{ }^{\circ} \mathrm{Pb}$ for this 
lake is consistent with estimates of purely chemical remobilization developed in chapter 6.

This chapter is also a case study in the application of $210 \mathrm{~Pb}$ dating to the interpretation of a complex lake history. Bickford has gone through at least three stages in its development. Like Bickford, many study sites are not undisturbed, but have undergone episodes of dam building or watershed alterations. These events produce cores with kinks and other non-steady-state shapes along with dissimilarities in profiles at different locations in a basin. Here we use a combination of historical records, sediment profiles, and knowledge gained about $21^{\circ} \mathrm{Pb}$ cycling to explain the observed anomalies and unravel the complicated record of change at this location.

\subsection{METHODS}

Cores were collected by divers in July 1981 using 2.4 and $3.0 \mathrm{~cm}$ diameter metal tubing, frozen, and extruded after melting the outer surface of the core by dipping in warm water. The extruded core, kept frozen by occasional dipping in liquid nitrogen, was cut into sections with a hacksaw blade. Additional cores were collected by divers in November 1984 in $3.9 \mathrm{~cm}$ diameter plastic tubing that had been pre-cut vertically on two sides and taped back together. These cores were opened at the hinge upon return to the laboratory and sliced at 0.5 to $1.0 \mathrm{~cm}$ intervals with a knifeblade. Two additional cores were collected in August and September 1985 especially for analysis of porewaters. These were taken by divers from the deepest part of the lake in $12.7 \mathrm{~cm}$ diameter PVC pipe. Collection and processing of these cores is described in section 6.2.1. Sediment samples were taken after porewaters had been separated by centrifuging and decanting. Finally 
two cores were taken by divers in November 1986 using the same PVC pipe. In this case the larger cores were used to provide sufficient material for ${ }^{137} \mathrm{Cs}$ analysis rather than porewater collection. These cores were sectioned in the same way but without centrifuging. Cores are designated by the last two digits of the year of collection followed by an additional digit indicating its order of collection within that year. For example, core 84-5 was the 5th core collected in 1984. Sampling locations are shown in Figure $2 \mathrm{a}$, and were selected to include all depths and basin bottom types.

The outside of each core section was sliced away, the volume and weight of the remaining sample determined, and the sample dried to constant weight at $105^{\circ} \mathrm{C}$. Transferred to a Teflon beaker, the sample was dissolved by fuming with concentrated $\mathrm{HNO}_{3}$ and $\mathrm{HF}$, and then brought to dryness twice with dilute $\mathrm{HCl}$ to eliminate any trace of $\mathrm{HF}$. The residual material was then measured for $21^{\circ} \mathrm{Pb}$ by alpha spectrometry of its grand-daughter ${ }^{210} \mathrm{Po}$ as described in Chapter 2.

\subsection{RESULTS AND DISCUSSION}

Results of these analyses are presented in Figures 5.4.3a through 1 and $5.8 \mathrm{a}$ through $\mathrm{d}$. Specific activity is plotted as a function of accumulated mass per area (rather than depth) to correct for changes in bulk density with depth caused by compaction. Values plotted are total $2{ }^{10} \mathrm{~Pb}$ uncorrected for support by ${ }^{226} \mathrm{Ra}$. At depth in the cores, where $210 \mathrm{~Pb}$ should be in equilibrium with its parent, nearly constant values between 2 and $3 \mathrm{dpm} / \mathrm{g}$ were observed. On the graphs, measured data are indicated by the open circles with error bars. The error bar on the $y$ axis is the one sigma counting error. The bar on the $\mathrm{x}$ axis does not indicate error, but rather the thickness of the sediment sampling 
interval. The continuous line is the results of a model calculation that will be described in section 5.4 .

Initial attempts to interpret the ${ }^{210} \mathrm{~Pb}$ activity vs. depth profiles in terms of sedimentation rates were not successful, even though many of the cores have sections that plot as straight lines on graphs of log of specific activity vs. cumulative mass. Sedimentation rates determined from these sections were in the range of 20 to $40 \mathrm{mg} / \mathrm{cm}^{2} \mathrm{y}$. Most of the cores were taken from areas of the lake basin that were added in 1970 when a new dam raised the water level by $7 \mathrm{~m}$. Multiplying a sedimentation rate of about $30 \mathrm{mg} / \mathrm{cm}^{2} \mathrm{y}$ by 15 years gives only $450 \mathrm{mg} / \mathrm{cm}^{2}$ of deposition, a value several times lower than the depths of high activity sediment observed at most locations. This means that sediment accumulation and processes that cause migration of deposited $210 \mathrm{~Pb}$ must have combined to create the observed profiles.

\subsection{SEDIMENT MIXING MODEL}

\subsubsection{MODEL DESCRIPTION}

In order to test whether ${ }^{210} \mathrm{~Pb}$ distributions are the result of deposition plus migration, and to estimate true sedimentation rates, a model was developed that takes advantage of the fact that sediment accumulation at Bickford Reservoix has not yet reached steady-state. In lakes that have been largely undisturbed for many $210 \mathrm{~Pb}$ half-lives, sediment profiles do not change with time because supply of ${ }^{210} \mathrm{~Pb}$ to the sediment surface is exactly balanced by decay within the sediment column. In a new lake with no sediment mixing, relatively high activity sediments begin to accumulate on low activity substrate. The rate of accumulation is indicated both by the rate of $210 \mathrm{~Pb}$ decrease with depth and also by the total thickness of higher activity sediments. In a new 
lake with partially mixed sediments, the situation is more complicated. Mixing may entrain high activity lake sediments down into the low activity substrate, giving a false sense of the "bottom" of the lake deposited material. Mixing also influences the shape of the ${ }^{210} \mathrm{~Pb}$-depth curve so that sedimentation rates based on these profiles would be exroneous. In order to circumvent these two difficulties a numerical model was developed that simulates mixing and sedimentation in a nonsteady state system.

For the purposes of the model, mixing was assumed to be Fickian, or pseudo-diffusional. It is important to understand that here, and elsewhere in this discussion, the term "mixing" is used very loosely to refer to all non-depositional processes that might influence ${ }^{210} \mathrm{~Pb}$ distributions in sediments. This could include chemical redistribution by diffusive or advective transport in pore waters as well as physical translocation as would occur during bioturbation. The term "mixing" is used for brevity, but it does not imply identification of a unique mechanism. There was no independent evidence for or observation of solid phase mixing of these sediments. The only restriction on the process(es) referred to as "mixing" is that it be Fickian. The governing equation for such a system is:

$$
\partial \mathrm{C} / \partial t=\mathrm{D}\left(\partial^{2} \mathrm{C} / \partial \mathrm{z}^{2}\right)-\omega(\partial \mathrm{C} / \partial \mathrm{z})-\lambda \times \mathrm{C}+\mathrm{P}
$$

where $C$ is the concentration of the radionuclide on solids, $D$ is the Fickian transport coefficient (assumed to be constant), $\omega$ is the sedimentation rate, $\lambda$ is the radioactive decay constant, and $P$ is the production rate from a parent radionuclide (BERNER [1980]). Analytical solutions exist for this equation for steady-state, where the term on 
the left is equal to zero. I was unable to find a solution for the nonsteady-state case with variable bulk density, and so instead I developed a numerical simulation model, SEDIMIX. This model breaks the sediment profile into minute depth increments and sequentially calculates each of the right hand terms in the governing equation for the initial conditions (first time increment). The results of this series of calculations are then used in the next time increment and the process is repeated up to the age of the core (the period from reservoir filling in 1970-71 to the time the core was taken).

The inputs to SEDIMIX are: 1) the bulk density profile, 2) the size of the time and depth increments, 3) the input rate of $210 \mathrm{~Pb}$ at the sediment water interface, 4) the supported activity, 5) the age of the core, 6) the mixing depth, 7) the sedimentation rate, and 8 ) the sediment mixing rate. The output of the model is a ${ }^{210} \mathrm{~Pb}$ activity vs. depth profile, which can be compared to the measured data. In practice, values for sediment accumulation and mixing rates are assumed, the model run, the output compared to the measurements, and the process repeated with a different combination of mixing and sedimentation rates. In this way an optimum combination of sediment mixing and accumulation rates can be found.

Comparison of the goodness-of-fit was carried out by calculating the root mean square error of the predicted curve relative to the measured data. The result of SEDIMIX analysis is a matrix of such r.m.s. error values for various sedimentation and mixing rates. The combination of sedimentation and mixing that gives the lowest r.m.s. error is judged to be the "correct" combination. Typically the best fit yielded an r.m.s. error close to $5 \%$ with a doubling of the error for a 
change in either sedimentation or mixing of \pm 5 to $20 \%$. The change in goodness-of-fit was more sensitive to sedimentation rate than to mixing, suggesting that the assigned sedimentation rates are slightly more certain. Figure 5.4.1a illustrates a typical pattern of variation in r.m.s. error as a function of different combinations of sedimentation and mixing. As is clear from this figure, fairly small departures away from the best-case combination lead to significant decreases in the success of the model's prediction. In other words, although the SEDIMIX approach does not yield a unique solution, it does provide a quite small cluster of reasonable possibilities.

\section{4 .2 MODEL IMPLEMENTATION}

The model input parameters were determined as follows. Bulk density profiles were measured on the cores or on duplicates collected at the same time and location. The size of the time and depth increments were dictated by the mode1. Finite difference models are subject to instabilities for certain combinations of depth and time increments. "Safe" combinations can be determined by stability analysis, which typically defines a safe ratio of the depth and time increments as a function of a nondimensional number such as the mesh Reynold's number (the ratio of convection to diffusion). For this mode1, a formal stability analysis was not carried out, but it was found by trial and error that the model was unstable for cases where the depth increment (in $\mathrm{g} / \mathrm{cm}^{2}$ ) was less than 10 times the time increment (in $\mathrm{y}$ ). In order to provide a margin of safety it was decided to use a $\Delta x / \Delta t$ ratio of 20 . Another problem with finite difference models is their inherent numerical diffusion. Because the depth increments used in the model are finite, and each is assumed to be perfectly mixed, a pulse of 
FIGURE 5.4.1a R.M.S. ERROR OF A SEDIMIX GENERATED PROFILE AS A FUNCTION OF SEDIMENTATION AND MIXING RATES

SEDIMIX RESULTS FOR CORE $81-1$

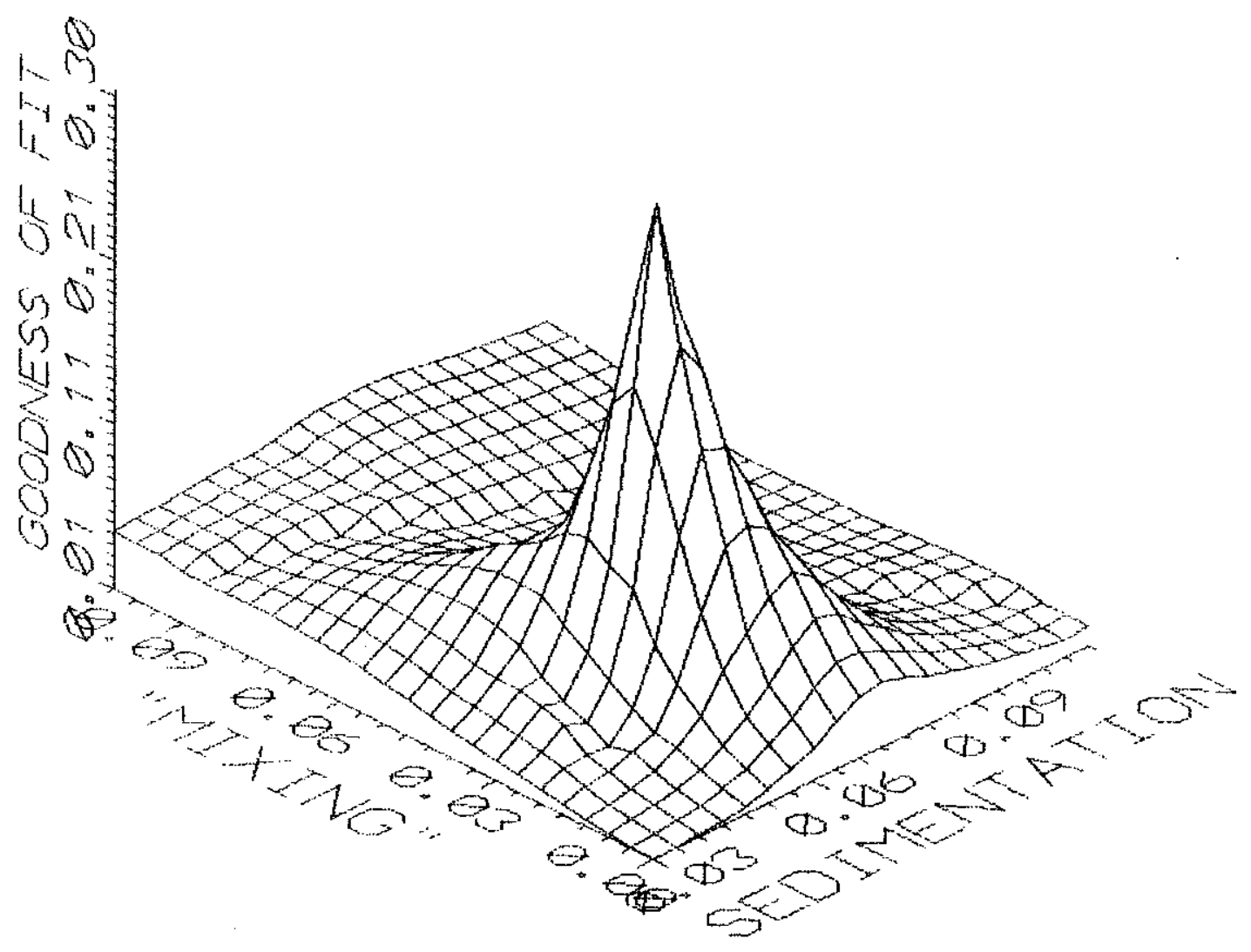

$$
\begin{aligned}
& \text { UNITS: } \begin{array}{ll}
\text { SEDIMENTATION } & -\mathrm{cm} / \mathrm{y} \\
\text { MIXING } & -\mathrm{cm}^{2} / \mathrm{y} \\
\text { GOODNESS OF FIT }-.01 / \text { R.M.S error }
\end{array}
\end{aligned}
$$


material in one interval has a slight tendency to be transmitted to neighboring intervals at a rate slightly greater than explicit advection and diffusion. This transport, termed numerical diffusion, decreases with the size of the depth increment. Trial and error runs showed that numerical diffusion did not influence the selection of optimum values of sedimentation and mixing rates when the depth increment was smaller than $0.05 \mathrm{~g} / \mathrm{cm}^{2}$. To allow a margin of safety, the depth increment was set to $0.02 \mathrm{~g} / \mathrm{cm}^{2}$. The 20:1 ratio between depth and time described above then set the time interval at $0.001 \mathrm{y}$.

The age of the cores was calculated as the difference between January 1981 and the date the core was collected. Records of the City of Fitchburg, Department of Public Works show that the reservoir filled completely within a 3 month period ending in January 1985. Before the reservoir was filled all of the topsoil and old lake sediments in the basin (except for one area to be discussed later) was stripped off and trucked out of the reservoir. Photographs taken just before the lake was filled show that all the organic soil material was removed, exposing pale-brown, mineral subsoil that should be almost free of excess ${ }^{210} \mathrm{~Pb}$. This material was loosened and reworked locally by wave action during reservoir filling, producing a veneer of soft, excess ${ }^{210} \mathrm{~Pb}$-free substrate upon which lake sediments began to accumulate. One area that was not stripped was the bottom of the old lake basin. In this area a sma11 turn of the century dam drowned a pre-existing bog (Figure 2b). Soil here would not support the weight of earth moving equipment and was left intact. As a result, cores from this region (numbers 84-3, 84-4, 84-5, and 86-1) contained sediment that was much older than the rest of the lake, and were not analyzed using the numerical model. 
The input rate of $210 \mathrm{~Pb}$ at the sediment water interface was found by correcting the inventory of excess $210 \mathrm{~Pb}$ in each core for the time of deposition. Excess $21^{\circ} \mathrm{Pb}$ was calculated as measured $21^{\circ} \mathrm{Pb}$ minus support, which was taken to be equal to constant ${ }^{210} \mathrm{~Pb}$ values at depth in the core or in nearby cores. As was described above, sediment at depth in the profiles may include upland subsoil exposed during reservoir construction. As such it is not necessarily equivalent to "old" lake-deposited sediment, and it may have a different ${ }^{226} \mathrm{Ra}$ content. On the other hand, the mineral fraction of all lake sediments is just soil material eroded from the watershed, and thus should be similar to soil in the basin. In any event, small errors in this assumed value would not affect the results significantly, since unsupported $210 \mathrm{~Pb}$ was much greater than any reasonably expected value for supported $210 \mathrm{~Pb}$.

The mixing depth was assumed to be equal to the thickness of sediments containing high $210 \mathrm{~Pb}$ levels. A single layer model was used because several of the cores had smooth profiles that argued against the likelihood of multiple layers with different mixing rates (as has been observed in some marine locations [e.g. CARPENTER et al. \{1982\}, DeMASTER et al. (1985\}]).

\subsubsection{MODEL RESULTS}

Sediment accumulation and mixing rates for the cores are listed in Table 5.4.3a. Figures 5.4.3a through 5.4.31 compare the measured data to the best-fit mode1 run. In three cases (cores 84-2, 84-6, and 84-7) the number of sections containing excess $210 \mathrm{~Pb}$ was insufficient to apply 
TABLE $5.4 .3 \mathrm{a}$ SEDIMENT ACCUMULATION AND MIXING RATES

\begin{tabular}{|c|c|c|c|c|}
\hline \multirow{3}{*}{ CORE } & WATER & & \multirow{2}{*}{\multicolumn{2}{|c|}{$\begin{array}{l}210 \mathrm{~Pb} \\
\text { INPUT }\end{array}$}} \\
\hline & DEPTH & ACCUMULATION & & \\
\hline & (m) & $\left(\mathrm{g} / \mathrm{cm}^{2} \mathrm{y}\right)$ & $\left(\mathrm{cm}^{2} / \mathrm{y}\right)$ & $\left(\mathrm{dpm} / \mathrm{cm}^{2} \mathrm{y}\right)$ \\
\hline $81-1$ & 5.2 & .060 & .030 & 1.56 \\
\hline $81-2$ & 8.0 & .100 & .035 & 1.36 \\
\hline $81-4$ & 4.5 & $(.000-.200)^{1}$ & $(.000-.480)^{1}$ & 1.65 \\
\hline $81-5$ & 6.0 & .175 & .080 & 3.39 \\
\hline $81-6$ & 11.5 & .190 & .055 & 5.58 \\
\hline $84-1$ & 12.0 & .070 & .030 & 2.13 \\
\hline $84-2$ & 12.0 & $\leq .115^{2}$ & $?$ & 1.08 \\
\hline $84-6$ & 4.0 & $\leq .020^{2}$ & $?$ & .44 \\
\hline $84-7$ & 4.6 & $\leq .070^{2}$ & $?$ & .84 \\
\hline $85-1$ & 12.0 & .060 & .040 & 2.33 \\
\hline $85-2$ & 12.0 & .085 & .090 & 2.85 \\
\hline $86-2$ & 6.5 & .015 & .085 & .58 \\
\hline
\end{tabular}

${ }^{1}$ Good fits possible for combinations of mixing and accumulation rates covering a large range.

${ }^{2}$ Number of sediment sections insufficient to apply accumulation/mixing mode1. Accumulation rate upper limit determined from total depth of high activity sediments. 
FIGURE 5.4.3a and $b$ : SOLTD PHASE 210Pb DATA FOR CORES $81-1$ AND $81-2$

MODEL: CORE 81-1

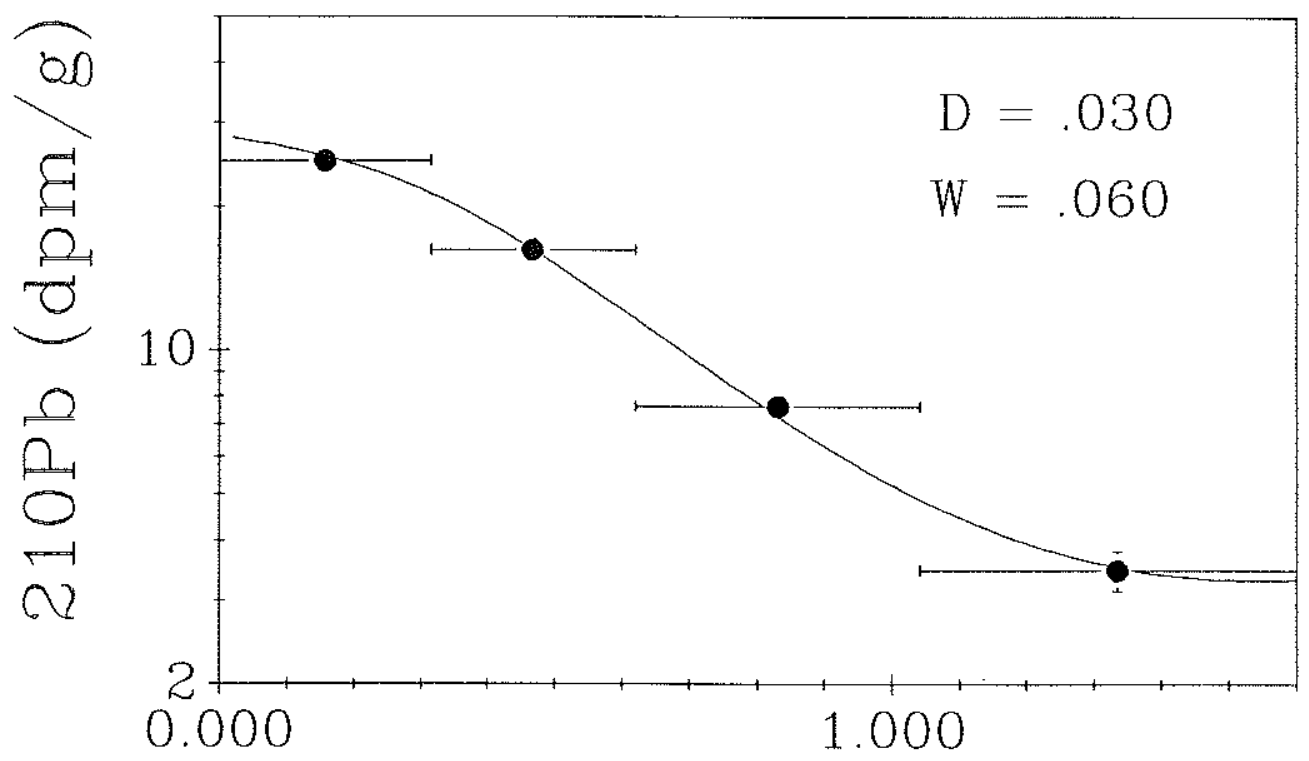

MODEL: CORE 81-2

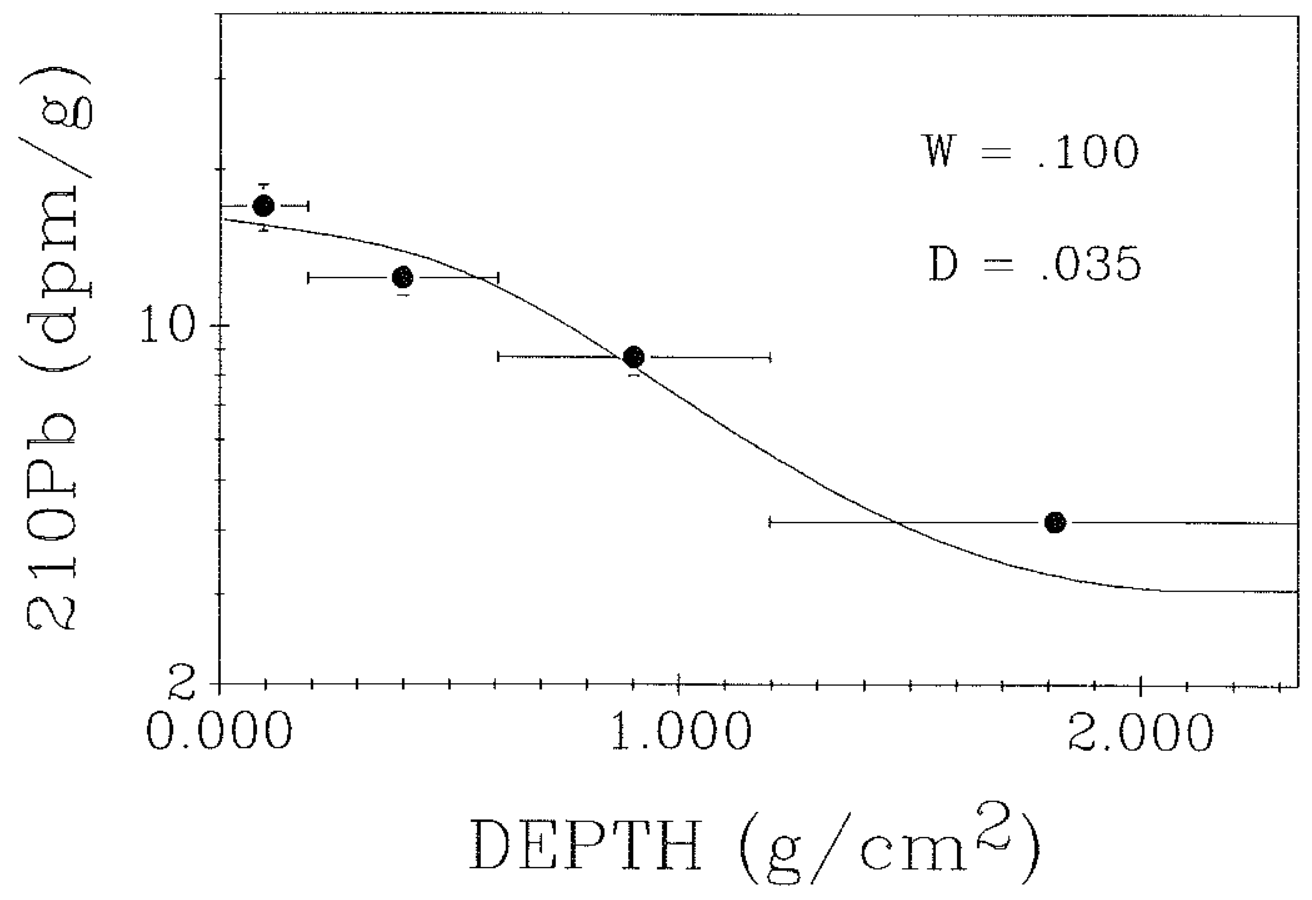


FIGURE 5.4.3c and $d$ : SOLID PHASE 210Pb DATA FOR CORES 81-4 AND 81-5

MODEL: CORE $81-4$

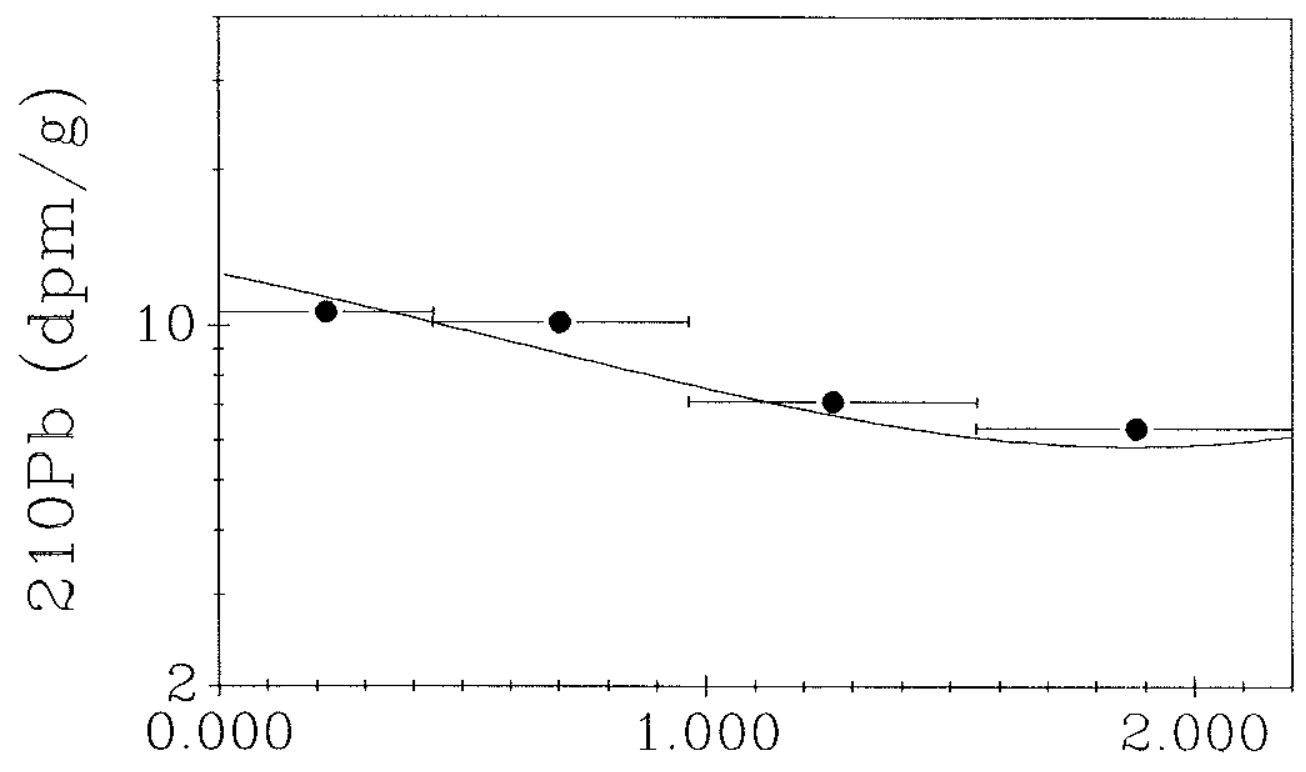

MODEL: CORE $81-5$

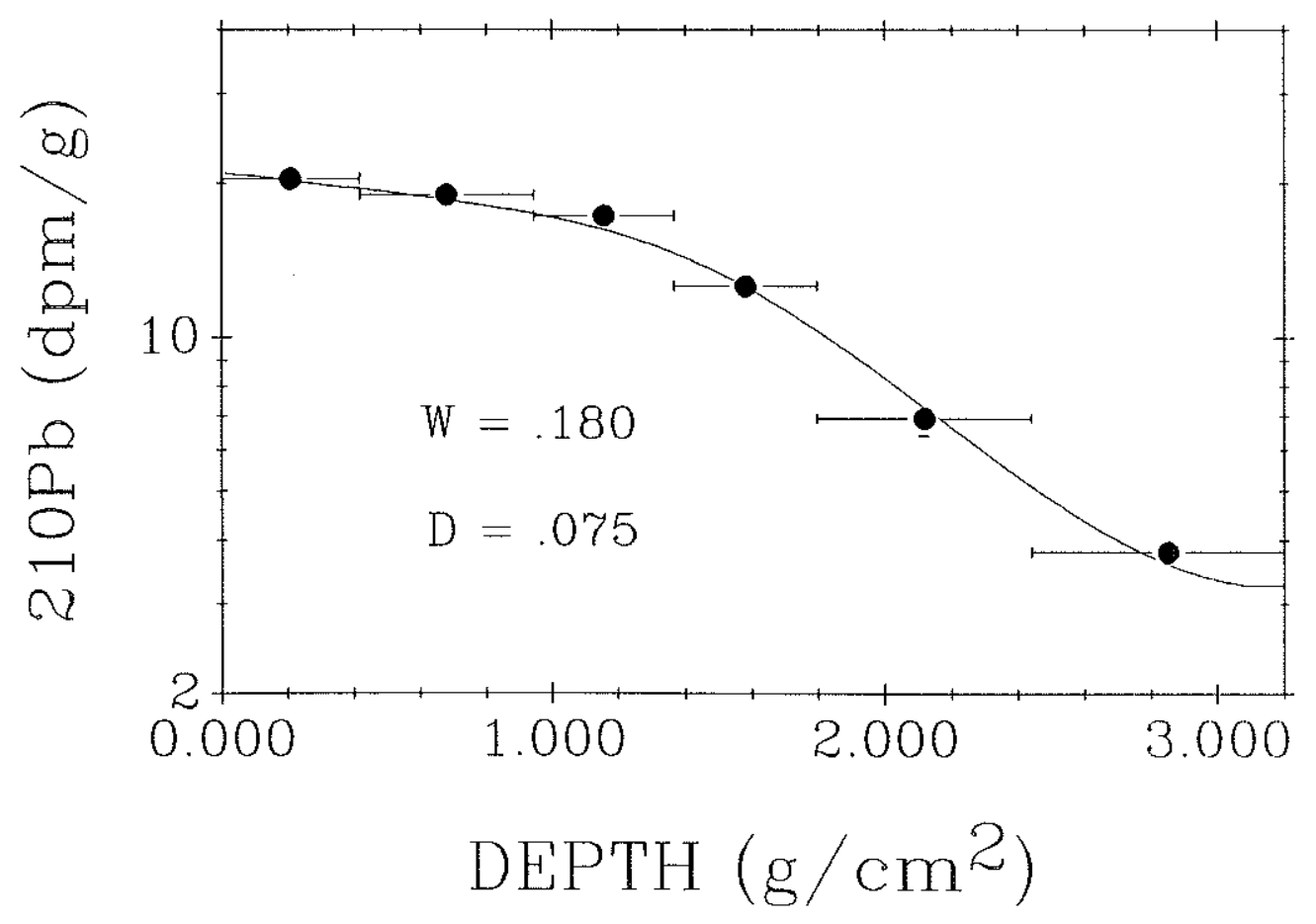


FIGURE $5.4 .3 \mathrm{e}$ and $\mathrm{f}$ : SOLID PHASE $210 \mathrm{~Pb}$ DATA FOR CORES $81-6$ AND 84-1

MODEL: CORE 81-6

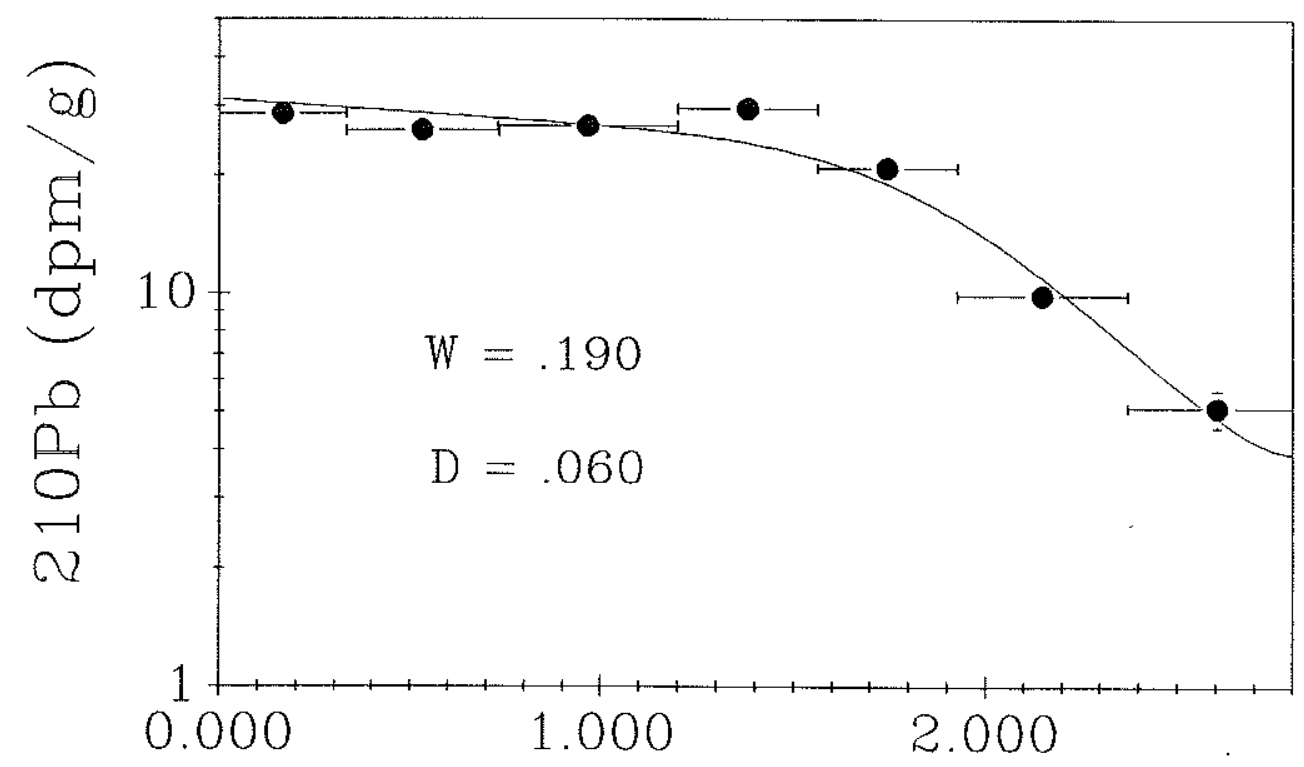

MODEL: CORE 84-1

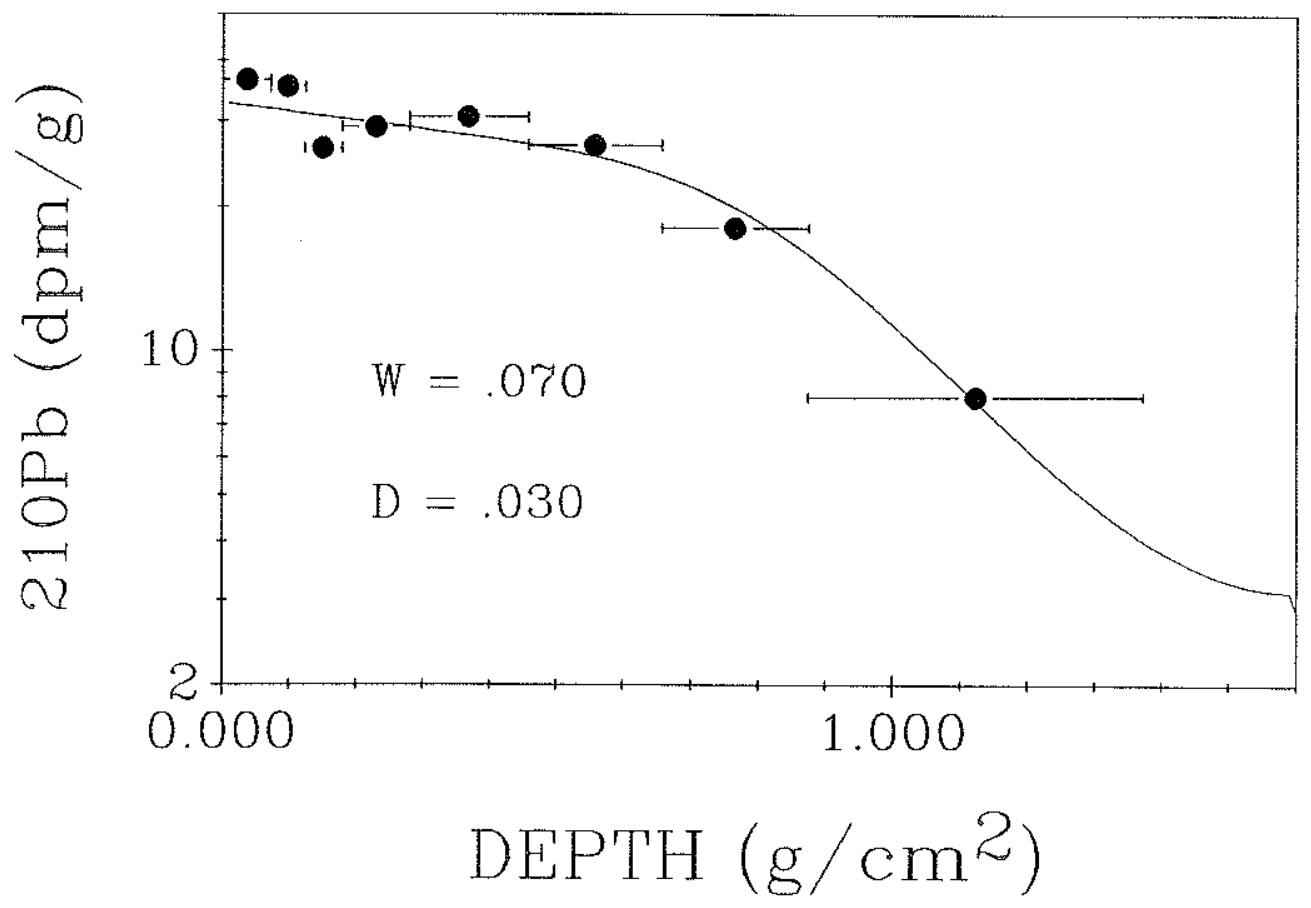


FIGURE 5.4.3g and h: SOLID PHASE 210Pb DATA FOR CORES 84-2 AND 84-6
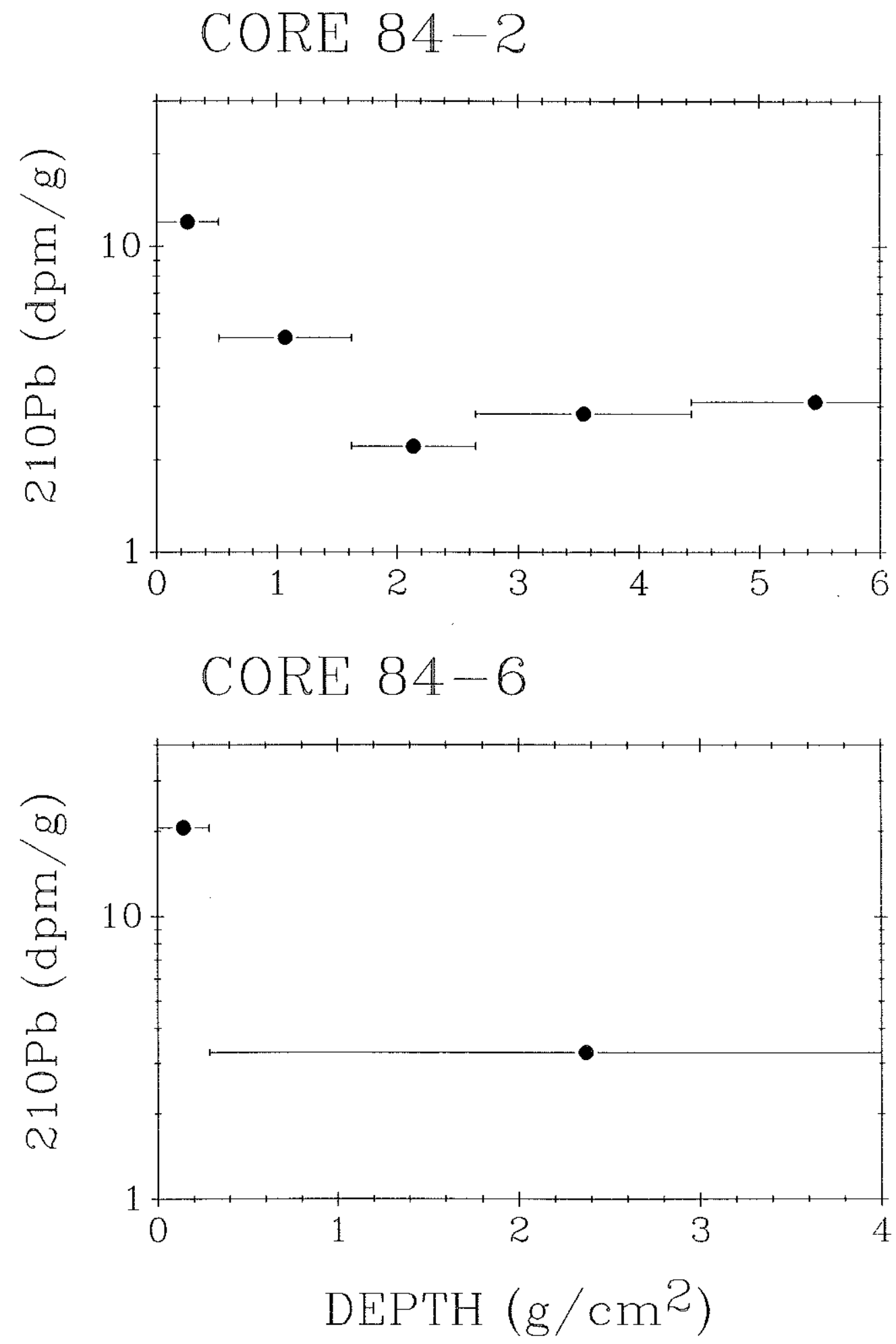
FIGURE 5.4.3i and $j$ : SOLID PHASE 210Pb DATA FOR CORES 85-1 AND 85-2

MODEL: CORE 85-1

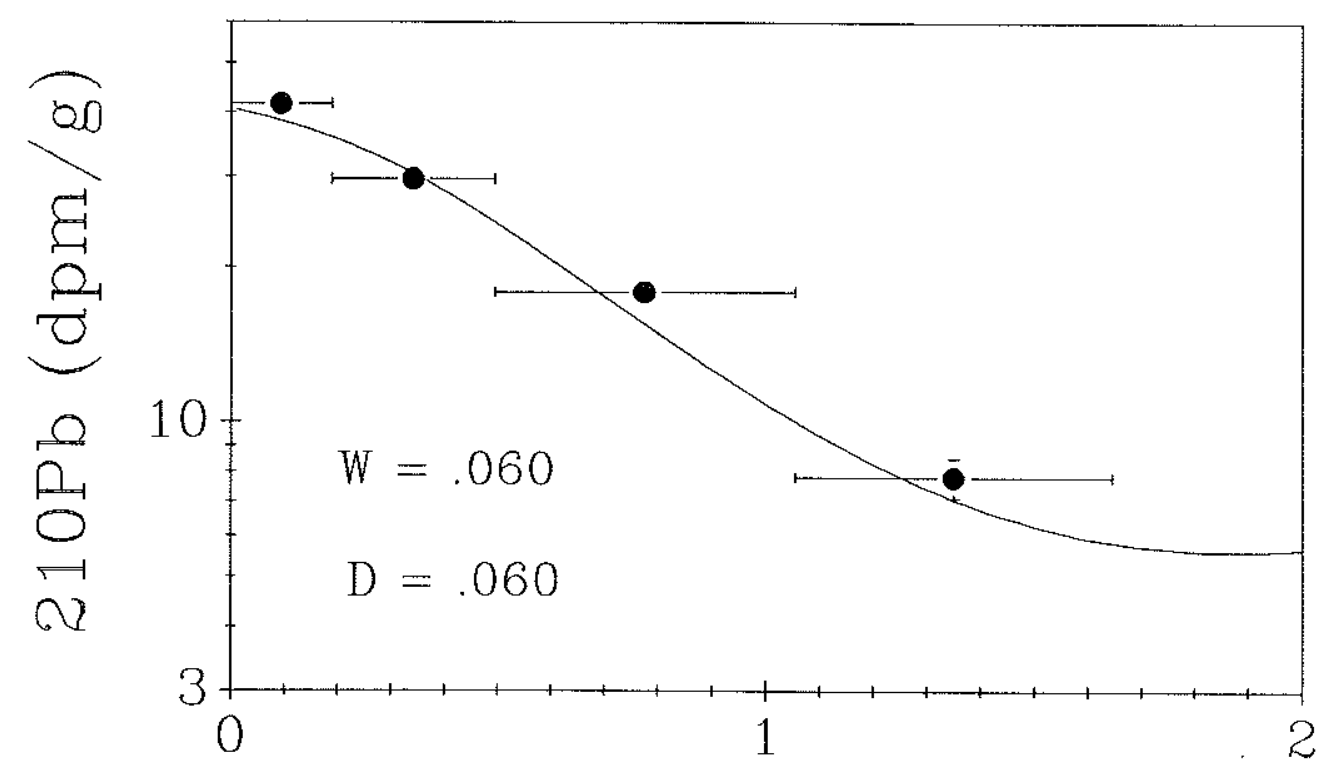

MODEL: CORE 85-2

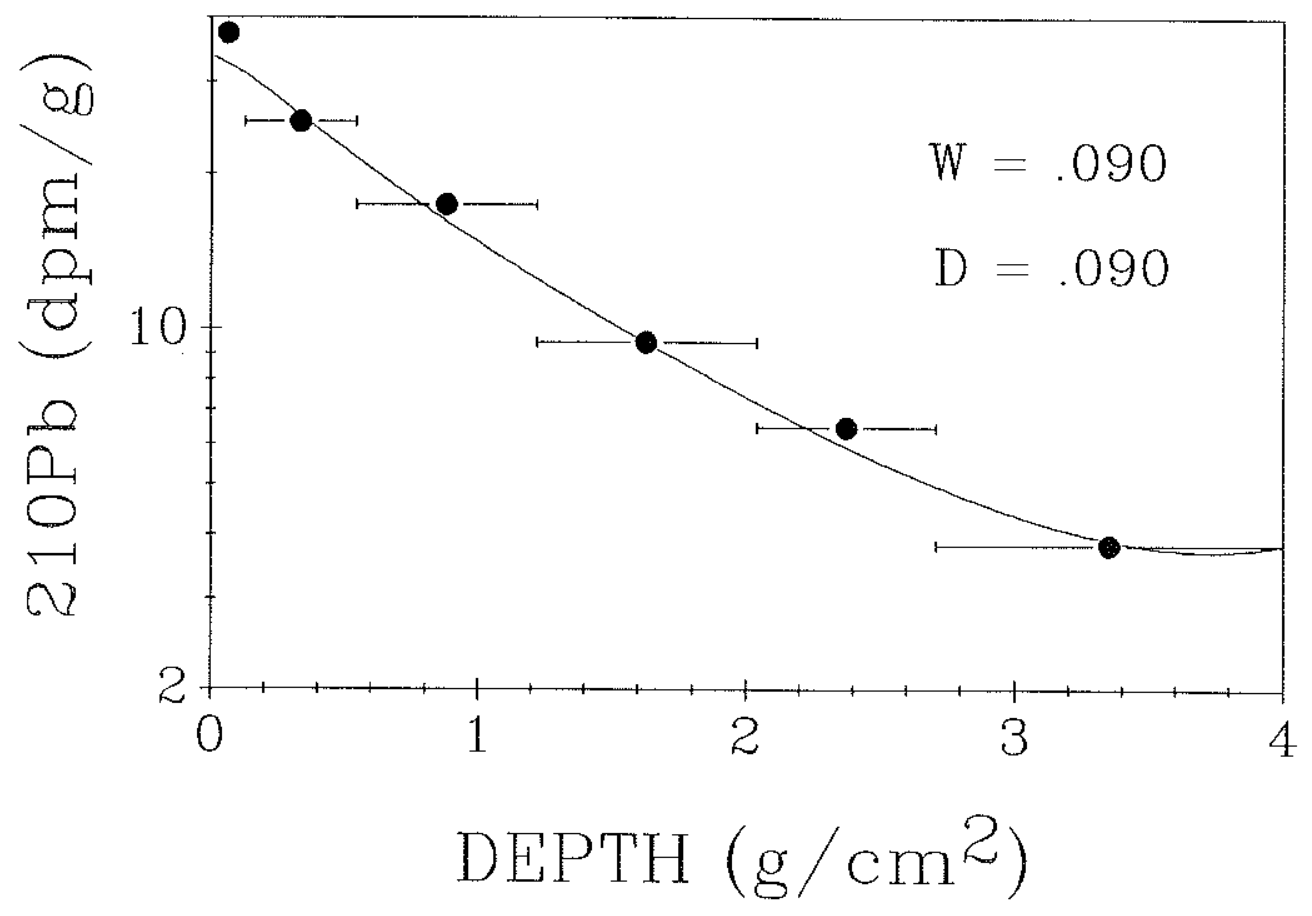


FIGURE 5.4.3k and 1: SOLID PHASE 210Pb DATA FOR CORES 84-7 AND 86-2
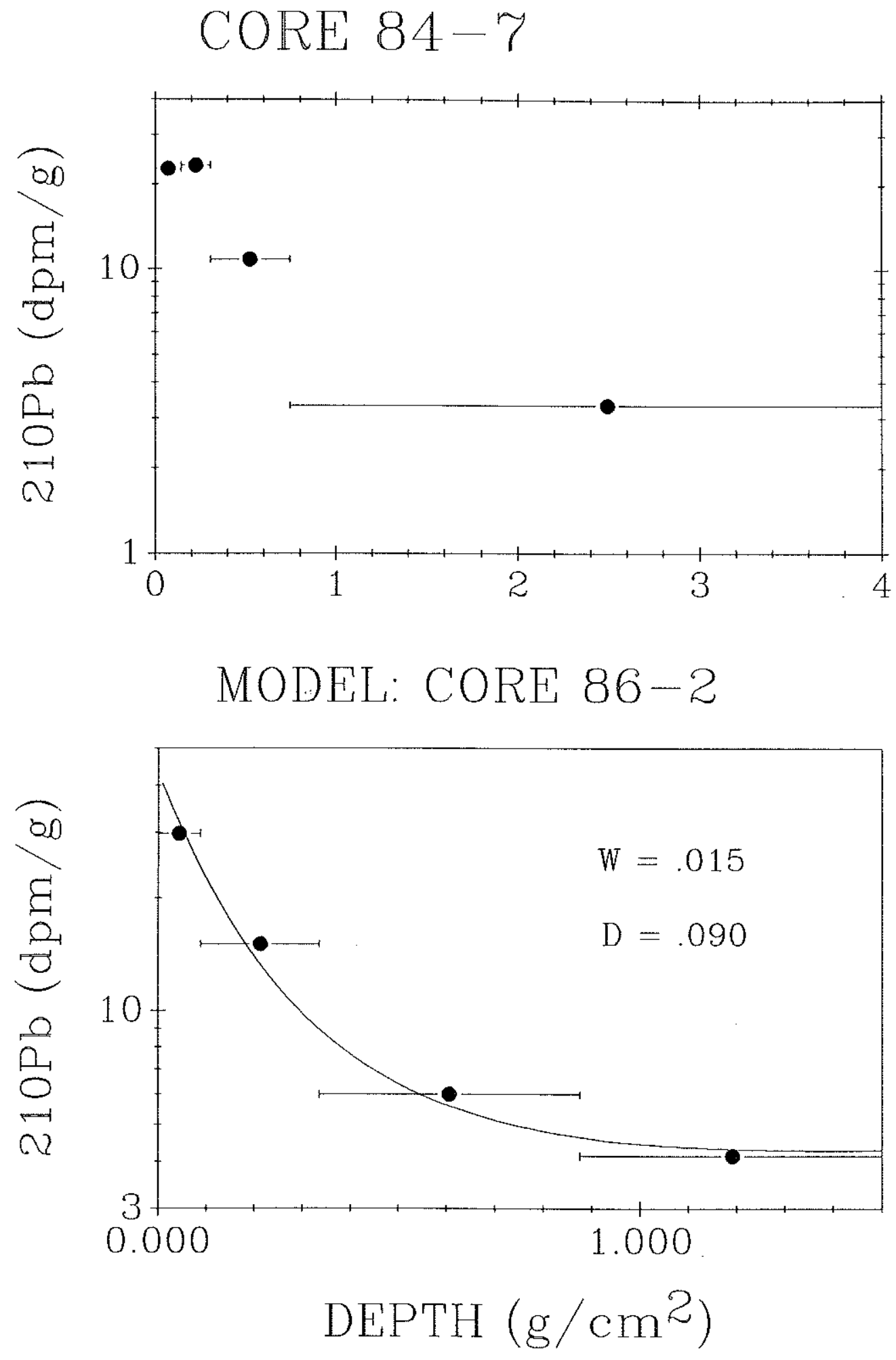
the accumulation/mixing model. In these cases, an upper limit for the accumulation rate was determined by dividing the thickness of high activity sediment by the time since reservoir filling.

\subsection{SEDIMENT ACGUMULATION RATES}

Sediment accumulation rates calculated with the model are comparable to values measured in a number of other lakes. A typical value for Bickford was $100 \mathrm{mg} / \mathrm{cm}^{2} \mathrm{y}$, which, when combined with a bulk density near $0.5 \mathrm{~g} / \mathrm{cm}^{3}$, is equivalent to a sedimentation rate of 0.2 $\mathrm{cm} / \mathrm{y}$. This falls near the middle of the range of lake sedimentation rates calculated by the $210 \mathrm{~Pb}$ method reported in the literature. Large lakes with low areal inputs of allochthonous materials have sediment accumulation measured in hundredths of a centimeter per year, while small and eutrophic lakes may collect as much as a few centimeters of sediment annually. The sediment accumulation rate in Bickford is comparable to that in nearshore marine locations (e.g. CARPENTER et al. [1981], HUH et al. [1987]), but much higher than deep ocean sites (BROECKER and PENG [1982]).

Within Bickford, the rate of sediment accumulation varies by more than a factor of ten (range 0.015 to $0.190 \mathrm{~g} / \mathrm{cm}^{2} \mathrm{y}$ ). Part of this variation seems to be caused by sediment focusing while some seems related to other factors including the influence of microtopography and localized sources of allochthonous sediment near stream mouths.

Sediment focusing is the preferential deposition of sediments in deeper parts of a lake. The cause of this phenomenon is not well known, but at least three processes probably contribute. 1) Sediments resuspended from shallow areas vulnerable to wind induced currents may be deposited in part to deeper areas. 2) Deeper sediments are overlain 
by a longer water column within which particle formation and aggregation can take place. 3) In some lakes, sediment slumping or turbidity currents may transport sediments downslope (BLOESCH and EVANS [1982]). Whatever the cause, the influence of sediment focusing has been observed in a number of lake basins (LEHMAN [1975], LIKENS and DAVIS [1975], EVANS and RIGLER [1980], DAVIS and FORD [1982], DILLON and EVANS [1982], EVANS and RIGLER [1983], DAVIS et a1. [1984]).

Focusing can involve sediments as a whole or it can be restricted to specific components. As an example, stable lead profiles presented by DILLON and EVANS (1982) revealed that surficial lead concentrations and sediment inventories increased with depth in two lakes. On the other hand, the total depth to which lead penetrated in the cores was nearly constant throughout the lakes. Since this depth represents sediments deposited during the last $100 \mathrm{y}$ (approximately), it appears that bulk sediments are not focused, even though lead is. An alternative explanation is that mixing rather than sedimentation controls the depth of lead penetration. But even if that is the case, the variation in concentration of lead in surficial sediments implies that lead (or its carrier phase) behaves differently from bulk sediment material. Another example of preferential focusing of an element is shown by EVANS and RIGLER's (1983) data for phosphorus, whose concentration (not inventory) increased in surface sediments linearly with water depth. Although the long-term net effect of sediment focusing has been well documented (see above), it has not been observed in short term sediment trap studies. DAVISON et al. (1982) found no focusing of iron in Esthwaite Water, U.K., and HESSLEIN et a1. (1980) saw no evidence of focusing of a suite of metal radiotracers. One 
possible explanation is that focusing is episodic, occurring infrequently during major storms.

Figures $5.5 \mathrm{a}$ and $5.5 \mathrm{~b}$ illustrate variations in bulk sedimentation and $210 \mathrm{~Pb}$ accumulation rates as a function of water depth. On both graphs, some cores were not included. Cores from the northern basin were excluded (accumulation rate graph only) because it was impossible to determine a sedimentation rate for them (see below). Cores 81-4 and 81-5 were excluded because they were taken from locations probably influenced by deltaic deposits from West Wachusett and Provencial Brooks, and thus are not typical of the open-lake depositional regime. The three cores for which only upper limits to the sedimentation rates could be determined were included at the maximum value. Adjusting the rates for these three cores downward to account for mixing would improve the correlation, but it was not known how large an adjustment was appropriate. (These cores could be included in the $21{ }^{\circ} \mathrm{Pb}$ inventory correlation without any correction.)

Overall, the graphs demonstrate that there is a moderate correlation between water depth and both bulk sedimentation and $210 \mathrm{~Pb}$ inventory. For sedimentation rate the correlation coefficient is .56 (N $=10$ ), which is significant at the $90 \%$ level (i.e. there is only a $10 \%$ probability of as great a correlation of the same number of data pairs drawn from a uncorrelated parent population [BEVINGTON, 1969]). The true correlation is probably even greater than this because cores at the lower sedimentation rate end of the curve may be artificially high due to a core selection bias of the SCUBA divers. In shallow parts of the lake, the thickness of soft lake sediments overlying firm, upland subsoil was quite variable. Some areas had greater sediment accumulation 
FIGURE 5.5a BULK SEDIMENT ACCUMULATION RATE AS A FUNCTION OF THE DEPTH OF THE OVERLYING WATER COLUMN

\section{SEDIMENTATION vs. Z}

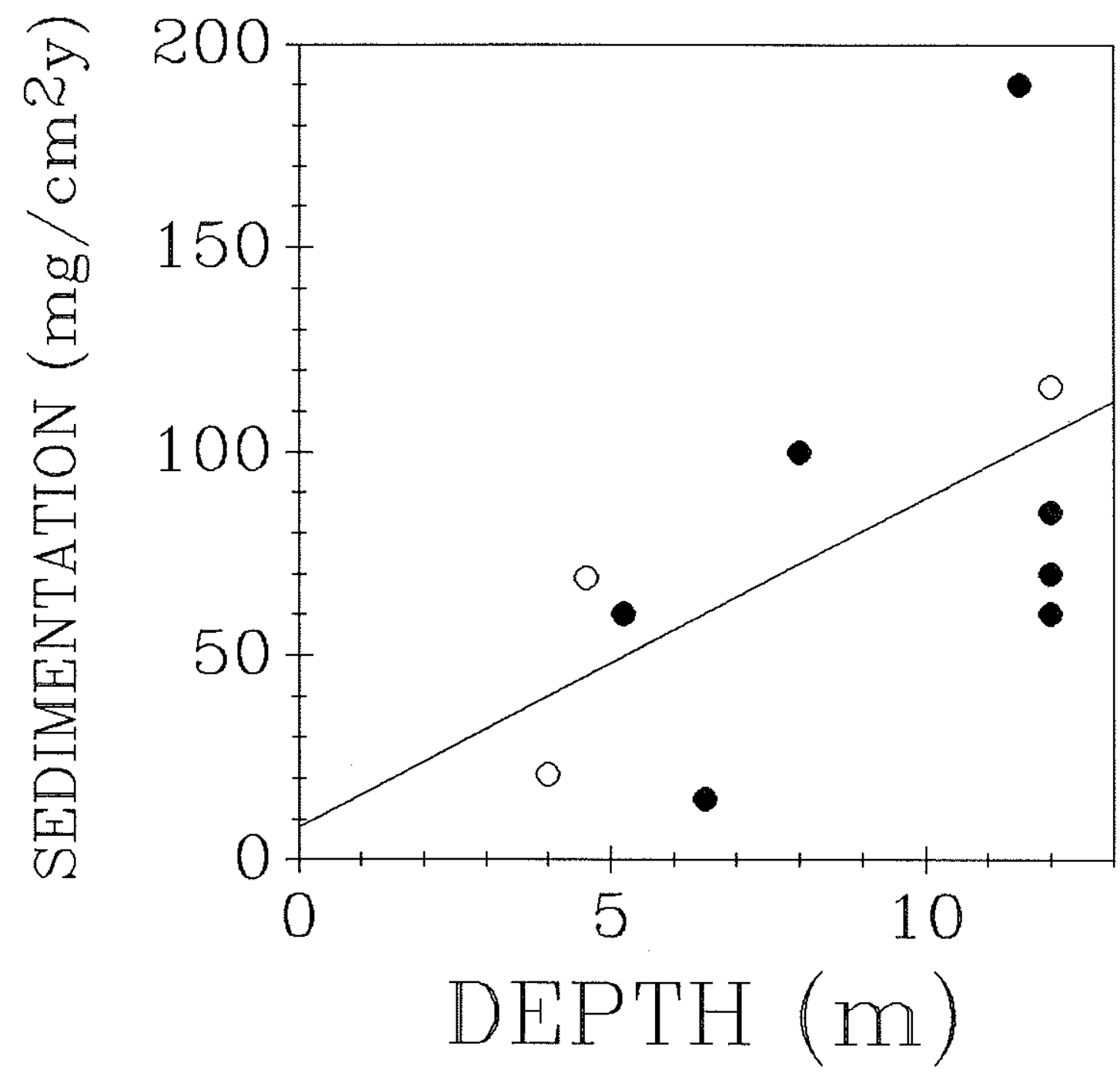


FIGURE 5.5b 210Pb ACCUMULATION RATE AS A FUNCTION OF THE DEPTH OF THE OVERLYING WATER COLUMN
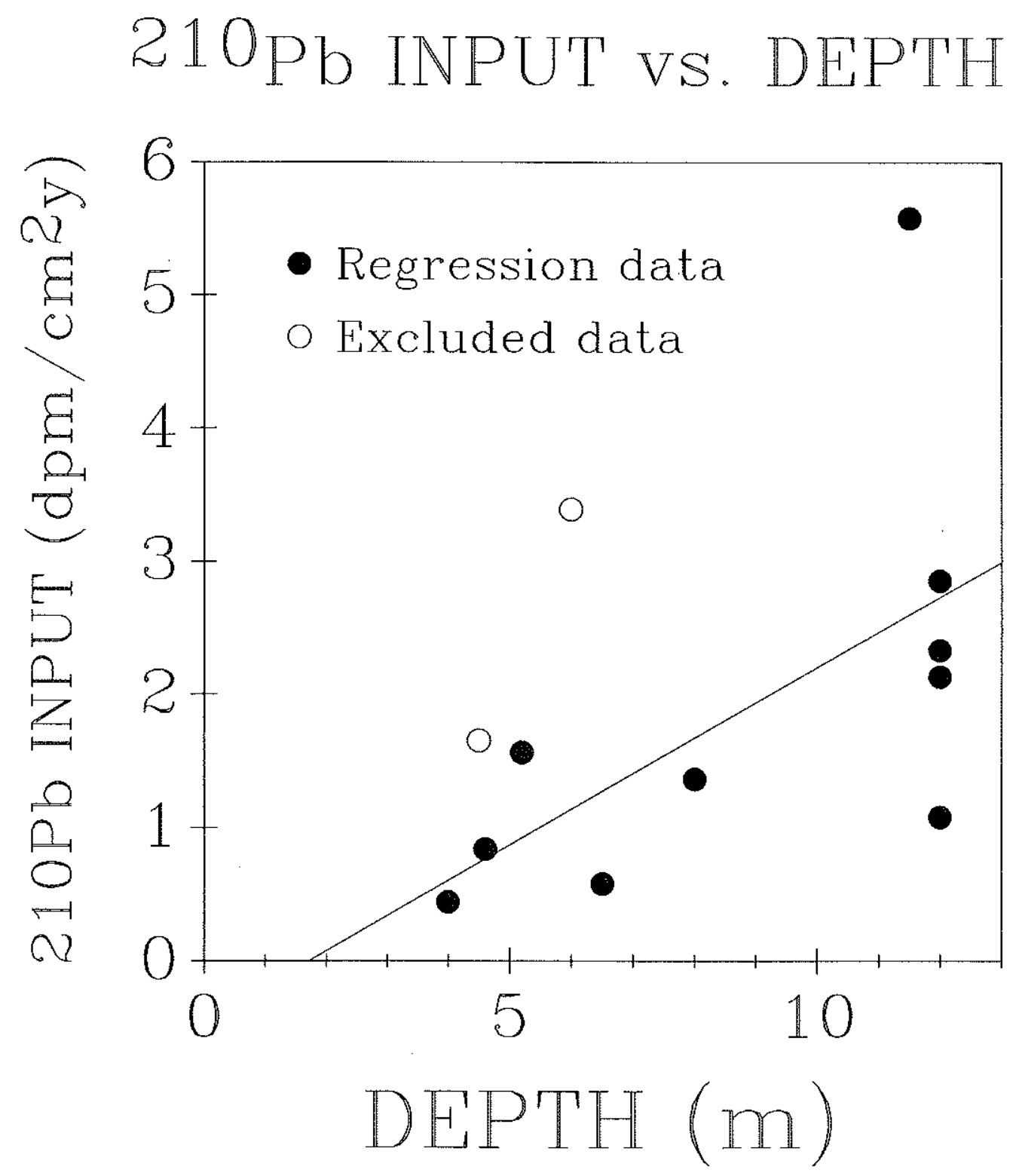
than others, and this difference probably reflected the irregular microtopography. Earth moving equipment left the lake bottom with a great deal of relief having a scale of tens of centimeters. Soft sediment tended to be redistributed locally from microridges to microvalleys. Divers collecting cores in shallow parts of the basin would preferentially sample the valleys simply because there was inadequate soft sediment on the ridges to recover a core of acceptable length. In deeper parts of the lake, ample soft sediment was ubiquitous, so divers could collect cores at random. For this reason, cores taken from the deeper parts of the lake are typical of local conditions, while cores from shallower areas represent sediment accumulation rates that are greater than the local average.

\subsection{SEDIMENT $210 \mathrm{~Pb}$ INVENTORIES}

$210 \mathrm{~Pb}$ sediment inventories $\left(\mathrm{dpm} / \mathrm{cm}^{2}\right)$ also show a correlation with depth $(r=.61, N=10)$, also significant at the $90 \%$ level (Figure 5.5b). This implies that not only bulk sediment, but also $210 \mathrm{~Pb}$ is preferentially deposited in the deeper parts of the lake. Taken together these two conditions imply that there should be a fairly constant specific activity of $210 \mathrm{~Pb}$ in freshly deposited sediments, at least in this lake. This is clearly shown by plotting annual $210 \mathrm{~Pb}$ input (inventory corrected for the age of the core) as a function of the calculated sedimentation rate (Figure 5.6a). Several points should be noted. First, the data plot close to a straight line, confirming that $210 \mathrm{~Pb}$ specific activity is nearly constant in freshly settled sediment. The slope of the line gives the magnitude: $22 \mathrm{dpm} / \mathrm{g}$. This value represents the concentration of $210 \mathrm{~Pb}$ in material at the moment that it reaches the sediment water interface. The actual concentration in 
FIGURE $5.6 \mathrm{a}$ 210Pb BUILD-UP IN SEDIMENTS VS. THE BULK SEDIMENT ACCUMULATION RATE

\section{$210_{\mathrm{Pb} \text { INPUT vs. ACCUMULATION }}$}

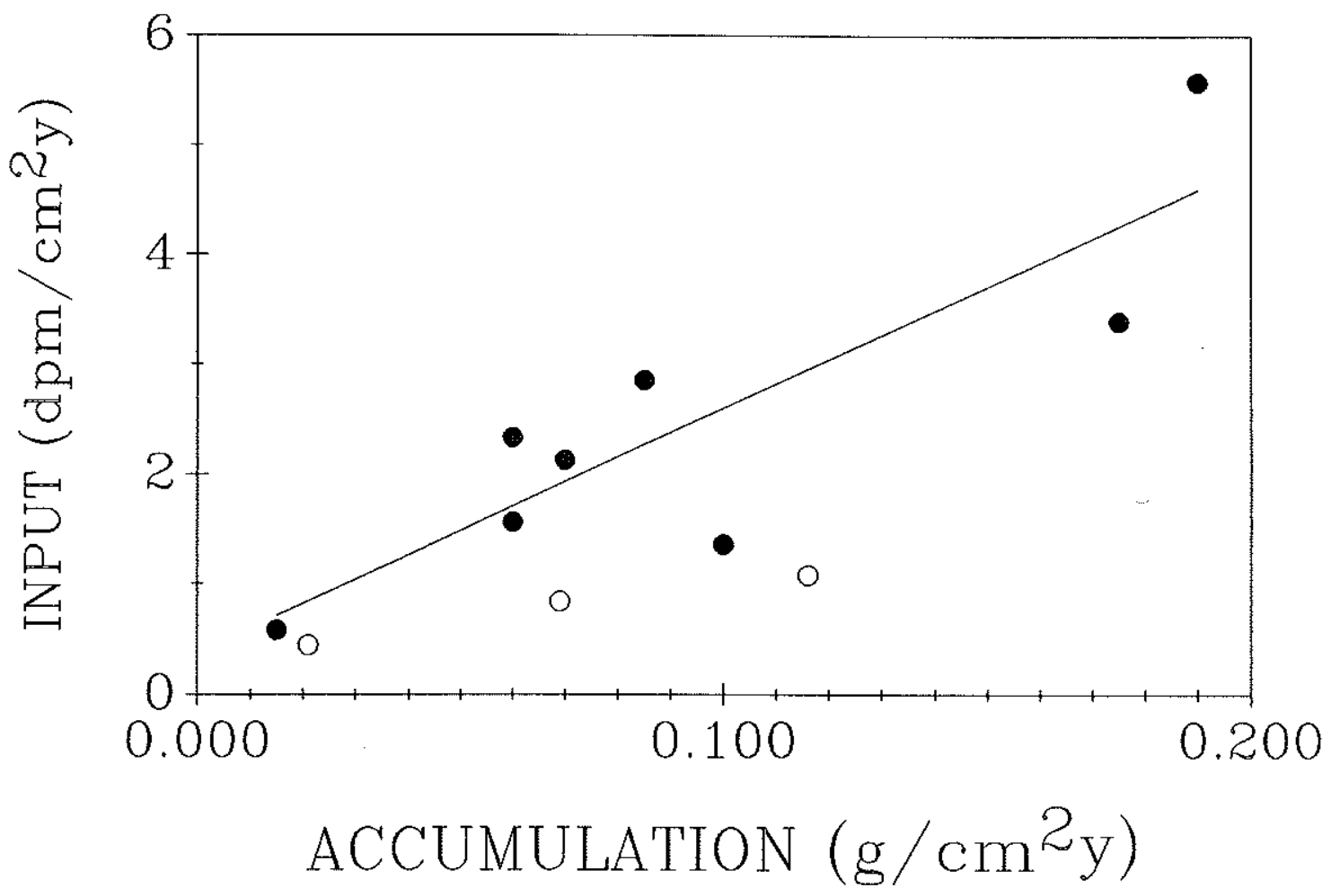


surficial sediment may be different from this value as the result of processes that either concentrate or dilute ${ }^{210} \mathrm{~Pb}$. These could include mixing, remineralization of organic matter, and diffusive remobilization of $2{ }^{20} \mathrm{~Pb}$. In fact, the measured concentration of ${ }^{210} \mathrm{~Pb}$ in surficial sediments does vary by factors of 2 higher and lower than the predicted value of $22 \mathrm{dpm} / \mathrm{g}$ (range of measured activities in surficial sediments = 10.6 to 41.6 ; see Figures 5.4 .3 a through 5.4 .31 ) implying that both types of processes are active at different locations. Another point is that the correlation coefficient for this graph is high $(\mathrm{r}=.867, \mathrm{~N}=$ 8$, confidence level $=99.58)$. The higher level of correlation compared to Figures $5.5 \mathrm{a}$ and $\mathrm{b}$ means that constant specific $210 \mathrm{~Pb}$ activity holds for all types of sediment redistribution, not just that from shallow to deep parts of the basin. Also, the good correlation supports the accuracy of the assigned sedimentation rates and increases confidence in the effectiveness of the sediment mixing model. A final point concerns the three cores for which we have only been able to assign sedimentation rate upper limits. Although these have not been included in calculation of the regression, they do conform to expectation, lying to the right of the curve (plotted as open circles in Figure 5.6a) in the direction of excess sedimentation rate.

It is possible to combine the observed relation between sedimentation rate and water depth with information on the shape of the basin (the hypsographic curve) to derive an estimate of total ${ }^{210} \mathrm{~Pb}$ deposition in the sediments of the lake. To do this the lake was broken into $0.1 \mathrm{~m}$ depth increments and the area of bottom lying at each depth determined. This area was then multiplied by the predicted $210 \mathrm{~Pb}$ input rate as a function of depth (Figure 5.5b), using the assumption that 
there was no permanent deposition of ${ }^{210} \mathrm{~Pb}$ above $1.7 \mathrm{~m}$ depth, the $\mathrm{x}$ intercept of the regression equation. The sum of the results for all the depth increments was divided by the total area of the lake to arrive at the average basin-wide $2{ }^{10} \mathrm{~Pb}$ input rate, $1.1 \mathrm{dpm} / \mathrm{cm}^{2} \mathrm{y}$. BENOIT and HEMOND (1987) presented a mass balance for this lake and found that the sedimentation flux averaged $0.75 \mathrm{dpm} / \mathrm{cm}^{2} \mathrm{y}$ over the course of one year. During the 132 days of the current study, we calculated an average $210 \mathrm{~Pb}$ settling flux of $1.08 \pm .06 \mathrm{dpm} / \mathrm{cm}^{2} \mathrm{y}$ and measured a flux of $0.84 \pm .09$ $\mathrm{dpm} / \mathrm{cm} 2 \mathrm{y}$. All of these measurements and calculations of the sedimentation flux agree with one another and with the calculated longterm basin-wide ${ }^{210} \mathrm{~Pb}$ input rate within their respective uncertainties. This implies that the assumptions behind the mass-balance model are correct, that the sediment trap fluxes are accurate, and that sedimentation in this lake is similar on long (10 y) and short (1 y) time scales. It also suggests that little excess $2{ }^{10} \mathrm{~Pb}$ was left in the basin before the new reservoir was filled and that excess ${ }^{210} \mathrm{~Pb}$ not excavated from the northern basin was not redistributed throughout the rest of the basin.

\subsection{SEDIMENT MIXING RATES}

Mixing rates derived using SEDIMIX ranged from .030 to $.090 \mathrm{~cm}^{2} / \mathrm{y}$. (For Core $81-4$ the mixing rate was indeterminate but could have been in the range from 0.00 to $0.50 \mathrm{~cm}^{2} / y$ with a sedimentation rate of from 0.200 to $\left.0.0 \mathrm{~g} / \mathrm{cm}^{2} \mathrm{y}.\right)$. A number of investigators have measured particle reworking or sediment mixing rates, though so far, most measurements have been on marine sediments. In general, mixing rates tend to increase from deeper to shallower locations, reflecting the greater availability of organic substrate for benthic organisms, and the 
increasing possibility of direct storm driven mixing. In the deep-sea, mixing rates are generally less than $1 \mathrm{~cm}^{2} / \mathrm{y}$ (PENG et al. [1979], 0.12 $\mathrm{cm}^{2} / \mathrm{y} ;$ COCHRAN and KRISHNASWAMI [1980], $0.032 \mathrm{~cm}^{2} / \mathrm{y} ;$ DeMASTER and COCHRAN [1982], 0.03 to $0.4 \mathrm{~cm}^{2} / \mathrm{y}$ ). On the continental slope and shelf values rise to the range of from 1.0 to $30 \mathrm{~cm}^{2} / \mathrm{y}$ (CARPENTER et al. [1982], 3 to $30 \mathrm{~cm}^{2} / y$, Washington coast slope and shelf; DeMASTER et al. [1985], $26 \mathrm{~cm}^{2} / \mathrm{y}$ in the upper $5 \mathrm{~cm}$ and $2 \mathrm{~cm}^{2} / \mathrm{y}$ from 5 to $25 \mathrm{~cm}$ in continental shelf deposits of the East China Sea; COCHRAN and ALLER [1979], 9 to $19 \mathrm{~cm}^{2} / \mathrm{y}$ for the New York Bight). In coastal and estuarine location, mixing rates can rise to the $100^{\prime} \mathrm{s}$ or $1000^{\prime} \mathrm{s}$ (ALLER et al. [1980], less than 0.3 to $50 \mathrm{~cm}^{2} / y$ in Long Island Sound; CARPENTER et al. [1985] 0.9 to greater than 370 in the Puget Sound region; CARPENTER et a1. [1984], 0.25 to $3000 \mathrm{~cm}^{2} / y$ in the Puget Sound estuary). Mixing rates in Lakes Huron and Michigan have been measured in the range from 1 to $10 \mathrm{~cm}^{2} / \mathrm{y}$ (ROBBINS et a1. [1977], LYNCH and OFFICER [1984], CHRISTENSEN and BHUNIA [1986]). On the other hand, a high degree of preservation and resolution of peaks in the profiles of fallout radionuclides indicates that mixing is extremely low in many lakes (FARMER [1978], JAAKKOLA et a1. [1983], MILLER and HEIT [1986]). From this brief summary it is clear that mixing rates in the sediments of Bickford Reservoir are comparable to the lowest values measured in the deep ocean. In the deepest part of the lake basin, the low mixing rate may be associated with seasonal anoxia, which would discourage permanent colonization by bioturbators. It also seems possible that because of the relative youth of the lake basin (since the time of reservoir enlargement) there has not yet been time for establishment of extensive infauna. In any event, in view of the common occurrence of lakes with 
low sediment mixing rates noted above, the situation in Bickford has many precedents.

The low rate of sediment mixing in Bickford has two important ramifications. First, a low mixing rate is consistent with a low rate of bioirrigation. This in turn supports the idea that uptake of ${ }^{210} \mathrm{~Pb}$ by direct sediment sorption is likely to be much lower than removal by scavenging onto suspended particulate matter (section 4.4.3). Second, the magnitude of the molecular diffusion coefficient in the fluid phase is more than 2000 times greater than that of non-depositional ${ }^{210} \mathrm{~Pb}$ redistribution which we have been referring to as sediment "mixing". The relative magnitude of these two processes is consistent with the possibility that $210 \mathrm{~Pb}$ is redistributed via strictly chemical remobilization (section 6.5 ).

\subsection{SEDIMENTATION PROCESSES IN THE NORTHERN BASIN}

As mentioned earlier, interpretation of the the four cores collected from the northern basin (Figures $5.8 \mathrm{a}$ through d) was problematic. All of the cores were collected from the broad plain that had been successively a bog, the bottom of a shallow lake, and part of the modern reservoir (Figure 2b). Two cores had steep declines in $210 \mathrm{~Pb}$ activity with depth and two had more gradual declines. Calculating apparent sedimentation rates for these cores yields values in the range from 4 to $30 \mathrm{mg} / \mathrm{cm}^{2} \mathrm{y}$, and these axe upper limits if any mixing has occurred. Cores from this depth should have sedimentation rates near 70 $\mathrm{mg} / \mathrm{cm}^{2} \mathrm{y}$ based on Figure $5.5 \mathrm{a}$.

The explanation for these observations probably rests with the peculiar physical characteristics of these sediments. Sediments from this region have high porosities and are composed largely of the remains 
FIGURE 5.8a and $\mathrm{b}$ : SOLID PHASE 210Pb DATA FOR CORES 84-3 AND 84-4
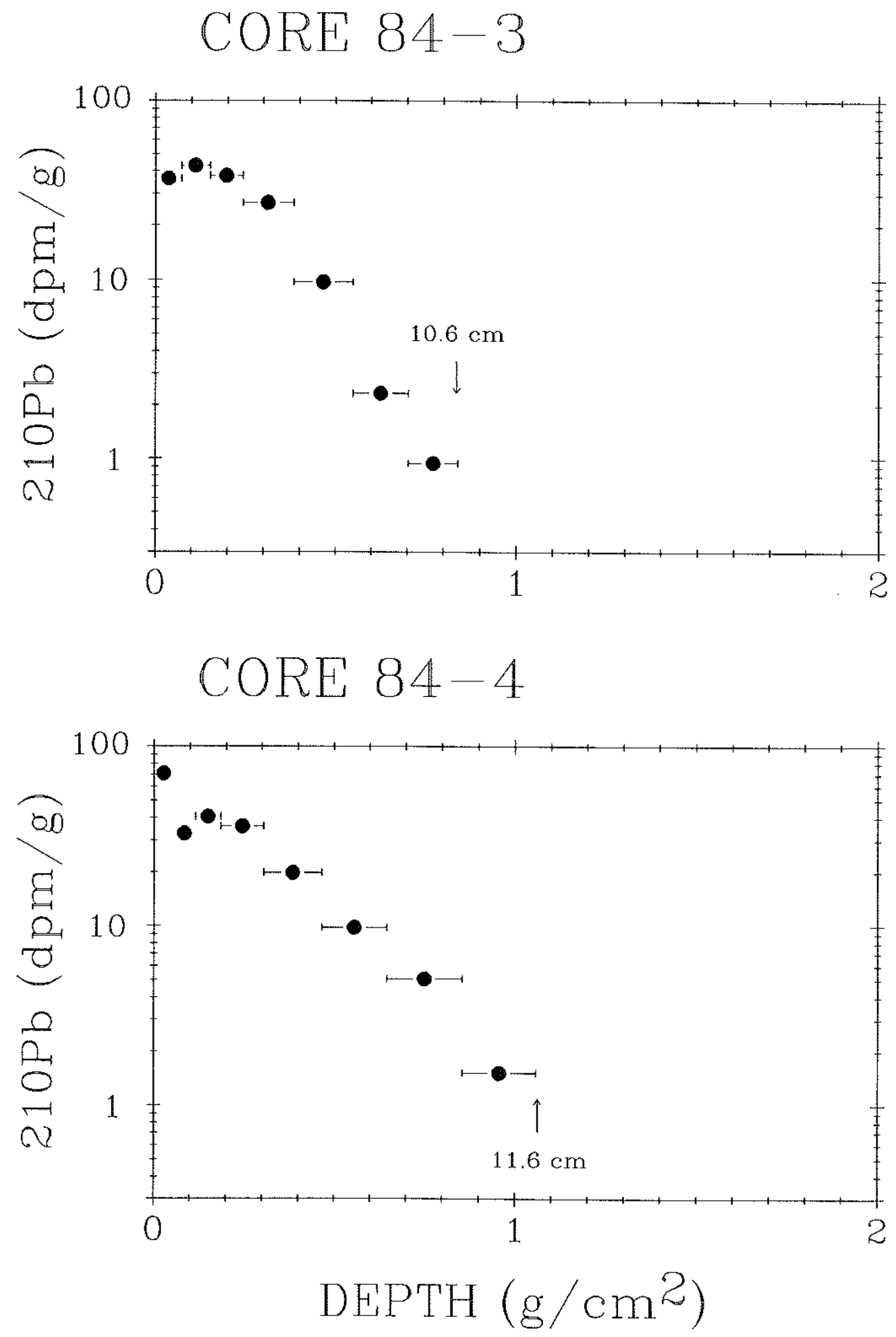
FIGURE $5.8 \mathrm{c}$ and $\mathrm{d}$ : SOLID PHASE 210Pb DATA FOR CORES 84-5 AND 86-1

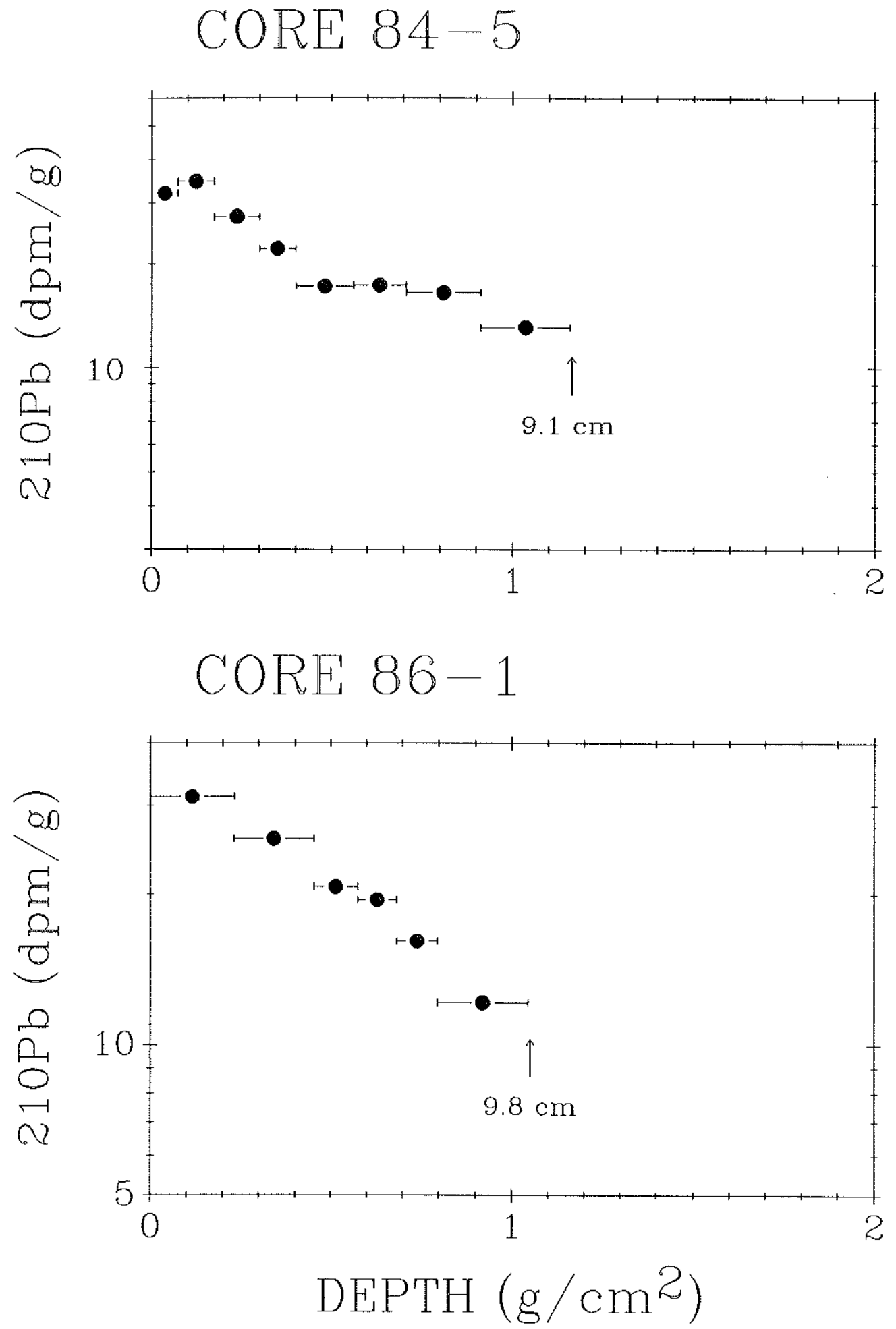


of woody plants. They have a high organic content and low bulk density, and they contain obvious pieces of rotting stems and roots. Attempts to collect cores were often stymied by encountering roots or stems that blocked further core-tube insertion. In general, pushing on the sediment surface was resisted by the springiness of the substrate. Sediment accumulation before construction of the low dam probably was as a bog or other sub-aerial wetland. After flooding, there was only a very slow accumulation of sediment because a small watershed and the absence of influent streams meant a very limited supply of mineral material. After the construction of the high dam, sediment accumulated in topographic lows in the somewhat hummocky surface of the old bog. Because of the extremely high porosity and structural framework of the sediments, fine material high in $2{ }^{\circ} \mathrm{Pb}$ has been able to penetrate into the depths of the sediment, but not by a conventional "mixing" process. Instead it has been by gravitational settling of new particles downward into the partially-intact, dead-plant framework.

According to this scenario, cores $84-3$ and $84-4$ are composed of a thin veneer of recently deposited mud overlying older bog material containing little newer sediment. Much of the inventory of $21^{\circ} \mathrm{Pb}$ that has been deposited at these sites in the last 100 years has either resettled at nearby locations, was driven out laterally by core shortening during collection (HONGVE and ERLANDSEN [1979]), or has penetrated so deep in the sediment column as to be unsampled by these cores. The following facts support this hypothesis. 1) The springy nature of the sediments, their consistently high porosity, and their high organic content are all consistent with boglike sediments with a large volume of interstices and a flexible yet stable structure. Bulk 
densities at the bottoms of these cores were very low $(0.06$ to 0.08 $\mathrm{g} / \mathrm{cm}^{3}$ ) even though they had apparently been compressed in length during collection, judging from the relative length of the cores and the insertion depth. As the downward motion of the core tube compressed sediment in front of it, particles in the interstices of the sediment may well have been driven laterally out of the path of collection. 2) $210 \mathrm{~Pb}$ drops to very low levels at depth in these cores $(0.9$ and 1.5 $\mathrm{dpm} / \mathrm{g}$ and decreasing), consistent with a dearth of mineral material, which tends to be higher in ${ }^{226} \mathrm{Ra}$. 3) The cores as taken probably do not include all of the ${ }^{210} \mathrm{~Pb}$ originally deposited at these locations since they contained inventories equivalent to input rates of 0.45 and $0.57 \mathrm{dpm} / \mathrm{cm}^{2} \mathrm{y}$ whereas the true delivery over time has been a constant 1 $\mathrm{dpm} / \mathrm{cm}^{2} \mathrm{y}$. If the zone of exponential decrease with depth in these cores represents the rate of accumulation of material in the bog then the slopes of the lines indicate rates of 4.2 and $7.8 \mathrm{mg} / \mathrm{cm}^{2} \mathrm{y}$.

Cores $84-5$ and 86-1 have higher total inventories and more gradual decreases of $210 \mathrm{~Pb}$ activity with depth than cores $84-3$ and $84-4$ even though they were collected from the same area. Bulk densities in these cores were also slightly higher, averaging 0.107 and $0.124 \mathrm{~g} / \mathrm{cm}^{3}$, with little variation downcore. Despite the differences, these cores were also characterized by very high porosities (90\%), high organic matter, and a composition dominated by dead woody plants. The deepest interval sampled on both of these cores had $210 \mathrm{~Pb}$ activities well above expected levels for support by ${ }^{226} \mathrm{Ra}$, but extrapolating the reduction in ${ }^{210} \mathrm{~Pb}$ with depth downward yields estimated input rates of 1.01 and 1.14 $\mathrm{dpm} / \mathrm{cm}^{2} \mathrm{y}$ (measured inventories alone were equivalent to inputs of 0.67 and $0.68 \mathrm{dpm} / \mathrm{cm}^{2} \mathrm{y}$ ). I believe that these cores were taken from 
topographic lows where greater quantities of recent lake-deposited sedimentary material had accumulated. Much of this material had penetrated downward into the interstices of the sedimentary framework giving the observed activity-depth distribution. This pattern does not represent traditional mixing processes, and as such SEDIMIX was not applied to these cores. It was impossible to know on the basis of four cores what fraction of the northern basin was like cores 84-3 and 84-4 and what fraction was like cores $84-5$ and 86-1. Also, it was not known how much $210 \mathrm{~Pb}$ had penetrated the bog-like sediments below the coring depths, though the measured inventories and known history of the basin suggest that it was substantial. As a result, it was impossible to assign $210 \mathrm{~Pb}$ input rates to the northern basin, and these cores were excluded from Figures $5.5 \mathrm{a}$ and $\mathrm{b}$.

\subsubsection{EVIDENCE FROM ${ }^{137} \mathrm{Cs}$}

Background

In an attempt to resolve some of the questions regarding sedimentation processes in the northern basin, the fallout radionuclide ${ }^{137} \mathrm{Cs}$ was measured on core $86-1$ and, for comparison purposes, on core 86-2, collected outside of the northern basin at a comparable depth. ${ }^{137} \mathrm{Cs}$ is a fallout radionuclide that is used in an entirely different fashion from $210 \mathrm{~Pb}$ for determining sedimentation rates. ${ }^{137} \mathrm{Cs}$ was introduced into the environment by atmospheric weapons testing in the $50^{\prime} \mathrm{s}$ and $60^{\prime} \mathrm{s}$. The assumptions behind ${ }^{137} \mathrm{Cs}$ dating are: 1) ${ }^{137} \mathrm{Cs}$ introduced into the atmosphere was quickly transferred to the ground by rainfall, 2) ${ }^{137} \mathrm{Cs}$ deposited on a lake's watershed was either quickly transferred to the lake or was held in the watershed more or less irreversibly, 3) ${ }^{137} \mathrm{Cs}$ in the lake was transferred rapidly and 
quantitatively to sediments, 4) the radionuclide is not preferentially concentrated by chemically distinct layers in the sediments, and 5) the radionuclide is chemically immobile in sediments. If these conditions are met, and the ${ }^{137} \mathrm{Cs}$ has not been redistributed by mixing, then a concentration peak in sediments corresponds to maximum fallout in 1963, and an average sedimentation rate since that time can be determined assuming that the top of the core has not been lost during collection. (In some cores a secondary peak can be resolved corresponding to a secondary maximum in 1958-59).

In many cores, we11-resolved peaks have been observed, and in these cases ${ }^{137} \mathrm{Cs}$ dates compare well with other dating methods such as varves, $210 \mathrm{~Pb}$, and other fallout radionuclides (e.g. WAN et a1. [1987]). On the other hand, resolution of fallout peaks shows a broad range (MILLER and HEIT [1986], DAVIS et al. [1984]); ${ }^{137} \mathrm{Cs}$ does seem to be chemically mobile in some sediments (DAVIS et al. [1984]); almost none of the assumptions of the ${ }^{137} \mathrm{Cs}$ dating method have been directly tested. Nevertheless, even if it fails as a dating method, ${ }^{137} \mathrm{Cs}$ measurements can provide useful information about geochemical cycling in lakes.

By measuring ${ }^{137} \mathrm{Cs}$ I hoped to do the following: 1) compare total inventories in locations representing both the pre-and post-1970 lake basin, 2) provide a second dating technique against which ${ }^{210} \mathrm{~Pb}$ results could be compared, and 3) gain additional information about mixing processes in the sediments. The two cores for ${ }^{137} \mathrm{Cs}$ analysis were taken from comparable locations one of which $(86-1)$ had been a part of the basin since before the start of atmospheric weapons testing and the other of which (86-2) was added to the basin well afterwards (1970), and whose ${ }^{137} \mathrm{Cs}$ inventory had presumably been removed in the course of 
reservoir construction. I expected to find a subsurface peak (1963) and a high inventory in core 86-1. Direct atmospheric deposition of ${ }^{137} \mathrm{Cs}$ in Massachusetts was $25 \mathrm{dpm} / \mathrm{cm}^{2}$ corrected to the date of coring (MILLER and HEIT [1986], DOMINIK et a1. [1981]), and this is the amount expected in core 86-1 if all of the assumptions were met exactly and there was no contribution from the watershed. In fact sediment cores containing inventories much greater and much less than direct atmospheric deposition have been documented (MILLER and HEIT [1986], DAVIS et al [1984]). About 108 of the total ${ }^{137} \mathrm{Cs}$ (corrected to 1986) was deposited after 1970, so for core 86-2 I expected a much lower inventory that would commence in the 1970 sediment stratum but reach slightly greater depths due to sediment mixing (calculated to be $0.085 \mathrm{~cm}^{2} / y$ by SEDIMIX).

Results for the two cores are plotted in Figures 5.8.1a and b. For core $86-1$ (located within the old basin), ${ }^{137} \mathrm{Cs}$ is approximately constant from the surface to $0.7 \mathrm{~g} / \mathrm{cm}^{2}$ and drops quickly at greater depths. The measured inventory in this core was $5.3 \mathrm{dpm} / \mathrm{cm}^{2}$ with an estimated total for this core (calculated by downward extrapolation) of $7.1 \mathrm{dpm} / \mathrm{cm}^{2}$. Using different assumptions about the functionality of change in activity with depth had little effect on this estimate. For core 86-2 (the comparison core in the newest part of the basin), high levels of ${ }^{137} \mathrm{Cs}$ were restricted to the zone corresponding to sediment deposited since reservoir filling $\left(0.015 \mathrm{~g} / \mathrm{cm}^{2} \mathrm{y} \times 15.8 \mathrm{y}=0.24 \mathrm{~g} / \mathrm{cm}^{2}\right)$. ${ }^{137} \mathrm{Cs}$ decreased approximately exponentially with depth to at least 3.4 $\mathrm{g} / \mathrm{cm}^{2}$, and had a measured inventory of $2.9 \mathrm{dpm} / \mathrm{cm}^{2}$, with a negligible amount anticipated below the core bottom because of the low activity. 
FIGURE 5.8.1 $\mathrm{a}$ and $\mathrm{b}$ : COMPARISON OF SOLID PHASE $137 \mathrm{Cs}$ AND $210 \mathrm{~Pb}$ DATA FOR CORES 86-1 AND 86-2
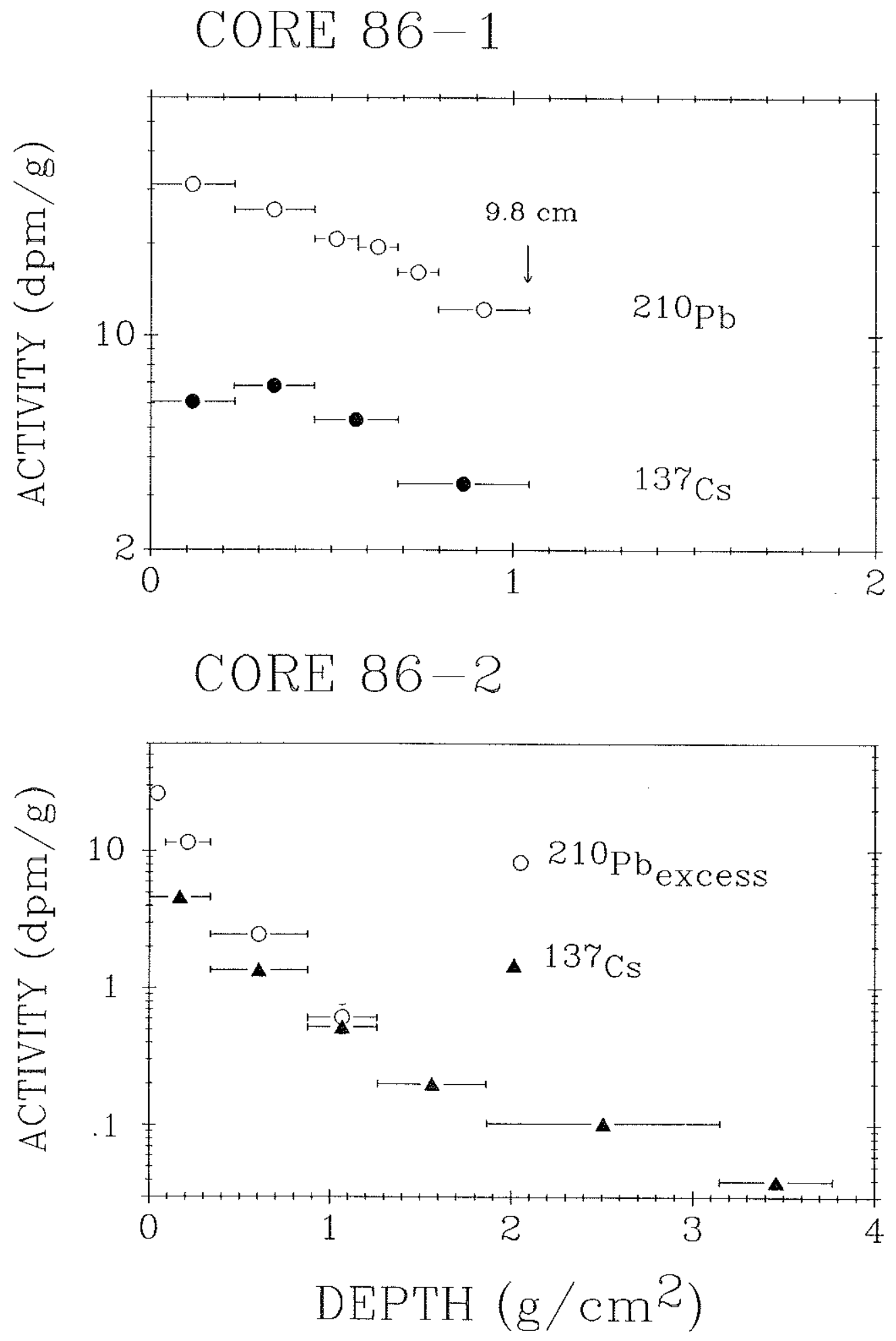
Core 86-2 (Post-1970 Basin)

The inventory in core 86-2 was equivalent to $12 \%$ of estimated atmospheric deposition at this site, in good agreement with the amount deposited at this location since it was flooded by the modern lake. That would be the case if: 1) no ${ }^{137} \mathrm{Cs}$ remained in the basin after reservoir construction, 2) losses through outflow were equal to gains from the watershed so that ${ }^{137} \mathrm{Cs}$ contained in sediments is equivalent to that delivered by direct atmospheric deposition alone. The magnitude of mixing can be estimated from the depth of penetration of ${ }^{137} \mathrm{Cs}$ by approximating ${ }^{137} \mathrm{Cs}$ delivery as a pulse input and using the formula:

$$
z=(2 \mathrm{D} t)^{1 / 2}
$$

where:

$$
\begin{aligned}
& z=\text { mean depth of penetration } \\
& D=\text { diffusion coefficient } \\
& t=\text { time of mixing }
\end{aligned}
$$

The value of $z$ is equivalent to half the distance from the maximum concentration to a depth where the concentration is 0.1 times the maximum (CSANADY [1973]). In core 86-2, concentration dropped to 108 of the maximum value in $2.6 \mathrm{~cm}$. The appropriate time interval for use in this calculation is the mean time of mixing $(7.9 \mathrm{y})$. The mixing rate, D, therefore is about 0.11 , in excellent agreement with the results of SEDIMIX, $0.085 \mathrm{~cm}^{2} / \mathrm{y}$. Both the inventory and pattern of distribution of ${ }^{137} \mathrm{Cs}$ in core $86-2$ are therefore consistent with ${ }^{137} \mathrm{Cs}$ dating as sumptions . 
Core 86-1 (Pre-1970 Sediments of the Northern Basin)

${ }^{137} \mathrm{Cs}$ in core $86-1$ did not show such simple behavior. The total inventory in this core was estimated at $7.1 \mathrm{dpm} / \mathrm{cm}^{2}$, less than 308 of the amount deposited at this site directly from the atmosphere. This deficit reflects losses either by the mechanism proposed for ${ }^{210} \mathrm{~Pb}$ at this location (gravitational settling of particles deep into the profile) or by chemical remobilization and diffusion. The distribution of ${ }^{137} \mathrm{Cs}$ with depth does not show a characteristic peak corresponding to the 1963 maximum, and this lack can not be explained by mixing of the upper layers since $210 \mathrm{~Pb}$ shows a marked and regular decline over the same region. Probably the most extensive study on the lacustrine geochemistry of ${ }^{137} \mathrm{Cs}$ is that of DAVIS et al. (1984). They found several lakes in whose sediments ${ }^{137} \mathrm{Cs}$ occurred at maximal levels adjacent to the sediment water interface, and in which $210 \mathrm{~Pb}$ increased exponentially to the surface, implying that sediment reworking was low. They also found that the depth of ${ }^{137} \mathrm{Cs}$ penetration was greater than that of unsupported $210 \mathrm{~Pb}$, indicating that molecular diffusion or preferential mixing of ${ }^{137} \mathrm{Cs}$-bearing particles was taking place. They proposed that diffusion/readsorption was the major mechanism for downward penetration of ${ }^{137} \mathrm{Cs}$ in their samples and concluded that much of the near-surface concentration of ${ }^{137} \mathrm{Cs}$ was caused by the same mechanism, perhaps augmented by water column recycling. Delayed delivery from the watershed was suggested as an alternative mechanism that could create surficial zones of high activity in the absence of sediment reworking. This latter explanation seems unlikely, since it would require ${ }^{137} \mathrm{Cs}$ input from the watershed to increase over time. 
The distribution of ${ }^{137} \mathrm{Cs}$ in core $86-1$ probab1y resulted from diffusion and readsorption processes. DAVIS et al. (1984) point out that, "In sediment with much organic matter, $\ldots \ldots$ and with minimal amounts of clay minerals, .... Cs would be expected to be relatively mobile"; the sediments of core $86-1$ are almost pure organic matter with very little clay. Diffusion and readsorption in isotropic sediments would only cause a smearing of the 1963 peak, without a shift in its position, so additional factors must be involved. One possibility is that diffusion out of the sediments combined with water column cycling and redeposition concentrates ${ }^{137} \mathrm{Cs}$ in the surficial zone. Another is that surficial sediments have a higher capacity for cesium sorption. That would be consistent with addition of material containing more clays occurring since the capture of two upland streams in 1970. Still another possibility is that porewater advection from the aquifer into the lake resists downward diffusion and causes a net displacement upward each time a cesium atom undergoes a desorption-sorption cycle.

Core $86-1$ seems to fit a pattern seen in the 1 iterature; ${ }^{137} \mathrm{Cs}$ profiles can be classified according to their total ${ }^{137} \mathrm{Cs}$ inventory. Cores with inventories of ${ }^{137} \mathrm{Cs}$ equal to or greater than the amount delivered by direct atmospheric deposition tend to have well resolved peaks that occur significantly below the surface (MILLER and HEIT [1986]). Cores with inventories substantially less than direct atmospheric deposition, like core $86-1$, tend to have poorly resolved peaks and often have maxima adjacent to the sediment water interface (DAVIS et al. [1984]). This should be the case if processes that cause migration and concentration of ${ }^{137} \mathrm{Cs}$ at the surface are also responsible for low inventories. Of the mechanisms mentioned above, water column 
recycling and groundwater invasion would tend to cause losses from the sediments. HESSLEIN et a1. (1980) found that ${ }^{134} \mathrm{Cs}$ added as a spike to a whole lake was removed from solution very slowly compared to the metals $\mathrm{Fe}, \mathrm{Zn}$, Co, and $\mathrm{Hg}$. Also, cesium had a very low tendency to be scavenged by SPM (occurring $97 \%$ in the dissolved form), and as a result it could not penetrate to hypolimnetic sediments during stratification. BRUNSKILL et al. (1984) carried out a mass balance for ${ }^{137} \mathrm{Cs}$ on Fayetteville Green Lake (NY) and found that there was a cycle of dissolution and sedimentation and that losses must have occurred from the lake via outflow. This agrees with the findings of ALBERTS et al. (1979) who documented seasonal water column cycling of ${ }^{137} \mathrm{Cs}$ introduced into a cooling pond by a reactor leak. Data contained in a number of papers show that ${ }^{137} \mathrm{Cs}$ mobility tends to be associated with 1 ow ${ }^{137} \mathrm{Cs}$ inventories. Profiles with the lowest inventories in MILLER and HEIT (1986) and PENNINGTON et a1. (1973) were also those with the longest downward tails (indicative of diffusion).

A review of the literature also shows that there tends to be a correlation between total ${ }^{137} \mathrm{Cs}$ inventory and the depth of the cesium maximum below the sediment water interface. In Figure 5.8.1c I have plotted data from MILLER and HEIT (1986), DAVIS et a1. (1984), PENNINGTON et al. (1973), and ROBBINS and EDGINGTON (1975). The correlation coefficient is 0.85 for $n=26$ (confidence leve $1 \gg 99.98$ ), surprisingly high considering the large number of variables and the diversity of lakes. This relationship could have two causes: 1) higher delivery of solids from the watershed causes greater delivery of ${ }^{137} \mathrm{Cs}$ it carries (i.e. the concentration of ${ }^{13^{7}} \mathrm{Cs}$ on solids delivered to all lakes is nearly constant), or 2) higher sedimentation rate makes for 
FIGURE $5.8 .1 \mathrm{c}$ 137Cs INVENTORY AS A FUNCTION OF SEDIMENT ACCUMULATION RATE

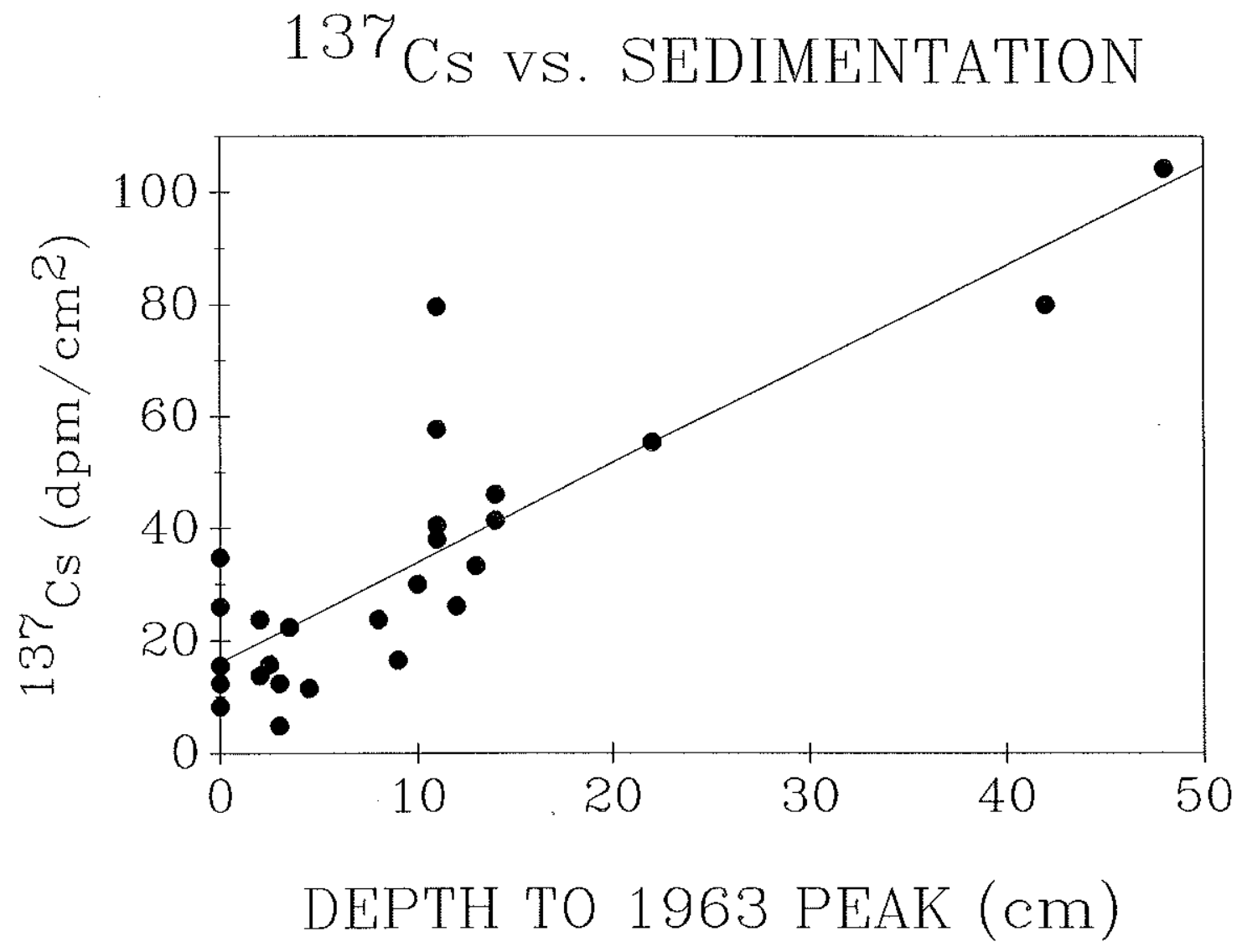

Data from PENNINGTON et a1. (1973), ROBBINS and EDGINGTON (1975), DAVIS et aI. (1984), and MILLER and HEIT (1986). 
more efficient scavenging within the lake. In any event, lower sedimentation rates seem to be associated with $10 \mathrm{w}{ }^{137} \mathrm{Cs}$ inventories.

In light of the above discussion, the low inventory of ${ }^{13^{7}} \mathrm{Cs}$ in core 86-1 was probably caused by a combination of factors. First, a low clay content reduced the tendency of the sediments to sorb cesium when it initially entered the lake and as a result losses occurred via outflow. Later, the same lack of sorptive capacity combined with high porosity allowed ${ }^{137} \mathrm{Cs}$ to diffuse readily. ${ }^{137} \mathrm{Cs}$ transported in this manner, perhaps aided by lakeward porewater advection, enters the water column seasonally, and there it is either flushed from the lake, taken up by sediments in other parts of the lake, or redeposited to the top of the sediment column, yielding the top-heavy distribution observed in core 86-1. The consequence of this scenario is that ${ }^{137} \mathrm{Cs}$ is of little value in determining sedimentation rates in the northern basin. Also, since its geochemical cycling is different from that of ${ }^{210} \mathrm{~Pb}$ in these very silicate-poor sediments, ${ }^{137} \mathrm{Cs}$ sheds little new light on the curious distribution patterns of radiolead in this part of the lake. Still, one fact is clear from the ${ }^{137} \mathrm{Cs}$ analysis. Despite incomplete initial deposition and later remobilizational losses, the inventory of ${ }^{137} \mathrm{Cs}$ in northern basin sediments is significantly greater than in sediments located outside the pre-1970 lake. This fact supports our conviction that northern basin sediments contain an unbroken record of deposition to well before the enlargement of the lake in 1970 . 


\section{CHAPTER 6 SEDIMENTS II $210 \mathrm{~Pb}$ SPECIATION AND REMOBILIZATION}

\subsection{INTRODUCTION}

Perhaps the single most important assumption of ${ }^{210} \mathrm{~Pb}$ geochronometry is immobility in sediments. Since the product of ${ }^{210} \mathrm{~Pb}$ decay is not measured, the technique depends on the assumption that the only cause of decrease in activity with depth is radioactive decay. If losses from or gains to a depth interval also occur via transport processes, errors in assigning ages will result. The assumption of immobility has not been rigorously tested, and in fact, several studies suggest that lead, despite its high particle reactivity, is mobile in some sediments. Several investigators have found that stable lead and $210 \mathrm{~Pb}$ seem to be largely associated with solid phases that are solubilized under the reducing conditions common in lake sediments (GUPTA and CHEN [1975], CARPENTER et al. [1981], DOMINIK et a1. [1983], SAKATA [1985], SIGG et al. [1987]). Studies in an experimental system have shown that $210 \mathrm{~Pb}$ is more mobile than either $\mathrm{Pu}$ or radioactively tagged particles, implying some degree of chemical mobility (SANTSCHI et al. [1983b]). Also, the release of ${ }^{210} \mathrm{~Pb}$ from sediments to the water column, as has been documented at Bickford and elsewhere (TANAKA et a1. [1983]), must result from remobilization. Finally, two recent studies on Swiss lakes seem to show cases where remobilization has led to changes in $2{ }^{10} \mathrm{~Pb}$ distribution that are great enough to cause dating errors (ERTEN et a1. [1985], WAN et al. [1987]).

In this chapter are presented the results of studies on the distribution of $210 \mathrm{~Pb}$ in both the solid phase and pore waters of the sediments in Bickford Reservoir where remobilization into the water column has been well documented. Sequential leaching experiments 
indicate that $210 \mathrm{~Pb}$ is associated with easily reducible solid phases. Reduction and solubilization of these solids leads to remobilization of lead from surficial sediments into the lake water column. Deeper in the sediment column, ${ }^{210} \mathrm{~Pb}$ is in apparent equilibrium with exchange onto transition metal oxides, leading to relatively high pore water concentration gradients that may be causing significant diffusive transport. A better understanding of the speciation of $210 \mathrm{~Pb}$ in both solid and interstitial fluids will be critical to evaluating the extent of ${ }^{210} \mathrm{~Pb}$ mobility in lake sediments.

\subsection{METHODS}

\subsubsection{SAMPLE COLLECTION AND TREATMENT}

Cores for pore water analysis were collected from pre-selected sites in the deep basin of the southwest corner of the lake (Figure 2a) in $12 \mathrm{~m}$ of water on 27 August and 25 September 1985. These samples were collected with special care to prevent exposure of anoxic pore water to atmospheric oxygen. Core tubes were created from lengths of $12.7 \mathrm{~cm}$ I.D. PVC tubing that were pre-cut into 1 and $2 \mathrm{~cm}$ sections and then taped back together with electrical tape. This design allowed collection of a large volume of sediment from each depth interval and facilitated sectioning cores in a glove box. SCUBA divers carefully inserted tubes into the sediments and sealed the tops with Caplugs ${ }^{\text {NM}}$. Then the divers excavated a hole adjacent to each tube until it was possible to slide a second Caplug under the bottom, completing the seal. Two cores taken in this manner were brought to the surface in their original vertical orientation by the two divers. At the surface an assistant fixed the Caplugs to the cores with two hose clamps and lifted them onboard ship and into an ice-filled styrofoam chest. Cores were 
judged airtight since they showed no leakage of water at the bottom seal and remained free of gas at the top (clearly visible through the semitranslucent Caplug).

Cores were then transported to the Woods Hole Oceanographic Institution and placed in a nitrogen filled glove box within 3 or 4 hours of collection. The atmosphere within the chamber was monitored and cores were not opened unless the partial pressure of $\mathrm{O}_{2}$ had fallen below $0.02 \mathrm{~atm}$. Each core was held rigidly by a clamp, the top opened, and overlying water siphoned off and saved for filtration in a sealed, $\mathrm{N}_{2}$-flushed jar. Each section of the core was then untaped in turn, the section slid quickly to the side, and the sediments either allowed to fall or actively pushed down into a funnel leading to a pre-weighed, 1 liter centrifuge jar. Surficial sediments were soupy and brown in color with black spots. Macroscopic pieces of decaying organic debris were also evident. With depth the sediments became stiffer and changed from brown to gray. A $1 \mathrm{~cm}$ section of core had a volume of $125 \mathrm{~cm}^{3}$, so corresponding depth increments from both cores were placed in a single jar. The jars were flushed with a stream of $\mathrm{N}_{2}$, sealed, weighed, and transferred to the centrifuge where they were spun down for $20 \mathrm{~min}$ at 4 ${ }^{\circ} \mathrm{C}$ and $4500 \mathrm{G}$.

After centrifuging, the tubes were returned to the glove box, and the supernatant water, which was pale yellow-brown in color, was decanted into an elevated aspirator bottle. A $142 \mathrm{~mm} \times 0.45 \mu$ Millipore ${ }^{\text {M }}$ Durapore filter was placed in a Teflon lined stainless steel holder, the apparatus closed, and the entire assembly and connecting tubing flushed with a stream of $\mathrm{N}_{2}$ gas. The inlet was connected to the bottle and the water pumped through the filter into sample jars using a 
peristaltic pump. In the end, the lines were cleared of the final few $\mathrm{cm}^{3}$ of 1 iquid with $\mathrm{N}_{2}$ pressure. Aliquots were taken for measurement of dissolved Fe and Mn, alkalinity, sulfides, and DOC (dissolved organic carbon). Final pore water volumes for $21{ }^{\circ} \mathrm{Pb}$ analysis ranged from 45 to $140 \mathrm{~cm}^{3}$ for paired $1 \mathrm{~cm}$ thick sections.

\section{3 RESULTS AND DISCUSSION}

\subsubsection{SOLID PHASE $210 \mathrm{~Pb}$}

Results of solid phase measurements of $21^{\circ} \mathrm{Pb}$ on these two cores (85-1 and 85-2) are described in section 5.4.3, and are presented in Table 6.3.1a and Figures 5.4.3i and $j$. Both cores had r.m.s. errors of $7 \%$ for the best-fit combination of sedimentation and mixing rates. For core $85-1$ the sedimentation rate was $0.050 \pm 0.010 \mathrm{~g} / \mathrm{cm}^{2} \mathrm{y}$ (about 0.5 $\mathrm{cm} / \mathrm{y}$ ) and the mixing rate $0.060 \pm 0.030 \mathrm{~cm}^{2} / \mathrm{y}$. For core $85-2$ the equivalent values were $0.085 \pm 0.020 \mathrm{~g} / \mathrm{cm}^{2} \mathrm{y}$ (about $0.5 \mathrm{~cm} / \mathrm{y}$ ) and 0.091 $\pm 0.030 \mathrm{~cm}^{2} / \mathrm{y}$. The error estimates represent the ranges that produced a doubling in the r.m.s. error of the SEDIMIX generated profile compared to measurements. Both of these cores showed a nearly exponential decrease in $21^{\circ} \mathrm{Pb}$ specific activity with depth, and the apparent sedimentation rates, assuming no mixing, would be 0.024 and 0.046 $\mathrm{g} / \mathrm{cm}^{2} \mathrm{y}$. (The fact that the apparent sedimentation rates are lower than the actual rates may seem surprising, since mixing usually causes apparent sedimentation rates to be higher than true sedimentation rates. The opposite is true, however, if steady state has not been reached, as in Bickford.) 
TABLE 6.3.1a SOIID PHASE $210 \mathrm{~Pb}$ DATA FOR CORES 85-1 AND 85-2

$\begin{array}{cc}\text { DEPTH } & 210 \mathrm{~Pb} \\ (\mathrm{~cm}) & (\mathrm{dpm} / \mathrm{g})\end{array}$

CORE 85-1
$0-0.19$
$41.6 \pm 1.6$
$0.19-0.50$
$29.7 \pm 1.2$
$0.50-1.06$
$17.9 \pm 1.2$
$1.06-1.64$
$7.8 \pm 0.7$

CORE $85-2$

$\begin{array}{rr}0-0.13 & 37.3 \pm 1.6 \\ 0.13-0.54 & 25.2 \pm 1.2 \\ 0.54-1.22 & 17.4 \pm 1.3 \\ 1.22-2.04 & 9.4 \pm 0.6 \\ 2.04-2.71 & 6.5 \pm 0.3 \\ 2.71-4.00 & 3.8 \pm 0.3\end{array}$




\subsubsection{PORE WATER $210 \mathrm{~Pb}$ AND $210 \mathrm{PO}$}

Pore water concentrations

Pore water concentrations of $210 \mathrm{Po}$ and $210 \mathrm{~Pb}$ along with those of dissolved $\mathrm{Fe}, \mathrm{Mn}, \mathrm{pH}$, and alkalinity are presented in Table 6.3.2a and in Figures 6.3.2a and 6.3.2b. The following points are noteworthy. First, the profiles taken on the two dates are similar, with $210 \mathrm{~Pb}$ concentrations increasing from the sediment water interface down to a depth of from 2 to $4 \mathrm{~cm}$, and decreasing thereafter. Second, the concentration of the radionuclides is about two orders of magnitude higher in pore waters than in typical lake water. Third, the activity of $2{ }^{10} \mathrm{Po}$ and $210 \mathrm{~Pb}$ were not significantly different from each other. Fourth, steep concentration gradients extend in either direction from a mid-depth maximum. The high pore water concentrations and the steep concentration gradients suggest that diffusional transport of the radionuclides may be important, as will be discussed in a later section. Finally, $210 \mathrm{~Pb}$ in the overlying water sample (25 September) is close to the value measured nearby in the water column and much lower than in pore water from the top sediment section. This implies that there was little exchange of water between the sediments and the overlying water during sample collection, transport, and processing.

Precedents for these measurements are few, but suggest that high pore water concentrations of these radionuclides may be common. COCHRAN and KRISHNASWAMI (1980) measured uranium series radionuclides in pore waters from the north equatorial Pacific, and found $210 \mathrm{~Pb}$ values in the range from 30 to $200 \mathrm{dpm} / 100 \mathrm{~kg}$, roughly $20 \%$ of ${ }^{226} \mathrm{Ra}$ levels. The authors expressed the belief that most of the $210 \mathrm{~Pb}$ grew in from $22{ }^{2} \mathrm{Rn}$ after pore water extraction, and thus did not reflect in situ 
TABLE 6.3.2a PORE WATER CHEMISTRY

DATE

$\begin{array}{lcccccc}\text { DEPTH } & 210 \mathrm{~Pb} & 210 \mathrm{Po} & \mathrm{Fe} & \mathrm{Mn} & \mathrm{pH} & \text { ALKALINITY } \\ (\mathrm{cm}) & \mathrm{dpm} / 100 \mathrm{~kg} & \mathrm{dpm} / 100 \mathrm{~kg} & \mathrm{mg} / 1 & \mathrm{mg} / 1 & & \mathrm{mEq} / 1\end{array}$

27 August

$\begin{array}{ccrcccc}112 \mathrm{~m} & (9.7) & (32.1) & (1.15) & (0.38) & - & - \\ 0.0-1.2 & 280 \pm 23 & 313 \pm 38 & 1.52 & 0.36 & 5.90 & 0.11 \\ 1.2-2.2 & 407 \pm 29 & 281 \pm 35 & 1.52 & 0.41 & 6.21 & 0.15 \\ 2.2-3.2 & 379 \pm 32 & 424 \pm 46 & 1.46 & 0.37 & 6.25 & 0.14 \\ 3.2-4.2 & 529 \pm 49 & 577 \pm 81 & 1.65 & 0.29 & 6.34 & 0.10\end{array}$

25 September ${ }^{2}$

$\begin{array}{crccccc}{ }^{1} 12 \mathrm{~m} & (31 \pm) & (30 \pm) & (6.98) & (0.49) & -- & -- \\ { }^{3}<0.0 & 63 \pm 7 & 256 \pm 64 & 3.09 & 0.37 & 6.80 & 0.19 \\ 0.0-0.75 & 438 \pm 49 & 4<880 & 4.66 & 0.31 & 6.60 & 0.16 \\ 0.75-1.75 & 371 \pm 36 & 4<740 & 6.23 & 0.34 & 6.83 & 0.22 \\ 1.75-2.75 & 665 \pm 80 & 4<1330 & 3.76 & 0.28 & 6.98 & 0.21 \\ 2.75-3.75 & 574 \pm 76 & 4<1150 & 4.66 & 0.30 & 6.98 & 0.21 \\ 3.75-4.75 & 357 \pm 44 & 4<720 & -- & -- & -- & -- \\ 4.75-6.0 & 200 \pm 32 & 4<400 & 4.71 & 0.32 & 6.90 & 0.23\end{array}$

${ }^{1}$ Values in parenthesis measured on water column samples from $12 \mathrm{~m}$.

${ }^{2}$ No measurable sulfide in any of the September pore waters when measured 1 October on preserved samples

${ }^{3}$ Signifies water overlying the core.

4210 Po was not measured on these core until 219 days after collection. At that time ${ }^{210} \mathrm{Po}$ was identical to ${ }^{210} \mathrm{~Pb}$. The actual $210 \mathrm{Po}$ at the time of sampling may have been greater or less than $210 \mathrm{~Pb}$, but reached secular equilibrium through radioactive decay. The tabulated values represent calculated upper limits; $21{ }^{\circ}$ Po greater than the tabulated level could not have decayed down to a level that was statistically equal to $210 \mathrm{~Pb}$ (958 confidence level) within $219 \mathrm{~d}$. The lower limit is 0 in each case. 
FIGURE 6.3.2a PORE WATER CONCENTRATIONS OF 210Pb, ALKALINITY,

MANGANESE, AND IRON - 27 AUGUST 1985 (CORE 85-1)

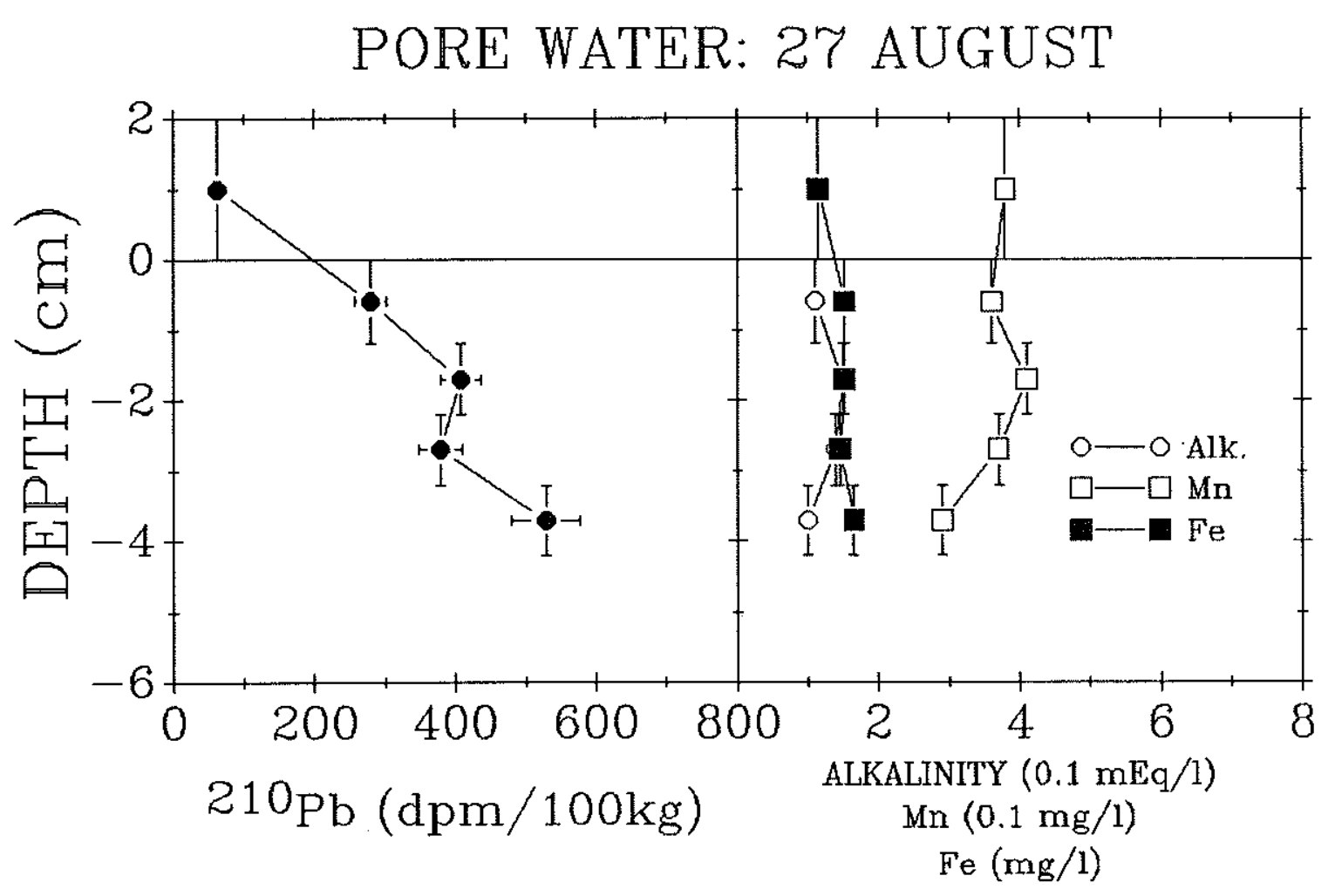


FIGURE 6.3.2b PORE WATER CONCENTRATIONS OF 210Pb, ALKALINITY,

MANGANESE, IRON, AND SULFIDE - 25 SEPTEMBER 1985 (CORE 85-2)

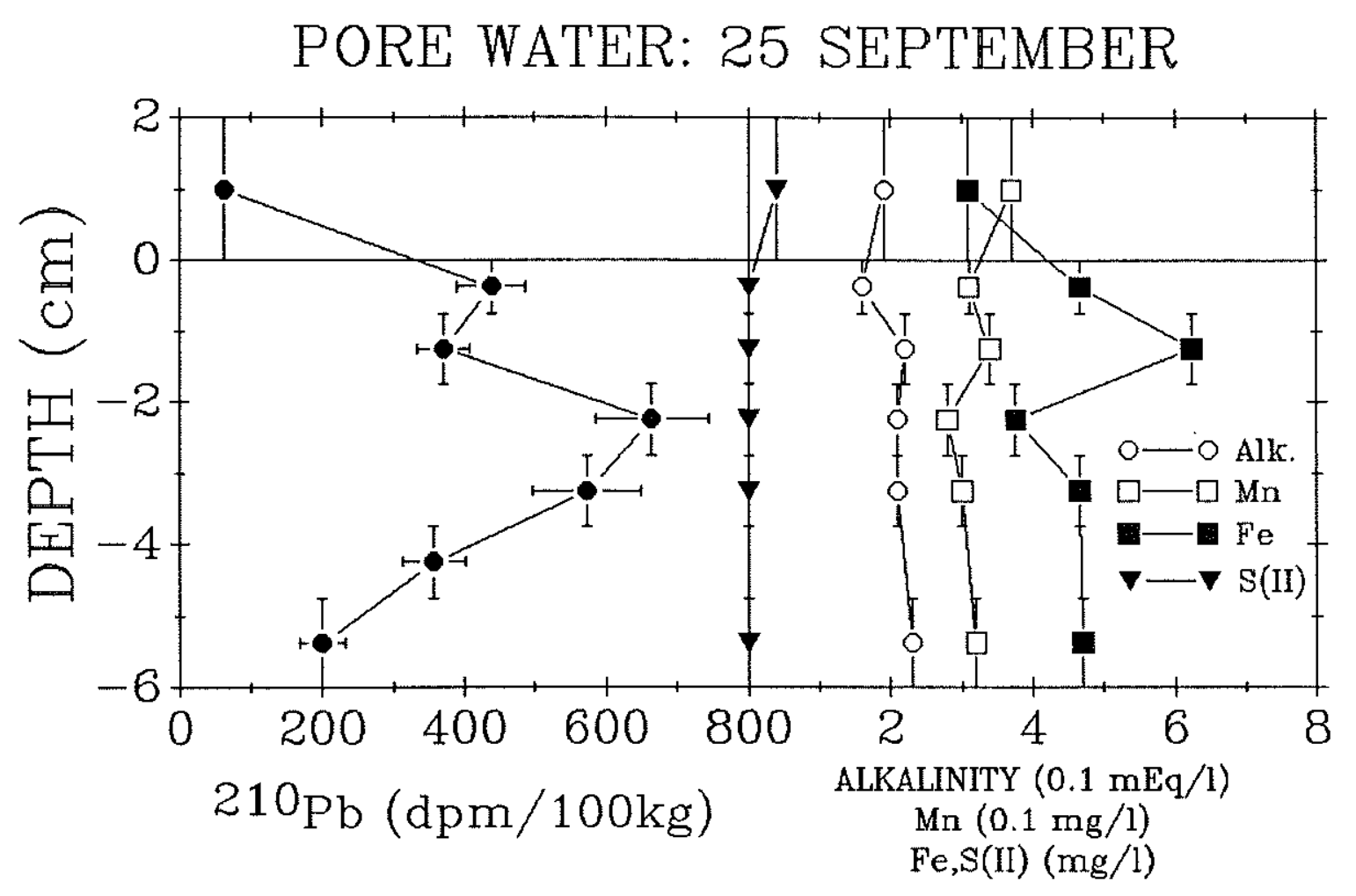


concentrations. They had not degassed the pore waters and there were no $222 \mathrm{Rn}$ measurements to test this hypothesis.

KRISHNASWAMI et al. (1982) measured uranium series radionuclides in groundwaters drawn from Connecticut aquifers whose lithology was similar to that in the Bickford watershed. They found $21^{\circ} \mathrm{Pb}$ concentrations ranging from 5,140 to $280,000 \mathrm{dpm} / 100 \mathrm{~kg}$. Again these were believed to have largely grown in from ${ }^{22} \mathrm{Rn}$ after collection. The well producing the highest $2{ }^{10} \mathrm{~Pb}$ level was resampled using a degassing technique that immediately removed any ${ }^{22} \mathrm{Rn}$. ${ }^{210} \mathrm{~Pb}$ decreased to $27,600 \mathrm{dpm} / 100 \mathrm{~kg}$, a still very high level. Using an approximate ${ }^{22} \mathrm{Rn}$ level they then estimated a retardation factor of 43,000 for $210 \mathrm{~Pb}$ in this aquifer. In the same study, in situ ${ }^{210}$ Po was measured to be from 130 to 44,700 $\mathrm{dpm} / 100 \mathrm{~kg}$.

BUESSELER et al. (1982, unpublished data) measured ${ }^{210}$ Po levels of $200 \mathrm{dpm} / 100 \mathrm{~kg}$ in pore waters from anoxic sediments of Gull Pond, MA. Equivalent $210 \mathrm{~Pb}$ measurements were not made. Surface lake waters had $210 \mathrm{Po}$ levels near $10 \mathrm{dpm} / 100 \mathrm{~kg}$ whereas bottom waters were near 30 $\mathrm{dpm} / 100 \mathrm{~kg}$, so perhaps the pore waters were a source of ${ }^{210} \mathrm{Po}$ to the lake. WAN et al. [1987]) measured $21{ }^{\circ} \mathrm{Pb}$ pore water concentrations of $130 \mathrm{dpm} / 100 \mathrm{~kg}$ in Greifensee, Switzerland.

Taken together these few studies show that pore water 210 Po and $210 \mathrm{~Pb}$ tend to fall in the neighborhood of hundreds of $\mathrm{dpm} / 100 \mathrm{~kg}$, much higher than typical lake levels (TALBOT and ANDREN [1984], BENOIT and HEMOND [1987]).

It is significant that activities of ${ }^{210} \mathrm{Po}$ and $210 \mathrm{~Pb}$ in Bickford pore waters were equal to each other. Since the pore waters were not degassed immediately after collection, there remains the possibility 
that ${ }^{210} \mathrm{~Pb}$ is derived from ingrowth after extraction and does not represent in situ levels. Assuming that this is the case, is it possible to imagine a model whereby dissolved $21{ }^{\circ} \mathrm{Po}$ and $2{ }^{\circ} \mathrm{Pb}$ must necessarily be equal? Let's assume that in the sediments, ${ }^{210} \mathrm{~Pb}$ is generated from a relatively constant amount of ${ }^{222} \mathrm{Rn}$ whose concentration was determined by a balance between production by alpha recoil and loss by radioactive decay. The $210 \mathrm{~Pb}$ production rate (in atoms per time) will be the same as the ${ }^{222} \mathrm{Rn}$ activity (in dpm). In a steady state system, the activity of $210 \mathrm{~Pb}$ (which we assume is instantaneously and quantitatively sorbed) will be equal to the ${ }^{222} \mathrm{Rn}$ activity: $A_{\mathrm{Pb}}=A_{\mathrm{Rn}}$. $21{ }^{\circ} \mathrm{Pb}$ that would grow-in to an extracted pore water sample is: $\mathrm{A}_{\mathrm{Pb}}=$ $\mathrm{A}_{\mathrm{Rn}} / \div \lambda_{\mathrm{Rn}} / \lambda_{\mathrm{Pb}}$ ) $=\mathrm{A}_{\mathrm{Rn}} / 2140$. So the total amount of $210 \mathrm{~Pb}$ in situ (a11 on solids) and the amount measured on a pore water sample after ingrowth are both proportional to the amount of ${ }^{222} \mathrm{Rn}$ in solution. ${ }^{210} \mathrm{Po}$, which has been measured, is in turn derived from decay of $210 \mathrm{~Pb}$, with the total activities being equal: $\mathrm{A}_{\mathrm{Po}}=\mathrm{A}_{\mathrm{Pb}}$. The fraction of this total that is in solution (as opposed to sorbed to solids) will depend on the partition coefficient for $21{ }^{\circ} \mathrm{Po}$. The solution concentration is given by: ${ }^{210} \mathrm{Po}$ solution $=210 \mathrm{Po}_{\text {solids }} / \mathrm{K}_{\mathrm{D}}$ (for $\left.\mathrm{K}_{\mathrm{D}} \gg 0\right) .\left(\mathrm{K}_{\mathrm{D}}\right.$ is defined as the ratio of the concentration of the trace material in the solid phase to its concentration in the aqueous phase). The ratio of 210 Po in solution to $210 \mathrm{~Pb}$ generated by ingrowth in an extracted pore water sample (the two values measured in Bickford pore waters by this scenario) is thus:

$$
\frac{\left(\mathrm{A}_{\mathrm{Rn}} / \mathrm{K}_{\mathrm{D}}\right)}{\left(\mathrm{A}_{\mathrm{Rn}} / 2140\right)}=2140 / \mathrm{K}_{\mathrm{D}}
$$


Thus, the observed equivalence between pore water ${ }^{210} \mathrm{Po}$ and ${ }^{210} \mathrm{~Pb}$ could result from a coincidence; the partition coefficient for $2{ }^{\circ}$ Po may be equal to the ratio of the decay constants of $222 \mathrm{Rn}$ and ${ }^{210} \mathrm{~Pb}, 2140$. In reality, the sediments do not conform to this simple scheme. For one thing, this model requires that the system be in steady-state, otherwise the total activity of ${ }^{210} \mathrm{~Pb}$ could be much less than the $222 \mathrm{Rn}$ activity. These sediments have been in place for less than one ${ }^{210} \mathrm{~Pb}$ half-life; previously they were subaerial, and diffusion of ${ }^{22} \mathrm{Rn}$ may have left them substantially inequilibrated. More importantly, excess $210 \mathrm{~Pb}$ in solids is much greater than support from ${ }^{226} \mathrm{Ra}$, so the pore water concentration of $21^{\circ} \mathrm{Po}$ is unlikely to be proportional to pore water ${ }^{222} \mathrm{Rn}$. Instead, the measured equivalence of $21{ }^{\circ} \mathrm{Po}$ and ${ }^{210} \mathrm{~Pb}$ probably results from some relation between their pore water concentrations, implying that the measured $210 \mathrm{~Pb}$ values are real and not artifacts. Why are $210 \mathrm{Po}$ and $210 \mathrm{~Pb}$ equal? The first possibility is that $210 \mathrm{Po}$ grows in from $210 \mathrm{~Pb}$ in situ and then stays in solution. This requires that the pore waters be several ${ }^{210}$ Po half-lives old (138 d), and that the ${ }^{210} \mathrm{Po}$ so-produced is not readsorbed. The first condition is unlikely since measured seepage rates should replace pore fluids to a depth of from 4 to $12 \mathrm{~cm}$ every 210 Po half-life. The second condition is also quite unlikely unless the pore water $210 \mathrm{~Pb}$ is actually complexed by high molecular weight organic molecules or held on the surface of colloids. Even then, 210 Po might be torn free from the complexing colloid or 1 igand by the energetic $\beta$-decay of ${ }^{210} \mathrm{Bi}(1.16 \mathrm{MeV}),{ }^{210} \mathrm{Po}$ would then be free to resorb to sedimentary solids.

The second possibility depends on the fact that most of the total $210 \mathrm{Po}$ and $210 \mathrm{~Pb}$ in the sediments is in the solid phase. $210 \mathrm{Po}$ and $210 \mathrm{~Pb}$ 
are almost certainly in secular equilibrium, so if the partition coefficients for ${ }^{210} \mathrm{Po}$ and $2{ }^{\circ} \mathrm{Pb}$ are the same, then so will be their pore water activities. This seems reasonable, since $2{ }^{10} \mathrm{Po}$ and $21^{\circ} \mathrm{Pb}$ partitioning (and implicitly $\mathrm{K}_{\mathrm{D}}$ 's) tend to be fairly similar (within a factor of 2), at least in the water column. The simplicity of this explanation makes it the preferred choice, and this lends support to the assumption that the measured $210 \mathrm{~Pb}$ values are not artifacts. Calculation of partition coefficients

Measurements of stable lead indicate that $210 \mathrm{~Pb}$ concentrations in solution were not controlled by the solubilty of inorganic lead compounds ( $\mathrm{K}_{\mathrm{sp}}$ values taken from HEM [1976]). In order to place the interpretation of the pore water data in a quantitative framework, partition coefficients $\left(K_{D}\right)$ were calculated. The goal of these calculations is to evaluate the possibility that reversible sorption reactions (including surface complexation) may control lead and polonium solubility in the pore waters. It is possible that some $210 \mathrm{~Pb}$ may not be amenable to sorption-desorption with pore water because it is bound at sites within the interior of carrier phases. However, sequential leaching studies in this research and elsewhere (DOMINIK et al. [1983]) indicate that $210 \mathrm{~Pb}$ is associated with reducible phases. Once these are solubilized, ${ }^{210} \mathrm{~Pb}$ is free to participate in sorption-desorption on the copious sedimentary surface. In addition to reductive dissolution, other possible sources for $210 \mathrm{~Pb}$ - - alpha recoil or formation in solution from ${ }^{22} \mathrm{Rn}$.- also create free dissolved forms that can participate in ion exchange reactions.

The definition of $\mathrm{K}_{\mathrm{D}}$ used for these calculations is: 


$$
\mathrm{K}_{\mathrm{D}}=\frac{[210 \mathrm{~Pb}]_{\text {solid }}}{\left[{ }^{210} \mathrm{~Pb}\right]_{\text {solution }}}
$$

Where:

$$
\begin{aligned}
& {[210 \mathrm{~Pb}]_{\text {solid }}=210 \mathrm{~Pb} \text { activity/mass sediment }} \\
& {[210 \mathrm{~Pb}]_{\text {solution }}=210 \mathrm{~Pb} \text { activity/mass pore water. }}
\end{aligned}
$$

This formulation assumes that adsorption can be described by a linear isotherm:

$$
\left(\mathrm{C}_{\mathrm{ads}}\right)=\mathrm{AC}^{\mathrm{a}} \text {, }
$$

where $\mathrm{C}$ is concentration in the aqueous phase, $\mathrm{A}$ is a constant, and $\mathrm{a}=$ 1 in the linear case. This approach has been used to describe the behavior of radionuclides in other lacustrine sediments (e.g. LERMAN and LIETZKE [1975]), and successfully describes many other sorption data sets, especially where the sorbate is present at trace levels. The results of the calculations are presented in Table 6.3.2b.

The partition coefficient falls in the range from 1,500 to 15,000, and generally decreases with depth. Below about $3 \mathrm{~cm}$ in both cores, $\mathrm{K}_{\mathrm{D}}$ is constant at around 1,700 . Stable lead was measured on some sections of core 85-2, allowing independent calculation of $\mathrm{K}_{\mathrm{D}}$ 's (Table 6.3.2c). These agreed with those calculated from $2{ }^{\circ} \mathrm{Pb}$ within the statistical uncertainty. This concordance is further support for the belief that measured $210 \mathrm{~Pb}$ levels are not artifacts, and implies that stable and radioactive lead have similar behaviors in these sediments, and that $210 \mathrm{~Pb}$ levels are not controlled by $\alpha$-recoil. 
TABLE $6.3 .2 \mathrm{~b} \quad 210 \mathrm{~Pb}$ PARTITION COEFFICIENTS

DATE

DEPTH

$\mathrm{K}_{\mathrm{D}}\left({ }^{2}{ }^{\circ} \mathrm{Pb}\right)$

$\mathrm{K}_{\mathrm{D}}(\mathrm{Pb})$

$\mathrm{K}_{\mathrm{r}} 1$

27 August

$$
0-1.2 \quad 14,900 \pm 1300
$$

$-$

2,500

$1.2-2.2$

$7,300 \pm 590$

$--$

2,600

$2.2-3.2$

$4,700 \pm 510$

- 3,500

$3.2-4.2$

$1,470 \pm 190$

$-\cdot$

1,300

25 September
$0-0.75$
$8,500 \pm 1020$
$8,300 \pm 1170^{2}$
1,600

$0.75-1.75$

$6,800 \pm 740$

$5,800 \pm 820$

3,400

$1.75-2.75$

$2,600 \pm 370$

-

2,400

$2.75-3.75$

$1,640 \pm 240$

$2,100 \pm 300$

2,000

$3.75-4.75$

$1,810 \pm 240$

-

1,800

$4.75-6.0$

$1,910 \pm 330$

$1,200 \pm 170$

3,200

${ }^{1}$ The retardation coefficient, $K_{r}$, includes the effect of the relative masses of solids and water per unit volume of sediments

${ }^{2}$ Errors estimated assuming a 108 uncertainty for stable $\mathrm{Pb}$ measurements

${ }^{3} \mathrm{~A} \mathrm{~K}_{\mathrm{D}}$ of about 2,700 can be calculated for ${ }^{210} \mathrm{~Pb}$ in sediments of Greifensee, Switzerland, from data contained in WAN et al. (1987)

${ }^{4} \mathrm{~K}_{\mathrm{D}}$ 's for ${ }^{210}$ Po not significantly different from those for ${ }^{210} \mathrm{~Pb}$ 
TABLE 6.3.2 C STABLE LEAD IN CORE 85-2

STABLE LEAD

DATE

$\begin{array}{ccc}\text { DEPTH } & \text { PORE WATER } & \text { SOLIDS } \\ (\mathrm{cm}) & (\mu \mathrm{g} / 1) & (\mu \mathrm{g} / \mathrm{g})\end{array}$

25 September

\begin{tabular}{|c|c|c|c|}
\hline 0 & -0.2 & - & 127 \\
\hline 0 & -0.75 & 5.9 & 49 \\
\hline 0.75 & -1.75 & 6.6 & 38 \\
\hline 1.75 & -2.75 & - & 29 \\
\hline 2.75 & -3.75 & 12.3 & 26 \\
\hline 3.75 & -4.75 & - - & 21 \\
\hline 4.75 & -6.0 & 7.7 & 9 \\
\hline
\end{tabular}


Comparison with partition coefficients in lab and field studies

Section 6.5 .2 will discuss factors that may control the magnitude and variation of $\mathrm{K}_{\mathrm{D}}$ in Bickford sediments are. The following discussion attempts to compare and reconcile the Bickford data with results in the literature.

The calculated $\mathrm{K}_{\mathrm{D}}$ values are low compared to values determined in laboratory studies for the adsorption of stable lead on a number of pure compounds. JEAN and BANCROFT (1986) measured a $\mathrm{K}_{\mathrm{D}}$ of 1500 for lead on $\mathrm{FeS}_{2}$ at $\mathrm{pH}$ 6.5. GADDE and LAITENEN (1974) found $\mathrm{K}_{\mathrm{D}}$ 's of 13,500 and 3,000 for hydrous iron and aluminum oxides at $\mathrm{pH} 6.5$. The $\mathrm{K}_{\mathrm{D}}$ for lead on hydrous manganese oxide cannot be determined at $\mathrm{pH} 6.5$ from their data since the adsorption edge is near $\mathrm{pH} 2$ (the value would be $>200,000)$. By comparison, SWALLOW et al. found a value of $\mathrm{K}_{\mathrm{D}}$ of about 500,000 for lead on hydrous iron oxide at $\mathrm{pH} 6.5$. The difference between the results of these two studies may be, in part, an expression of a solids effect. When experiments have been carried out under a range of solid to solution ratios, partitioning seems to favor the solution phase disproportionately at high solids concentrations. The difference between these two studies conforms to this pattern; SWALLOW et al. worked with 60 times less hydrous iron oxide per volume than did GADDE and LAITENEN, and their data show a lesser tendency for adsorption on solids (expressed per mass of solids). The difference may also relate to experimental method; GADDE and LAITENEN used polarography on unfiltered samples while SWALLOW et al. used atomic absorption on filtered samples. The two techniques may have measured different lead pools. Another possible explanation of the difference is that the free energy of adsorption changes as surface sites approach saturation. 
GADDE and LAITENEN used a lead to iron mole ratio of $1: 6$, close to saturation, while SWALLOW et al. worked below 1:10. In further support of this hypothesis, in one series of experiments carried out by Swallow and coworkers at a ratio of $1: 5, \mathrm{~K}_{\mathrm{D}}$ was much lower. The difference between the results of these two studies also illustrates the difficulty encountered when trying to extrapolate from one experimental system to another; even in these two studies carried out on very similar, pure (albeit amorphous) substances, very different results were generated. One explanation for apparent inconsistencies in sorption data under different experimental conditions has been presented by DZOMBACK (1986). The issue of the solids effect (O'CONNOR and CONNOLLY [1980]) deserves further discussion since sediments represent an extreme: the highest possible concentration of solids per volume. The solids effect has been explained both as an experimental artifact and as a real phenomenon. High levels of solids might take Ionger to equilibrate thus leading to erroneously low apparent sorption values if sufficient time is not allowed before measurement. There is also evidence that solids can produce colloids, which complex metals and cause high apparent dissolved metal concentrations and low $\mathrm{K}_{\mathrm{D}}{ }^{\mathrm{s}} \mathrm{s}$. There are several mechanisms whereby high solids concentrations could cause true reductions in sediment sorption when expressed per area of available surface. For one, at high solids concentrations the double layers of adjacent particles might overlap, changing the coulombic term of the sorption energy equation. Another simpler, physical explanation is that at high solids concentrations particles in aggregates partially block each other's surfaces thereby reducing total surface area per mass of solids. Whatever the cause, one might expect lower values of $k_{D}$ in 
sediments than would be predicted based on extrapolation from laboratory experiments carried out at much lower particle concentrations.

In general, sorption of lead on metal oxides shows a strong $\mathrm{pH}$ dependence, with much greater retention by solids at higher $\mathrm{pH}$. The simplest mode1 -- $\mathrm{Pb}^{2}$ exchanging for two hydrogen ions - predicts that the $\log$ of the partition coefficient would vary by a factor of two for a change in $\mathrm{pH}$ of one unit, neglecting surface potential changes. Other functionalities are possible, but sorption of metals on transition metal oxides is always greatly influenced by $\mathrm{pH}$. In cores $85-1$ and $85-2$, the observed variation of $\mathrm{K}_{\mathrm{D}}$ with depth cannot be explained by a $\mathrm{pH}$ effect since the change is slight and is in the wrong direction. If anything, the measured increase in $\mathrm{pH}$ with depth should have led to an increase in $\mathrm{K}_{\mathrm{D}}$ deeper in the sediment profile.

To summarize this comparison of partition coefficients measured in the laboratory with values determined in situ in Bickford sediments, the following points should be emphasized. $\mathrm{K}_{\mathrm{D}}$ values measured in Bickford tend to fall at the low end of the range measured for pure substances in laboratory experiments, that is, $210 \mathrm{~Pb}$ seems to have a greater tendency to desorb from these sediments than would be predicted by modeling them as, for example, freshly precipitated hydrous iron oxide. Having said that, it is important to be aware of the vast differences between the two types of systems compared. Most laboratory studies are carried out on freshly prepared materials that are relatively uniform (if sometimes amorphous) in composition. Even so, differences in the mode of preparation of solids can lead to different results from one study to another (HOHL and STUMM [1976]). Changes in solids with aging have been noted in the short term (SWALLOW et al. [1980]) and diagenetic 
conversion from amorphous to more well defined crystalline forms over the long term will almost certainly cause additional changes.

Laboratory studies are carried out at high concentrations of the sorbed metal and close to the limit of surface site saturation. The relative importance of specific and electrostatic free energy terms is plainly not the same in a laboratory study with a metal to sorbent ratio of $1: 10$ as it is in Bickford Reservoir sediments with a ratio of 1:1000. Laboratory studies are conducted in a region where sorption is undoubtedly highly non-linear, and it is hard to extrapolate from these conditions to those where a simple $\mathrm{K}_{\mathrm{D}}$ approach to sorption provides an adequate approximation of trace metal behavior. Another factor that influences our ability to extrapolate from laboratory to field studies is the issue of dissolved phase speciation; to what extent is the measured $210 \mathrm{~Pb}$ in pore water free to sorb onto solids? This question will be addressed in section 6.5.2.

\section{3 .3 IRON AND MANGANESE}

The geochemistry of iron and manganese is of special interest since their behavior is linked with that of ${ }^{210} \mathrm{~Pb}$ and ${ }^{210} \mathrm{Po}$, judging from sequential leaching results, the cycling of the radionuclides in the Bickford water column, and studies elsewhere (BACON et a1. [1976,1980], CARPENTER et al. [1981,1984], DOMINIK et al. [1983]). A summary of iron and manganese in the pore waters of cores 85-1 and 85-2 was presented in Table 6.3.2a and Figures 6.3.2a and 6.3.2b. Additional data on core 852, including measurements of solid phase iron and manganese phases, are listed in Table 6.3.3a.

The figures show clearly that dissolved iron and manganese do not have steep concentration gradients in the pore waters on either date. 
TABLE $6.3 .3 \mathrm{a}$ IRON AND MANGANESE IN CORE $85-2$

IRON

DATE DEPTH

$$
\text { REDUCIBLE }{ }^{1} \text { RESIDUAL }{ }^{2}
$$$$
(\mathrm{mg} / \mathrm{g})
$$$$
(\mathrm{mg} / \mathrm{g})
$$

25 September

$\begin{array}{rrrrr}{ }^{3} 0-0.2 & 39.6 & -- & - & - \\ 0-0.75 & 17.9 & 16.0 & .180 & .243 \\ 0.75-1.75 & 16.0 & 16.2 & .172 & .202 \\ 1.75-2.75 & 14.9 & 21.2 & .153 & .232 \\ 2.75-3.75 & 14.8 & 22.5 & .144 & .250 \\ 3.75-4.75 & 13.9 & 17.8 & .135 & .220 \\ 4.75-6.0 & 9.7 & 13.5 & .115 & .243\end{array}$

${ }^{1}$ Samples treated with strong reducing reagent used for sequential leaching experiments. Heated at $95^{\circ}$ for $3 \mathrm{~h}$. Centrifuged, decanted through $0.45 \mu$ filter. Heated with $1 \mathrm{M} \mathrm{NH}_{4} \mathrm{Ac}$. Centrifuged, decanted through $0.45 \mu$ filter. Rinsed with $\mathrm{dH}_{2} \mathrm{O}$, centrifuged, decanted through $0.45 \mu$ filter.

${ }^{2}$ Residue from above treated sequentially with concentrated $\mathrm{HF}, 30 \mathrm{8} \mathrm{H}_{2} \mathrm{O}_{2}$, and $0.28 \mathrm{HNO}_{3}$.

${ }^{3}$ Interfacial floc, collected as described in section 6.6 
Furthermore, levels of these metals are similar in the water column and in interstitial water. Taken together, these two facts imply that pore waters are not a significant supplier of $\mathrm{Fe}$ or Mn to the water column, and that the high water column concentrations of the transition metals must come from some other source.

Mn Solubility

An important issue is what controls the solubility of the two transition metals in the pore waters and bottom waters of Bickford Reservoir. Over the time period for which pore water measurements were made, the two metals behaved differently. Dissolved Mn remained relatively constant between the two sampling dates, while dissolved $\mathrm{Fe}$ increased substantially, growing by a factor of 6 in the water column and 3 in pore waters.

Concentration is controlled ultimately by a balance between supply and removal processes. Supply of these two metals to pore waters is almost certainly dominated by reductive solubilization of metal oxides. Removal can be either chemical -- precipitation of a new solid -- or physical - transport out of the sediments by either advection or diffusion. Manganese presents the simpler case since it did not change in concentration nor did it have any concentration gradients that would promote diffusional fluxes. The most likely solids that could limit $\mathrm{Mn}^{2+}$ solubility are carbonates, phosphates and sulfides. These can all be ruled out since manganous forms are more soluble than respective ferrous forms, yet iron was an order of magnitude more concentrated than manganese. Also unlikely is a balance between the rate of reduction and the rate of removal by transport. The lack of significant concentration gradients means that diffusive or advective fluxes are negligible, and 
so must be the rate of reduction in the absence of any other removal processes. The apparent lack of Mn reduction is further supported by the increasing iron levels during this period; one would not expect much iron to be reduced until the bulk of the easily reducible manganese had been depleted (FROELICH et al. [1979]).

It thus seems that manganese levels in these reducing sediments are controlled by availability. All of the manganese that can be reduced easily is solubilized and diffuses out of the sediments. Once in the water column, reoxidation is very slow (STUMM and MORGAN [1970, WILSON (1980), CHAPNICK et al. (1982), DIEM and STUMM [1984], SUNDA and HUNTSMAN [1987]) and this probably allows a majority of the manganese to be flushed from the lake before it can be returned to the sediments by reprecipitation. Because of this net loss of manganese from sediments, there is a large decrease in the Mn to Fe ratio in bottom sediments compared to the SPM from which they are derived. The ratio dxops from approximately 1:10 in SPM (collected in the epilimnion) and in sediment trap material to $1: 100$ in bottom sediments. If iron is conservative, then this implies that 908 of deposited manganese is subsequently lost from the lake. Since the low solid phase Mn:Fe ratios extend right up to the sediment water interface, it appears that manganese is lost from the bottom before it can be buried or mixed below the surface. Quite probably, most of the manganese delivered by particles to the sediment water interface over the course of the year is lost during the period of bottom water anoxia each summer.

Iron Solubility

Control of iron solubility is more complex as attested by increasing concentrations over time and by development of pore water 
gradients. Dissolved iron was near saturation with respect to siderite and vivianite. That assessment was based on the following calculations and assumptions. Carbonate concentration was calculated from the alkalinity and $\mathrm{pH}$ assuming that other weak acids contributed negligibly to alkalinity. On 27 August the calculated ion product was less than the $\mathrm{K}_{\mathrm{sp}}$ for $\mathrm{FeCO}_{3}$ by a factor of 100 , but this margin had decreased to only a factor of 3 on 25 September. Clearly iron levels were rapidly approaching the limit of siderite solubility.

Saturation with respect to vivianite, $\mathrm{Fe}_{3}\left(\mathrm{PO}_{4}\right)_{2}$, was evaluated using an estimated value for the concentration of total phosphorus in the pore waters. Phosphorus constitutes $0.8 \%$ (by mass) of organic matter according to the Redfield ratio. Sediments had a bulk density of about $0.7 \mathrm{~g} / \mathrm{cm}^{3}$, and these solids contained about 208 organic matter (based on loss on ignition, LOI). Combining these numbers allows calculation of the total phosphorus as 0.035 mole/liter of whole sediment. By comparison, iron is present at a concentration of 0.50 mole/liter. Clearly $\mathrm{Fe}$ is in considerable excess relative to $P$, so even if all the phosphorus were in the form of vivianite, additional iron could be free to enter pore waters. Phosphorus can be more concentrated in sedimentary organic matter than is indicated by the Redfield ratio, but phosphorus would need to be more than 108 of LOI to approach the iron level.

Pyrrhotite, FeS, is extremely insoluble, such that the more abundant species - Fe(II) or S(-II) - - will control the solubility of the other (DAVISON and HEANEY [1978]). As is shown in Figures 6.3.2a and $6.3 .2 \mathrm{~b}$, iron was abundant in the pore waters, while total $\mathrm{S}(-\mathrm{II})$ was below the limit of detection. To test whether pyrrhotite formation 
could be limiting sulfide in these sediments, maximum permissible total sulfide was calculated from the measured iron and $\mathrm{pH}$ values, and the $\mathrm{K}_{\mathrm{sp}}$ measured by DAVISON and HEANEY (1978) under conditions very similar to those in these sediments. For August 27, an average Fe concentration of $27 \mu \mathrm{M}$ and a $\mathrm{pH}$ of 6.2 was used to calculate a maximum $\mathrm{S}$ (II) concentration of $160 \mu \mathrm{M}(5 \mathrm{mg} / 1)$. For September 25 , Fe was $85 \mu \mathrm{M}$ and $\mathrm{pH}$ 6.9 for a maximum S(II) level of $3.5 \mu \mathrm{M}(0.1 \mathrm{mg} / 1)$. On the earlier date, the measured sulfide level was well below the calculated maximum, indicating that precipitation of pyrrhotite did not limit sulfide solubility. On the later date, increases in iron and $\mathrm{pH}$ drove the calculated maximum S(II) concentration down below the limit of detection of the methylene blue colorimetric sulfide test (about $5 \mu \mathrm{M}$ ), so it could not be determined whether FeS solubility was limiting. Similar arguments could be made about the total abundance of sulfur in sediments as were made for phosphorus, since sulfur and phosphorus make up about equal fractions of organic matter. This means that iron is in considerable excess of sulfur in whole sediments of Bickford, making it less likely that sulfur could ultimately limit iron solubility. Fe-organic Complexes

The above discussion on limits to iron solubility has assumed implicitly that the measured ixon is all in the free dissolved form. In fact, much of the iron may be complexed. Inorganic complexes of iron are weak so the most important ligand in these soft, fresh waters is likely to be humates. Indeed, soft, freshwater sediments have the ideal characteristics to promote complexation of metals by humic substances: high concentrations of DOC and relatively low levels of major cations 
$\left(\mathrm{Ca}^{2}{ }^{+}, \mathrm{Mg}^{2+}\right)$ that would compete for or reduce the apparent affinity of the ligands for trace metals.

The potential for organic complexation can be estimated using conditional stability constants for ferrous iron-humate complexes. These stability coefficients can be used much in the same manner as traditional stability constants when applied to a system under conditions (acid-base status, major ion chemistry) similar to those used in the experiment from which they were calculated. A conditional stability constant for iron-humate complexation of $10^{5}$ was estimated from a summary in MOREL (1983). The concentration of DOC was assumed to be about $10 \mathrm{mM} \mathrm{C}(120 \mathrm{mg} /$ liter), which is near the high end of the natural range in freshwaters, but is consistent with the yellow color of the extracted pore waters. Combined with an approximate mass per mole of complexation sites of $125 \mathrm{~g}$ (SUNDA and HANSON [1979]), this yields a concentration of sites of about $1 \mathrm{mM}$, an order of magnitude higher than that of iron. Based on these assumptions, virtually all of the iron can be expected to occur in association with DOC, with only 18 in the free dissolved form. This is in agreement with the findings of KROM and Sholkovitz (1978) for anoxic marine pore waters.

One consequence of this scenario would be that sulfide levels could be almost two orders of magnitude higher than values calculated above and still not cause pyrrhotite saturation. This is one way that ferrous iron and sulfide could coexist at "impossibly" high levels in solution. Since DOC levels are likely to change very slowly in this system, the observed rapid increase in pore water ixon could be explained as resulting from a change in the conditional stability constant brought about by the-documented increase in $\mathrm{pH}$ during the same period. At 
higher $\mathrm{pH}$, the lower concentration of $\mathrm{H}^{+}$causes the humates to complex additional $\mathrm{Fe}^{2+}$. These estimates are quite rough - - the magnitude of the stability coefficient is little more than an educated guess - - but they demonstrate the potential importance of organic complexation to iron speciation in fresh pore waters. Clearly measurements of both the concentration of DOC and its potential for complexation are needed for proper understanding of the pore water behavior of trace metals in systems of this sort.

\section{3 .4 ALKALINITY}

As shown in Figures 6.3.2a and b, alkalinity of both overlying and interstitial waters increased between the two sampling dates. Judging from the constancy of $\mathrm{Mn}^{2+}$ and $S$ (II) and the increase of $\mathrm{Fe}^{2+}$, the pe of these sediments is poised in the range of iron reduction. This reaction can be expressed by the equation:

$$
\mathrm{Fe}(\mathrm{OH})_{3}+2 \mathrm{H}^{+}+1 / 4 \mathrm{CH}_{2} \mathrm{O}=\mathrm{Fe}^{2+}+1 / 4 \mathrm{H}_{2} \mathrm{CO}_{3}+5 / 2 \mathrm{H}_{2} \mathrm{O}
$$

where $\mathrm{CH}_{2} \mathrm{O}$ represents organic matter. Since the equation is expressed in terms of the principal components at the $\mathrm{CO}_{2}$ equivalence point, the consumption of $\mathrm{H}^{+}$indicates that two equivalents of alkalinity are produced for each mole of iron reduced (MOREL [1983]). (Using other oxidized forms of iron such as hematite, $\mathrm{Fe}_{2} \mathrm{O}_{3}$, or goethite, $\mathrm{FeOOH}$, does not change the result). That conclusion does not agree with the measured increase in the two parameters since the ratio of $\Delta$ alkalinity to $\Delta \mathrm{Fe}^{2^{+}}$is less than 0.1 , not 2 as predicted. This discrepancy implies either that: 1) organic matter is not the reductant, 2) the increase in $\mathrm{Fe}^{2+}$ does not derive (in the short term) from $\mathrm{Fe}^{3^{+}}$reduction, 3) 
alkalinity is preferentially removed from the system relative to ferrrous iron, or 4) there was an error in the alkalinity titration. The first possibility could occur if sulfide diffused upward from depth, but oxidation of sulfide by iron causes almost as great an increase in alkalinity as does oxidation of organic matter. One mechanism that could facilitate possibility \#2 is a $\mathrm{pH}$ induced change in the Fe-humate stability coefficient. The third possibility could take place because of the relative retardation factors for $\mathrm{Fe}^{2+}$ and alkalinity. Ferrous iron, as a divalent metal, will have a relatively high tendency to sorb to sediment solids, thereby decreasing the rate at which it can diffuse through sediments. Alkalinity, on the other hand, is carried by compounds that can be modeled as dissolved $\mathrm{NaHCO}_{3}$; neither monovalent sodium ion nor bicarbonate would be retarded as much as ferrous iron. Another possibility for alkalinity loss is stripping of ammonia gas from sediments by bubbles, but this is unlikely in view of the high solubility of ammonia. The final possibility, an error in the titrations, is perhaps most likely. This measurement was carried out in contact with the atmosphere. To the extent that $\mathrm{Fe}^{2+}$ was rapidly oxidized to $\mathrm{Fe}^{3+}$, the alkalinity measurements would be erroneously low. This hypothesis implies that alkalinity may have been much higher than the measured value.

\subsubsection{SULFIDE}

Results of sulfide analyses on pore waters are shown in Figure 6.3.2b. Data on sulfide in the water column have already been presented in Table 4.3.6a. Sulfide was not detected in any of the pore waters tested, though the 1 imit of detection was a relatively high $0.16 \mathrm{mg} / \mathrm{l}$ ( 5 $\mathrm{mM})$. This was because only a small volume of porewater could be spared 
for the measurements, and because analyses were performed on samples preserved with zinc acetate. Tests showed that this latter practice reduced the sensitivity by about a factor of three during the five days the samples were stored before measurement.

The possibility that sulfide was limited by ferrous iron through precipitation of pyrrhotite was discussed above. Lead may in turn be limited by sulfide through precipitation of galena. As was discussed in chapter 4 in relation to the water column, the presence of any sulfide should result in the quantitative precipitation of lead, assuming that complexation by humates or other ligands does not act to keep lead in solution. The presence of stable lead and $210 \mathrm{~Pb}$ in porewaters argues that sulfide is, in fact, absent as do the sulfide measurements, allowing for analytical problems described above. On the other hand, it is surprising that sulfide occurs in the water column but not the sediments. Like iron and manganese, sulfide in the water column seems to come from a source other than diffusion from sediment pore waters. This will be discussed in section 6.6 below.

\subsection{SEQUENTIAL LEACHING RESULTS}

Results of sequential leaching analysis on core 85-2 are presented in Table 6.4a and Figure 6.4a. Included for comparison are equivalent data on SPM and typical sediment trap material, from which sediments are ultimately derived. Also included is surficial sediment collected by a procedure described below (section 6.6 ) and representing the upper 1 or $2 \mathrm{~mm}$ of sediment.

For $210 \mathrm{~Pb}$, several trends are apparent. First, the $1 \mathrm{M} \mathrm{MgCl}_{2}$ leach was a small proportion and decreased monotonically with depth, accounting for 14 to $28 \%$ of the total ${ }^{210} \mathrm{~Pb}$ in the sediment solids. The 
TABLE 6.4a SEQUENTIAL LEACHING OF CORE 85-2 AND WATER COLUMN SOLIDS.

$\begin{array}{ccccccr} & \begin{array}{c}\text { MgCl} \\ (8)\end{array} & \begin{array}{c}\text { WEAK } \\ \mathrm{NH}_{2} \mathrm{OH} \\ (8)\end{array} & \begin{array}{c}\text { STRONG } \\ \mathrm{NH}_{2} \mathrm{OH} \\ (8)\end{array} & \begin{array}{c}\mathrm{H}_{2} \mathrm{O}_{2} \\ (8)\end{array} & \begin{array}{c}\mathrm{HF} \\ (8)\end{array} & \begin{array}{c}\text { TOTAL } \\ 210 \mathrm{~Pb} \\ (\mathrm{dpm} / \mathrm{g})\end{array} \\ \text { SPM } & 22 & 27 & 4 & 18 & 28 & 230 \\ \text { SURFACE FLOC } & 19 & 51 & 21 & 2 & 6 & 160 \\ 0-0.8 \mathrm{~cm} & 28 & 20 & 34 & 10 & 8 & 37.3 \\ 0.8-1.8 \mathrm{~cm} & 19 & 24 & 39 & 8 & 11 & 25.2 \\ 1.8-2.8 \mathrm{~cm} & 21 & 23 & 29 & 9 & 17 & 17.4 \\ 2.8-3.8 \mathrm{~cm} & 14 & 32 & 30 & 13 & 12 & 9.4 \\ 3.8-4.8 \mathrm{~cm} & 16 & 16 & 38 & 10 & 20 & 6.5 \\ 4.8-7.0 \mathrm{~cm} & 14 & 16 & 39 & 7 & 25 & 3.8\end{array}$


FIGURE 6.4a SEQUENTIAL LEACHING ANALYSIS OF CORE 85-2 AND OF CERTAIN WATER COLUMN SOLIDS

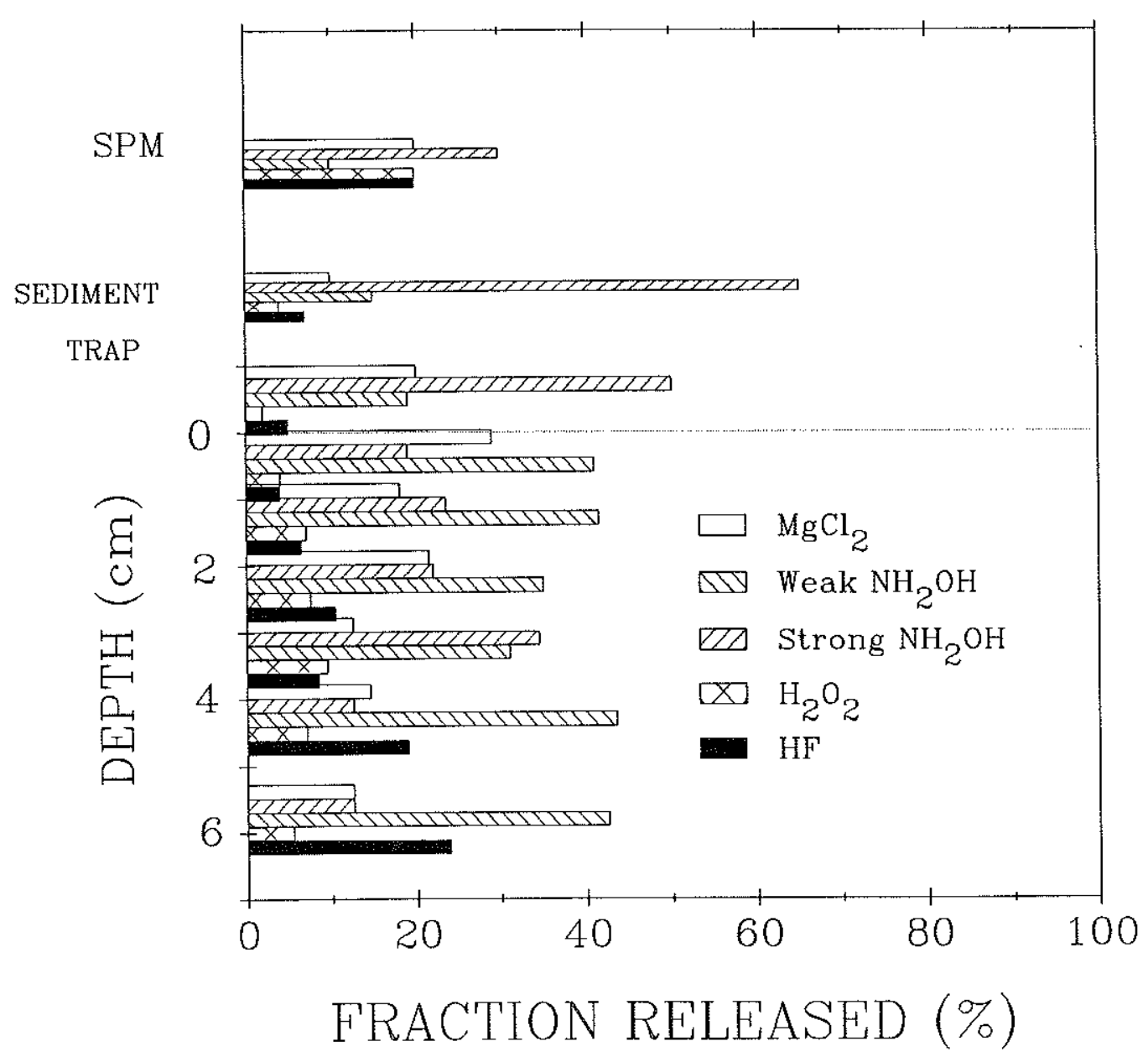


reducible fraction accounted for more than half of the total ${ }^{210} \mathrm{~Pb}$ at all depth intervals and in water column solids as well. Within this category, there was a trend for an increasing proportion in the more strongly reducing subfraction $\left(0.25 \mathrm{M} \mathrm{NH}_{2} \mathrm{OH} \cdot \mathrm{HCl}\right.$ in $0.25 \mathrm{M}$ acetic acid) with depth. This tendency is most strongly pronounced when water column or surficial sediments are compared to the deeper sediments. In the water column and at the sediment water interface, the easily reducible subfraction $\left(0.1 \mathrm{M} \mathrm{NH}_{2} \mathrm{OH} \cdot \mathrm{HCl}\right.$ in $\left.0.01 \mathrm{M} \mathrm{HNO}_{3}\right)$ was $77 \%$ of all reducible $210 \mathrm{~Pb}$, while in the sediments themselves that percentage dropped to $38 \%$. That pattern of a decreasing proportion in the weak reducing fraction may reflect the increasingly reducing redox potential with depth; $210 \mathrm{~Pb}$ that is associated with easily reducible solids in the water column is remobilized with increasing depth of burial. It then transfers to more refractory solids, including those that require more strongly reducing conditions for solubilization.

The chemical and physical conditions of the weak and strong reducing leaches were tuned to maximize differentiation between the release of iron and manganese (CHAO [1972]). This expectation was borne out by measurements of total ixon and manganese in the leachates. On average 908 of reducible manganese was released in the weak reducing leach while 908 of the reducible iron was released in the strong reducing leach. In addition to these pools, it should be remembered that about half of the total iron and manganese in the sediments was not reducible, and was only released by $\mathrm{HF}$ treatment. Furthermore, roughly 908 of all the manganese originally delivered to the sediment water interface is lost back to the water column (section 6.3.3) and thus the most easily reducible Mn fraction is not found in the sediments at all. 
Manganese is thus seen to have a continuum in its lability. The majority is easily reduced (and very slowly reoxidized), so that, shortly after deposition, it is lost from sediments permanently. of that which remains, about half ( 58 of total deposition) is solubilized by $0.1 \mathrm{M} \mathrm{NH}_{2} \mathrm{OH} \cdot \mathrm{HCl} / 0.01 \mathrm{M} \mathrm{HNO}_{3}$. 58 more ( 0.58 of total deposition) is only reduced by the stronger hydroxylamine treatment $(0.25 \mathrm{M}$ $\mathrm{NH}_{2} \mathrm{OH} \cdot \mathrm{HCl} / 0.25 \mathrm{M}$ acetic acid). The remaining 58 , solubilized by $\mathrm{HF}$, is highly refractory and is presumably contained within silicates.

For iron the breakdown is similar, but with important differences. Since iron is reduced at a more negative redox potential than $\mathrm{Mn}$ and because it is rapidly reoxidized, there is probably little net loss from sediments. This is true even though an amount of iron equivalent to a full year's supply cycles out from and back in to hypolimnetic sediments each summer. Like Mn, $5 \%$ of total deposited iron is solubilized by the weak hydroxylamine treatment. Unlike, Mn, an additional $45 \%$ is released by the strong hydroxylamine leach. A full $50 \%$ is released only by concentrated HF.

$\mathrm{H}_{2} \mathrm{O}_{2}$ (30\% in $0.01 \mathrm{M} \mathrm{HNO}_{3}$ ) released approximately 108 of solid phase $2{ }^{\circ} \mathrm{Pb}$ at all depths in the sediment profile as well as in sediment trap material. To the extent that this leaching step mimics organic matter decomposition, organic matter does not seem to play an important role in $210 \mathrm{~Pb}$ cycling in Bickford bottom waters. That conclusion is consistent with the observed linkage of ${ }^{210} \mathrm{~Pb}$ with transition metals.

The amount of $210 \mathrm{~Pb}$ associated with the HF fraction is small and fairly constant. The magnitude of this fraction is about $1.1 \mathrm{dpm} / \mathrm{g}$, similar to the constant $210 \mathrm{~Pb}$ activity at depth that has been attributed to ${ }^{226} \mathrm{Ra}$ support. One interpretation would be that this fraction is 
${ }^{210} \mathrm{~Pb}$ supported by ${ }^{226} \mathrm{Ra}$, which occurs in silicate detritus and is thus not leached except by complete dissolution of the sediments in HF. However, KRISHNASWAMI et al. (1982) have presented evidence that virtually all of the supported $21^{\circ} \mathrm{Pb}$ in aquifers (and by analogy sediments) should be released from solids into interstitial water through the action of alpha recoil. If they are correct, then the $\mathrm{HF}$ leach fraction may represent something like an extremely refractory organic component that forms in situ and binds $21^{\circ} \mathrm{Pb}$ after it has been created via decay.

\subsection{CONTROLS ON $210 \mathrm{~Pb}$ PARTITIONING AND TRANSPORT}

The measurement of high levels of $210 \mathrm{~Pb}$ in pore waters and the observation of substantial ${ }^{210} \mathrm{~Pb}$ releases from sediments to the water column point to the possibility of $2{ }^{\circ} \mathrm{Pb}$ remobilization and redistribution within sediments. The following sections describe the available evidence, discuss some areas of uncertainty, and attempt to estimate the possible magnitude of $2{ }^{20} \mathrm{~Pb}$ mobility in the sediments of Bickford Reservoir.

First a simple diffusion-ion exchange model will be used to estimate the rate of ${ }^{210} \mathrm{~Pb}$ transport in pore waters and the potential for migration of the solid phase radionuclide. Afterwards, complications to the simple model will be discussed and their potential impact evaluated semi-quantitatively. Then the subject of possible controls on solid phase-pore water partitioning will be considered

\subsubsection{ESTIMATES OF $210 \mathrm{~Pb}$ MOBILITY}

As was described earlier (Section 5.4.1), the non-depositional term referred to as "mixing" in the SEDIMIX model could be any physical redistribution process that obeyed Fick's laws. The presence of high 
levels of $210 \mathrm{~Pb}$ in pore water raises the possibility that molecular diffusion, rather than sediment mixing, is the process responsible for departure from simple depositional $210 \mathrm{~Pb}$ profiles quantified by the mode1. A rough estimate of this flux is given in Table 6.5.1a. Although the concentration gradient of $210 \mathrm{~Pb}$ in pore waters is much lower than in the solid phase, the molecular diffusion coefficient in pore waters is much greatex than the diffusional mixing coefficient inferred for sediment solids by SEDIMIX. The result is that the products of these pairs of terms (diffusive flux according to Fick's first law) are about equal. This suggests that, by itse1f, molecular diffusion is sufficient to account for all of the non-depositional $210 \mathrm{~Pb}$ transport in these sediments. That hypothesis is discussed further in the following paragraphs.

\subsubsection{Detailed Calculation of Pore Water Fluxes}

Assumptions and Calculations

The simplest model for calculating pore water fluxes uses the following assumptions: 1) pore water concentrations are steady-state, 2) diffusion is the only process transporting $210 \mathrm{~Pb}$ in pore waters, and 3 ) the diffusion coefficient is the same as that of free dissolved $\mathrm{Pb}^{2+}$ at the same temperature. The appropriateness of these assumptions will be discussed below.

Table 6.5.1.1a presents fluxes calculated using these assumptions. For the top-most segment on each date, the concentration gradient was calculated as the difference in $210 \mathrm{~Pb}$ between the top segment and the overlying water divided by half the thickness of the layer. Fluxes based on solid phase concentration gradients and SEDIMIX-determined mixing rates (chapter 5) are included for comparison. Three key points 
TABLE 6.5.1a COMPARISON OF PORE WATER DIFFUSION AND SEDIMIX "MIXING" FLUXES .

$\begin{array}{ccr}{[\mathrm{dC} / \mathrm{dz}]} & {[\mathrm{D}]} & {[\mathrm{dC} / \mathrm{dz} \times \mathrm{D}]} \\ & & \\ \text { DIFFUSION } & \text { CONCENTRATION } & \text { DIFFUSIVE } \\ \text { COEFFICIENT } & \text { GRADIENT } & \text { FLUX } \\ \left(\mathrm{cm}^{2} / \mathrm{y}\right) & \left(\mathrm{dpm} / \mathrm{cm}^{4}\right) & \left(\mathrm{dpm} / \mathrm{cm}^{2} \mathrm{y}\right) \\ \text { SEDIMIX "Mixing" } & & \\ \\ \end{array}$


TABLE 6.5.1.1a DIFFUSIVE $210 \mathrm{~Pb}$ FLUXES IN PORE WATERS

\begin{tabular}{|c|c|c|c|c|c|}
\hline & & & & & APPARENT $^{3}$ \\
\hline & DEPTH $^{1}$ & CONCENTRATION & DIFFUSION ${ }^{2}$ & DIFFUSIVE & MIXING \\
\hline DATE & $\begin{array}{l}\text { INTERVAL } \\
\quad(\mathrm{cm})\end{array}$ & $\begin{array}{l}\text { GRADIENT } \\
\left(\mathrm{dpm} / \mathrm{cm}^{4}\right)\end{array}$ & $\begin{array}{c}\text { COEFFICIENT } \\
\left(\mathrm{cm}^{2} / \mathrm{y}\right)\end{array}$ & $\begin{array}{c}\text { FLUX } \\
\left(\mathrm{dpm} / \mathrm{cm}^{2} \mathrm{y}\right)\end{array}$ & $\begin{array}{c}\text { FLUX } \\
\left(\mathrm{dpm} / \mathrm{cm}^{2} \mathrm{y}\right)\end{array}$ \\
\hline 27 AUG & $0-0.6$ & .0045 & 200 & $-0.90^{4}$ & - \\
\hline & $0.6-3.7$ & .0008 & 200 & $-0.16^{5}$ & -.07 \\
\hline 25 SEPT & $0-0.4$ & .0100 & 200 & $-2.0^{4}$ & - \\
\hline & $0.4-2.3$ & .0012 & 200 & $-0.24^{5}$ & -0.28 \\
\hline & $2.3-5.4$ & -.0014 & 200 & $+0.28^{5}$ & +0.28 \\
\hline
\end{tabular}

${ }^{1}$ Measured from the sediment water interface (positive downwards).

${ }^{2}$ From LI and GREGORY (1974).

${ }^{3} \mathrm{Calculated}$ by multiplying the solid phase ${ }^{210} \mathrm{~Pb}$ concentration gradient by the apparent mixing rate as determined by SEDIMIX. Negative fluxes are in the upward direction.

${ }^{4}$ The large upward flux from the topmost layer on both dates is equal to or greater than the measured increase in the water column.

${ }^{5}$ Calculated diffusive fluxes are as great as the non-depositional flux referred to as "mixing" (see section 5.4.1) in the SEDIMIX mode1 formulation. This suggests that the process referred to as "mixing" may in fact be transport by molecular diffusion in pore waters. 
should be noted. First, the pore water flux from the upper $1 \mathrm{~cm}$ of sediments is sufficient to supply all of the $210 \mathrm{~Pb}$ released to the water column as indicated by the constant flux-horizontal mixing model $(0.7$ $\left.\mathrm{dpm} / \mathrm{cm}^{2} \mathrm{y}\right)$. Second, below $1 \mathrm{~cm}$, the flux drops to a lower value so that, in the short term, $210 \mathrm{~Pb}$ released to the water column must come only from the surficial layer of sediments and not deeper in the profile. Third, the calculated pore water fluxes are comparable in magnitude and direction to the non-burial component of sedimentary $210 \mathrm{~Pb}$ transport as calculated by SEDIMIX.

\subsubsection{Sources of Uncertainty}

Potential errors can be divided according to their relation to one of the three model assumptions. The first is that the sediments are in steady-state. While this assumption is not strictly valid on a time scale of decades, solid phase chemistry probably does not change substantially from year to year. Pore water chemistry was similar in August and September, but no information is available regarding the remainder of the year. The two controlling parameters that might be expected to change are temperature and dissolved oxygen. The former varies from about $3^{\circ}$ to $12^{\circ} \mathrm{C}$ (Figure $4.5 .1 \mathrm{~b}$ ), which could influence the diffusion coefficient (variation of $\pm 15 \%$ ) and the rate of microbiological activity (perhaps a factor of two). Dissolved oxygen levels probably do not change except in surficial sediments; oxygen cannot penetrate far unless sediments are very low in organic matter. Overall, these changes are likely to have a minor effect. The very large reservoir of $210 \mathrm{~Pb}$ in the solid phase should serve as a buffer to maintain pore water $210 \mathrm{~Pb}$ near the measured levels. The key consequence of the steady-state assumption is that for every $210 \mathrm{~Pb}$ atom sorbed by 
sediments, another is released. As a result, pore waters "see" the same gradient at all times, and the diffusional flux calculation does not explicitly include a correction for ion exchange. That correction is contained implicitly in the pore water gradient, which is about $10^{3}$ to $10^{4}$ lower than it would be in the absence of sorption onto sediments. The second assumption is that diffusion is the only means of $210 \mathrm{~Pb}$ transport in pore waters. Other possibilities include advection caused by burial, bioirrigation, and groundwater flow. Low apparent sediment mixing rates (section 5.7) imply that the activity of benthic organisms is low, and this includes bioirrigation. Burial advection is negligible at less than $0.2 \mathrm{~cm} / \mathrm{y}$. Groundwater seepage velocities measured in this part of the basin ranged from 11 to $37 \mathrm{~cm} / \mathrm{y}$. For an average pore water leve1 of $400 \mathrm{dpm} / 100 \mathrm{~kg}$, this amounts to an advective flux of from 0.04 to $0.15 \mathrm{dpm} / \mathrm{cm}^{2} \mathrm{y}$, which is less than the diffusive flux, but may at times be an important secondary contributor to pore water transport.

The third assumption is that transport is governed by a diffusion coefficient equal to that of free dissolved lead. Two principal corrections might be considered: 1) the effect of porosity and tortuosity, and 2) the effect of dissolved phase speciation. Diffusion in pore waters is slowed (compared to the rate in an open water column) by the presence of the solid sedimentary matrix, which reduces the cross-sectional area of the fluid and also increases the path length of diffusion. Typically the true diffusion coefficient is reduced by a factor of from 2 to 20 by these effects, depending on the characteristics of the sediments. The sediments under consideration had porosities exceeding 708 in all but one layer, so the apparent diffusion coefficient should be from 50 to $100 \%$ of the open water value (MANHEIM 
[1970]). (See a1so ANDREWS and BENNET [1981] who measured diffusion coefficients from 74 to 878 of free water values for near-surface sediments even in fine muds). $21{ }^{\circ} \mathrm{Pb}$ Speciation In Pore Water

The other correction, that for dissolved phase speciation, is more complicated. The calculations for Table 6.5.1.1a were carried out assuming that $210 \mathrm{~Pb}^{2+}$ is the principal species in pore waters. Instead, much of the lead may exist as complexes or colloids having diffusion coefficients different from free dissolved lead. The effect could range from a slight increase - in the case of small, electroneutral complexes -- to a large decrease -- for lead on microscopic colloids. Table $6.5 .1 \mathrm{~b}$ presents results of an analysis of the inorganic, dissolved-phase speciation of lead. The calculations, carried out by hand, are approximate since they use estimated values for some of the ligands and do not take into account competition from other metals, notably ferrous iron. Nevertheless, refinement of the results would still reach the same conclusion: that inorganic complexation with major anions is unimportant to the speciation of dissolved lead.

One type of inorganic ligand has not been included in this analysis: polysulfides. These have been implicated as a potential controller of trace metal speciation and solubility in a number of studies (JACOBS and EMERSON [1982], BOULEGUE [1983], LYONS and FITZGERALD [1983], JACOBS et a1. [1985]). Furthermore, Bickford surficial sediments possess characteristics that would make them a likely site for the formation of polysulfides (CHEN and GUPTA [1973]): proximity to sources of sulfide and oxygen, and a $\mathrm{pH}$ near 7 . Still, evaluation of the potential importance of this ligand to $210 \mathrm{~Pb}$ 
TABLE $6.5 .1 \mathrm{~b}$ INORGANIC LEAD SPECIATION ${ }^{1}$

$\begin{array}{ccc}\text { LIGAND } & \text { CONCENTRATION } & \begin{array}{c}\text { FRACTION } \\ \text { OF } \\ \text { DISSOLVDD } \\ \text { LEAD } \\ (8)\end{array} \\ -- & -- & \\ - & 0.1 & 64^{2} \\ \mathrm{OH}^{-} & 0.1 & 13 \\ \mathrm{CO}_{3}^{2-} & 150 & 13 \\ \mathrm{SO}_{4}^{2-} & 75 & 6 \\ \mathrm{HPO}_{4}^{2-} & 150 & 4 \\ \mathrm{C1}^{4} & & <1\end{array}$

${ }^{1}$ Al1 stability constants from MOREL (1983), except for carbonate (WHITFIELD and TURNER [1979]).

${ }^{2}$ Free dissolved lead 
speciation is beyond the scope of this study. More importantly, complexation by polysulfides probably would not have a substantial effect on the rate of diffusion in pore waters because of their relatively small size.

Two other kinds of ligands -- humates and colloids -- can be very large compared to inorganic metal complexes, and might cause a substantial lowering of the effective diffusion coefficient for lead. Using assumptions similar to those presented for iron in section 6.3.3, and a humic acid-lead stability coefficient in the range from 6.5 to 7.5 (STEVENSON [1976], DICKSON et a1. [1977], MOREL [1983]), the dissolved phase speciation of lead in these sediments might be dominated by DOC. At the same time, it must be remembered that this is only speculation since neither the concentration of humates nor their conditional stability constant or molecular weight and potential influence on diffusion have been measured in this system. This issue is discussed further below.

The role of colloids was also not measured in these sediments largely because no appropriate methodology yet exists. Still, the common observation of a "solids effect" in laboratory studies and the failure to explain many environmental data sets in terms of thermodynamic theory suggest that colloids can play an important role in the liquid phase speciation of metals (MOREL and GSCHWEND [1987]). This is especially true in sediments, which with their very high concentration of solids have the potential to produce correspondingly large amounts of colloids (GSCHWEND and WU [1985]). The influence of colloids on the speciation and transport of metals is a critical area for further research. 


\section{How Important Is Speciation?}

We have been discussing pore water lead speciation because of its possible influence on the diffusive flux of ${ }^{210} \mathrm{~Pb}$. If $2{ }^{20} \mathrm{~Pb}$ is bound to vexy large ligands, then diffusion might be slowed, and fluxes calculated above could be overestimates. It is clear that our knowledge of this subject remains very limited, but three factors argue that pore water diffusive transport may still be important to solid phase $210 \mathrm{~Pb}$ redistribution even if much of the $210 \mathrm{~Pb}$ is associated with high molecular weight humic acids or other colloids.

First, studies have shown cases where trace metals complexed by large molecules seem to diffuse as rapidly as in the free dissolved form. BOTHNER et al. (1980) found that mercury released from marine sediments as measured in flux chambers was equal to that predicted on the basis of pore water concentration gradients and a diffusion coefficient close to that expected for $\mathrm{Hg}^{2}+$. This was so even though mercury is largely associated with high molecular weight colloids (molecular weight $>5000$ ) in the water column and with high molecular weight humics (molecular weight $>150,000$ ) in the sediment solid fraction (JACKSON et a1. [1980]). Second, as was described above, groundwater related pore water advection is not negligible, and this mechanism would transport $210 \mathrm{~Pb}$ irrespective of its speciation in the liquid phase. In fact, increased dissolved phase lead complexation augments its pore water concentration and facilitates its transport by this process.

\subsubsection{Significance of Diffusive Transport}

To summarize, calculations have been presented showing that pore water diffusion can be an important mechanism for ${ }^{210} \mathrm{~Pb}$ redistribution in sediments. Most of the potential problems with this model have been 
shown to be minor. The chief uncertainty involves questions of dissolved phase speciation and its potential effect on diffusion rates, and this is a key area for further research.

The comparison presented in Table 6.5.1.1a shows that pore water diffusion is equal in magnitude to the Fickian transport process attributed to sediment mixing in the SEDIMIX model (section 5.4). This being so, I conclude that ${ }^{210} \mathrm{~Pb}$ distributions in the sediments of Bickford Reservoir are controlled by only two processes: 1) sediment accumulation and 2) pore water diffusion/advection of chemically remobilized lead; sediment mixing has a negligible role. The consequence of chemical remobilization can be important for ${ }^{210} \mathrm{~Pb}$ geochronology. As an example, cores 81-1, 81-2, 85-1, and 85-2 (Figures $5.4 .3 \mathrm{a}, \mathrm{b}, \mathrm{i}$, and $\mathrm{j}$ ) have $210 \mathrm{~Pb}$ distributions that decrease exponentially with depth and seem consistent with ${ }^{210} \mathrm{~Pb}$ dating assumptions. Calculation of apparent sedimentation rates yielded values that were clearly wrong because they are inconsistent with the known history of the basin (section 5.3). True rates, calculated as described in section 5.4, differed from the apparent rates by factors ranging from 2.0 to 3.3 . This error is all attributable to chemical remobilization and might be present in sediments that are not physically disturbed, as corroborated by the presence of varves and well-resolved man-made radionuclide layers. Chemical remobilization might thus explain the curious findings of WAN et a1. (1983). The physical and chemical characteristics of the sediments of Bickford are similar to those in most soft water lakes, so chemical remobilization and redistribution of $210 \mathrm{~Pb}$ may be a widespread phenomenon. 


\subsubsection{SEDIMENT-PORE WATER PARTITIONING}

Table $6.3 .2 \mathrm{~b}$ presented partition coefficients calculated for ${ }^{210} \mathrm{~Pb}$ and stable lead in cores 85-1 and 85-2. Those data show a consistent pattern of $\mathrm{K}_{\mathrm{D}}$ decreasing from near 10,000 at the sediment water interface to about 1,000 at depth. There are least three possible explanations for the observed trend: 1) changes in dissolved phase speciation, 2) the solids effect, and 3) variation in the characteristics of the sediments with depth.

If most pore water $210 \mathrm{~Pb}$ is complexed by humates, then changes in the availability of the ligand could cause an apparent change in partitioning with depth. For this to be true in these sediments, the ligand would need to increase with depth so that dissolved lead would increase compared to the no-complexation case, thereby giving rise to an apparent $\mathrm{K}_{\mathrm{D}}$ decrease. That seems unlikely since humate production is presumably the product of organic matter decomposition, which should decrease with depth. It cannot be argued that deeper sediments are older and have had more time for humates to accumulate, since pore water advection should flush DOC downward. Rather, levels of of humic acids probably reflect instantaneous production rates along with advective input from above.

Since there is a significant change in the concentration of solids per volume with depth, the variation in $\mathrm{K}_{\mathrm{D}}$ might be caused by the solids effect $\left(0^{\prime}\right.$ CONNOR and CONNOLLY [1980]). Here the trend is in the right direction; pore water ${ }^{210} \mathrm{~Pb}$ increases in deeper sediments where the higher concentration of solids will produce a greater quantity of colloids (MOREL and GSCHWEND [1987]). Figure 6.5.2a is a plot of $\mathrm{K}_{\mathrm{D}}$ as a function of the concentration of solids in Bickford sediments. Also 
FIGURE $6.5 .2 \mathrm{a}$ PARTITIONING OF $210 \mathrm{~Pb}$ IN BICKFORD SEDIMENTS -

$\mathrm{K}_{\mathrm{D}}$ 'S AS A FUNCTION OF SOLIDS CONCENTRATION

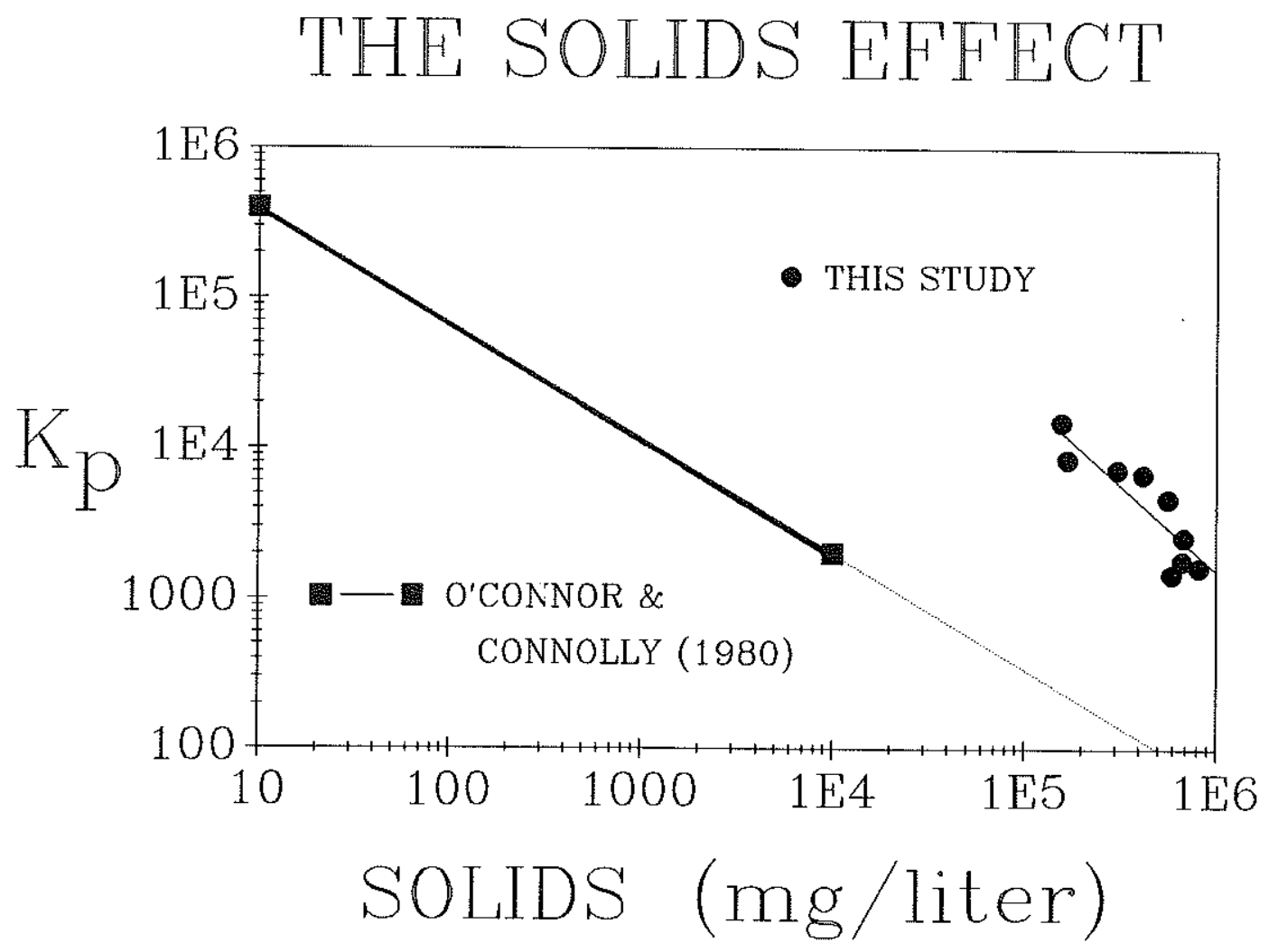


shown are data from $0^{\prime}$ CONNOR and CONNOLLY (1980) valid for both organic and inorganic hydrophobic compounds. The Bickford data decrease more rapidly with increasing solids than the trend defined by $0^{\prime}$ Connor and Connolly, and they fall well above it. In fact, Figure $6.5 .2 \mathrm{a}$ could be interpreted as indicating no further decrease in $\mathrm{K}_{\mathrm{D}}$ with solids concentration from $10^{3}$ to $10^{6} \mathrm{mg} / 1$ iter.

By default this leaves the final possibility, that changes in the sediment's sorptive characteristics are responsible for the change in partitioning. These changes might come about either because of the build up of specific sedimentary components in certain layers as a result of redox cycling, or because of diagenetic "aging" of sediments as they are buried, or both. Several lines of evidence point to the potential importance of iron in this scheme. These include: 1) the observed association and co-cycling of $2{ }^{10} \mathrm{~Pb}$ with $\mathrm{Fe}$ and $\mathrm{Mn}$ in the water column, 2) the large fraction of sedimentary $210 \mathrm{~Pb}$ released by the reduction steps of sequential leaching experiments, 3) the abundance of iron in sediments, 4) the probable creation of freshly exposed iron oxide surfaces by iron dissolution/precipitation during redox cycling, 5) the preferential concentration of iron in oxidized surficial sediments, and 6) the likelihood that iron compounds undergo diagenetic alterations (such as increased crystallinity) as they age.

To understand how iron might control $210 \mathrm{~Pb}$ partitioning, consider current theory on the distribution of hydrophobic organic compounds between sediments and water. The partition coefficient onto bulk sediments has the designation " $\mathrm{K}_{\mathrm{p}}$ " and is defined much the same as $\mathrm{K}_{\mathrm{D}}$. $K_{p}$ has been found to depend both on the organic content of the sediments, $f_{O C}$, and on the intrinsic lipophilicity of the compound, $\mathrm{K}_{O C}$ : 


$$
\mathrm{K}_{\mathrm{p}}=\mathrm{f}_{O C} \mathrm{~K}_{O C}
$$

Considering the extreme heterogeneity of sediments, it seems likely that various constituents have different "plumbophilicities", sorbing lead more or less strongly. If one component, such as iron, had a high enough plumbophilicity and were abundant enough, it could well dominate lead partitioning, just as organic matter controls the partitioning of hydrophobic compounds.

To test this hypothesis it is only necessary to know the plumbophilicity of sedimentary iron and then, by comparison with observed partitioning, it would be possible to determine the quantity of iron that is needed. Mathematically:

so,

$$
\mathrm{K}_{\mathrm{D}}=\mathrm{f}_{F e^{\mathrm{K}}} \mathrm{Ke-Pb}
$$

$$
\mathrm{f}_{F e}=\mathrm{K}_{\mathrm{D}} / \mathrm{K}_{F e-P b}
$$

Where:

$$
\begin{aligned}
& \mathrm{f}_{\mathrm{Fe}} \equiv \text { fraction of sedimentary mass composed of active iron, } \\
& \text { i.e. iron solids having a high tendency to sorb lead } \\
& \mathrm{K}_{\mathrm{Fe}-\mathrm{Pb}} \equiv \text { tendency of active iron to sorb lead, calculated in the } \\
& \text { same manner as a } \mathrm{K}_{\mathrm{D}}
\end{aligned}
$$

Assuming that $\mathrm{K}_{\mathrm{Fe}-\mathrm{Pb}}$ has the same value as was measured for particulate iron in the hypolimnion $\left(2.3 \times 10^{6}\right), f_{F e}$ can be calculated. Table 6.5.2a summarizes this analysis for core 85-2 along with measured concentrations of solid phase iron from Table 6.3.3a. The results show that $\mathrm{f}_{F e}$ is less than reducible iron, meaning that $\mathrm{K}_{\mathrm{Fe}-\mathrm{Pb}}$ may be less than the water column $\mathrm{K}_{\mathrm{D}}$, or that active iron is a subfraction of reducible iron, or both. The ratio between $f_{F e}$ and reducible iron does 
TABLE $6.5 .2 \mathrm{a}$ CALCULATION OF ACTIVE IRON ${ }^{1}$

$\begin{array}{lccc}\text { DEPTH } & & \text { REDUCIBLE } \\ (\mathrm{cm}) & \mathrm{K}_{\mathrm{D}}{ }^{2} & \mathrm{f}_{F e} & \text { IRON }^{3} \\ & & (8) & (8)\end{array}$

$\begin{array}{clll}0-0.75 & 8,500 & 0.37 & 1.8 \\ 0.75-1.75 & 6,800 & 0.30 & 1.6 \\ 1.75-2.75 & 2,600 & 0.11 & 1.5 \\ 2.75-3.75 & 1,640 & 0.07 & 1.5 \\ 3.75-4.75 & 1,810 & 0.08 & 1.4 \\ 4.75-6.0 & 1,910 & 0.08 & 1.0\end{array}$

1"ACTIVE IRON" is defined as iron solids with a high affinity for lead.

${ }^{2} \mathrm{~K}_{\mathrm{D}}$ for 1 ead.

${ }^{3}$ Protocol for the determination of "reducible iron" described in Note 1 of Table 6.3.3a. 
not vary drastically with depth $\left(\mathrm{f}_{F e} / \mathrm{Fe}_{\text {red. }}=5-208\right)$, suggesting that the sorptive characteristics of the active iron fraction do not change radically with time. This analysis demonstrates the plausibility of $210 \mathrm{~Pb}$ partitioning control by iron. If the true $\mathrm{K}_{\mathrm{D}}$ is much lower than the value assumed, or if a very small fraction of sedimentary iron is available for sorption, then other solids may be important. Manganese is 100 times less abundant in these sediments than iron, but it could still be consequential in view of its high affinity for lead (e.g. GADDE and LAITENEN [1974]), LEWIS [1977], WANG et al. [1986], BALISTRIERI and MURRAY [1986]). Also, bulk solids could be important, since they are 100 times more abundant than iron, but if so, it is difficult to explain the decrease in $K_{D}$ with depth. Iron is appealing for a number of reasons enumerated above. Most importantly, depletion of iron with depth provides a simple explanation for changing $\mathrm{K}_{\mathrm{D}}$, and iron enrichment at the sediment watex interface could help explain seasonality of ${ }^{210} \mathrm{~Pb}$ release into the water column, as will be described in the next section. 6.6 THE SEDIMENT WATER INTERFACE - SURFICIAL FLOCS

At several points in this study we have presented evidence showing that a thin layer of surficial sediments seems to have singular characteristics and to behave differently from the rest of the sediment column. In this section, that evidence is summarized, evidence from other similar studies is reviewed, and the interface is discussed with a view to understanding the physicochemical conditions that combine to endow it with its unique character.

Evidence From This Study

Most of the chemical substances examined showed substantial increases in the water column that could not have been supported by pore 
water diffusional fluxes from depth in the sediment profile. Concentration gradients of dissolved iron in pore waters (Figures 6.3.2a and $\mathrm{b}$ ) were much too low to support the $10 \mathrm{mg} / \mathrm{cm}^{2} \mathrm{y}$ flux from sediments calculated in section 4.3.4. Since the input could not have come from settling particles, it must have been derived from surficial sediments. Similarly, manganese increased in the water column even though it exceeded the concentration in pore waters (Figures $6.3 .2 \mathrm{a}$ and $\mathrm{b}$ ). Sulfide was recorded in the lower water column at up to $10 \mu \mathrm{M}$ (Table 4.3.6a), but was below the limit of detection in pore water. The analysis of ${ }^{210} \mathrm{~Pb}$ behavior in sections 4.5 .3 and 6.5.1.1 showed that releases to the water column could only have been supported by diffusive fluxes from the uppermost $1 \mathrm{~cm}$ of sediments, not deeper. Again, remobilization from settling particles was also ruled out as a possible source. In all of these instances, substantial releases of substances into the water column were derived from a superficial layer of sediments.

Prompted by these results, an effort was made to collect some of this surface material. SCUBA divers had commonly noted the existence of a thin layer of extremely fine, almost neutrally buoyant substance at the sediment water interface. When working on the bottom, the divers' slightest movement produced a cloud of this flocculent sediment that made seeing difficult. The collection strategy took advantage of that property, operationally defining the floc as any matexial dislodged by weak currents. A rectangular box, $15 \mathrm{~cm}$ deep and with an open side with an area of $860 \mathrm{~cm}^{2}$, was placed onto the sediment water interface (opening down) at an estimated speed of $0.1 \mathrm{~m} / \mathrm{s}$. This action stirred up interfacial floc inside the box. The box was then lifted just enough to 
clear the surface, and the lid was slid underneath and sealed. Returned to the ship, the rapidly stirred slurry was subsampled and passed through a GF/C (glass fiber) filter. Material on the filter was then analyzed for the chemical and physical characteristics summarized in Table 6.6a. Included for comparison are data from the second section of core 85-2 (0.8 to $1.8 \mathrm{~cm})$, which was collected in the conventional manner. The contrast between the two layers is striking. Most dramatic is iron; based on Table $6.6 \mathrm{a}$ and information from section 4.3.4, floc could be composed of about $50 \%$ high-iron particulates that form the water column SPM peak. Interestingly, LOI is only slightly enhanced, suggesting that organic matter is not at the root of the floc's unusual characteristics. The concentration of $210 \mathrm{~Pb}$ in $\mathrm{floc}(160 \mathrm{dpm} / \mathrm{g}$ ) is higher than the value derived in section 5.6 for average material being added to the sediment-water interface $(22 \mathrm{dpm} / \mathrm{g})$ or the specific activity of sediment trap material collected at this location ( 34 $\mathrm{dpm} / \mathrm{g}$ ), implying that the radionuclide was concentrated after deposition. One possible mechanism is re-adsorption by iron oxides of chemically remobilized ${ }^{210} \mathrm{~Pb}$ diffusing upward in pore waters.

\section{Background: Metal Cycling Near the Sediment Water Interface}

Many investigators have observed unusual physical and chemical characteristics of sediments near the sediment water interface. The most common observation has been that of elevated levels of metals in sedimentary solids and, more recently, in pore waters. Some enrichment can be attributed to industrial age increases in anthropogenic inputs, but some reflects post-depositional concentration processes (PRICE et al. [1976]). The metals showing the greatest enrichments are those that are directly redox active, especially iron and manganese. LYNN and 
TABLE $6.6 \mathrm{a}$ CHARACTERISTICS OF INTERFACIAL FLOC

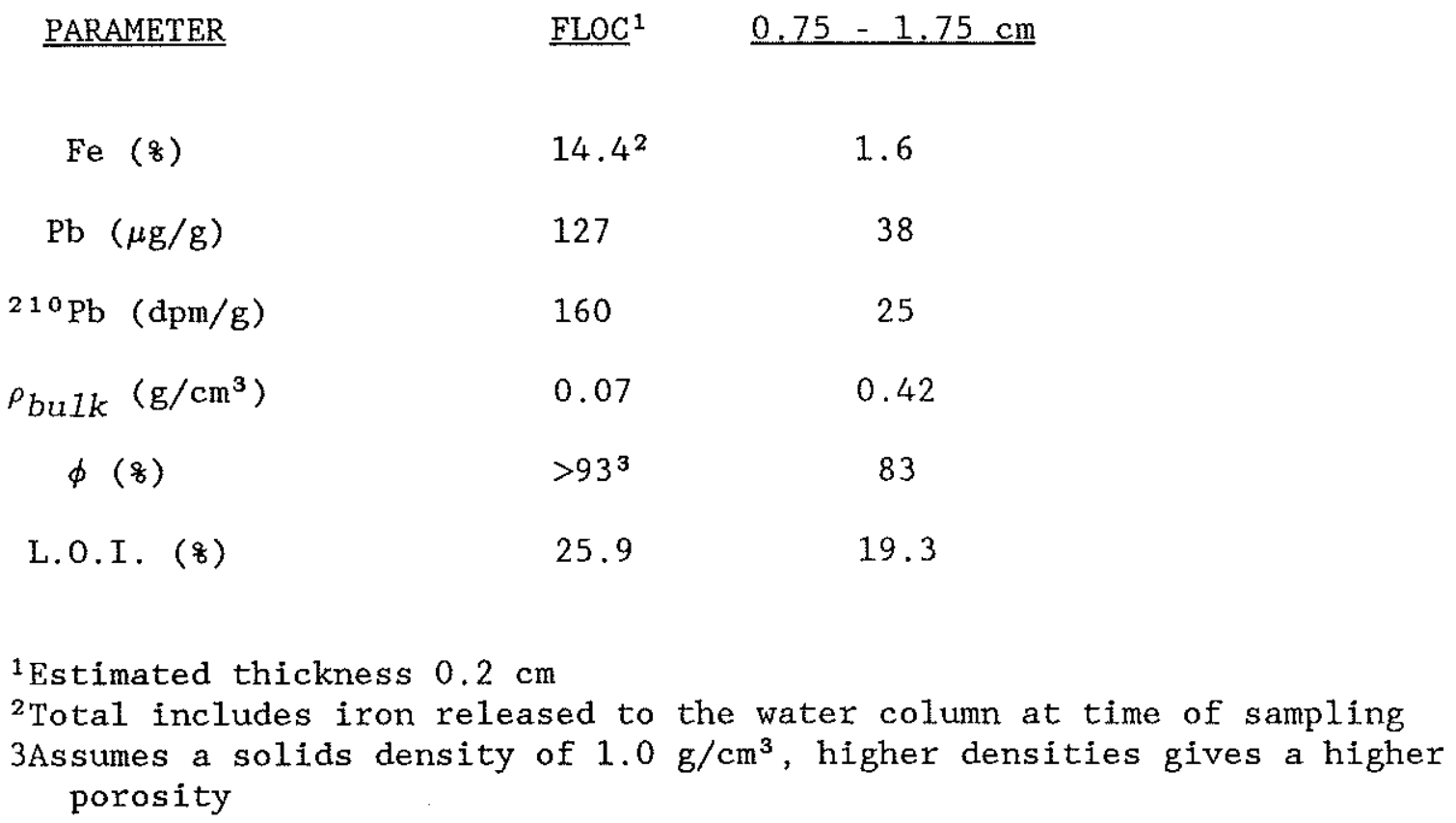


BONATTI (1965), LI et al. (1969), CALVERT and PRICE (1972) SKEI and PAUS (1979), EL GHOBARY (1982), BALISTRIERI and MURRAY (1986), and WANG et al. (1986) are just a few examples. In the limit, transition metal crusts or nodules can be formed (see GORHAM and SWAINE [1965] for an early example in the lacustrine environment).

Recent pore water studies have shed additional light on metal cycling immediately at the sediment water interface, sometimes producing surprising results. WANG et al. (1986) found that many metals were enriched near the surface due to anthropogenic inputs to Lake Geneva. $\mathrm{Mn}, \mathrm{P}$, and Co were additionally enhanced, probably due to concentration by a diffusion-reprecipitation mechanism. At the time of measurement, the Mn gradient in pore waters decreased away from the surface, and these authors postulated that a tripling of $\mathrm{Mn}$ in the upper $0.5 \mathrm{~cm}$ was caused in part by release from the sediment water interface, diffusion upward to oxygenated regions of the lake, reprecipitation, and sinking. Sediment trap data supported this contention. This is the same mechanism that we have proposed for the genesis of iron-rich interfacial flocs in Bickford. Interestingly, lead was enriched correlative with manganese, and this association was explained as resulting from concentration through repeated cycles of release and rescavenging rather than a very recent, abrupt increase in the anthropogenic lead flux. Work by SUNDBY et al. (1986) in a coastal marine setting also showed a difference between metal cycling at the interface and in deeper sediments. They found that porewater gradients predicted a diffusive flux toward the interface, but under oxygenated conditions, flux chambers revealed net uptake by sediments of the transition metals $\mathrm{Fe}$, $\mathrm{Mn}$, and Co. The implication is that metals can be supplied to the 
sediment water interface both from above and below when the water column is oxygenated. When the water column was allowed to go anoxic, the metals were released from sediments. Two of these, $\mathrm{Fe}$ and $\mathrm{Co}$, were discharged at rates orders of magnitude higher than could be supported by pore water diffusional fluxes. This means that, at least temporarily, the flux was supplied by material that had accumulated in a thin layer at the surface.

WESTERLUND et al. (1986) found that interfacial sediments played a unique role in the cycling of the trace metals $\mathrm{Cd}, \mathrm{Cu}, \mathrm{Ni}$, and $\mathrm{Zn}$. In this study, pore water concentrations predicted fluxes downward from the interface at the same time that flux chamber measurements documented releases to the oxygenated water column. They concluded that there was a thin layer near the sediment surface from which the metals were discharged in either direction. This release is the opposite of the effect described above for $\mathrm{Fe}, \mathrm{Mn}$ and $\mathrm{Co}$, and reflects association of $\mathrm{Cd}, \mathrm{Cu}, \mathrm{Ni}$ and $\mathrm{Zn}$ with a phase (at least in this system) that is solubilized by oxidation. Attempts to identify the phase were inconclusive.

Together these studies show that interfacial sediments are an important and sometimes controlling link in the chain of metal cycling in the sediment-water system. Depending on redox conditions and the specific metal, the interface can serve as either a sink or source of dissolved material to the rest of the system, and that role can change seasonally.

Floc Genesis and Diagenesis

The unique physical and chemical conditions at the sediment water interface make it the locus of a great deal of geochemical activity and 
help to explain the existence of interfacial floc. At the risk of stating the obvious, the key feature of this region is that is an interface, a discontinuity in several parameters of geochemical importance. As a density interface or more or less solid surface it is the ultimate repository of gravitationally transported material from the water column. This includes easily reducible organic matter, which helps to explain the the abundance of macroscopic organisms found here. These, through their feeding activities, can mix sediments, giving rise to higher rates of advection and mixing which keep them porous. The interface often marks the furthest penetration of light, so it often serves as a home for bacteria that also use it for support or as a source of reduced sulfur. Diffusivity changes rapidly in this region, increasing by orders of magnitude in going from molecular to eddy diffusion. Dissolved oxygen and dissolved reduced sulfide often meet at this interface. That could cause the build up of metals that are immobilized both by coprecipitation with oxidized transition metals and by the formation of insoluble sulfides.

Perhaps most importantly from the standpoint of metal cycling, the sediment water interface marks a sharp gradient in dissolved oxygen and, as a result, in pe. Early seminal work by MORTIMER $(1941,1942)$, and recent fine-scale measurements by REVSBECH et al. (1980), REIMERS et al. (1984), and JORGENSEN and REVSBECH (1985) have documented the shape of the dissolved oxygen profile down to the sub-millimeter scale. Typically, $\mathrm{O}_{2}$ penetrates to a depth of $1-2 \mathrm{~mm}$ before depletion by organic matter oxidation reactions. If sediments are low in dissolved sulfide, metals that are carried by reducible transition metal oxides can be free to diffuse until they encounter the oxygen gradient. There, 
reprecipitation of iron and manganese rescavenges the auxiliary metals, and should lead to a thin layer high in these components. That is likely to be one mechanism behind the formation of interfacial floc in Bickford. Measurements show that sulfide is absent, while ${ }^{210} \mathrm{~Pb}$, stable lead, and (to some extent) iron all have pore water gradients favoring diffusion toward the surface. Even the typical depth of oxygen penetration matches our estimates of the floc layer thickness.

The floc layer may also be generated by a second process, which is active when overlying water is anoxic. Dissolved iron and trace metals are transported by eddy diffusion to the oxycline, where they reprecipitate, and sink back to the sediment water interface. The operation of this cycle in Bickford has been described in detail (chapter 4). The mechanism involved in the two processes is similar: diffusion to and reprecipitation at an oxygen interface. But perhaps only cycling in the water column can explain the flocculent texture of the interface. Precipitation of iron in the interstices of surficial sediments might be expected to create a denser, more consolidated product. Later, dissolution and eventual reprecipitation in the open water column could then produce the looser textured material observed by SCUBA divers. By contrast, the ferromanganese crusts observed in many lakes might result when the water column portion of the dissolutionprecipitation cycle is absent. One additional factor that might promote the loose texture of the floc is periodic disturbance by wind-driven currents during the seasons when the water column is well mixed, though no such episodes were observed in the course of this study. 


\section{CHAPTER 7 SUMMARY}

OVERVIEW

The focus of this work has been on geochemical cycling of $21{ }^{\circ} \mathrm{Pb}$ in the lacustrine environment including the water column, sediments, and their interactions with each other. A special goal was to elucidate processes that might influence the distribution and fluxes of the radionuclide in ways that could effect sediment dating by ${ }^{210} \mathrm{~Pb}$, in other words, to test the assumptions of the method.

During the warm season, the upper lake is well-mixed while the deepest parts of the lake are stratified; distinct chemical and physical regimes prevail in each zone. In the mixed surface layer, ${ }^{2} 10^{\circ} \mathrm{Pb}$ levels participate in a dynamic balance between inputs and outputs that results in nearly constant water column concentrations. In the bottom waters, development of anoxic conditions solubilizes transition metals and liberates $210 \mathrm{~Pb}$ that seems to be associated with them. This input is not matched by an equivalent output, and $210 \mathrm{~Pb}$ levels rise right up to the time when stratification is destroyed by fall mixing. In this 1ake, net losses of the remobilized ${ }^{210} \mathrm{~Pb}$ may have been minimized by low rates of transport caused by unusually stable, non-turbulent conditions during stratification.

The source of the dissolved transition metals and $210 \mathrm{~Pb}$ is the sediments, and pore water measurements reveal high absolute levels and concentration gradients that help to explain the releases. Diffusional transport down those concentration gradients is sufficient, if continuous throughout the year, to redistribute solid phase $210 \mathrm{~Pb}$ to an extent that would cause dating errors. The partitioning of $210 \mathrm{~Pb}$ between solids and solution in these sediments changes dramatically with 
depth, and that variation is argued to depend on the changing concentration of an actively sorptive sub-fraction, probably iron oxides. Our understanding of $210 \mathrm{~Pb}$ partitioning and transport is hampered by a lack of knowledge on speciation. It seems likely that humates may exert an important influence by binding $210 \mathrm{~Pb}$ and holding it in solution against competition from solids and sulfide, but this hypothesis remains to be verified.

Bickford Reservoir was a demanding test of the ${ }^{210} \mathrm{~Pb}$ dating method; sediments have not had enough time to reach steady state conditions, and different parts of the basin seem to be responding differently from each other, sometimes over short distances. Especially problematical were cores from a section of the lake where lacustrine sediments have been deposited over bog-like ones. In many cores throughout the lake, sedimentation rates calculated by the usual methodology were unrealistically low based on the known basin history. Because of this, a computer model was used to find the combination of sedimentation and Fickian redistribution that gave the best fit to the measured data. Results derived in this way indicated that the accumulation of both bulk sediment and $210 \mathrm{~Pb}$ increases with water depth. The magnitude of Fickian $210 \mathrm{~Pb}$ redistribution was no greater than that of diffusion in pore water. This means that the anomalous solid phase $2{ }^{10} \mathrm{~Pb}$ distributions described above were probably caused by chemical remobilization rather than sediment mixing.

$210 \mathrm{~Pb}$ CYCLING IN THE EPILIMNION

Cycling of $210 \mathrm{~Pb}$ in the mixed upper layer of Bickford was investigated by means of a mass balance. Measured inputs were precipitation and stream inflow, and outputs were outflow and sinking 
particulate matter; radioactive support and decay were insignificant. The mass balance closed within the uncertainty of the measurements, and this implies that no important inputs or outputs were overlooked. Specifically, direct uptake by sediments seems to be inconsequential, as would seem likely for lakes in which bioirrigation does not reduce the sediment isolating effect of the benthic boundary layer. Closure also implies the success of application of the mass balance and supports the reliability of previous studies at this site (BENOIT and HEMOND [1987]). The mass balance in Bickford in the summer is similar to that during the rest of the year except that higher evapotranspiration and lowered streamflow minimizes the importance of stream inputs and outputs. $210 \mathrm{~Pb}$ cycling in the epilimnion is characterized by a balance between input by precipitation and streams and output on sinking particulate matter and outflow. Because of this, the relative rates of outflow and scavenging control what fraction of total ${ }^{210} \mathrm{~Pb}$ inputs are ultimately deposited in sediments. Long term changes in this proportion could lead to erroneous $210 \mathrm{~Pb}$ geochronology, so it is crucial to understand the factors that influence the two output pathways. Outflow is a comparatively simple function, being equal to inflow as a very good first approximation; the estimation of inflow has already been well studied by hydrologists. The key then is to understand processes that control the lesser known pathway: scavenging combined with particle aggregation and settling. So far, little is known about this process except that the scavenging agent may differ from lake to lake and the rate can change substantially at different times of the year. 
$21{ }^{\circ} \mathrm{Pb}$ CYCLING BELOW THE EPILIMNION

In the stratified part of the water column, $210 \mathrm{~Pb}$ distributions exhibit a more complex pattern than in the epilimnion. Mixing is much slower, and this leads to large changes in concentration with location. In addition redox conditions change dramatically with time, most inputs and outputs are non-point sources making them more difficult to measure, and $210 \mathrm{~Pb}$ cycling is linked with that of transition metals.

In order to understand $210 \mathrm{~Pb}$ transport in bottom waters, eddy diffusivity was calculated as a function of position and time using the heat flux gradient method. These calculations were complicated in Bickford because both radiant heating and heat exchange with sediments had to be explicitly included to derive meaningful results. The results suggest that their is frequently an underestimation of the importance of sediments to hypolimnetic heat budgets, and this can lead to significant errors in calculating eddy diffusion. A simple finite difference model calculation allows accurate estimation of this term.

The results show that vertical transport is very low, and this is because the steep density gradient causes high stability. The maximum depth in Bickford happens to coincide with the base of the metalimnion during most of the summer. Because of this, stratification extends all the way to the bottom, and this lake has a rate of vertical mixing that is as low as in any region of any (non-ice covered) lake yet reported. Both $2{ }^{10} \mathrm{~Pb}$ and iron show similar patterns of remobilization and seem to be linked judging from sequential leaching studies as well. As has been documented in previous studies, iron is released in substantial amounts as soon as the overlying water column goes anoxic. Transported to the oxygen interface, dissolved iron reprecipitates upon oxidation 
forming a particulate iron maximum at some distance from the bottom. Some of this particulate iron may be mixed upward, but much of it sinks back to the bottom as demonstrated by sediment trap measurements. Late in the season when thermocline erosion begins, the cycle is accentuated as the particulate iron maximum is driven downward through a zone of increasingly high total iron concentrations. $2{ }^{\circ} \mathrm{Pb}$ follows iron out of the sediment and is rescavenged in the particulate maximum zone (based on partitioning data) and returned to the bottom (based on sediment trap fluxes). Scavenging by iron in ths way may help to prevent remobilized $210 \mathrm{~Pb}$ from returning to the epilimnion.

Attempts to recreate the observed $2{ }^{210} \mathrm{~Pb}$ and iron distributions using the calculated eddy diffusivities were unsuccessful; vertical turbulent transport was insufficient in magnitude to produce the high water column levels. Instead, it was possible to describe water column distributions very accurately using a horizontal transport/dilution model. The release of iron and $210 \mathrm{~Pb}$ from sediments follows a step function: no discharge before anoxia and an instantaneous increase to a constant value thereafter. Material released in this way is transported very rapidly by horizontal turbulence so that concentration depends only on the time since anoxia, the area of sediments (a measure of the source), and the volume of water in a given stratum (a measure of dilution). One difference between iron and $210 \mathrm{~Pb}$ is that the former becomes depleted and stops being released, while the latter is given off at a constant rate over the entire anoxic period. 210 Po releases are only partially explained by this model; $21{ }^{\circ} \mathrm{Po}$ begins to be remobilized before complete anoxia, and the model correlation shows much scatter. 
Quite 1ikely, additional sources, transport mechanisms, or removal pathways are active for this radionuclide.

Overal1, remobilization seems not to have had an important net effect on the ${ }^{210} \mathrm{~Pb}$ content of sediments, but this may be due in part to the unusual characteristics of the basin: a small volume of water below the epilimnion and stratification all the way to the bottom. In Bickford, gradual thermocline erosion continues right to the sediment water interface, so remobilized $210 \mathrm{~Pb}$ is prevented from escaping by steady precipitation of iron. In a lake with a large hypolimnetic volume, thermocline erosion reaches the bottom of the metalimnion and then the hypolimnion mixes rapidly with the rest of the lake. Depending on the relative volume of epilimnion and hypolimnion, and the rapidity of mixing, lead scavenging, particle settling, and outflow, a large fraction of the annual $210 \mathrm{~Pb}$ input to the lake could be lost during the fal1 overturn.

APPLICATION OF $21^{\circ} \mathrm{Pb}$ GEOCHRONOLOGY TO NON-STEADY STATE SEDIMENTS

Previous studies have indicated that sedimentation may not be homogeneous throughout a lake, so cores were taken from a variety of depths and locations in the basin. Initial attempts to date sediments using the constant initial concentration model (C.I.C.) were unsuccessful because the derived sedimentation rate was inadequate to have caused accumulation of the observed thickness of sediment in the time since reservoir filling. Some cores also had inflections that were inconsistent with the C.I.C. mode1. Instead it was assumed that net distributions came from a combination of sedimentation (advective) and Fickian (diffusive) redistribution, and I used a finite difference mode1 to find the best-fit combination of these two processes for each core. 
The results obtained were reasonable in that: 1) they account for the observed inventories and depths of penetration in the allotted time, 2) the magnitude of the two processes are within the range observed in other lakes of low productivity, 3) the mixing rate in one core was confirmed by the penetration depth of $\left.{ }^{137} \mathrm{Cs}, 4\right)$ calculated sediment accumulation rates correlate well with total input rates as might be expected. The calculated magnitude of the diffusive transport component of the model was equivalent to that of pore water diffusion, so it seems likely that chemical remobilization rather than solid phase mixing is responsible for the departure from purely depositional profiles.

One problem area for $210 \mathrm{~Pb}$ dating analysis was a section of the bottom that had previously been occupied by a wetland. These sediments had very high porosities and a skelatal framework composed of decaying woody plant remains. This led to $210 \mathrm{~Pb}$ profiles that appeared normal (exponential decrease with mass depth) but which where highly variable in shape from one core to the next, and which had low inventories compared to similar water depths in other parts of the lake. ${ }^{137} \mathrm{Cs}$ analysis of one of the cores supported the contention that this part of the basin does include sediments older than the present dam. Comparison with another ${ }^{137} \mathrm{Cs}$ core taken from a different area suggested that much of the ${ }^{137} \mathrm{Cs}$ delivered to this site from the atmosphere was either not delivered to the sediments or was subsequently lost from them. Because of the great difference in chemical behavior between the two radionuclides, it was impossible to make further inferences on ${ }^{210} \mathrm{~Pb}$ behavior based on ${ }^{137} \mathrm{Cs}$. 
$21{ }^{\circ} \mathrm{Pb}$ DISTRIBUTION AND TRANSPORT IN PORE WATERS

An understanding of $2{ }^{10} \mathrm{~Pb}$ diagenesis and transport in sediments depends critically on a knowledge of pore water processes. ${ }^{210} \mathrm{~Pb}$ and ancillary geochemical parameters were measured in two cores taken from the deepest part of the lake in August and September. The results reveal ${ }^{210} \mathrm{~Pb}$ and $210 \mathrm{Po}$ present at levels two orders of magnitude higher than in the water column and having steep concentration gradients, while $\mathrm{Fe}, \mathrm{Mn}$, and alkalinity had relatively small gradients (though they may be more pronounced at other times of the year). Sulfide was absent when measured in the September core. Partitioning between solids and solution suggests $\mathrm{K}_{\mathrm{D}}$ values for ${ }^{210} \mathrm{~Pb}$ in the range from 1500 to 15000 , decreasing monotonically with depth. This variation may result from the decreasing abundance of a minor subfraction of the solids having a high sorptive potential. Iron is a likely candidate based on several lines of evidence.

Diffusive fluxes calculated from Fick's first law indicate that releases to the water column must come only from a thin layer of sediments near the interface. This may correspond to a very thin layer of flocculent material observed at the sediment water interface by SCUBA divers. Further analysis indicates that it has unusual physical and chemical properties, including high concentrations of iron and other metals. This enrichment can be explained in terms of diffusive transport and reprecipitation at a redox interface that migrates seasonally from the sediment water interface into the water column and back. The diffusive flux at depth within the pore waters is sufficient to cause redistribution of $210 \mathrm{~Pb}$ in some cores to a degree that can compromise ${ }^{210} \mathrm{~Pb}$ dating. 


\section{BIBLIOGRAPHY}

ALBERTS J.J., TILLY L.J. AND VIGERSTAD T.J. (1979) Seasonal cycling of cesium-137 in a reservoir. Sci. 203, 649-651.

ANDREWS D. AND BENNETT A. (1981) Measurements of diffusivity near the sediment-water interface with a fine scale resistivity probe. Geochim. Cosmochim. Acta 45, 2169-2175.

APPLEBY P.G. and OLDFIELD F. (1978) The calculation of lead-210 dates assuming a constant rate of supply of unsupported $210 \mathrm{~Pb}$ to the sediment. Catena 5, 1-8.

APPLEBY P.G., OLDFIELD F., THOMPSON R., HATTUNEN R., AND TOLONEN K. (1979) $210 \mathrm{~Pb}$ dating of annually laminated lake sediments from Finland. Nature 280, 53-55.

APPLEBY P.G. and OLDFIELD F. (1983) The assessment of $210 \mathrm{~Pb}$ data from sites with varying sediment accumulation rates. Hydrobiologia 103, $29-$ 35 .

BACON M.P., SPENCER D.W. AND BREWER P.G. (1976) ${ }^{210} \mathrm{~Pb} /{ }^{26} \mathrm{Ra}$ and $210 \mathrm{Po} /{ }^{210} \mathrm{~Pb}$ disequilibria in seawater and suspended particulate matter. Earth Planet. Sci. Lett. 32, 277-296.

BACON M.P., BREWER P.G. SPENCER D.W., MURRAY J.W AND GODDARD J. (1980) Lead-210, polonium-210, manganese and iron in the Cariaco Trench. Deep-Sea Res. 27A, 119-135.

BALISTRIERI L.S. AND MURRAY J.W. (1986) The surface chemistry of sediments from the Panama Basin: the influence of Mn oxides on metal adsorption. Geochim. Cosmochim. Acta 50, 2235-2243.

BARNES R.S., BIRCH P.B., SPYRIDAKIS, AND SCHELL W.R. (1978) Changes in the sedimentation histories of lakes using lead-210 as a tracer of sinking particulate matter. In: Proceedings of the International Symposium on Isotope Hydrology 1978; Vo1 2. I.A.E.A. Proc. Ser. No. STI/PUB/493, pp. 875-898.

BAXTER M.S., CRAWFORD R.W., SWAN D.S. AND FARMER J.G. (1981) $210 \mathrm{~Pb}$ dating of a Loch Lomond sediment core by conventional and particle track methods and some geochemical observations. Earth P1anet. Sci. Lett. 53, 434-444.

BELLINGER D., LEVITON A., WATERNAUX C, NEEDLEMAN H. AND RABINOWITZ M. (1987) Longitudinal analyses of prenatal and postnatal lead exposure and cognitive development. New England J. Med. 316, 1037-1043.

BENNET J.T. AND CARPENTER R. (1979) Concentrations and tempora1 variations of ${ }^{210} \mathrm{Po},{ }^{210} \mathrm{~Pb}$, and $\mathrm{Al}$ in the surf zone ecosystem of Copalis Beach, Washington. Est. Coast. Mar. Sci. 8, 127-140. 
BENNINGER L.K. (1978) $210 \mathrm{~Pb}$ balance in Long Island Sound. Geochim. Cosmochim. Acta 42, 1165-1174.

BENNINGER L.K., LEWIS D.M., AND TUREKIAN K.K. (1975) The use of natural $\mathrm{Pb}-210$ as a heavy metal tracer in the river-estuarine system. In: Marine Chemistry in the Coastal Environment (T.M. Church, ed.). Acs Symp. Ser. 18, 202-210.

BENOIT G. and HEMOND H.F. (1987a) Biogeochemical mass balance of 210 Po and $210 \mathrm{~Pb}$ in a New England Lake, Geochim. Cosmochim. Acta. 51, 14451456.

BENOIT G. AND HEMOND H.F. (1987b, in preparation) $210 \mathrm{~Pb}$ remobilization and cycling in hypolimnetic water under the influence of seasonal anaerobisis.

BENOIT G. AND HEMOND H.F. (1987c, in preparation) Distribution and focusing of $210 \mathrm{~Pb}$ in the sediments of a lake with a complex history of anthropogenic alteration.

BERNER R.A. (1980) Ear1y Diagenesis; a theoretical approach. Princeton University Press, Princeton, N.J. 241 pp.

BERTINE K.K. AND MENDECK M.F. (1978) Industrialization of New Haven, CT, as recorded in reservoir sediments. Env. Sci. Tech. 12, 201-207.

BEVINGTON P.R. (1969) Data Reduction and Error Analysis for the Physical Sciences. McGraw-Hill, New York. 336 pp.

BINFORD M.W. AND BRENNER (1986) Dilution of $210 \mathrm{~Pb}$ by organic sedimentation in lakes of different trophic states, and application to studies of sediment-water interactions. Limnol. Oceanogr. 31, 584-595.

BIRCH P.B., BARNES R.S., and SPYRIDAKIS D.E. (1980) Recent sedimentation and its relationship with primary productivity in four western Washington lakes. Limnol. Oceanogr. 25, 240-247.

BIRGE, E.A., JUDAY, C. AND MARCH H.W. (1927) The temperature of the bottom deposits of Lake Mendota; a chapter in the heat exchanges of the lake. Trans. Wisc. Acad. Sci. Arts Lett. 23, 187-232.

BISHOP J.K.B, and BISCAYE P.E. (1982) Chemical characterization of individual particles from the nepheloid layer in the Atlantic Ocean. Earth. Planet. Sci. Lett. 58, 265-275.

BLACK J.N. (1956) The distribution of solar radiation over the earth's surface. Arch. Meteorol. Geophys. Biok1imatol. 7, 165-189.

BLOESCH J. AND EVANS R.D. (1982) Lead-210 dating of sediments compared with accumulation rates estimated by natural markers and measured with sediment traps. Hydrobiologia 92, 579-586. 
BLOMQUIST S. AND HAKANSON L. (1981) A review on sediment traps in aquatic environments. Arch. Hydrobio1. 91, 101-132.

BOTHNER M.H., JAHNKE R.A., PETERSON M.L., and CARPENTER R. (1980) Rate of mercury loss from contaminated estuarine sediments. Geochim. Cosmochim. Acta 44, 273-285.

BOULEGUE J. (1983) Trace metals ( $\mathrm{Fe}, \mathrm{Cu}, \mathrm{Zn}, \mathrm{Cd}$ ) in anoxic environments. In Trace Metals in Sea Water (eds. C.S. Wong, E. Boyle, K.W. Bruland, J.D. Burton and E.D. Goldberg), pp. 563-577. Plenum Press.

BOYLE E.A. AND J.M. EDMOND (1975) Determination of trace metals in aqueous solution by APDC chelate co-precipitation. In Analytical Methods in Oceanography (ed. T.R.P. Gibbs, Jr.), pp. 44-55.

BROECKER W.S. AND PENG T.-H. (1982) Tracers in the Sea. Eldigio Press, Columbia Univ., Palisades, NY. 690 pp.

BROOKS B.E. (1984) Bioturbation: minimal effects on the magnetic fabric of some natural and experimental sediments. Earth Planet. Sci. Lett. $67,367-376$.

BRUGAN R.B. (1978) Pollen indicators of land-use changes in southern Connecticut. Quat. Res. 9, 349-362.

BRUNSKILL G.J. and WILKINSON P. (1984) Annual flux of uranium series radionuclides from precambrian shield watersheds of the arctic and temperate zone in Canada. Gan. J. Fish. Aquat. Sci.

BRUNSKILL G.J., LUDLAM S.D. AND PENG T.-H. (1984) Fayetteville Green Lake, New York, U.S.A. VIII. Mass balances for ${ }^{137} \mathrm{Cs}$ in water, varved and non-varved sediments. Chem. Geol. 44, 101-117.

BUESSELER K.O., BENOIT G. AND SHOLKOVITZ E. R.(1982, unpub1ished) Measurements on pore waters of Gu11 Pond, MA.

BUESSELER K.O., BENOIT G. AND SHOLKOVITZ E.R. (1985) A pore water study of plutonium in a seasonally anoxic lake, J. Environ. Radioactivity 2, 283-292.

CALVERT S.E. AND PRICE N.B. (1972) Diffusion and reaction profiles of dissolved manganese in the pore waters of marine sediments. Earth Planet. Sci. Lett. 16, 245-249.

CARPENTER R., BENNET J.T. AND PETERSON M.L. (1981) $21{ }^{\circ} \mathrm{Pb}$ activities in and fluxes to sediments of the Washington continental slope and shelf. Geochim. Cosmochim. Acta 45, 1155-1172.

CARPENTER R., BENNET J.T. AND PETERSON M.L. (1982) $210 \mathrm{~Pb}$-derived sediment accumulation and mixing rates for the Washington continental slope. Mar. Geo1. 48, 135-164. 
CARPENTER R., PETERSON M.L., BENNET J.T. AND SOMAYAJULU (1984) Mixing and cycling of uranium, thorium and $210 \mathrm{~Pb}$ in Puget Sound sediments. Geochim. Cosmochim. Acta 48,1949-1963.

CARPENTER R., PETERSON M.L. AND BENNET J.T. (1985) $210 \mathrm{~Pb}$-derived sediment accumulation and mixing rates for the greater Puget Sound region. Mar. Geol. 64, 291-312.

CHAO T.T. (1972) Selective dissolution of manganese oxides from soils and sediments with acidified hydroxylamine hydrochloride. Soil Sci. Soc. Amer. Proc. 36, 764-768.

CHAPNICK S.D., MOORE W.S. AND NEALSON K.H. (1982) Microbially mediated manganese oxidation in a freshwater lake. Limnol. Oceanogr. 27, 10041014 .

CHEN K.Y. AND GUPTA S.K. (1973) Formation of polysulfides in aqueous solution. Env. Lett. 4, 187-200.

CHRISTENSEN E.R. AND BHUNIA P.K. (1986) Modeling radiotracers in sediments: Comparison with observations in Lakes Huron and Michigan. J. Geophys. Res. 91C, 8559-8571.

COCHRAN J.K. AND ALLER R.C. (1979) Particle reworking in sediments from the New York Bight Apex: Evidence from ${ }^{234} \mathrm{Th} /{ }^{238} \mathrm{U}$ disequilibria. Est. Coast. Mar. Sci. 9, 739-747.

COCHRAN J.K. AND KRISHNASWAMI S. (1980) Radium, thorium, uranium, and $210 \mathrm{~Pb}$ in deep-sea sediments and sediment pore waters from the north equatorial Pacific. Am. J. Sci. 280, 849-889.

COLMAN J.A. AND ARMSTRONG D.E. (1987) Vertical eddy diffusivity determined with $222 \mathrm{Rn}$ in the benthic boundary layer of ice-covered lakes. Limno1. Oceanogr. 32, 577-590.

CORNETT R.J., CHANT L., and LINK D. (1984) Sedimentation of $\mathrm{Pb}-210$ in Laurentian Shield lakes. Water Pol1. J. Canada 19, 97-109.

CSANADY G.T. (1973) Turbulent Diffusion in the Environment. Riedel.

DANIELSON L.G. (1982) On the use of filters for distinguishing between dissolved and particulate fractions in natural waters. Water Res. 16, $179-182$

DASCH J.M. (1985) Direct measurement of dry deposition to a polyethylene bucket and various surrogate surfaces. Environ. Sci. Tech. 19, 721725 .

DAVIS M.B. and FORD M.S. (1982) Sediment focusing in Mirror Lake, New Hampshire. Limno1. Oceanogr. 27, 137-150.

DAVIS R.B., HESS C.T., NORTON S.A., HANSON D.W., HOAGLAND K.D., and ANDERSON D.S. (1984) ${ }^{137} \mathrm{Cs}$ and ${ }^{210} \mathrm{~Pb}$ dating of sediments from soft- 
water lakes in New England (U.S.A.) and Scandanavia, a failure of ${ }^{137}$ Cs Dating. Chemical Geology 44, 151-185.

DAVISON W. AND HEANEY S.I. (1978) Ferrous iron-sulfide interactions in anoxic hypolimnetic waters. Limnol. Oceanogr. 23, 1194-1200.

DAVISON W. AND SEED G. (1983) The kinetics of the oxidation of ferrous iron in synthetic and natural waters. Geochim. Cosmochim. Acta 47,6779.

DAVISON W., HEANEY S.I., TALLING J.F., AND RIGG E. (1980) Seasonal transformations and movements of iron in a productive English lake with deep-water anoxia. Schweiz. Z. Hydrol. 42, 196-224.

DAVISON W., WOOF C., AND RIGG E. (1982) The dynamics of iron and manganese in a seasonally anoxic lake; direct measurement of fluxes using sediment traps. Limnol. Oceanogr. 27, 987-1003.

DeMASTER D.J. AND COCHRAN J.K. (1982) Particle mixing rates in deep-sea sediments determined from excess ${ }^{210} \mathrm{~Pb}$ and ${ }^{32} \mathrm{Si}$ profiles. Earth Planet. Sci. Lett. 61, 257-271.

DeMASTER D.J., McKEE B.A., NITTROUER C.A., JIANGCHU Q. AND GUODONG C. (1985) Rates of sediment accumulation and particle reworking based on radiochemical measurements from continental shelf deposits in the East China Sea. Continental Shelf Res. 4, 143-158.

DICKSON A., MANTOURA R.F.C AND RILEY J.P. (1977) The complexation of metals with humic materials in natural waters. Estuar. Coast. Mar. Sci 7.

DIEM D. AND STUMM W. (1984) Is dissolved $\mathrm{Mn}^{2+}$ being oxidized by $\mathrm{O}_{2}$ in absence of Mn-bacteria or surface catalysts? Geochim. Cosmochim. Acta $48,1571-1573$.

DILLARD J.W. AND HOBBS B.B. (1980) Galvanic deposition of 210 Po at a rotating nickel disk electrode. In Radioelement Analysis: Progress and Problems (W.S. Lyon, ed.) Ann Arbor Science Publishers, Inc. 424 pp.

DILLON P.J. and EVANS R.D. (1982) Whole-lake lead burdens in sediments of lakes in southern Ontario. Hydrobiologia 91, 121-130.

DOMINIK J., MANGINI A. AND MULLER G. (1981) Determination of recent deposition rates in Lake Constance with radioisotopic methods. Sedimentology 28, 653-677.

DOMINIK J., RAPIN, F. AND VERNET J.-P. (1983) Sequential chemical extractions of $\mathrm{Pb}-210$, Po-210, stable lead and other metals from marine and lacustrine sediments. In: Intnl. Conf. on Heavy Metals in the Envt., Heidelberg. pp. 1078-1081.

DUTTON J.A AND BRYSON R.A. (1962) Heat flux in Lake Mendota. Limnol. Oceanogr. 7, 80-96. 
DUYCKAERTS G. AND LEJEUNE R. (1960) Quelques separations de radioisotopes au moyen de 1 'acide ethylenediaminetetraacetique. J. Chromatogr. 3, 58-62.

EL GHOBARY H. (1982) $\mathrm{Fe}, \mathrm{Mn}, \mathrm{Cu}$ and $\mathrm{Zn}$ in interstitial water of nearshore sediments. Mar Geol. 47, M11-M20.

ERTEN H.N., von GUNTEN H.R., ROSSLER E., and STURM M. (1985) Dating of sediments from Lake Zurich (Switzerland) with ${ }^{210} \mathrm{~Pb}$ and ${ }^{137} \mathrm{Cs}$.

Schweiz. Z. Hydrol. 47, 5-11.

ESHLEMAN K.N. (1985) Hydrochemica1 response of a New England watershed to acid deposition. Ph.D. dissertation, Massachusetts Institute of Technology.

EVANS R.D. and RIGLER F.H. (1980) Calculation of the total anthropogenic lead in the sediments of a rural Ontario lake. Env. Sci. Tech. 14, 216-218.

EVANS R.D. and RIGLER F.H. (1983) A test of lead-210 dating for the measurement of whole lake soft sediment accumulation. Can. J. Fish. Aquat. Sci. 40, 506-515.

EVANS H.E., DILLON P.J., SCHOLER P.J., AND EVANS R.D. (1986) The use of $\mathrm{Pb} /{ }^{210} \mathrm{~Pb}$ ratios in lake sediments for estimating atmospheric fallout of stable lead in south-central Ontario, Canada. Sci. Tot. Env. 54, 77-93.

FARBER E.A. AND MORRISON C.A. (1977) Clear day design values. ASHRAE GRP. 170. American Society of Heating, Refrigeration, and Airconditioning Engineers, New York.

FARMER J.G. (1978) The determination of sedimentation rates in Lake Ontario using the ${ }^{210} \mathrm{~Pb}$ dating method. Can. J. Earth Sci. 15, 431-437.

FIGGINS P.E. (1961) The Radiochemistry of Polonium, National Academy of Science-National Research Council, Office of Technical Services, Dept. of Commerce, Washington, D.C., $68 \mathrm{pp}$.

FLYNN W.W. (1968) The determination of low levels of polonium-210 in environmental materials. Anal. Chim. Acta 43, 221-227.

FROELICH P.N., KLINKHAMMER G.P., BENDER M.L., LUEDTKE N.A., HEATH G.R., CULLEN D., DAUPHIN P., HAMMOND D. AND MAYNARD V. (1979) Early oxidation of organic matter in pelagic sediments of the eastern equatorial Atlantic:Suboxic diagenesis. Geochim. Cosmochim. Acta 43, 1075-1090.

GADDE R.R. AND LAITINEN H.A. (1974) Studies of heavy metal adsorption by hydrous iron and manganese oxides. Ana1. Chem. 46, 2022-2026. 
GAILLARD J.-F., JEANDEL C., MICHARD G., NICOLAS E., AND RENARD D. (1986) Interstitial water chemistry of Villefranche Bay sediments: Trace metal diagenesis. Mar. Chem. 18, 233-247.

GLEASON G. (1980) An improved ion exchange procedure for the separation of barium from radium. In Radioelement Analysis: Progress and Problems (W.S. Lyon, ed.). Ann Arbor Science Publishers, 424 pp.

GOLDBERG E.D. (1963) Geochronology with $210 \mathrm{~Pb}$. In Radioactive Dating, pp. 121-131. International Atomic Energy Agency, Vienna.

GOLDBERG E.D., GRIFFIN J.J., HODGE, V., KOIDE M., AND WINDOM H. (1979) Pollution history of the Savannah River estuary. Env. Sci. Tech. 13, $588-594$.

GORHAM E. AND SWAINE D.J. (1965) The influence of oxidizing and reducing conditions upon the distribution of some elements in lake sediments. Limnol. Oceanogr. 10, 268-279.

GSCHWEND P.M. AND WU S.-C. (1985) On the constancy of sediment-water partition coefficients of hydrophobic organic pollutants. Env. Sci. Tech. 20, 187-.

GUPTA S.K. AND CHEN K.Y. (1975) Partitioning of trace metals in selective chemical fractions of nearshore sediments. Env. Letters 10, $129-158$.

HARADA K. AND TSUNOGAI S. (1982) $2{ }^{\circ} \mathrm{Pb}$ and $21^{\circ} \mathrm{Po}$ in settling particles in Funka Bay: Does lead dissolve at the bottom? Abstracts Annual Meet. Geochem. Soc. Japan. Ryukyu Univ., p. 175.

HARGRAVE B.T. AND BURNS N.M. (1979) Assessment of sediment trap collection efficiency. Limnol. Oceanogr. 24, 1124-1136.

HEIT M., TAN Y., KLUSEK C., and BURKE J.C. (1981) Anthropogenic trace metals and polycyclic aromatic hydrocarbon levels in sediment cores from two lakes in the Adirondack acid lake region. Water Air Soil Pollut. 15, 441-464.

HEM J.D. (1976) Geochemical controls on lead concentrations in stream water and sediments. Geochim. Cosmochim. Acta 40, 599-609.

HESSLEIN R.H., BROECKER W.S., and SCHINDLER D.W. (1980) Fates of metal radiotracers added to a whole lake: Sediment-water interactions. Can. J. Fish. Aquat. Sci. 37, 378-386.

HIRSCHBERG D.J. AND SCHUBEL J.R. (1979) Recent geochemical history of flood deposits in the northern Chesapeake Bay. Est. Coast. Mar. Sci. $9,771-784$.

HOHL H. AND STUMM $W$. (197) Interaction of $\mathrm{Pb}^{2}+$ with hydrous \#\#-Al ${ }_{2} \mathrm{O}_{3} \cdot \mathrm{J}$. Coll. Interf. Sci. 55, 281-289. 
HOLTZMAN R.B. (1964) Lead-210 and Polonium-210 in potable waters in Illinois. In The Natural Radiation Environment (eds. J.A. Adams and W.M. Lowden), PP. 227-237. University of Chicago Press.

HONGVE D. AND ERLANDSEN A.H. (1979) Shortening of surface sediment cores during sampling. Hydrobiologia 65, 283-287.

HUH C. -A., ZAHNLE D.L., SMALL L.F. AND NOSHKIN V.E. (1987) Budgets and behaviors of uranium and thorium series isotopes in Santa Monica Basin sediments. Geochim. Cosmochim. Acta 51, 1743-1754.

HUTCHINSON, G.E. (1975) A Treatise on Limnology. Vo1. 1: Geography, Physics, and Chemistry. Wiley Interscience, New York. 1015 pp.

IMBODEN D.M. AND EMERSON S. (1978) Natural radon and phosphorus as limnological tracers: Horizontal and vertical eddy diffusion in Greifensee. Limno1. Oceanogr. 23, 77-90.

IQBAL M. (1983) An Introduction to Solar Radiation. Academic Press, Toronto. $390 \mathrm{pp}$.

JAAKKOLA T., TOLONEN K., HUTTUNEN P. AND LESKINEN S. (1983) The use of fallout ${ }^{137} \mathrm{Cs}$ and $239,240 \mathrm{Pu}$ for dating of lake sediments. Hydrobiologia 103, 15-19.

JACKSON T.A., KIPPHUT G., HESSLEIN R.H., and SCHINDLER D.W. (1980) Experimental study of trace metal chemistry in soft-water lakes at different $\mathrm{pH}$ levels. Can. J. Fish. Aquat. Sci. 37, 387-402.

JACOBS L. AND EMERSON S. (1982) Trace metal solubility in an anoxic fjord. Earth Planet. Sci. Lett. 60, 237-252.

JACOBS L., EMERSON S. AND SKEI J. (1985) Partitioning and transport of metals across the $\mathrm{O}_{2} / \mathrm{H}_{2} \mathrm{~S}$ interface in a permanently anoxic basin: Framvaren Fjord, Norway. Geochim. Cosmochim. Acta 49, 1433-1444.

JASSBY A. AND POWELL T. (1975) Vertical patterns of eddy diffusion during stratification in Castle Lake, California. Limnol. Oceanogr. $20,530-543$.

JEAN G.E. AND BANCROFT G.M. (1986) Heavy metal adsorption by sulphide mineral surfaces. Geochim. Cosmochim. Acta 50, 1455-1463.

JENNE E.A. (1967) Controls on Mn, Fe, Co, NI, Cu, and $\mathrm{Zn}$ concentrations in soils and water: the significant role of hydrous $\mathrm{Mn}$ and $\mathrm{Fe}$ oxides. In: Trace Inorganics in Water. Advances in Chemistry Ser. 73, 337-387. Amer. Chem. Soc., Washington, D.C.

JORGENSEN B.B. AND REVSBECH N.P. (1985) Diffusive boundary layers and the oxygen uptake of sediments and detritus. Limno1. Oceanogr. 30, 111-122.

JOSEPHSON J. (1986) Implementing superfund. Env. Sci. Tech. 20, 23-28. 
KHARKAR D.P., THOMSON J., TUREKIAN K.K. AND FORSTER W.O. (1976) Uranium and thorium decay series nuclides in plankton from the Caribbean. Limnol. Oceanogr. 21, 269.

KOIDE M. AND BRULAND K.W. (1975) The electrodeposition and determination of radium by isotopic dilution in sea water and sediments simultaneously with other natural radionuclides. Analytica Chimica Acta $75,1-19$.

KRISHNASWAMI S., LAL D., MARTIN J.M., and MEYBECK M. (1971) Geochronology of lake sediments. Earth Planet. Sci. Lett. 11, 407-414.

KRISHNASWAMI S., BENNINGER L.K., ALLER R.C., AND VON DAMM K.L. (1980) Atmospherically derived radionuclides as tracers of sediment mixing and accumulation in near-shore marine and lake sediments: Evidence from ${ }^{7} \mathrm{Be},{ }^{210} \mathrm{~Pb}$, and $239,240 \mathrm{Pu}$. Earth Planet. Sci. Lett. 47, 307-318.

KRISHNASWAMI S., GRAUSTEIN W.C., TUREKIAN K.K. AND DOWD J.F. (1982) Radium, thorium and radioactive lead isotopes in groundwaters: App1ication to the in situ determination of adsorption-desorption rate constants and retardation factors. Water Resour. Res. 18, 1633-1675.

KROM M.D. AND SHOLKOVITZ E.R. (1978) On the association of iron and manganese with organic matter in anoxic marine pore waters. Geochim. Cosmochim. Acta 42, 607-611.

LAMBERT C.E., JEHANNO C., SILVERBERG N., BRUN-COTTON J.C., and CHESSELET R. (1981) Log-normal distributions of suspended particles in the open ocean. J. Mar. Res. 39, 77-98.

LAXEN D.P.H. AND CHANDLER I.M. (1982) Comparison of filtration techniques for size distribution in freshwaters. Ana1. Chem. 54, $1350-$ 1355 .

LAXEN D.P.H. AND CHANDLER I.M. (1983) Size distribution of iron and manganese species in freshwaters. Geochim. Cosmochim, Acta 47, 731741 .

LEE D.R. (1977) A device for measuring seepage flux in lakes and estuaries. Limnol. Oceanogr. 22, 140-147.

LEHMAN J.T. (1975) Reconstructing the rate of accumulation of lake sediment: the effect of sediment focusing. Quat. Res. 5, 541-550.

LERMAN A. AND LIETZKE T.A. (1975) Uptake and migration of tracers in lake sediments. Limnol. Oceanogr. 20, 497-510.

LEWIS D.M. (1977) The use of $21{ }^{\circ} \mathrm{Pb}$ as a heavy metal tracer in the Susquehanna River system. Geochim. Cosmochim. Acta 41, 1557-1564.

LI Y.-H. AND GREGORY S. (1974) Diffusion of ions in sea water and in deep-sea sediments. Geochim. Cosmochim. Acta 38, 703-714. 
LI Y.-H., BISCHOFF J AND MATHIEU G. (1969) The migration of manganese in Atlantic basin sediments. Earth Planet. Sci. Lett. 7, 265-270.

LI Y.-H., SANTSCHI P.H., KAUFMAN A., BENNINGER L.K., and FEELY H.W. (1981) Natural radionuclides in waters of the New York Bight. Earth P1anet. Sci. Lett. 55, 217-228.

LIKENS G.C. and DAVIS M.P. (1975) Post-glacial history of Mirror Lake and its watershed in New Hampshire, U.S.A.: an initial report. Verh. int. Verein Limnol. 19, 982-993.

LYNCH D.R AND OFFICER C.B. (1984) Nonlinear parameter estimation for sediment cores. Chem. Geol. 44, 203-225.

LYNN D.C. AND BONATTI E. (1965) Mobility of manganese in diagenesis of deep-sea sediments. Mar. Geol. 3, 457-474.

LYONS W.B. AND FITZGERALD W.F. (1983) Trace metals speciation in nearshore anoxic and suboxic pore waters. In Trace Metals in Sea Water (eds. C.S. Wong, E. Boyle, K.W. Bruland, J.D. Burton and E.D. Goldberg), pp. 621-641. P1enum Press.

MANHEIM F.T. (1970) The diffusion of ions in unconsolidated sediments. Earth Planet. Sci. Lett. 9, 307-309.

MARTIN J.-M. AND MEYBECK M. (1979) Elemental mass-balance of material carried by major world rivers. Mar. Chem. 7, 173-206.

MCCAFFREY R.J. (1977) A record of the accumulation of the sediment and trace metals in a Connecticut, USA, salt marsh. Ph.D. thesis, Yale Univ. 156 pp.

McCALL P.L., ROBBINS J.A. AND MATISOFF G. (1984) ${ }^{137} \mathrm{Cs}$ and $210 \mathrm{~Pb}$ transport and geochronologies in urbanized reservoirs with rapidly increasing sedimentation rates. Chem. Geol. 44, 33-65.

MEGUMI K. (1978) A problem in $210 \mathrm{~Pb}$ geochronologies of sediments. Nature $274,885-887$.

MILLARD H.T., JR. (1963) Quantitative radiochemical procedure for analysis of polonium-210 and lead-212 in minerals. Analytical Chemistry 35, 1017-1023.

MILLER K.M. and M. HEIT (1986) A time resolution methodology for assessing the quality of lake sediment cores that are dated by ${ }^{137} \mathrm{Cs}$. Limno1. Oceanogr. 31, 1292-1300.

MOORE H.E. and POET S.E. (1976) ${ }^{210} \mathrm{~Pb}$ fluxes determined from $210 \mathrm{~Pb}$ and ${ }^{226} \mathrm{Ra}$ soil profiles. J. Geophys. Res. 81, 1056-1058.

MOREL F.M.M. (1983) Principles of Aquatic Chemistry. Wiley-Interscience, New York. 446 pp. 
MOREL F.M.M. AND GSCHWEND P.M. (1987) The role of colloids in the partitioning of solutes in natural waters. In Aquatic Surface Chemistry: Chemical Processes at the Particle-Water Interface, (W. Stumm, ed.). Wiley. pp. 405-422.

MORTIMER C.H. (1941) The exchange of dissolved substances between mud and water in lakes; I and II. J. Eco1, 29, 280-329.

MORTIMER C.H. (1942) The exchange of dissolved substances between mud and water in lakes; III and IV. J. Ecol. 30, 280-329.

MURCHIE S.L (1985) ${ }^{210} \mathrm{~Pb}$ dating and the recent geologic history of Crystal Bay, Lake Minnetonka, Minnesota. Limnol. Oceanogr. 30, 1154 1170 .

NG A. and PATTERSON C. (1981) Natural concentrations o lead in ancient Arctic and Antarctic ice. Geochim. Cosmochim. Acta 45, 2109-2121.

NORTON S.A., HESS C.T., BLAKE G.M., MORRISON M.L., AND BARON J. (1985) Excess unsupported $210 \mathrm{~Pb}$ in lake sediment from Rocky Mountain Lakes: A groundwater effect. Can. J. Fish. Aquat. Sci. 42, 1249-1254.

NOZAKI Y., THOMSON J AND TUREKIAN K.K. (1976) The distribution of $210 \mathrm{~Pb}$ and $2{ }^{\circ} \mathrm{Po}$ in the surface waters of the Pacific Ocean. Earth Planet. Sci. Lett. $32,304-312$.

NRIAGU J. (1978) The Biogeochemistry of Lead in the Environment. E1sevier, Amsterdam. $393 \mathrm{pp}$.

NYFFELER U.P., SCHINDLER P.W., WIRZ U.E., AND IMBODEN D.M. (1983) Chemical and geochemical studies of Lake Biel II. A chemical approach to lake mixing. Schweiz. Z. Hydrol. 45, 45-61.

O'CONNOR D.J. AND CONNOLLY J.P. (1980) The effect of concentration of adsorbing solids on the partition coefficient. Water Res. 14, 1517-.

OLDFIELD F., APPLEBY P.G., and BATTARBEE (1978) Alternative $2{ }^{20} \mathrm{~Pb}$ dating: Results from the New Guinea highlands and Lough Erne. Nature $271,339-342$.

OLDFIELD F. and APPLEBY P.G. (1984) Empirical testing of $210 \mathrm{~Pb}$-dating models for lake sediments. In Lake Sediments and Environmental History (eds. E.Y. Hayworth and J.W.G. Lund), pp. 93-124. University of Minnesota Press, Minneapolis.

ORLOB G.T. AND SELNA L.G. (1970) Temperature variations in deep reservoirs. J. Hydraul. Div. ASGE, 391-410.

PENG T.-H., BROECKER W.S. AND BERGER W.H. (1979) Rates of benthic mixing in deep-sea sediment as determined by radioactive tracers. Quaternary Res. 11, 141-149. 
PENNINGTON W., CAMBRAY R.S $S_{137}$ and FISHER E.M. (1973) Observations on lake sediments using fallout ${ }^{137} \mathrm{Cs}$ as a tracer. Nature $242,324-326$.

PRICE N.B., MALCOLM S.J. AND HAMILTON-TAYLOR J. (1976) Environmental impact of lead and zinc in recent sediments. In Biogeochemistry of Estuarine Sediments. Proc. UNESCO/SCOR Workshop. Melreux, Belgium.

QUAY P.D., BROECKER W.S., HESSLEIN R.H. AND SCHINDLER D.W. (1980) Vertical diffusion rates determined by tritium tracer experiments in the thermocline and hypolimnion of two lakes. Limnol. Oceanogr. 25, $201-218$.

RAMA, KOIDE M. AND GOLDBERG E.D. (1961) Lead-210 in natural waters. Sci. $134,98-99$.

RAPIN F. AND FORSTNER U. (1983) Sequential leaching techniques for particulate metal speciation: The selectivity of various extractants. In International Conference on Heavy Metals in the Environment, 2. Heidelberg, September 1983.

RAPIN F., TESSIER A., CAMPBELL P.G.C., AND CARRIGNAN R. (1986) Potential artifacts in the determination of metal partitioning in sediments by a sequential extraction procedure. Environ. Sci. Tech, 20, 836-840.

REIMERS C.E., KALHORN S., EMERSON S.R. AND NEALSON K.H. (1984) Oxygen consumption rates in pelagic sediments from the Central Pacific: First estimates from microelectrode profiles. Geochim. Cosmochim. Acta 48, $903-910$.

REVSBECH N.P., SORENSEN J., BLACKBURN T.H. AND LOMHOLT J.P. (1980) Distribution of oxygen in marine sediments measured with microelectrodes. Limno1. Oceanogr. 25, 403-411.

ROBBINS J.A. AND EDGINGTON D.N. (1975) Determination of recent sedimentation rates in Lake Michigan using ${ }^{210} \mathrm{~Pb}$ and ${ }^{137} \mathrm{Cs}$. Geochim. Cosmochim. Acta 39, 285-304.

ROBBINS J.A., KREZOSKI J.R., AND MOZLEY S.C. (1977) Radioactivity in sediments of the Great Lakes: Postdepositional redistribution by deposit-feeding organisms. Earth Planet. Sci. Lett. 36, 325-333.

ROBBINS J.A., EDGINGTON D.N., AND KEMP A.L.W. (1978) Comparative $210 \mathrm{~Pb}$, ${ }^{137} \mathrm{Cs}$, and pollen geochronologies of sediments from Lake Ontario and Erie. Quaternary Research 10, 256-278.

ROMAN D. (1984) Electrodeposition of Radium on stainless steel from aqueous solutions. Int. J. Appl. Radiation Isot. 35, 990-992.

SAKATA M. (1985) Diagenetic remobilization of manganese, iron, copper and lead in anoxic sediment of a freshwater pond. Water Res. 19, 10331038 .

SALOMONS W. AND FORSTNER U. (1980) Environ. Technol. Lett. 1, 506-517. 
SANTSCHI P.H., LI Y. -H. AND BELL J. (1979) Natural radionuclides in the water of Narragansett Bay. Earth Planet. Sc1. Lett. 45, 201-213.

SANTSCHI P.H., BOWER P., NYFFELER U.P., AZEVADO A. AND BROECKER W.S. (1983a) Estimates of the resistance to chemical transport posed by the deep-sea boundary layer. Limnol. Oceanogr. 28, 899-912.

SANTSCHI P.H., LI Y. -H., ADLER D.M., AMDURER M., BELL J., AND NYFFELER U.P. (1983b) The relative mobility of natural ( $\mathrm{Th}, \mathrm{Pb}$ and $\mathrm{Po}$ ) and fallout ( $\mathrm{Pu}, \mathrm{Am}, \mathrm{Cs}$ ) radionuclides in the coastal marine environment: results from model ecosystems (MERL) and Narragansett Bay. Geochim. Cosmochim. Acta 47, 201-210.

SCHAULE B.K. and PATTERSON C.C. (1983) Perturbations of the natural lead depth profile in the Sargasso Sea by industrial lead. In Trace Metals in Sea Water (eds. C.S. Wong, E. Boyle, K.W. Bruland, J.D. Burton and E.D. Goldberg), pp. 487-503. Plenum Press.

SCHELL W.R. (1977) Concentrations, physico-chemical states and mean residence times of $210 \mathrm{~Pb}$ and $210 \mathrm{Po}$ in marine and estuarine waters. Geochim. Cosmochim. Acta 41, 1019-1031.

SCHINDLER D.W., HESSLEIN R.H., WAGEMAN R., and BROECKER W.S. (1980) Effects of acidification on mobilization of heavy metals and radionuclides from the sediments of a freshwater lake. Can. J. Fish. Aquat. Sci. 37, 373-377.

SERVANT J. AND DELEPART M. (1979) Lead and lead-210 in some river waters in the southwestern part of France. Importance of the atmospheric contribution. Env. Sci. Tech. 13, 105-107.

SETTLE D.M. AND PATTERSON C.C. (1980) Lead in Albacore: Guide to lead in Americans. Science 207, 1167-1176.

SHOLKOVITZ E. R. AND COPLAND D. (1982) The chemistry of suspended mattex in Esthwaite Water, a biologically productive lake with a seasonally anoxic hypolimnion. Geochim. Cosmochim. Acta 46, 393-410.

SIGG L., STURM M, AND KISTLER D. (1987) Vertical transport of heavy metals by settling particles in Lake Zurich. Limnol. Oceanogr. 32, $112-130$.

SKEI J.M. AND PAUS P.E. (1979) Surface metal enrichment and partitioning of metals in a dated sediment core from a Norwegian fjord. Geochim. Cosmochim. Acta 43, 239-246.

SMITH R.M. AND MARTELL A.E. (1976) Critical Stability Constants: Inorganic Complexes, vol. 4. Plenum Press, New York.

STEVENSON F.J. (1976) Stability constants of $\mathrm{Cu}^{2+}, \mathrm{Pb}^{2+}$ and $\mathrm{Cd}^{2+}$ complexes with humic acids. Sol1 Sci. Soc. Am. J. 40, 665-672. 
STILLER M. (1979) Sedimentation patterns in Lake Kinneret (Tiberias). In Isotopes in Lake Studies. International Atomic Energy Agency, Vienna.

STILLER M. AND IMBODEN D.M. (1986) $21{ }^{\circ} \mathrm{Pb}$ in Lake Kinneret waters and sediments: Residence times and fluxes. In Sediments and Water Interactions (ed. P.G. Sly), pp. 501-511. Springer-Verlag, New York.

STUMM W. AND MORGAN J.J. (1970) Aquatic Chemistry. Wiley-Interscience, New York. 583 pp.

SUAREZ D.L. AND LANGMUIR D. (1976) Heavy metal relationships in a Pennsylvania soil. Geochim. Cosmochim. Acta 40, 589-598.

SUNDA W.G. AND HANSON P.J. (1979) In Chemical Modeling in Aquatic Systems (E.A. Jenne, ed.). ACS Symposium Series 93. ACS, Washington, D.C.

SUNDBY B., ANDERSON L.G., HALL P.0.J., IVERFELDT A., RUTGERS VAN DER LOEFF M.M. AND WESTERLUND S.F.G (1986) The effect of oxygen on release and uptake of cobalt, manganese, iron and phosphate at the sedimentwater interface. Geochim. Cosmochim. Acta 50, 1281-1288.

SWALLOW K.C., HUME D.N. AND MOREL F.M.M. (1980) Sorption of copper and lead by hydrous ferric oxide. Env. Sci. Tech. 14, 1326-1331.

TALBO'T R.W. (1981) Atmospheric fluxes and geochemistries of stable lead, lead-210, and polonium-210 in Crystal Lake, Wisconsin. Ph.D. dissertation. Univ. of Wisconsin. $258 \mathrm{pp}$.

TALBOT R.W. and ANDREN A.W. (1984) Seasonal variations of $210 \mathrm{~Pb}$ and 210 Po concentrations in an oligotrophic lake. Geochim. Cosmochim. Acta $48,2053-2063$.

TALVITIE N.A. (1972) Electrodeposition of actinides for alpha spectrometric determination. Anal. Chem. 44, 280-283.

TANAKA N., TAKEDA Y. AND TSUNOGAI S. (1983) Biological effect on removal of Th-234, Po-210 and $\mathrm{Pb}-210$ from surface water in Funka Bay, Japan. Geochim. Cosmochim. Acta 47, 1783-1790.

TESSIER A., CAMPBELL P.G.C. AND BISSON M. (1979) Sequential extraction procedure for the speciation of particulate trace metals. Anal. Chem. $51,844-851$.

THRELKELD J.L. AND JORDAN R.C. (1958) Direct solar radiation available on clear days. Trans. Am. Soc. Heat. Refrig. Air-cond. Eng, 64, 45-68.

TIPPING E. (1981) The adsorption of aquatic humic substances by iron oxides. Geochim. Cosmochim. Acta 45, 191-199.

TIPPING E., WOOF C. AND COOKE D. (1981) Iron oxide from a seasonally anoxic lake. Geochim. Cosmochim. Acta 45, 1411-1419. 
TODD J.F. (1984) The aquatic geochemistry of the particle-reactive radionuclides ${ }^{210} \mathrm{Po},{ }^{210} \mathrm{~Pb}$, and ${ }^{7} \mathrm{Be}$. Ph.D. dissertation, Old Dominion University.

TUREKIAN K.K. (1977) The fate of trace metals in the ocean. Geochim. Cosmochim. Acta 42, 1139-1144.

TUREKIAN K.K., KHARKAR D.P. AND THOMSON J. (1974) The fates of $210 \mathrm{~Pb}$ and ${ }^{210} \mathrm{Po}$ in the ocean surface. Rech. Atmos. 8, 639-646.

TUREKIAN K.K., NOZAKI Y., and BENNINGER L.K. (1977) Geochemistry of atmospheric radon and radon products. Annual Rev. Earth Planet Sci. 5, $227-255$.

VON DAMM K.L., BENNINGER L.K., AND TUREKIAN K.K. (1979) The $210 \mathrm{~Pb}$ chronology of a core from Mirror lake, New Hampshire. Limnol. Oceanogr. 24, 434-439.

VAN DEN WINKEL P., DE CORTE F. AND HOSTE J. (1971) Anion exchange in acetic acid solutions. Anal. Chim. Acta 56, 241-259.

WAN G.J., SANTSCHI P.H., STURM M., FARRENKOTHEN K., LUECK A., WERTH E., and SCHULER C. (1987) Natural $\left({ }^{210} \mathrm{~Pb}, 7 \mathrm{Be}\right)$ and fallout $\left({ }^{137} \mathrm{Cs}\right.$, $239,240 \mathrm{Pu},{ }^{\circ} \mathrm{Sr}$ ) radionuclides as geochemical tracers of sedimentation in Greifensee, Switzerland. Chemical Geology 63, 181-196.

WANG Z.J., EL GHOBARY H., GTOVANOLI F. AND FAVARGER P.-Y. (1986) Interpretation of metal profiles in a sediment core from Lake Geneva: metal mobility or pollution. Schweiz. Z. Hydrol. 48, 1-17.

WESTERLUND S.F.G., ANDERSON L.G., HALL P.O.J., IVERFELDT A, RUTGERS VAN DER LOFF M.M. and SUNDBY B. (1986) Benthic fluxes of cadmium, copper, nickel, zinc and lead in the coastal environment. Geochim. Cosmochim. Acta 50, 1289-1296.

WETZEL, R.G. (1975) Limnology. W.B. Saunders Co., Philadelphia. 743 pp.

WHITE J.R. and DRISCOLL C.T. (1985) Lead cycling in an acidic Adirondack lake. Env. Sci. Tech. 19, 1182-1187.

WHITFIELD M. AND TURNER D.R. (1979) The theoretical studies of the chemical speciation of lead in seawater. In Lead in the Marine Environment (eds: M. Branica and Z. Konrad).

WILSON D.E. (1980) Surface and complexation effects on the rate of $\mathrm{Mn}$ (II) oxidation in natural waters. Geochim. Cosmochim. Acta 44, 13111317. 